\title{
EVOLUÇÃO DA CONTAMINAÇÃO POR NITRATO EM AQUÍFEROS URBANOS: ESTUDO DE CASO EM URÂNIA (SP)
}

\author{
ALINE MICHELLE BERNICE \\ Orientador: Prof. Dr. Ricardo César Aoki Hirata \\ DISSERTAÇÃO DE MESTRADO \\ Programa de Pós-Graduação em Recursos Minerais e Hidrogeologia
}

SÃO PAULO

2010 
Autorizo a reprodução e divulgação total ou parcial deste trabalho, por qualquer meio, para fins de estudo e pesquisa, desde que citada a fonte. 
Aos meus pais, Sueli e Paulo,

e irmão, Álvaro (in memoriam) 


\section{SUMÁRIO}

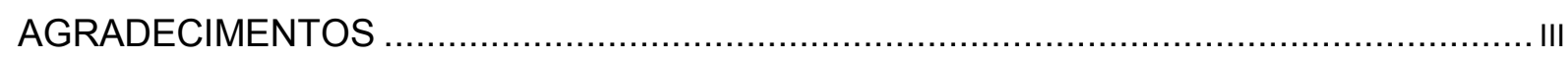

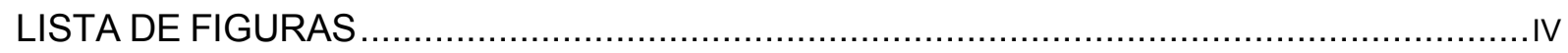

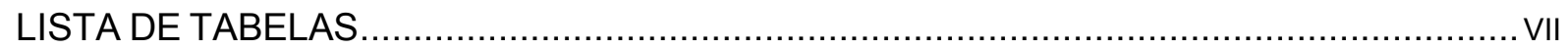

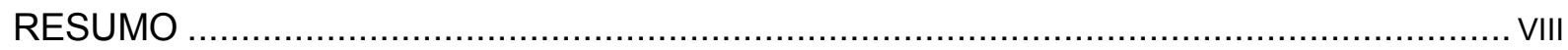

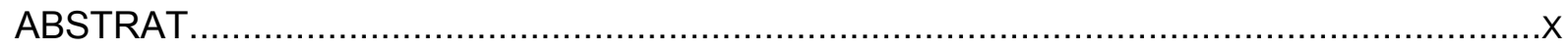

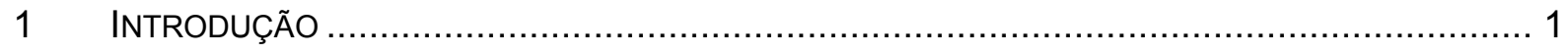

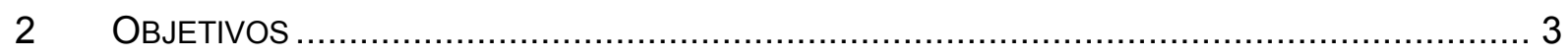

3 SISTEMAS DE SANEAMENTO IN SITU E A CONTAMINAÇÃO DAS ÁGUAS SUBTERRÂNEAS ......... 3

3.1. DINÂMICA DO NITROGÊNIO EM SUBSUPERFÍCIE ................................................. 3

3.2. SISTEMAS SÉPTICOS IN SITU E A CONTAMINAÇÃO DE AQUÍFEROS .............................. 6

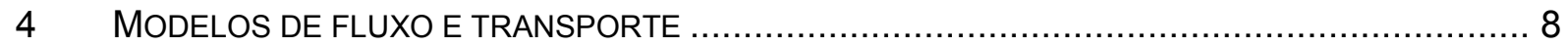

4.1. EQUAÇÃO DE FLUXO DA ÁGUA SUBTERRÂNEA ................................................. 10

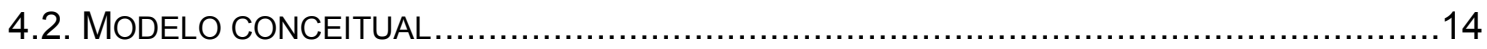

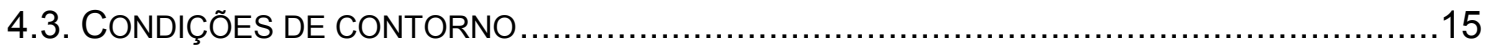

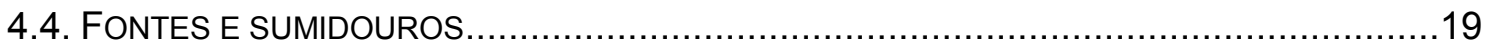

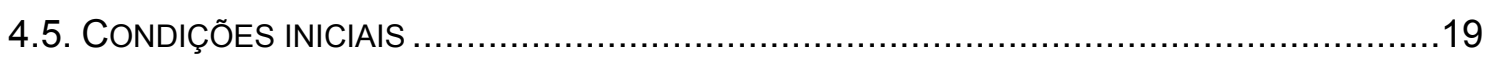

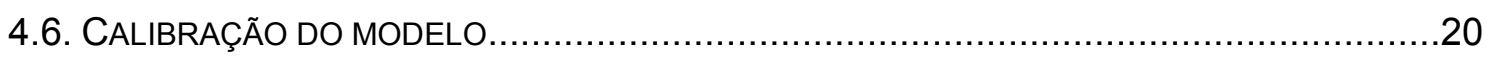

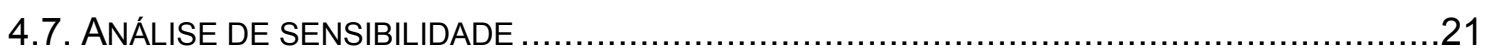

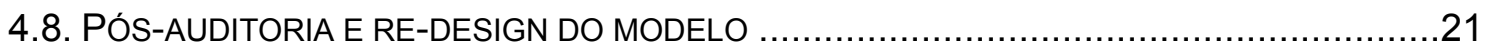

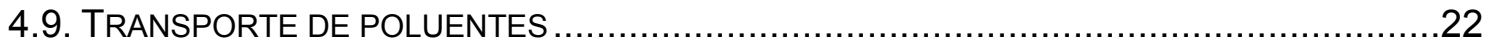

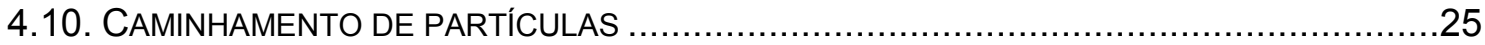

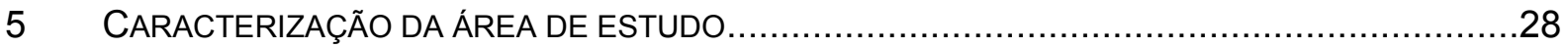

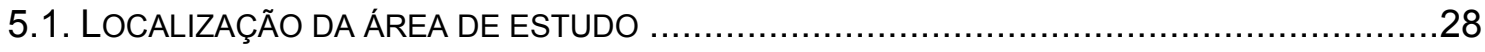

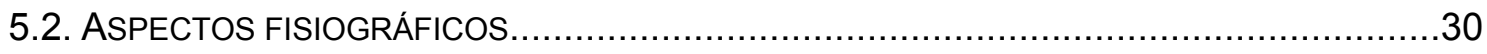

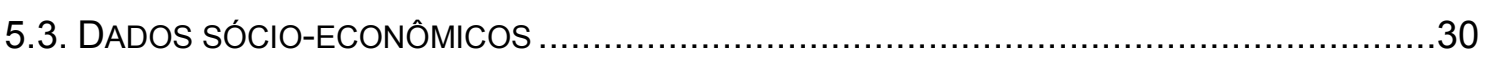

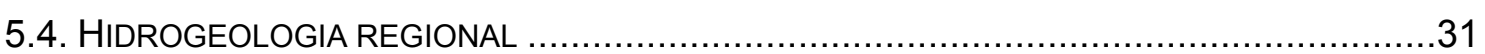

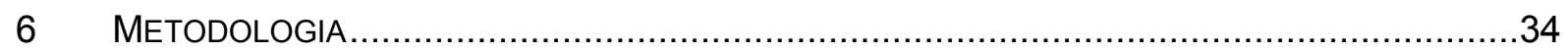

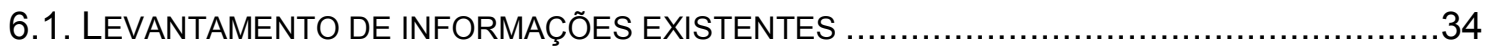

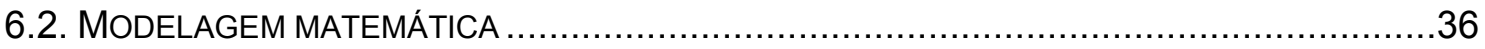

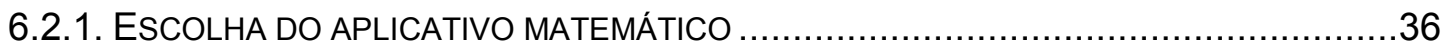

6.2.2. CONSTRUÇÃO DO MODELO MATEMÁTICO …..................................................

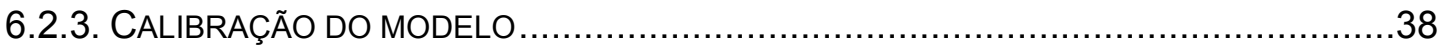




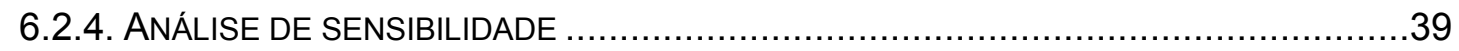

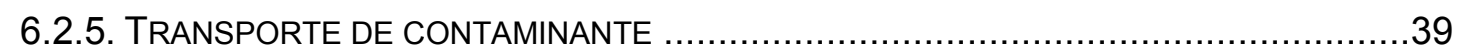

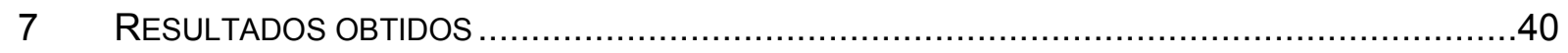

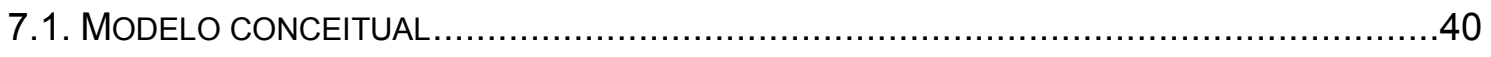

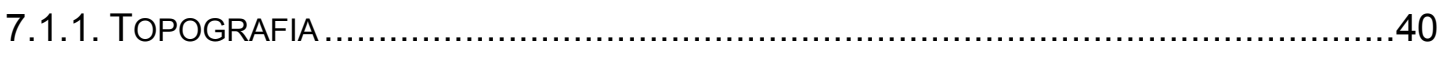

7.1.2. UNIDADES HIDROESTRATIGRÁFICAS ................................................... 40

7.1.3. HIDROGEOLOGIA LOCAL .................................................................. 43

7.1.4. PRECIPITAÇÃO, EVAPOTRANSPIRAÇÃO E RECARGA .....................................47

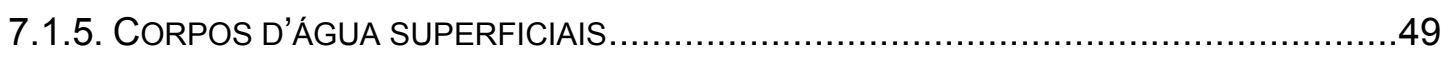

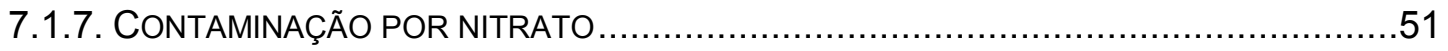

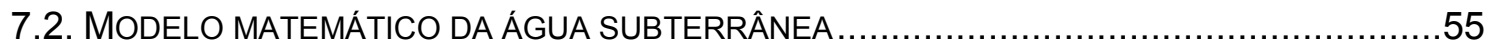

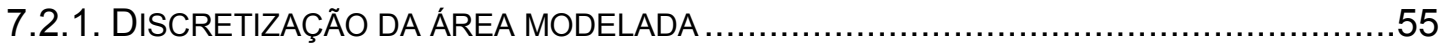

7.2.2. DEFINIÇÃO DAS CONDIÇÕES DE CONTORNO..................................................60

7.2.3. DEFINIÇÃO DAS UNIDADES HIDRÁULICAS E SEUS PARÂMETROS HIDROGEOLÓGICOS .63

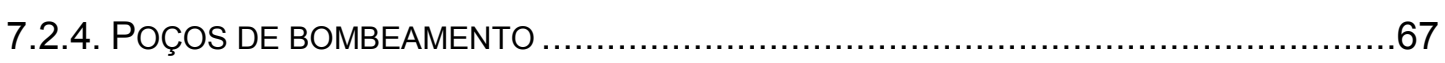

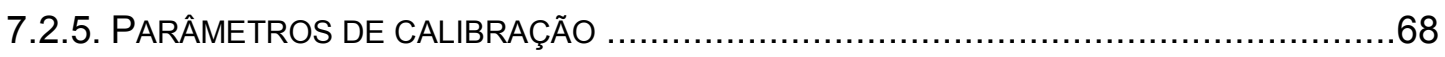

7.2.6. CALIBRAÇÃO DO MODELO MATEMÁTICO ......................................................69

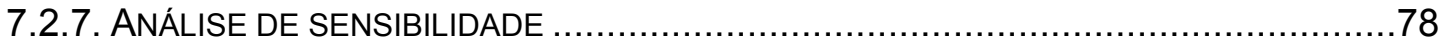

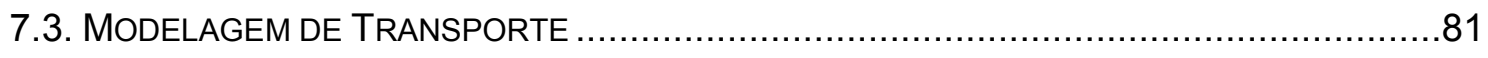

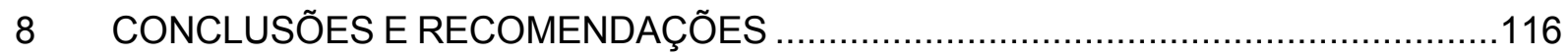

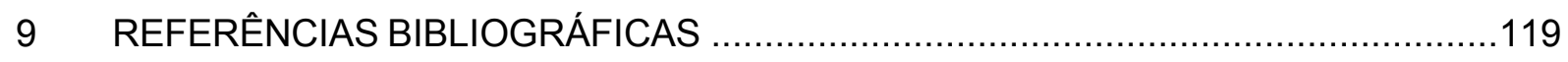




\section{AGRADECIMENTOS}

Registro o meu agradecimento a Deus, por ter me dado forças nos momentos mais difíceis, e pessoas e entidades, sem as quais a realização desta dissertação não seria possível.

Ao Prof. Dr. Ricardo César Aoki Hirata pela orientação durante todas as etapas de elaboração deste trabalho, pela amizade, paciência e ainda pelo exemplo de profissionalismo e dedicação à pesquisa.

Ao Instituto de Geociências da Universidade de São Paulo, em particular ao Departamento de Geologia Sedimentar e Ambiental, pela infra-estrutura fornecida e oportunidade de realização deste estudo.

A Servmar Serviços Técnicos Ambientais Ltda. pelas horas cedidas para desenvolvimento desta pesquisa.

Aos meus pais pela confiança, companheirismo, constante incentivo e pelo amor que me dedicam hoje e sempre.

Ao Flavio (Tamanduá) pelo carinho, compreensão, confiança e pelas incontáveis horas que deixamos de passar juntos para que eu pudesse concretizar meu sonho.

Cabe um agradecimento especial a todas as pessoas que direta ou indiretamente contribuíram de alguma maneira para que este trabalho pudesse ser realizado e me apoiaram mesmo nos momentos mais críticos de finalização da dissertação. 


\section{LISTA DE FIGURAS}

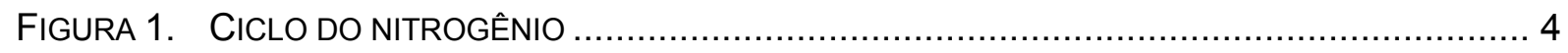

FIGURA 2. REPRESENTAÇÃO DO VOLUME ELEMENTAR DE UM AQUÍFERO (FETTER, 1988) .......11

FIGURA 3. EXEMPLOS DE CONDIÇÕES DE CONTORNO (CLEARY, 1989) …….......................16

FIGURA 4. LOCALIZAÇÃO DOS PONTOS PARA CÁLCULO DE V $V_{X}$ E V POR INTERPOLAÇÃO LINEAR PARA DETERMINAÇÃO DO CAMINHAMENTO DE PARTÍCULAS E DAS LINHAS DE TRAJETÓRIA (IRITANI,

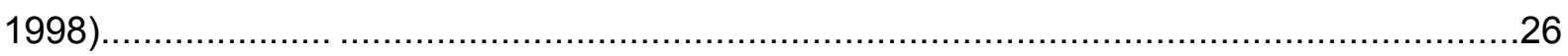

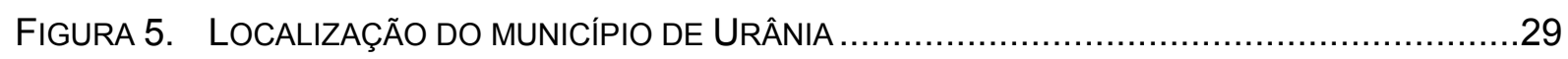

Figura 6. Configuração atual do substrato do Grupo BaURu no Estado de São

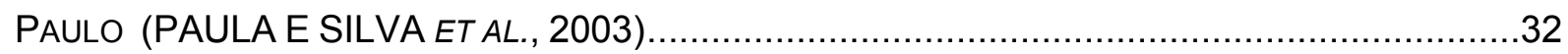

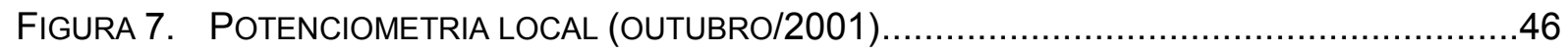

FIGURA 8. LOCALIZAÇÃO DOS PONTOS DE MEDIÇÃO NOS CÓRREGOS ……...........................50

Figura 9. LOCALIZAÇÃO dAS FOSSAS CADASTRADAS NO MUNICIPIO DE URÂNIA (CAGNON, 2003)

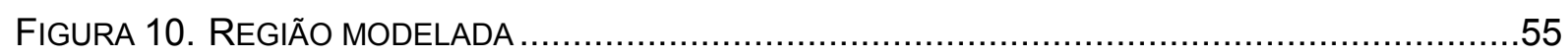

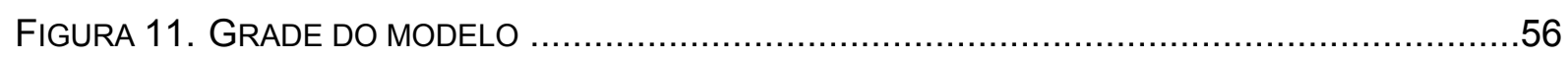

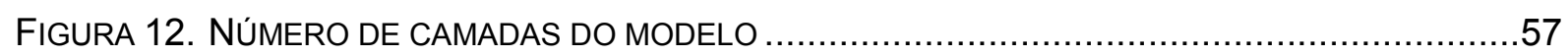

FIGURA 13. SUPERFICIE DA PRIMEIRA CAMADA DO MODELO .............................................58

FIGURA 14. VISUALIZAÇÃO ESPACIAL DA SUPERFÍCIE DE CONTATO ENTRE A PRIMEIRA E A

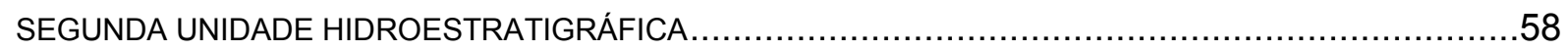

FIGURA 15. VISUALIZAÇÃO ESPACIAL DA SUPERFÍCIE DE CONTATO ENTRE A SEGUNDA E A

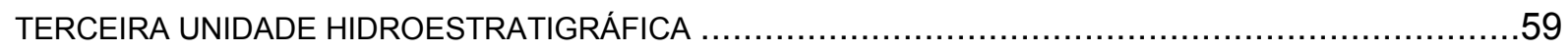

FIGURA 16. VISUALIZAÇÃO ESPACIAL DA BASE DA TERCEIRA UNIDADE HIDROESTRATIGRÁFICA....59 FIGURA 17. CONDIÇÕES DE CONTORNO ESTABELECIDAS PARA A PRIMEIRA CAMADA DO MODELO 61 FIGURA 18. CONDIÇÕES DE CONTORNO ESTABELECIDAS PARA AS DEMAIS CAMADAS DO

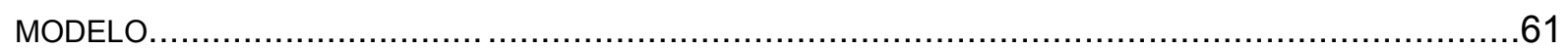

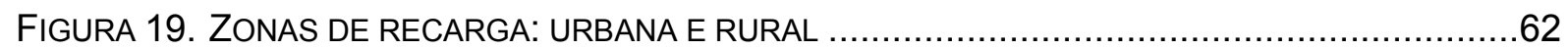

FIGURA 20. ZONAS HIDRÁULICAS DA UNIDADE HIDROESTRATIGRÁFICA SUPERIOR DA FORMAÇÃO ADAMANTINA

FIGURA 21. ZONAS HIDRÁULICAS DA UNIDADE HIDROESTRATIGRÁFICA INFERIOR DA FORMAÇÃO ADAMANTINA. .65

FIGURA 22. ZONA HIDRÁULICA DA UNIDADE HIDROESTRATIGRÁFICA DA ALTERAÇÃO DO BASALTO DA ForMAÇÃo SERRA GERAL. 65 
FIGURA 23. SEÇÃo REALIZADA NA LINHA 34 DO MOdELO MOSTRANDO AS DIFERENTES ZONAS DE

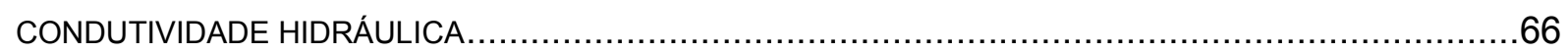

FIGURA 24. LOCALIZAÇÃO DOS POÇOS DE BOMBEAMENTO NO MODELO MATEMÁTICO .................68

FIGURA 25. LOCALIZAÇÃO DOS POÇOS DE OBSERVAÇÃO ....................................................69

FIGURA 26. CALIBRAÇÃO DO MODELO MATEMÁTICO - SITUAÇÃO 'SEM BOMBEAMENTO' ................72

FIGURA 27. CALIBRAÇÃO DO MODELO MATEMÁTICO - SITUAÇÃO 'COM BOMBEAMENTO' ...............72

FIGURA 28. BALANÇO DE ÁGUA TOTAL - SITUAÇÃO 'SEM BOMBEAMENTO' ................................73

FIGURA 29. BALANÇO DE ÁGUA TOTAL - SITUAÇÃO 'COM BOMBEAMENTO' ................................73

FIGURA 30. MAPA POTENCIOMÉTRICO - SITUAÇÃO 'SEM BOMBEAMENTO' (PLANTA E PERFIL DA

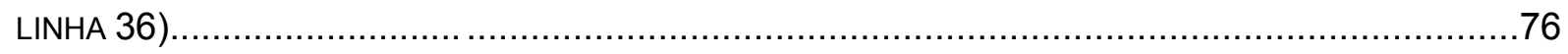

FIGURA 31. MAPA POTENCIOMÉTRICO - SITUAÇÃO 'COM BOMBEAMENTO’ (PLANTA E PERFIL DA

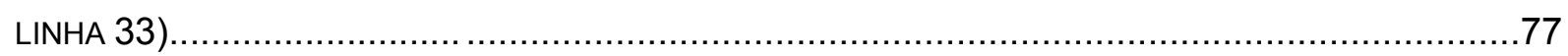

FIgURA 32. ANÁlise dE SENSIBILIDAdE DO MODELO MATEMÁtICO - SITUAÇÃO 'SEM

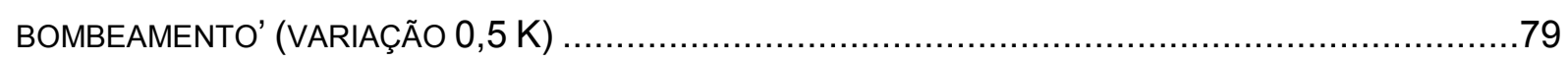

FIgURA 33. ANÁlise DE SENSIBILIDAdE DO MODELO MATEMÁtICO - SITUAÇÃO 'SEM

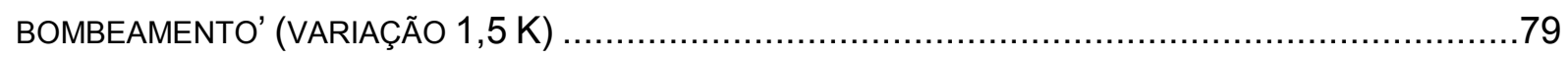

Figura 34. ANÁlise dE SENSibilidAde dO MOdELO MATEMÁtICO - SituAÇÃo 'SEM

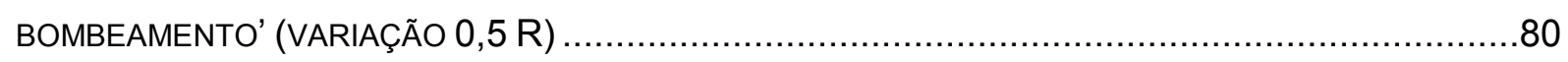

Figura 35. ANÁlise dE SENSibilidAdE dO MODELO MATEMÁtICO - SituAÇÃo 'SEM

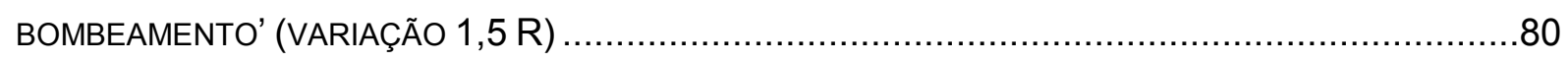

FIGURA 36. ÁREA URBANA DE URÂNIA COM CONCENTRAÇÃO CONSTANTE DE NITRATO NA PRIMEIRA CAMADA DO MODELO POR TODO O TEMPO SIMULADO (100 ANOS) ..............................82

FIGURA 37. LOCALIZAÇÃO DOS POÇOS DE OBSERVAÇÃO PO-100, PO-101 E PO-102 …...........82

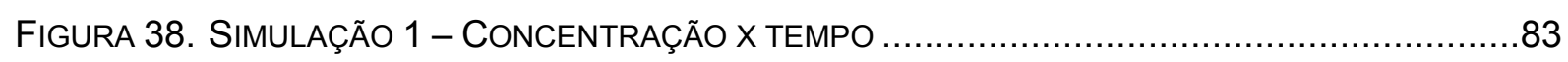

FIGURA 39. RESULTADOS DAS SIMULAÇÕES DA CONTAMINAÇÃO POR NITRATO NO AQUÍFERO

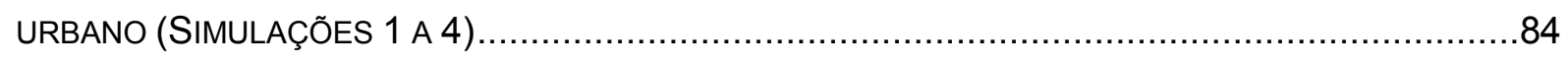

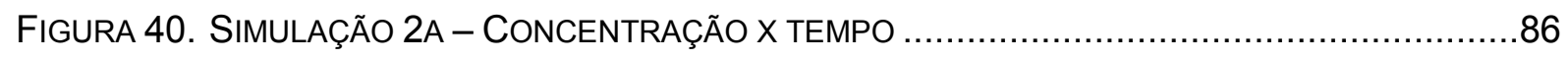

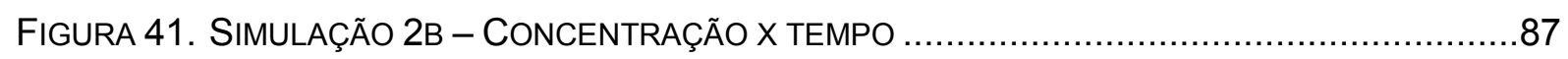

FIGURA 42. ÁREA URBANA DE URÂNIA COM CONCENTRAÇÃO CONSTANTE DE NITRATO NA PRIMEIRA CAMADA DO MODELO POR TODO O TEMPO SIMULADO (100 ANOS), COM OS POÇOS DE PRODUÇÃO ATIVOS.

FIGURA 43. LOCALIZAÇÃO DOS POÇOS DE OBSERVAÇÃo PO-100 A PO-102 EM RELAÇÃO AO

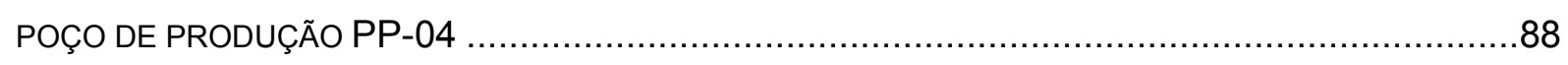

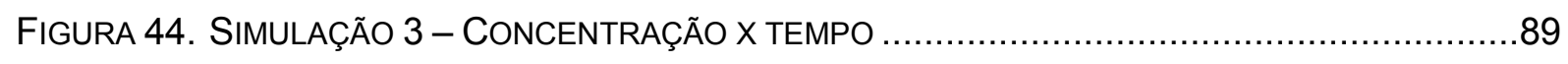


FIGURA 45. LOCALIZAÇÃO DAS PARTÍCULAS (EM VERDE) INSERIDAS AO REDOR DO PP-04 .90

FIGURA 46. TRAJETÓRIA DAS PARTÍCULAS - POÇOS DE PRODUÇÃO ATIVOS (PLANTA E PERFIL) ...91 FIGURA 47. TRAJETÓRIA DAS PARTÍCULAS - POÇOS DE PRODUÇÃO INATIVOS (PLANTA E PERFIL) 92

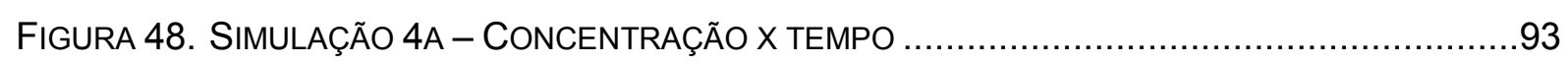

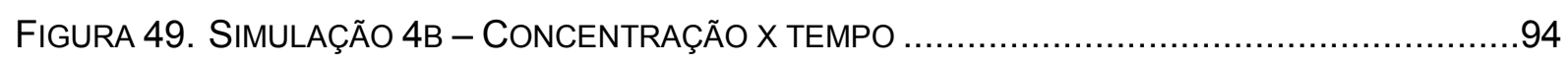

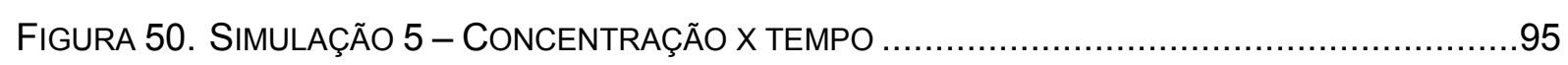

FIGURA 51. RESULTADOS DAS SIMULAÇÕES DA CONTAMINAÇÃO POR NITRATO NO AQUÍFERO

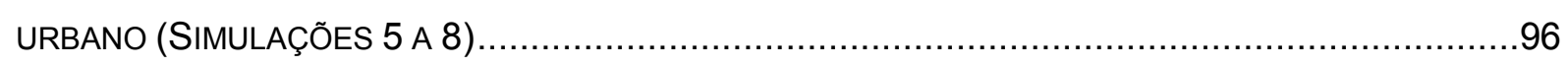

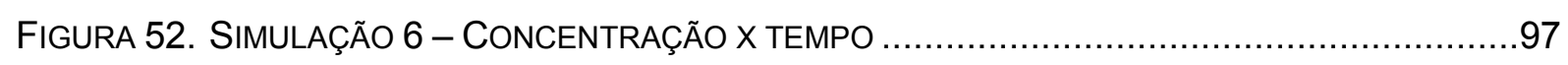

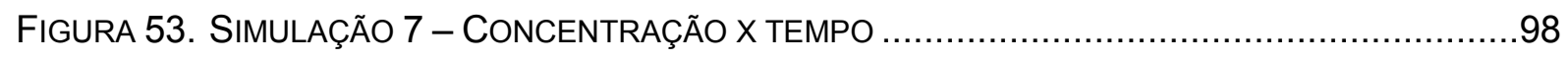

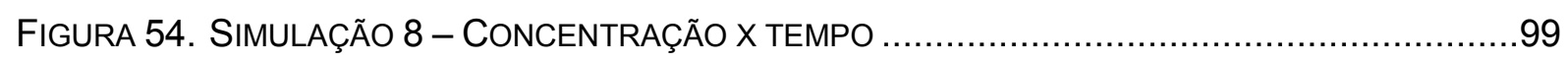

FIGURA 55. LOCALIZAÇÃO DAS FOSSAS CADASTRADAS EM URÂNIA - SP (EM ROSA) ................100

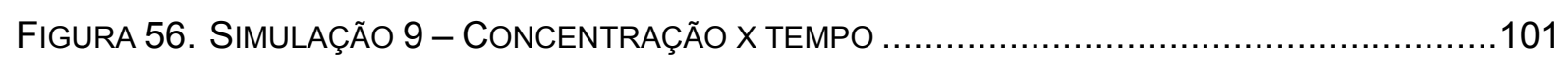

FIGURA 57. RESULTADOS DAS SIMULAÇÕES DA CONTAMINAÇÃO POR NITRATO NO AQUÍFERO

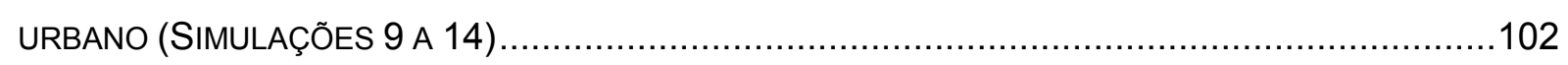

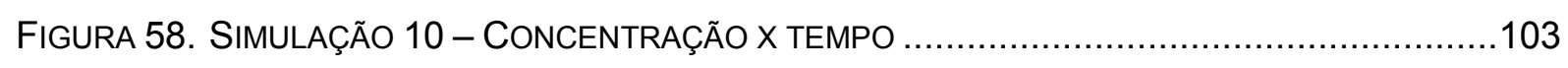

FIGURA 59. FONTES DE CONTAMINAÇÃO EM ÁREA DE 65 X 65 M ESPAÇADAS POR ÁREAS DE $130 \times$

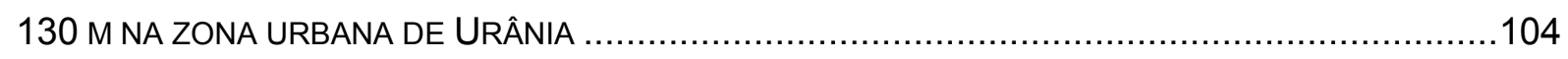

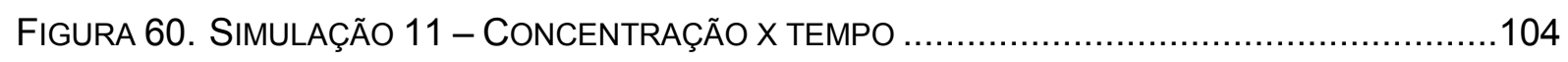

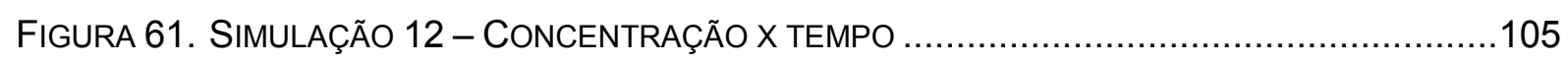

FIGURA 62. FONTES DE CONTAMINAÇÃO EM ÁREA DE 65 X 65 M ESPAÇADAS POR ÁREAS DE $65 \times$

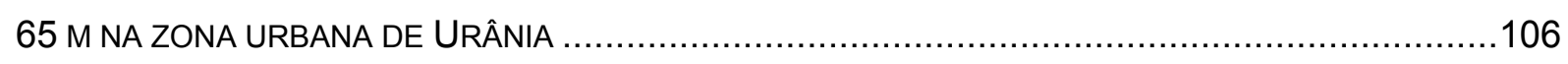

FIGURA 63. SIMULAÇÃO 13 - CONCENTRAÇÃO X TEMPO …...........................................107

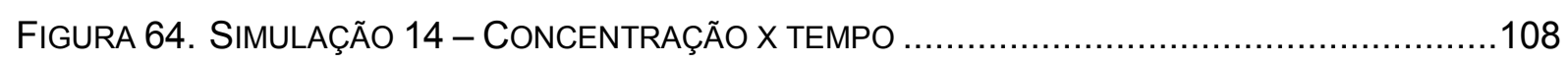

FIGURA 65. LOCALIZAÇÃO DOS POÇOS DE BOMBEAMENTO E DE OBSERVAÇÃO HIPOTÉTICOS NA

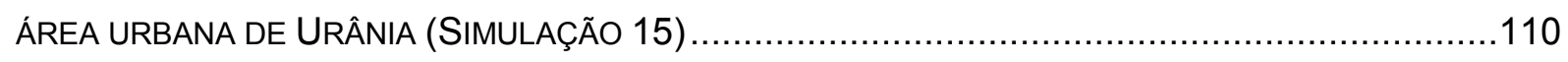

FIGURA 66. SIMULAÇÃO 15 - CONCENTRAÇÃO X TEMPO …...........................................111

FIGURA 67. RESULTADOS DAS SIMULAÇÕES DA CONTAMINAÇÃO POR NITRATO NO AQUÍFERO

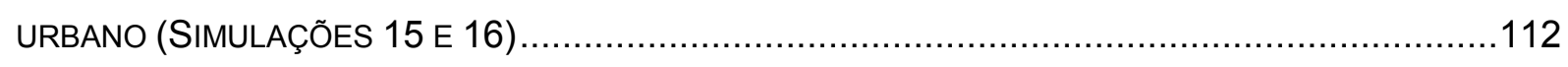

FIGURA 68. LOCALIZAÇÃO DOS POÇOS DE BOMBEAMENTO E DE OBSERVAÇÃO HIPOTÉTICOS NA

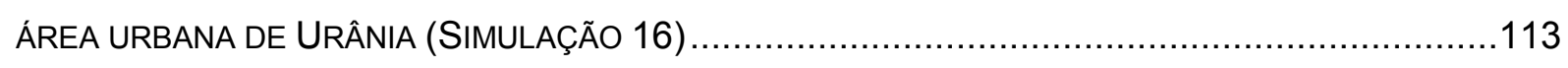

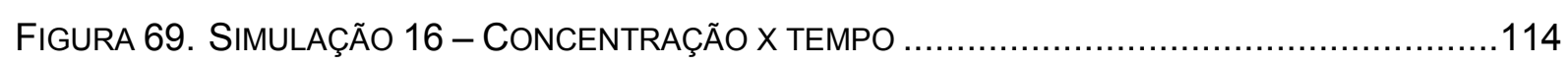




\section{LISTA DE TABELAS}

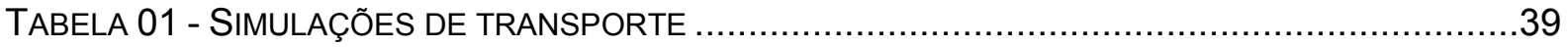

TABELA 02 - PROFUNDIDADE DA FoRMAÇÃo SERRA GERAL EM URÂNIA E REGIÃO ….................42

TABELA 03 - COORDENADAS EM UTM DOS POÇOS CADASTRADOS …....................................43

TABELA 04 - COTAS TOPOGRÁFICAS E MEDIDAS DE NÍVEL D’ÁGUA DOS POÇOS CADASTRADOS ....44

TABELA 05 - SUMÁRIO dOS PARÂMETROS HIDROGEOLÓGICOS PARA O AQUÍFERO ADAMANTINA .45

TABELA 06 - PRECIPITAÇÃO MENSAL EM URÂNIA (1959 A 2003)...........................................48

TABELA 07 - MEDIDAS DE CARGA HIDRÁULICA DOS CÓRREGOS ............................................49

TABELA 08 - EVOLUÇÃO DO USO E OCUPAÇÃO DO SOLO NO MUNICÍPIO DE URÂNIA ......................51

TABELA 09 - CONCENTRAÇÕES DE NITRATO NOS POÇOS EM URÂNIA - SP .................................54

TABELA 10 - PARÂMETROS HIDRÁULICOS ADOTADOS NO MODELO MATEMÁTICO .........................63

TABELA 11 - DADOS DOS POÇOS DE BOMBEAMENTO NO MUNICÍPIO DE URÂNIA ........................67

TABELA 12 - Resíduos CALCULAdOS ENTRE AS CARGAS HIDRÁUlicAS OBSERVADAS E DETERMINADAS PELO MODELO MATEMÁTICO ............................................................

TABELA 13 - BALANÇO TOTAL DE ÁGUA NO MODELO MATEMÁTICO .........................................71

TABELA 14 - RESULTADOS DOS VALORES DE CARGA HIDRÁULICA CALCULADOS PARA A CONDIÇÃO

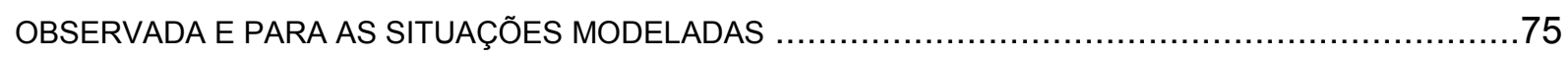

TABELA 15 - ANÁLISE DE SENSIBILIDADE DO MODELO MATEMÁTICO CONSTRUÍDO. .......................78

TABELA 16 - RESULTADOS DAS 16 SIMULAÇÕES EFETUADAS.................................................115 


\section{RESUMO}

A contaminação da água subterrânea por nitrato em áreas urbanas é um problema muito comum no Brasil. Geralmente muito dos estudos restringem-se em descrever somente os problemas associados às porções mais superficiais dos aquíferos. Mais recentemente, alguns trabalhos têm detectado a presença de nitrato nas partes mais profundas de aquíferos livres no Estado de São Paulo. Então, o principal objetivo desse trabalho foi o de avaliar os impactos potenciais do saneamento urbano no Aquífero Adamantina (livre, de porosidade primária, com 120 m de espessura saturada) na cidade de Urânia, simulando diferentes cenários de usos da terra, usando modelos numéricos de fluxo e transporte, com os softwares MODFLOW e MT3DMS.

A cidade de Urania é abastecida por água subterrânea e a rede de esgoto cobre quase a totalidade da área urbana, em um sistema operado pela SABESP (Companhia de Saneamento Básico do Estado de São Paulo). Poços privados e sistemas de saneamento in situ são práticas bastante comuns na cidade.

Os resultados da modelagem de fluxo permitiram identificar que o tempo de trânsito das águas subterrâneas entre sua área de recarga e a porção inferior do Aquífero Adamantina (120 m da superfície), sem a operação de poços de produção, é de aproximadamente 60 anos. Este tempo diminui para menos de 40 anos quando estes poços estão bombeando.

Caso a contaminação por nitrato seja de uma fonte constante em toda a área urbana, os resultados da modelação mostram que o aquífero tem capacidade de diluir apenas $30 \%$ da contaminação inicial. Considerando a construção de uma rede de esgoto totalmente eficiente, o modelo indicou que o tempo de recuperação das porções rasa e intermediária do aquífero é de 10 anos. Já na porção mais profunda, a contaminação perduraria por um período de 90 anos após o encerramento da fonte, com uma fração de $11 \%$ de sua concentração inicial, após 10 anos. Assim, conclui-se que a efetividade de estender a rede de esgoto no município em um período de 10 anos é uma medida interessante para mitigação do aquífero frente à contaminação por nitrato.

A capacidade máxima de diluição do contaminante pelo aquífero na área urbana de Urânia corresponde a fontes de contaminação de até $100 \mathrm{mg} / \mathrm{L}$ de nitrato oriundas de áreas de $65 \mathrm{~m}$ x $65 \mathrm{~m}$ na zona urbana do município, com um espaçamento de $130 \mathrm{~m} \times 130 \mathrm{~m}$ entre elas. 
A alternativa de contenção da contaminação para porções inferiores do aquífero por meio da existência de poços de produção com seção filtrante inserida na porção rasa do aquífero, visando à utilização desta água bombeada para usos menos nobres, enquanto os poços de produção destinados ao consumo humano, cujos filtros estariam posicionados na porção profunda, permaneceriam protegidos, somente se mostrou interessante quando as concentrações originais de nitrato forem inferior a $56 \mathrm{mg} / \mathrm{L}$, pois, desse modo, a capacidade de diluição do aquífero faria com que a concentração em água da porção profunda fosse inferior ao limite de potabilidade. 


\section{ABSTRAT}

Groundwater contamination by nitrate in urban areas is a very common problem in Brazil. Until now, many studies just describe the problem associated to shallowest part of aquifers. More recently, some works have detected the presence of nitrate in the deeper portion of some important unconfined aquifers in São Paulo state. Considering this potential problem, the main objective of this work was to evaluate the potential impacts of urban sanitation into the Adamantina Aquifer (primary porosity, unconfined aquifer with $120 \mathrm{~m}$ of saturated zone thickness) in the city of Urânia, simulating different land occupation scenarios using flow and transport mathematical models, respectively MODFLOW and MT3DMS codes.

The city of Urânia is totally supplied by groundwater and the sewage mains cover almost all the urban area. Both water and sewage mains are operated by the SABESP (State of Sao Paulo water company), but it is necessary to recognize an important number of private wells and also septic tanks and pit latrines operating in the city.

The numerical model results could estimate the groundwater transit time from the recharge to the Adamantina Aquifer bottom (120 mbs) in 60 years. When the water wells are pumping, this time is reduced to 40 years.

A big impact is expected when the city is not served by any sewage mains and all effluent is infiltrated direct into the soil. In this case, considering a concentration of $100 \mathrm{mg} / \mathrm{L}$, the nitrate will reach the whole aquifer (including its bottom part) with $70 \%$ of the original concentration, in 60 years. Taking into the consideration that all domestic effluent is drained by the public sewage mains, the time for recovery is about 10 years for the shallower and intermediate parts of the aquifer. For the deeper part, it takes more than 90 years, but the expected concentration is $<11 \%$ of the original one, after 10 years. This permits to conclude that the construction of an efficient public sewage mains network could be a good solution in a time frame of 10 years.

It is also possible to define that to dilute a constant load of nitrate of $100 \mathrm{mg} / \mathrm{L}$ in an area of $65 \times 65 \mathrm{~m}$, it is necessary to have an area of $130 \mathrm{~m} \times 130 \mathrm{~m}$ to keep the water below the Brazilian potable standards. 
An alternative solution for reducing the nitrate contamination impact in production wells is to operate a group of wells together to extract poor quality water from shallower part of the aquifer to avoid the contamination of deeper production wells. The numerical simulation demonstrates that it is possible only when the shallow aquifer contamination presents concentration below $56 \mathrm{mg} / \mathrm{L}$. The simulation also demonstrates that the solution is possible, but it is too difficult to operate. 


\section{INTRODUÇÃO}

Problemas de aquíferos degradados por nitrato $\left(\mathrm{NO}_{3}{ }^{-}\right)$têm preocupado administradores dos recursos hídricos subterrâneos em muitos países, sobretudo porque este contaminante possui ampla ocorrência mundial.

Concentrações superiores a $10 \mathrm{mg} / \mathrm{L}_{\text {de }} \mathrm{N}^{-N^{-}}{ }_{3}^{-}$(i.e. aproximadamente $44 \mathrm{mg} / \mathrm{L} \mathrm{NO}_{3}{ }^{-}$) podem, se verificadas na população, ocasionar casos de metahemoglobina principalmente em crianças com menos de seis meses de vida e alguns tipos de cânceres (USEPA, 1995).

Há uma nítida correlação entre sistemas de saneamento e a contaminação por nitrato e microorganismos patogênicos (FOSTER \& HIRATA, 1988). Os sistemas de saneamento, mesmo os bem construídos e operados, geram alguma poluição por fósforo e nitrato (DOMENICO \& SCHWARTZ, 1998; WILHELM et al., 1994).

Este problema é mais grave em áreas de grande densidade populacional e de baixa renda, como favelas e conjuntos habitacionais sem abastecimento e esgotamento sanitário por rede pública, onde frequentemente a população emprega fossas sépticas ou negras como meio de eliminação de esgoto e pode eventualmente contaminar a própria água que consome.

No ano 2000, segundo o IBGE (2002), 58 \% dos distritos brasileiros (5751 distritos dos 9848 existentes) não eram servidos por esgotamento sanitário, sendo que destes, $91 \%$ faziam o uso de fossas. A situação é ainda mais grave se forem consideradas apenas as regiões Norte e Centro-Oeste, onde as percentuais de municípios sem coleta de esgoto ultrapassam $94 \%$ e $88 \%$, respectivamente.

A despeito da grande importânica assinalada, estudos específicos da contaminação de nitrato, por saneamento ou atividades agrícolas, são ainda bastante restritos no Brasil, sobretudo quando o tema é enfocado com um alto grau de detalhamento.

Muitos dos relatos da contaminação por nitrato em águas subterrâneas em áreas urbanas no Brasil descrevem ainda o problema como superficial, não atingindo os poços mais profundos (CAGNON, 2003). Todavia, é importante lembrar que, nessas áreas contaminadas, o sistema de saneamento por meio da coleta de efluente doméstico já havia sido implementado há algumas décadas, e a agricultura já havia sido substituída por outras atividades, entretanto, a persistência do contaminante está fazendo com que o problema perdure e, dependendo de sua intensidade, atingindo porções profundas do aquífero. 
Assim, a questão que se insinua é até que ponto a contaminação por nitrato poderá compromer os aquíferos livres sedimentares em áreas urbanas.

De modo a fornecer subsídios necessários para solução dessa questão e propor novas formas de amenizar o problema, buscou-se entender a evolução da contaminação por nitrato em aquíferos livres sedimentares, tanto em sua porção rasa quanto na profunda, por meio da modelagem matemática de fluxo e transporte desse poluente.

Para tanto, o presente estudo foi realizado a partir de dados obtidos no município de Urânia, localizada na região noroeste do Estado de São Paulo, a 600 km da capital. Assim como cerca de $40 \%$ do território paulista, o referido município está assentado sobre os domínios do Aquífero Adamantina, pertencente ao Sistema Aquífero Bauru, que é um dos mais importantes reservatórios subterrâneos naturais de água do Estado de São Paulo, ocupando uma área de $104000 \mathrm{~km}^{2}$.

Este município foi selecionado por apresentar altos teores de nitrato na zona não saturada (BERTOLO \& HIRATA, 2000; BERTOLO, 2001) e na porção rasa do aquífero livre, muitas vezes excedendo os valores de potabilidade (HIRATA, 2000a; BERTOLO \& HIRATA, 2000; GUTIERREZ, 1999), além de um bom grau de conhecimento de sua hidrogeologia, hidrogeoquímica e de sua contaminação por nitrato (VIVIANI-LIMA, 2007; SANTOS, 2006; CAGNON, 2003; CESARINO, 2002; PALMÉR-RIVERA, 2002; BERTOLO, 2001; VARNIER, 2001 e 2007; ALMODOVAR, 2000; CHIESSI, 2000; MARQUES, 2000; GUTIERREZ, 1999 e 2003; CAMPOS, 1987).

Estes dados e informações permitiram estabelecer um modelo numérico para entender o problema de contaminação por nitrato e sua evolução futura no tempo e no espaço, em diferentes profundidades do aquífero e, partir dos resultados obtidos, a definição da melhor operação dos poços afim de mitigar os impactos nos poços de produção. Para estas finalidades foram realizadas induções das variações nas concentrações de nitrato, nas condições hidrogeológicas do meio e nas vazões e posicionamento dos filtros dos poços de captação de água.

Urânia é abastecida por água subterrânea, onde seus poços de produção e toda a rede de esgoto são gerenciados pela SABESP (Companhia de Saneamento Básico do Estado de São Paulo). Todavia, uma parte dos proprietários privados ainda utiliza sistema de saneamento do tipo misto, caracterizado pelo uso de fossas negras, e poços cacimbas e tubulares rasos para a captação de água. Soma-se a isto o fato de que em décadas passadas a presença de fossas sépticas e negras era bastante comum. 
A contaminação de aquíferos por nitrato não se restringe à Urânia, visto que o processo histórico de ocupação territorial foi muito semelhante ao que experimentaram os vários municípios onde o problema também ocorre. Embora não exista um levantamento sistemático da situação paulista, acredita-se que várias dezenas de cidades estejam convivendo com o problema (CAMPOS et al., 1994), incluindo grandes centros como São José do Rio Preto (BARCHA, 1980), Bauru (HIRATA, 2000b), Marília, Presidente Prudente, Ribeirão Preto, entre outros.

Desta forma, os resultados obtidos a partir deste estudo poderão ser aplicados em áreas urbanas de outras cidades abastecidas por água subterrânea, visando à gestão da vulnerabilidade de seus aquíferos livres sedimentares frente à contaminação por nitrato.

\section{OBJETIVOS}

Os objetivos principais desta pesquisa são:

- Avaliar os possíveis impactos na porção profunda do aquífero livre, a partir da contaminação de nitrato em áreas urbanas;

- Estabelecer a dinâmica de evolução temporal e espacial da contaminação rasa e profunda em aquíferos livres, a partir de substâncias persistentes e móveis;

- Propor medidas de gerenciamento do uso do terreno urbano, para mitigar problemas de contaminação por fontes dispersas, envolvendo o nitrato.

\section{SISTEMAS DE SANEAMENTO IN SITU E A CONTAMINAÇÃO DAS ÁGUAS SUBTERRÂNEAS}

\subsection{Dinâmica do nitrogênio em subsuperfície}

O movimento e a transformação dos compostos nitrogenados na biosfera podem ser caracterizados como o ciclo do nitrogênio (Figura 1).

O ciclo do nitrogênio é um dos mais importantes nos ecossistemas terrestres. $O$ nitrogênio é usado pelos seres vivos para a produção de moléculas complexas necessárias ao seu desenvolvimento, tais como aminoácidos, proteínas e ácidos nucleicos (WIKIPÉDIA on-line, acesso em 09 de abril de 2009), sendo indispensável à vida. É um elemento biologicamente ativo e participa de uma infinidade de reações que são importantes para a vida, e que afetam a qualidade da água. 


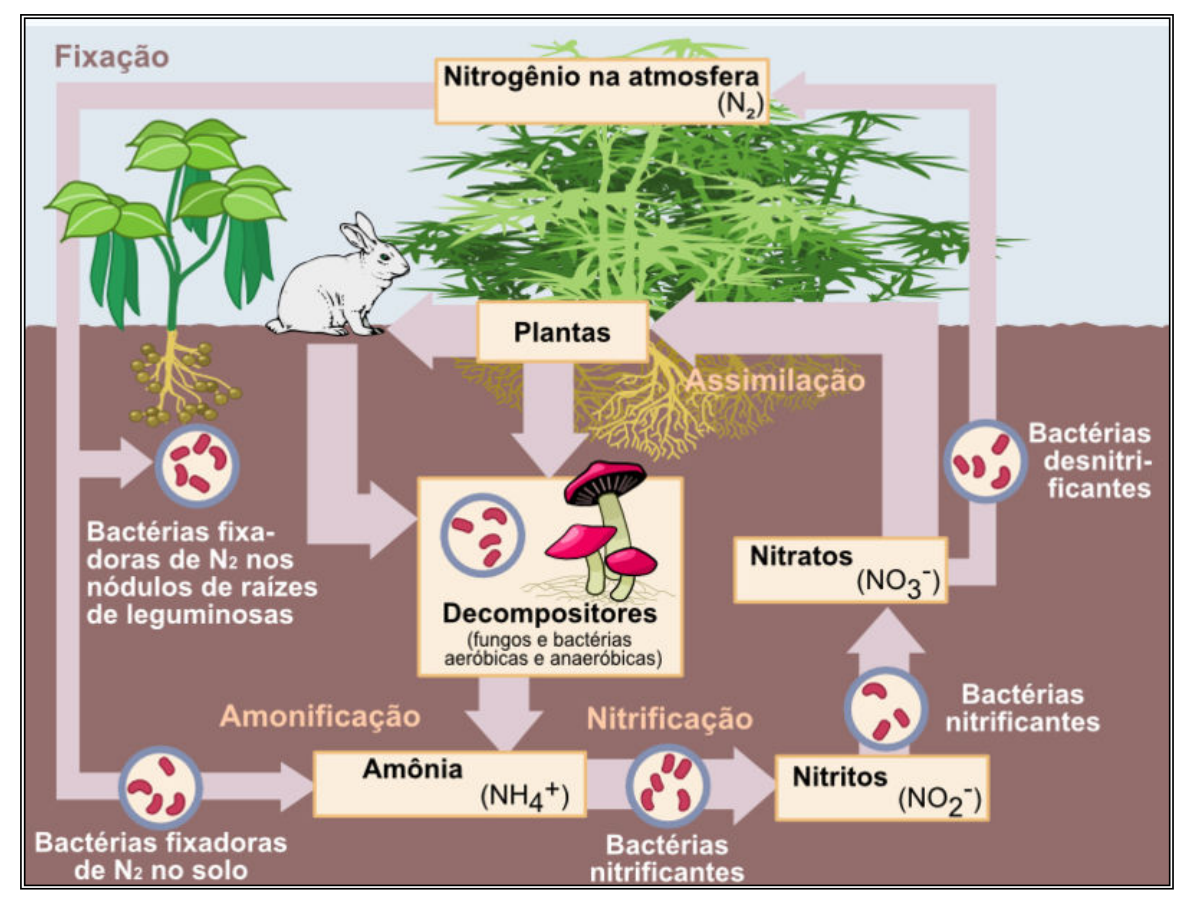

Fonte: http://pt.wikipedia.org/wiki/Ciclo do nitrog\%C3\%AAnio (acessado em 09/04/2009).

Figura 1. Ciclo do nitrogênio

O nitrogênio ocorre na natureza em sete estados de oxidação, variando desde -3 $\left(\mathrm{NH}_{3}\right)$, na forma mais reduzida, até $+5\left(\mathrm{NO}_{3}{ }^{-}\right)$, mais oxidada (STUMM \& MORGAN, 1996).

Os mecanismos de transporte primariamente responsáveis pelo movimento do nitrogênio no meio ambiente incluem precipitação, sedimentação em sistemas aquáticos, vento, movimento das águas subterrâneas e superficiais e volatilização. Estes mecanismos são controlados pela temperatura, pH, flora, microbiologia, potencial de oxidação e redução, e a disponibilidade no substrato de nutrientes e oxigênio.

Apesar de mecanismos de transporte e transformação serem tipicamente considerados como processos individuais, é importante reconhecer que estes compreendem uma dinâmica contínua e muitas vezes não é possível distinguir os limites que governam a transformação de formas específicas de nitrogênio (USEPA, 1994).

O nitrogênio orgânico pode propiciar à formação de nitrogênio amoniacal (amônio e amônia). $\mathrm{O}$ nitrogênio amoniacal $\left(\mathrm{NH}_{4}{ }^{+}\right)$pode seguir destinos diferentes no solo, como a geração de formas mais oxidadas, transferência para outros ecossistemas ou, até mesmo, troca catiônica entre os argilominerais e matéria orgânica, propiciando sua fixação no solo (NOMMIK \& VAHTRAS, 1982). 
Desta forma, a transformação dos compostos nitrogenados pode ocorrer por meio de diferentes mecanismos, dentre os quais incluem a amonificação, nitrificação e desnitrificação, apresentadas a seguir:

\section{a) Amonificação}

Grande parte do nitrogênio encontrado no solo provém de materiais orgânicos, nos quais existe sob a forma de compostos orgânicos complexos, tais como proteínas, aminoácidos, ácidos nucléicos e nucleótides.

Entretanto, estes compostos nitrogenados são, em geral, rapidamente decompostos em substâncias mais simples por organismos que vivem nos solos. As bactérias saprófitas e várias espécies de fungos são os principais responsáveis pela decomposição de materiais orgânicos. Estes microrganismos utilizam as proteínas e os aminoácidos como fonte para suas próprias proteínas e liberam o excesso de nitrogênio sob a forma de amônio. Este processo é denominado amonificação.

O nitrogênio pode ser fornecido sob a forma de gás amoníaco, mas este processo ocorre geralmente apenas durante a decomposição de grandes quantidades de materiais ricos em nitrogênio, como numa grande porção de adubo ou fertilizante. Em geral, a amônia produzida por amonificação é dissolvida na água do solo, onde se combina a prótons para formar o íon amônio.

\section{b) Nitrificação}

A oxidação do amoníaco, conhecida como nitrificação, é um processo que produz nitratos a partir do amoníaco $\left(\mathrm{NH}_{3}\right)$. Este processo é realizado por bactérias (bactérias nitrificantes) em dois passos: em uma primeira fase o amoníaco é convertido em nitritos $\left(\mathrm{NO}_{2}{ }^{-}\right)$e em uma segunda fase (através de outro tipo de bactérias nitrificantes) os nitritos são convertidos em nitratos $\left(\mathrm{NO}_{3}{ }^{-}\right)$, prontos a ser assimilados pelas plantas.

$\mathrm{O}$ nitrogênio na forma de nitrato $\left(\mathrm{NO}_{3}^{-}\right)$é um dos mais problemáticos e difundidos contaminantes dentre o vasto número de potenciais contaminantes das águas subterrâneas (KEENEY, 1986 apud CANTER, 1997). O nitrato também provém da utilização de adubos na agricultura, dos produtos de rejeição da criação de animais e de sistemas sépticos deficientes. 
c) Desnitrificação

A desnitrificação é o processo pelo qual o nitrogênio volta à atmosfera sob a forma de gás $\left(\mathrm{N}_{2}\right)$. Este processo ocorre através de algumas espécies de bactérias (tais como Pseudomonas e Clostridium) em ambiente anaeróbico. Estas bactérias utilizam nitratos alternativamente ao oxigênio como forma de respiração e libertam o $\mathrm{N}_{2}$, segundo a reação: $\mathrm{NO}_{3}^{-}+(5 / 6) \mathrm{CH}_{3} \mathrm{OH} \leftrightarrow(5 / 6) \mathrm{CO}_{2}+0,5 \mathrm{~N}_{2}+(7 / 6) \mathrm{H}_{2} \mathrm{O}+\mathrm{OH}^{-}$.

\subsection{Sistemas sépticos in situ e a contaminação de aquíferos}

Nitrato é um íon $\left(\mathrm{NO}_{3}{ }^{-}\right)$de grande mobilidade e persistência em aquíferos oxidados. As águas subterrâneas em condições naturais contêm, geralmente, teores de nitrato que variam entre 0,1 e $10 \mathrm{mg} / \mathrm{L}$. Contudo, em águas poluídas, os teores podem atingir valores na ordem de $200 \mathrm{mg} / \mathrm{L}$ e, em casos mais extremos, de $1000 \mathrm{mg} / \mathrm{L}$. Uma fonte comum de contaminação de aquíferos por nitrato é o uso de sistemas de saneamento in situ do tipo fossas sépticas e negras.

Os sistemas de saneamento in situ, mesmo as bem construídas e operadas, geram algum nível de poluição por fósforo e nitrato (DOMENICO \& SCHWARTZ, 1998; WILHELM et al., 1994). Segundo WILD (1977, apud CAGNON, 2003), os efluentes oriundos de esgotamento sanitário contribuem com até $40 \%$ da massa de nitrato presente nas águas superficiais, podendo ocasionar eutrofização daqueles corpos d'água.

Segundo FOSTER \& HIRATA (1988), há uma nítida correlação entre sistemas de saneamento e a contaminação por nitrato e microorganismos patogênicos.

Plumas contaminantes geradas por sistemas de saneamento in situ são descritas por vários autores em diversas situações hidrogeológicas (WOODWARD et al., 1961; WALKER et al., 1973; VIRARAGHAVAN \& WARNOCK, 1976; STARR \& SAWHNEY, 1980; FOSTER et al., 1987; ROBERTSON \& CHERRY, 1992; FERREIRA \& HIRATA, 1993; HIRATA, 2000c e VARNIER, 2001). O número de casos de contaminação por sistemas de fossas sépticas fez com que PATTERSON et al. (1971, apud LEWIS et al., 1982) recomendassem o não uso destes sistemas em áreas densamente povoadas.

De acordo com HIRATA (2000c), os efluentes domésticos municipais possuem elevadas concentrações de carbono orgânico, cloreto, nitrogênio, sódio, magnésio, sulfato e alguns metais, incluindo ferro, zinco e cobre, além de concentrações variadas de microorganismos patogênicos. Destes compostos, os que apresentam os maiores riscos à água subterrânea são o nitrogênio e os microrganismos patogênicos. 
O nitrogênio em fossas sépticas encontra-se cerca de $75 \%$ na forma amoniacal e 25 \% na forma orgânica, ou seja, o amônio é a forma predominante de nitrogênio que penetra em subsuperfície. Ele pode ser descarregado diretamente da fossa ou ser transformado a amônio por meio da conversão do nitrogênio orgânico, dentro do sistema de disposição de efluentes (CANTER \& KNOX, 1988).

ROBERTSON et al. (1991) investigaram os impactos causados por dois sistemas sépticos adjacentes à duas casas, localizados sobre aquíferos rasos, arenosos e nãoconfinados, em duas planícies da província de Ontário no Canadá, por meio de uma rede de monitoramento de água subterrânea. Nas duas áreas estudadas, a configuração das plumas demonstrou que o transporte destas por advecção é rápido em contrapartida a uma ineficiente dispersão e atenuação da pluma por dispersão. Observou-se também a ocorrência de um processo de desnitrificação associado aos sedimentos do leito do rio, ricos em carbono orgânico. As plumas das duas áreas foram caracterizadas, comparativamente aos valores de background, por meio dos baixos níveis de oxigênio dissolvido e $\mathrm{pH}$ e as altas concentrações de nitrato.

VARNIER (2001) desenvolveu estudos de detalhe sobre o impacto de fossas sépticas em aquíferos rasos. Os resultados destes trabalhos mostraram uma zonificação em três áreas, segundo o tipo de ambiente geoquímico e a disponibilidade de nitrogênio. Em uma zona mais próxima à fossa, nota-se que o ambiente é mais redutor, com predominância de nitrogênio amoniacal e carbono orgânico dissolvido. Na segunda zona, há a presença de amônio e nitrato, e na terceira, maior disponibilidade de oxigênio dissolvido próximo à saturação, e predominância de nitrato.

Uma das maiores preocupações relacionadas ao uso da água subterrânea com excessivas concentrações de nitrato está relacionada aos efeitos que podem causar à saúde humana. O mais importante efeito está relacionado à perda da capacidade de transporte/transferência do oxigênio no sangue, a metahemoglobinemia.

O Ministério da Saúde do Brasil, por meio da Portaria 518 de 2004, considera que uma água é não potável ou imprópria para o consumo quando as concentrações de nitrato $\left(\mathrm{NO}_{3}{ }^{-}\right)$ excedem $44 \mathrm{mg} / \mathrm{L}$ (i.e. $10 \mathrm{mg} / \mathrm{L}$ de $\mathrm{N}-\mathrm{NO}_{3}{ }^{-}$). 
Adicionalmente, outra preocupação relacionada à saúde pública é que muitos estudos mostraram que a ingestão de nitrito pode resultar em cânceres de muitos órgãos. $\mathrm{O}$ nitrito, e indiretamente o nitrato, pode reagir com amidas para formar nitrosaminas e nitrosamidas. Estudos comprovaram que a maioria destes compostos pode ser cancerígena a um grande número de espécies animais, além de mutagênica. A abundante ingestão de nitrato pode contribuir ao surgimento de câncer gástrico. Todavia, atualmente não existem estudos que comprovem a existência de uma relação direta entre a elevada ingestão de nitrato e algum tipo de câncer em seres humanos (FRASER et al., 1980 apud FERREIRA, 1999).

\section{MODELOS DE FLUXO E TRANSPORTE}

Em muitos casos, apenas o entendimento do sistema hidrogeológico não é suficiente para a tomada de medidas de proteção ou mesmo recuperação de uma área, fazendo-se necessário o entendimento dinâmico de sistemas complexos e a previsão de cenários distintos. Atualmente, a melhor ferramenta para esta necessidade é a modelagem matemática.

De acordo com ANDERSON \& WOESSNER (1992), a utilização de modelos matemáticos nos estudos de águas subterrâneas é o melhor caminho para realizar previsões adequadas acerca das consequências de uma determinada ação proposta.

Ainda, conforme WANG \& ANDERSON (1982), "um modelo é uma ferramenta projetada para representar uma versão simplificada da realidade". Uma vez que os sistemas de águas subterrâneas são muito complexos, a simplificação é necessária para facilitar as decisões de planejamento e gestão.

No entanto, a modelagem matemática requer um conhecimento mais detalhado do sistema a ser modelado, comparativamente às metodologias mais simples, para representar o comportamento do sistema físico real da água subterrânea através da solução de equações numéricas que regem os processos atuantes. Um dos principais desafios, no caso, é a transferência desse conhecimento para o modelo numérico.

Modelos de fluxo e transporte desenvolveram-se dos modelos físicos de laboratórios, que foram utilizados até o início da década de 70, para os softwares de modelos numéricos utilizados atualmente (BEAR \& VERRUIJT, 1987). 
Os procedimentos ou passos efetuados no computador para resolução das equações utilizadas para construir o modelo matemático formam o programa de computador ou software ou aplicativo ou simulador matemático. KONIKOW \& BREDEHOEFT (1992) chamam este software, construído para resolver as equações parciais através de algoritmos numéricos, de "modelo genérico".

Pelo fato da inexistência de um bom termo em português para a tradução de "computer code", que na língua inglesa é utilizado para identificar estes programas de computador utilizados para construir modelos matemáticos de um sistema físico de água subterrânea (ANDERSON \& WOESSNER, 1992), muitas vezes são referidos simplesmente como modelos, como por exemplo, modelo FLOWPATH (em HIRATA, 1994) ou modelo PLASM (em CLEARY, 1989). KONIKOW \& BREDEHOEFT (1992) chamam o modelo matemático de modelo específico, mas este termo não parece adequado, pois pode não esclarecer que é um modelo construído a partir de resolução de equações matemáticas.

Atualmente, o termo modelo usado em estudos da água subterrânea pode ser confundido com outros significados. Ele é usado para descrever: a teoria que explica os processos em consideração; o software de modelo numérico utilizado para simular estes processos; e a aplicação do software de modelagem numérica para o site específico (GUIGER, 1994, apud IRITANI, 1998). Neste texto, o termo modelo matemático será utilizado para representação matemática de um determinado sistema físico de água subterrânea e o termo software para referir-se ao programa de computador utlizado para construção do modelo matemático.

Modelos de fluxo e transporte apresentam muitas aplicações na solução de problemas de águas subterrâneas e, em muitos casos que envolvam condições geológicas complexas ou líquidos não-aquosos multifásicos, são a única opção. Algumas das aplicações podem ser (IRITANI, 1998):

- Como ferramenta para determinação de quanto e onde coletar dados de campo ou para avaliação da utilidade de dados de campo pré-existentes;

- Para compreensão e previsão de fenômenos de fluxo e transporte em sistemas de aquíferos heterogêneos, anisotrópicos e estratificados;

- Como ferramenta auxiliar na seleção de possíveis alternativas para remediar um aquífero contaminado;

- Para o delineamento de áreas de proteção da zona de contribuição do poço, sob condições geológicas de heterogeneidade e anisotropia; 
- Para previsão do destino e do transporte de contaminantes na água subterrânea, sob condições multifásicas, em sistemas aquíferos heterogêneos;

- Para otimização da gestão dos recursos de águas subterrâneas.

De acordo com ANDERSON \& WOESSNER (1992), existem três tipos principais de aplicações do modelo matemático:

- Previsível: o tipo mais comum, usado para prever o futuro;

- Interpretativo: usado para estudos do sistema e/ou organização de dados de campo;

- Genérico: usado para analisar o fluxo em sistemas hipotéticos, que podem ser úteis ao elaborar as diretrizes normativas para uma região específica.

Apesar dos resultados dos modelos matemáticos serem questionáveis em alguns casos, ainda assim, constituem a melhor ferramenta existente para a compreensão do sistema real e para previsão e comparação de alternativas ou cenários futuros.

Um modelo matemático é descrito pelas equações que governam o sistema, no caso deste estudo, a equação fundamental de fluxo de água subterrânea, pelas condições iniciais e de contorno, e pelas equações de transporte de contaminantes, como de advecção e dispersão.

\subsection{Equação de fluxo da água subterrânea}

A modelagem matemática de fluxo da água subterrânea consiste em parte nas equações diferenciais, condições iniciais e condições de contorno (GUIGER, 1994, apud IRITANI, 1998). Resolver o modelo significa calcular os valores de carga hidráulica em cada ponto do sistema (WANG \& ANDERSON, 1982).

A equação diferencial parcial tridimensional, aplicada a um modelo matemático que governa o fluxo da água subterrânea, considerando-se um meio heterogêneo, anisotrópico e em estado transiente, é derivada através da combinação matemática da equação de balanço de água e da lei de Darcy (ANDERSON \& WOESSNER, 1992; CLEARY, 1989). Se estas duas estão combinadas, e fontes/sumidouros e mudança no armazenamento estão incluídas, considerando-se um volume elementar representativo de um aquífero, com os eixos do sistema de coordenadas coincidentes com as principais direções do tensor de condutividade hidráulica, isto é, $x, y$ e $z$ colineares a $K_{x}, K_{y}$ e $K_{z}$, respectivamente, e considerando a água com uma densidade constante, a equação fundamental de fluxo tridimensional das águas subterrâneas no meio poroso pode ser descrita pela Equação 1 (MCDONALD \& HARBAUGH, 1988; CLEARY, 1991): 
$\frac{\partial}{\partial_{x}}\left(K_{x x} \frac{\partial h}{\partial x}\right)+\frac{\partial}{\partial_{y}}\left(K_{y y} \frac{\partial h}{\partial y}\right)+\frac{\partial}{\partial_{z}}\left(K_{z z} \frac{\partial h}{\partial z}\right)-W=S_{s} \frac{\partial h}{\partial t}$

Equação 1

Sendo,

$H \quad$ Carga hidráulica [L]

$K_{x} K_{y}$ e $K_{z} \quad$ Valores de condutividade hidráulica ao longo dos eixos cartesianos $x, y$ e $z$, respectivamente, que são considerados paralelos aos eixos da condutividade hidráulica $[\mathrm{L} / \mathrm{T}]$

$S_{s} \quad$ Armazenamento específico [1/L]. Utilizado em equações tridimensionais. Equivalente ao volume de água liberado $\left[\mathrm{L}^{3}\right]$, por unidade de volume de material poroso $\left[\mathrm{L}^{3}\right]$, por unidade de decréscimo da carga hidráulica [L]

$T \quad$ Tempo [T]

$W \quad$ Fluxo volumétrico por unidade de volume, que representam fontes e/ou sumidouros de água $\left[L^{3} / T L^{3}\right]$

ANDERSON \& WOESSNER (1992) ilustram como a equação fundamental de fluxo de água subterrânea foi derivada a partir da combinação do balanço de água e da lei de Darcy. Primeiramente, considera-se um volume elementar representativo de um aquífero, com volume igual a $\Delta x . \Delta y . \Delta z$ (Figura 2 ), onde o seu tamanho é suficientemente grande para representar as propriedades do meio poroso, mas, por outro lado, suficientemente pequeno para não refletir grandes mudanças na carga hidráulica.

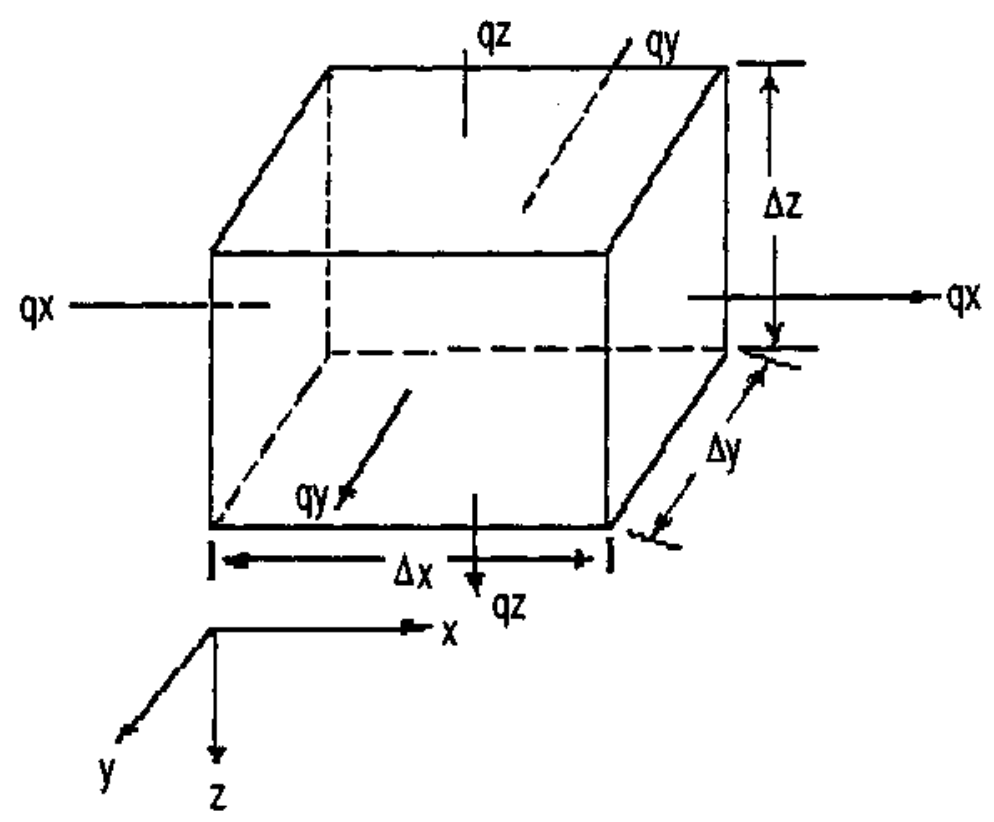

Figura 2. Representação do volume elementar de um aquífero (FETTER, 1988) 
O balanço de água dita que a diferença entre o fluxo de saída de água e o fluxo de entrada de água no volume elementar deve ser igual a mudança no armazenamento.

Dessa forma, considerando-se os fluxos de entrada e saída nos três eixos de coordenadas tem-se (Equação 2):

$$
\Delta V=q_{\text {OUT }}-q_{I N}-W
$$

\section{Equação 2}

Sendo que $W$ é colocado para representar fontes ou sumidouros no sistema. Assim, obtemse as Equações 3 e 4:

$$
\begin{array}{cc}
\left(\frac{\partial q_{x}}{\partial x}+\frac{\partial q_{y}}{\partial y}+\frac{\partial q_{z}}{\partial z}\right) \Delta x \Delta y \Delta z-W(\Delta x \Delta y \Delta z)=\frac{\Delta V}{\Delta t} & \text { Equação } 3 \\
\frac{\Delta V}{\Delta t}=-S_{s} \frac{\partial h}{\partial t} \Delta x \Delta y \Delta z & \text { Equação } 4
\end{array}
$$

Desta forma tem-se que (Equação 5)

$$
\frac{\partial q_{x}}{\partial x}+\frac{\partial q_{y}}{\partial y}+\frac{\partial q_{z}}{\partial z}=-S_{s} \frac{\partial h}{\partial t}+W \quad \text { Equação } 5
$$

Pela lei de Darcy (Equações 6 a 8):

$$
\begin{array}{ll}
q_{x}=-K_{x} \frac{\partial h}{\partial x} & \text { Equação 6 } \\
q_{y}=-K_{y} \frac{\partial h}{\partial y} & \text { Equação 7 } \\
q_{z}=-K_{z} \frac{\partial h}{\partial z} & \text { Equação 8 }
\end{array}
$$

Assim, a combinação da lei de Darcy com a equação de balanço de água, fornece a equação fundamental de fluxo da água subterrânea, como mostrado no início deste item. Caso não seja possível alinhar os principais tensores de condutividade hidráulica com as coordenadas do sistema, é necessário considerar as componentes cruzadas deste parâmetro na equação diferencial parcial (IRITANI, 1998), como segue (Equação 9): 


$$
\begin{aligned}
& \frac{\partial}{\partial x}\left(K_{x x} \frac{\partial h}{\partial x}\right)+\frac{\partial}{\partial x}\left(K_{x y} \frac{\partial h}{\partial y}\right)+\frac{\partial}{\partial x}\left(K_{x z} \frac{\partial h}{\partial z}\right)+ \\
& \frac{\partial}{\partial y}\left(K_{y x} \frac{\partial h}{\partial x}\right)+\frac{\partial}{\partial y}\left(K_{y y} \frac{\partial h}{\partial y}\right)+\frac{\partial}{\partial y}\left(K_{y z} \frac{\partial h}{\partial z}\right)+ \\
& \frac{\partial}{\partial z}\left(K_{z x} \frac{\partial h}{\partial x}\right)+\frac{\partial}{\partial z}\left(K_{z y} \frac{\partial h}{\partial y}\right)+\frac{\partial}{\partial z}\left(K_{z z} \frac{\partial h}{\partial z}\right)+ \\
& W(x, y, z, t)=S_{s} \frac{\partial h}{\partial t}
\end{aligned}
$$

Equação 9

Nesse estudo foi considerado um sistema tridimensional, heterogêneo e anisotrópico, com os eixos do sistema de coordenadas coincidentes com o tensor de condutividade hidráulica. Outros cenários, considerando sistemas bidimensionais ou unidimensionais, homogêneos ou isotrópicos podem ser encontrados em BEAR (1972), FREEZE \& CHERRY (1979), FETTER (1988), CLEARY (1989), ANDERSON \& WOESSNER (1992).

Quando considera-se situações simplificadas, de homogeneidade e isotropia, em uma ou duas dimensões, é possível resolver a equação de fluxo de forma analítica. Entretanto, métodos numéricos permitem maior amplitude de cenários a serem simulados e maior versatilidade na representação do sistema real, pois permitem discretizar a equação diferencial parcial nas variáveis de espaço $(x, y, z)$ (CLEARY, 1989).

Os métodos numéricos mais utilizados na modelagem matemática são o de diferenças finitas, utilizado neste estudo, e elementos finitos.

O método de elementos finitos é uma representação discretizada sobre uma área (CLEARY, 1989), sendo que a variação da carga hidráulica dentro do elemento é definido pela interpolação da carga nos nós. O elemento finito é, em geral, definido por triângulos, que podem ser refinados nas áreas de maior interesse, como áreas com alto gradiente hidráulico, permitindo um melhor ajuste ao formato da área. Entretanto, é um método mais difícil de ser manuseado, sendo, ainda, pouco utilizado para a modelagem matemática de fluxo de água subterrânea. 
O método de diferenças finitas é uma representação discretizada em um ponto (CLEARY, 1989), isto é, a carga hidráulica é definida no nó da malha e é extrapolada para toda a área que envolve o nó. Este método, empregado nos softwares de fluxo mais utilizados atualmente, tem a grade ou malha do modelo definida por linhas e colunas, apresentando um ajuste mais grosseiro ao formato da área modelada. Por outro lado, sua facilidade de utilização para entrada de dados e análise dos resultados do modelo matemático faz com que seja o método mais empregado no momento para a simulação de fluxo da água subterrânea. Quando as direções principais de condutividade hidráulica variam em todo o aquífero, não podendo ser ajustadas aos eixos das coordenadas, deve utilizar-se o método de elementos finitos.

A escolha de qualquer um dos métodos influencia a estrutura da grade do modelo, que pode, então, ser discretizada em elementos finitos ou em uma grade de diferenças finitas.

O software MODFLOW (MCDONALD \& HARBAUGH, 1988), escolhido para esse estudo, utiliza uma grade de diferenças finitas, onde o nó da célula, isto é, o ponto onde o valor de um dado ou informação é posicionado, está localizado no centro da célula ou bloco, sendo por isso, chamado de diferenças finitas centradas no bloco. Quando o dado é colocado na intersecção das linhas e colunas da malha que define a grade do modelo, tem-se uma abordagem de diferenças finitas com nós centrados na malha. Para definir as fronteiras do domínio de um modelo matemático, por exemplo, através de rios e cargas constantes, as diferenças finitas centradas no bloco são, matematicamente, mais fáceis de serem manipuladas e resolvidas (ANDERSON \& WOESSNER, 1992), o que leva a maioria dos softwares existentes a usarem este método, como no MODFLOW.

O MODFLOW permite a simulação em estado transiente ou estacionário, condições heterogêneas e anisotrópicas para as múltiplas camadas, discretizadas em uma grade irregular ou uniforme. Entretanto, simula somente o fluxo saturado, não podendo considerar o fluxo na zona não saturada, bem como também não considera diferenças de densidade de fluidos, efeitos de gradiente de temperatura e mudanças de viscosidade.

\subsection{Modelo conceitual}

O modelo conceitual consiste em compreender o sistema hidrogeológico em questão com base na interpretação e análise semi-qualitativa dos dados (WALTON, 1992) de forma a identificar as unidades hidroestratigráficas e suas características hidráulicas e o sistema de fluxo da água subterrânea. Este modelo conceitual norteará a definição do domínio do modelo, do tipo de aquífero a ser modelado, das condições iniciais e de contorno, e das fontes e sumidouros de água no sistema. 
A interpretação de mapas e perfis litológicos e perfilagens geofísicas de poços para a confecção de seções geológicas, combinada com a análise das propriedades hidráulicas, direcionam a definição das unidades hidroestratigráficas a serem utilizadas na modelagem matemática, caracterizando-as em extensão, continuidade lateral e espessura.

Os modelos numéricos requerem a definição de condições de contorno, onde são especificadas as cargas hidráulicas ou taxas de fluxo, para a delimitação da área modelada. ANDERSON \& WOESSNER (1992) sugerem que, sempre que possível, sejam adotadas como condições de contorno, fronteiras hidráulicas naturais, representadas por alguma feição física como contatos geológicos, rios e divisores de águas subterrâneas.

A compreensão do sistema de fluxo das águas subterrâneas é obtida através da avaliação dos mapas potenciométricos, podendo-se identificar as áreas de recarga e descarga da região de interesse e as feições que afetam, hidraulicamente, o sistema avaliado, inclusive, a influência antrópica como poços, drenos e tanques que podem funcionar como consumidores (sumidouros) ou fornecedores (fontes) de água.

\subsection{Condições de contorno}

As condições de contorno são utilizadas para definir, com base no sistema hidrogeológico real, as fronteiras hidráulicas ou físicas que delimitam o domínio do modelo.

As barreiras físicas podem ser exemplificadas como corpos superficiais de água ou presença de rocha impermeável. As barreiras hidráulicas não são visíveis, mas controlam o fluxo de água subterrânea no sistema e podem ser exemplificadas como os divisores de água ou as linhas de fluxo.

Há três tipos de condições de contorno matemáticas usados para representar os limites hidrogeológicos (ANDERSON \& WOESSNER, 1992):

- Primeiro tipo ou de Dirichlet, onde a carga é especificada no contorno (constante ou função do espaço e/ou do tempo). A carga hidráulica pode ser constante, como por exemplo um lago, ou variar em função do tempo e do espaço, como nos rios (CLEARY, 1989);

- Segundo tipo ou de Neumann, onde o fluxo é especificado no contorno. Exemplifica-se aqui o "não fluxo", isto é, fluxo igual a zero, simulando zonas impermeáveis ou fluxo nulo para divisores de águas subterrâneas. No software MODFLOW (MCDONALD \& HARBAUGH, 1988) é possível colocar a recarga especificada na primeira camada do modelo. 
- Terceiro tipo ou de Cauchy, corresponde a uma combinação dos dois tipos anteriores, no qual o fluxo é calculado com base na diferença entre a carga hidráulica especificada e a carga hidráulica calculada pelo modelo (ANDERSON \& WOESSNER, 1992). Este tipo de condição de contorno é utilizado para definir a drenança de um corpo d'água superficial.

A Figura 3, elaborada por CLEARY (1989), ilustra a aplicação destes três tipos de condição de contorno.

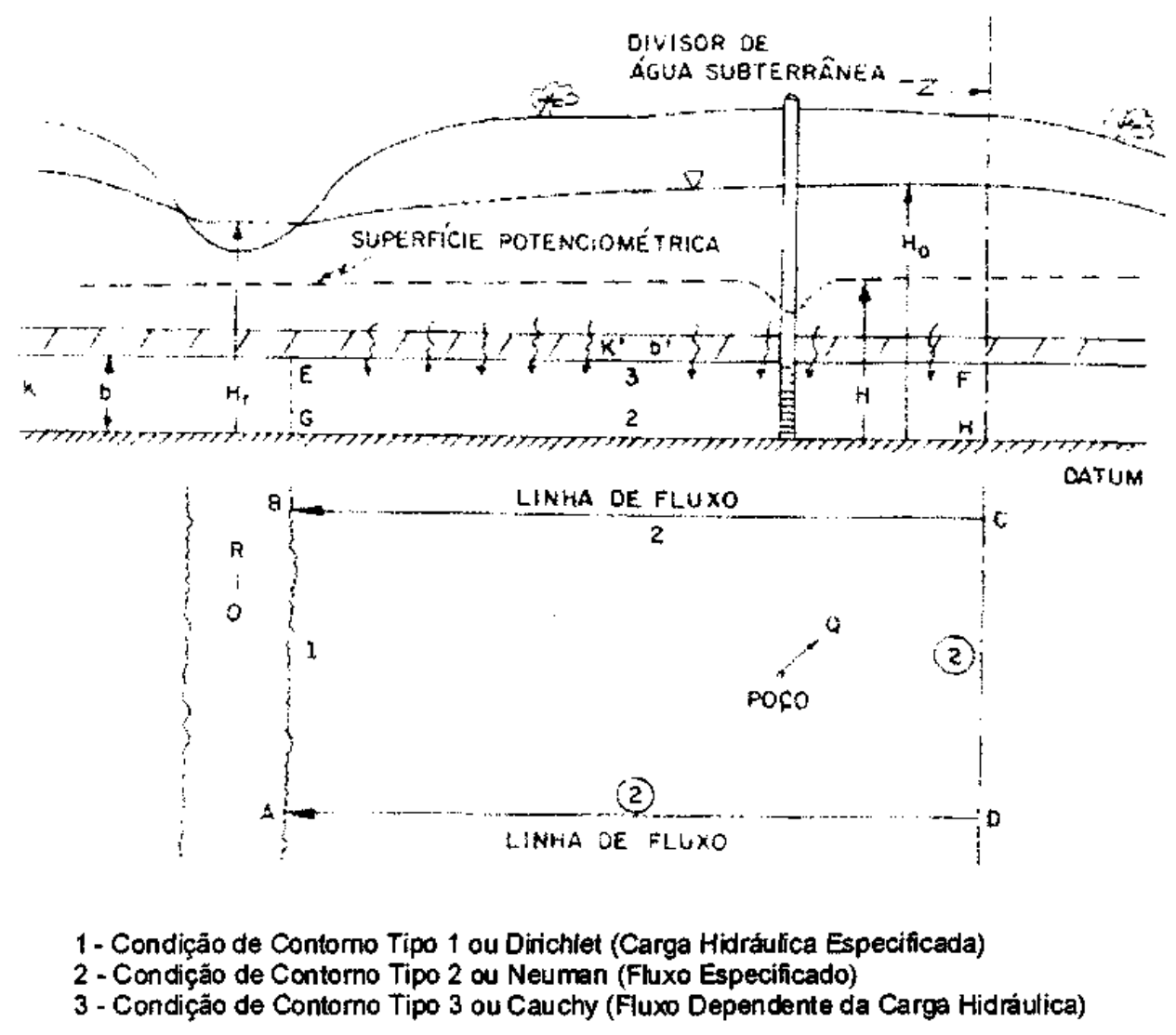

Figura 3. Exemplos de condições de contorno (CLEARY, 1989)

As condições de contorno que podem ser introduzidas no MODFLOW são: "não fluxo", carga hidráulica constante, fronteira de carga hidráulica genérica, rio, dreno, parede impermeável, recarga e evapotranspiração. Com exceção da fronteira de "não fluxo", estas condições de contorno podem ser variáveis no tempo, permitindo, por exemplo, representar a variação sazonal de recarga ou evapotranspiração. Ainda, todos estes tipos de fronteiras descritos acima podem também ser utilizados como condições internas de contorno. 
Para a seleção das condições de contorno é necessário compreender e estimar o provável sistema de fluxo da água subterrânea, identificando as feições físicas ou hidrogeológicas que deverão atuar como fronteiras ao domínio do modelo.

A condição de contorno Tipo 1 ou de carga especificada é representada no MODFLOW por Carga Constante, onde pode-se especificar um valor de carga hidráulica, célula a célula, para cada passo de tempo simulado. Esta carga hidráulica permanecerá constante no intervalo de tempo especificado, não apresentando nenhuma resistência para fornecimento ou retirada de água do sistema. Este tipo de fronteira pode simular rios ou lagos.

A condição de contorno de fluxo especificado (Tipo 2 ou Neuman) é utilizada para simular fronteiras onde existe uma taxa de fluxo de água que entra ou sai do sistema. $A$ recarga simulada por MODFLOW é considerada uma condição de contorno de fluxo (volume de água infiltrada em um período de tempo), podendo ser especificada com valores distintos célula a célula e para cada intervalo de tempo. Uma condição de contorno Tipo 2 geralmente utilizada é a fronteira denominada "não fluxo", assinalando-se células onde não passa um fluxo de água subterrânea, sendo usada para simular, por exemplo, divisores de águas ou barreiras impermeáveis. Em MODFLOW, esta condição é definida no modelo matemático especificando-se as células denominadas inativas.

A fronteira de fluxo dependente da carga hidráulica é representada no MODFLOW por diversas condições de contorno, a saber: rio, dreno, fronteira de carga hidráulica genérica ('general head boundary') e evapotranspiração. Neste tipo de condição de contorno, o fluxo depende da diferença entre a carga hidráulica especificada e a carga hidráulica calculada pelo modelo (Tipo 3 ou Cauchy).

No módulo de evapotranspiração do MODFLOW, simula-se a evapotranspiraçâo enquanto o nível da água no sistema, calculado pelo modelo, estiver acima da carga hidráulica especificada pelo usuário, denominada de "profundidade de extinção" (MCDONALD \& HARBAUGH, 1988).

Para os módulos de rio, dreno e fronteira de carga hidráulica genérica, MCDONALD \& HARBAUGH (1988) introduziram o conceito de condutância, que representa a resistência do meio à entrada ou saída de água através de qualquer uma dessas condições de contorno. A condutância é o produto da condutividade hidráulica multiplicada pela área atravessada pelo fluxo, dividido pela distância percorrida entre a carga hidráulica especificada e a calculada pelo modelo. 
Nos módulos de rio e dreno, a condutância representa a resistência do material na base de um rio ou de um dreno, que dificulta ou facilita a entrada/saída de água para o modelo. A condutância em um rio $\left(C_{\text {rio }}\right)\left[\mathrm{L}^{2} / \mathrm{T}\right]$ é calculada pela Equação 10 :

$$
C_{\text {rio }}=\left(\frac{K^{\prime} W L}{M}\right) \quad \text { Equação } 10
$$

Onde:

$K^{\prime}=$ condutividade hidráulica do material na base do rio $[\mathrm{L} / \mathrm{T}]$

$W=$ largura do rio $[\mathrm{L}]$

$L=$ comprimento da célula $[\mathrm{L}]$

$M=$ espessura do material na base do rio [L]

Enquanto a carga hidráulica calculada no modelo estiver acima da base do rio, há uma saída de água através desta fronteira. Em caso contrário, isto é, se a carga hidráulica calculada pelo modelo estiver abaixo da base do rio, há uma contribuição, entrada de água, do rio para o sistema.

No caso da condição de contorno dreno, o comportamento é semelhante, entretanto não há contribuição de água do dreno para o sistema caso a carga hidráulica calculada pelo modelo estiver abaixo da base do dreno, sendo útil para simular drenagens intermitentes ou a interferência de poços na drenagem local. A condutância do dreno é calculada da mesma forma que para a condição de contorno rio, considerando a condutividade hidráulica e espessura do material na base do dreno, a largura do dreno e o comprimento da célula.

A fronteira de fluxo pode ser especificada por meio de uma carga hidráulica genérica. O fluxo através da fronteira $(Q b)$ é calculado com base na diferença entre a carga hidráulica do aquífero no domínio do modelo e a carga hidráulica genérica, multiplicada pela resistência que a água sofre para entrar ou sair do sistema, isto é, a condutância. A fronteira de carga hidráulica genérica funciona como uma fonte infinita de água, com carga constante dentro dos períodos de tempo especificados pelo usuário do software. A resistência sofrida para a água sair ou entrar do sistema é representada pela condutância, que é o produto da condutividade hidráulica pela área atravessada pelo fluxo, dividido pela distância entre a fronteira e a carga genérica. A condutividade hidráulica refere-se ao material existente entre a fronteira do modelo e a carga hidráulica genérica, assumida a determinada distância do domínio modelado. 


\subsection{Fontes e sumidouros}

A água pode entrar ou sair do sistema modelado através das fronteiras e também através dos poços de injeção ou extração. As fontes ou sumidouros, que simulam esses poços de injeção/extração, são representados pelo termo $W(x, y, z, t)$ na equação de fluxo da água subterrânea. Para inserção de poços de injeção/extração no MODFLOW, é necessário a designação da vazão e do posicionamento dos filtros dos mesmos. Salienta-se que este software assinala o poço no centro da célula e, portanto, considera que o filtro do poço se estende por toda a camada onde o mesmo foi posicionado.

\subsection{Condições iniciais}

Após traduzidas as características reais do sistema hidrogeológico para o formato da linguagem matemática do software, através da definição da grade, das condições de contorno externas e internas e da discriminação das fontes e dos sumidouros de água, é necessário indicar as condições iniciais para que a equação de fluxo de água subterrânea possa ser resolvida, pois o software MODFLOW necessita de pelo menos um nó com carga hidráulica conhecida para poder calcular para o restante da área.

A condição inicial refere-se a distribuição tridimensional de carga hidráulica no domínio do modelo matemático no início da simulação, isto é, no tempo igual a zero.

Quando as medidas reais de carga hidráulica são conhecidas, estas podem ser utilizadas como condição inicial, otimizando a resposta do modelo nos primeiros passos de tempo de simulação, diminuindo o tempo para convergência dos cálculos. Isto implica em um fluxo inicial, com $h$ (carga hidráulica) diferente para cada posição $x, y, z$. Entretanto, segundo CLEARY (1989), esta informação é, na maioria das vezes, desconhecida na prática, o que leva grande parte dos modeladores a assumir uma carga hidráulica média e constante para todo o domínio do modelo, isto é, uma carga hidráulica $h$ igual para qualquer posição $x, y, z$.

Em simulações em estado transiente, costuma-se utilizar as cargas hidráulicas simuladas em estado estacionário como condição inicial (ANDERSON \& WOESSNER, 1992). 


\subsection{Calibração do modelo}

Após a entrada de dados, segue para a fase mais demorada, referente à calibração do modelo matemático de fluxo, onde os parâmetros de entrada são mudados de forma que o sistema modelado represente o sistema real.

O processo de calibração consiste em ajustar o modelo matemático simulado ao sistema hidrogeológico observado. Nesse processo, os parâmetros hidrogeológicos e as condições de contorno são ajustados para que as cargas hidráulicas simuladas pelo modelo matemático sejam semelhantes àquelas observadas no sistema real. $O$ processo de calibração mais comum é de 'tentativa e erro', onde os parâmetros são ajustados manualmente através de simulações sucessivas e comparação entre as cargas hidráulicas calculadas e observadas (ANDERSON \& WOESSNER, 1992).

Quando a diferença entre a carga hidráulica calculada e observada atingir um valor aceitável, previamente definido, o modelo será considerado calibrado. Esse valor aceitável é também chamado de "critério de calibração" e a diferença entre as cargas hidráulicas é tratada como "resíduo".

Há três maneiras mais comuns para calcular a média das diferenças entre as cargas hidráulicas observadas e calculadas no domínio do modelo. A média dos resíduos (denominado nos softwares como ME - 'mean error') é simplesmente a média da diferença entre as cargas hidráulicas calculadas pelo modelo $\left(h_{c a l c}\right)$ e observadas $\left(h_{o b s}\right)$. Essa média do resíduo é calculado pela Equação 11:

$$
M E=\frac{1}{n \sum_{i=1}^{n}\left(h_{o b s}-h_{c a l c}\right)}
$$

Onde $n$ é o número de valores de cafibração.

Este cálculo da média do resíduo considera os valores positivos e negativos, enquanto que a média do resíduo absoluto (referenciado como MAE - 'mean absolute error' nos softwares existentes) considera o valor absoluto da diferença entre a carga hidráulica observada e a calculada. Esta média absoluta é obtida pela Equação 12:

$$
M A E=\frac{1}{n \sum_{i=1}^{n}\left|\left(h_{o b s}-h_{c a l c}\right)_{i}\right|}
$$


O desvio padrão, isto é, a raiz quadrada da média dos quadrados do resíduo, é um dos critérios de calibração mais utilizados, sendo denominado nos softwares pela sigla RMS ('root mean squared'), e é calculado pela Equação 13:

$$
R M S=\left[\frac{1}{n \sum_{i=1}^{n}\left(h_{o b s}-h_{c a l c}\right)_{i}^{2}}\right]^{0,5}
$$

Equação 13

Outro critério de calibração mais utilizado é a porcentagem de desvio padrão normalizada (referenciada nos softwares como 'Normalized RMS'), que é calcula pela divisão do desvio padrão pela máxima diferença dos valores de carga hidráulica observada (Equação 14).

$$
\text { NormalizedRMS }=\frac{R M S}{\left(h_{\text {obs }}\right)_{\max }-\left(h_{\text {obs }}\right)_{\min }} \quad \text { Equação } 14
$$

\subsection{Análise de sensibilidade}

A análise de sensibilidade objetiva mostrar as incertezas do modelo calibrado advindas das estimativas feitas para os parâmetros hidráulicos, condições de contorno e intervenções no sistema natural como os poços de bombeamento (ANDERSON \& WOESSNER, 1992).

Esta análise de sensibilidade consiste em variar, sistematicamente, os valores dos parâmetros hidráulicos e das condições de contorno para verificar o seu efeito nas cargas hidráulicas calculadas pelo modelo matemático. Dessa forma, identificam-se os parâmetros mais sensíveis e seus efeitos no modelo calibrado.

\subsection{Pós-auditoria e re-design do modelo}

Pós-auditorias são feitas várias vezes ao ano após o modelo ser concebido e calibrado. Novos dados de campo são coletados e comparados com as previsões feitas pelo modelo. Se as previsões estiverem corretas, o modelo é validado para o site específico. Geralmente, pós-auditorias muitas vezes levam a modificações no modelo (ANDERSON \& WOESSNER, 1992). 
WHITE (1997) realizou uma pós-auditoria de um modelo de fluxo das águas subterrâneas de 1985. O modelo tinha previsto um maior rebaixamento ocasionado pelo bombeamento de poços de captação do que aquele que ocorreu. Como resultado da pósauditoria, os limites do aquífero dentro do modelo foram ajustados.

\subsection{Transporte de poluentes}

São inúmeros os fenômenos que controlam o transporte de contaminantes em meios porosos, onde o contaminante considerado é a massa de alguma substância dissolvida, movendo-se no meio fluido, ou com este (água) nos vazios do meio poroso (solo), seja ele saturado ou não (NOBRE, 1987).

O movimento de poluentes não depende apenas do fluxo do fluido no qual essas substâncias estão dissolvidas, mas sim de mecanismos que por sua vez dependem de processos físicos, químicos e biológicos.

O software utilizado neste estudo, o MT3DMS versão 5.2 (ZHENG, 2006), é um modelo tridimensional para simulação de transporte de um ou mais constituintes dissolvidos na água subterrânea. Foi originalmente desenvolvido por C. Zheng e P.P. Wang (1999), para ser utilizado em conjunto com modelos de diferenças finitas de fluxo, tal como o MODFLOW.

Proporciona ao usuário quatro modos de inserir uma fonte de contaminação: Concentração Constante; Concentração por Recarga; Concentração por Evapotranspiração; e Fonte Pontual, sendo que todas podem variar com o tempo.

No tipo Concentração Constante, as concentrações são fixadas em qualquer célula do modelo matemático. Já no tipo Concentração por Recarga, a concentração é indicada como advinda da infiltração a partir da zona não saturada. A condição de contorno de Concentração por Evapotranspiração especifica a concentração de cada espécie que acompanha o fluxo de evapotranspiração, mencionado no modelo de fluxo correspondente. Fontes Pontuais são aquelas fontes associadas com o fluxo do contorno como, por exemplo, a poços de injeção ou rios, e não necessariamente uma fonte pontual real.

Assim, dada a posição inicial das fontes de contaminação colocadas em qualquer lugar na célula, o MT3DMS, levando em conta a advecção, dispersão e reação química, e considerando que a componente da velocidade varia linearmente ao longo de cada eixo de coordenada, calcula o tempo de trânsito e a trajetória da massa contaminante dentro do domínio do modelo matemático. Admite como reações químicas, a sorção linear ou não linear e o decaimento de primeira ordem para as fases adsorvida e dissolvida. 
Nesse estudo, devido ao nitrato ser um composto persistente e, desse modo, não apresentar sorção e decaimento no meio, somente foram considerados os mecanismos de transporte de advecção, difusão e dispersão, os quais são discutidos a seguir.

\section{a) Transporte por advecção}

Advecção é o mecanismo de transporte ocasionado pelo fluxo de água, uma vez que com o deslocamento da água os contaminantes (solutos) presentes na mesma se movem na direção das linhas de fluxo com uma velocidade que, em princípio, é igual à velocidade média linear da água e não há alteração de sua concentração na solução. A Equação 15 é uma equação diferencial representativa do transporte por advecção na direção $x$ (NOBRE, 1987):

$$
\frac{\partial C}{\partial t}=-V_{x} \frac{\partial C}{\partial x} \quad \text { Equação } 15
$$

Onde $C$ é a concentração de soluto $\left[\mathrm{M} / \mathrm{L}^{3}\right]$ e $V_{X}$ é a velocidade linear média ou velocidade de percolação intersticial $[\mathrm{L} / \mathrm{T}]$. A velocidade média do fluxo $\left(V_{x}\right)$ pode ser calculada pela Equação 16 (ELBACHÁ, 1989).

$$
V_{x}=\frac{K}{n_{e}} \frac{\partial h}{\partial x} \quad \text { Equação } 16
$$

$\mathrm{Na}$ Equação $16, K$ é a condutividade hidráulica do solo [L/T], $n_{e}$ é a porosidade efetiva do solo (adimensional) e $\partial h / \partial x$ é o gradiente hidráulico (adimensional).

\section{b) Transporte por Gradiente de Concentração ou Difusão Molecular}

Devido ao gradiente de concentração existente em um fluido, ocorre o transporte de contaminantes por difusão molecular ou simplesmente difusão, ou seja, o soluto dissolvido em água desloca-se de uma área de maior concentração para uma área de menor concentração, visando equalizar a concentração em toda a massa de fluido. Este fenômeno ocorre independente da velocidade do fluido, mas é acentuado pela turbulência resultante dos mecanismos de mistura mecânica. A difusão do soluto é proporcional ao gradiente de concentração, a qual pode ser expressa pela primeira lei de Fick (ELBACHÁ, 1989), como expresso na Equação 17:

$$
\begin{aligned}
& j_{A x}=-D_{A B} \frac{\partial C_{A}}{\partial x} \quad \text { Equação } 17
\end{aligned}
$$


Onde $j_{A x}$ é o fluxo de massa de soluto por unidade de área por unidade de tempo $\left[\mathrm{M} / \mathrm{L}^{2} / \mathrm{T}\right]$, $D_{A B}$ é o coeficiente de difusão $\left[\mathrm{L}^{2} / \mathrm{T}\right]$ e $\partial \mathrm{C}_{\mathrm{A}} / \partial \mathrm{x}$ é o gradiente de concentração $\left[\mathrm{M} / \mathrm{L}^{3} / \mathrm{L}\right]$. $\mathrm{O}$ sinal negativo indica que o movimento ocorre das áreas de grande concentração para aquelas de menor concentração. Esses valores não variam muito com a concentração, mas dependem da temperatura, podendo variar em $50 \%$ para uma variação de $5^{\circ} \mathrm{C}$ (ROBINSON \& STOKES, 1965).

Em um meio poroso, especialmente de granulometria fina, a difusão é consideravelmente menor do que em uma solução livre. Isso se deve a tortuosidade das trajetórias de fluxo, pequeno volume de fluido para o fluxo e a retenção de íons e moléculas nas superfícies das partículas (MITCHELL, 1991). Sendo assim, deve-se usar um coeficiente de difusão efetiva, $D^{*}$, dado a seguir (Equação 18):

$$
D^{*}=\varpi D_{A B} \quad \text { Equação } 18
$$

Onde $\varpi$ é coeficiente de tortuosidade - adimensional (BEAR, 1972). Os valores de $\varpi$ são sempre menores que 1,0 e podem ser determinados por meio de ensaios de laboratório.

\section{c) Dispersão}

i) Transporte por mistura mecânica ou dispersão mecânica

A mistura mecânica é decorrente da dispersão em canais individuais, do desenvolvimento de velocidades médias diferentes em canais diferentes devidas à variação das dimensões dos poros ao longo das linhas de fluxo e do desvio da trajetória das partículas em decorrência da tortuosidade, reentrâncias e interligações entre os canais (BEAR, 1972).

A dispersão que ocorre na direção do fluxo é chamada dispersão longitudinal, a que ocorre na direção perpendicular ao fluxo é chamada dispersão transversal e a que ocorre na direção vertical ao fluxo é chamada de dispersão vertical. Assumindo que a dispersão pode ser descrita pela lei de Fick para difusão (Equação 18) e que a quantidade de mistura mecânica é função da velocidade linear média, pode-se introduzir um coeficiente de dispersão mecânica, conforme apresentado a seguir (ELBACHÁ, 1989) (Equações 19 a 21):

$$
\begin{array}{cc}
\text { Coeficiente de dispersão mecânica longitudinal }=\alpha_{L} V_{x} & \text { Equação } 19 \\
\text { Coeficiente de dispersão mecânica transversal }=\alpha_{T} V_{x} & \text { Equação } 20 \\
\text { Coeficiente de dispersão mecânica vertical }=\alpha_{Z} V_{x} & \text { Equação } 21
\end{array}
$$

Onde $\alpha_{L}$ é coeficiente de dispersividade longitudinal [L]; $\alpha_{T}$ é coeficiente de dispersividade transversal [L]; $\alpha_{Z}$ é coeficiente de dispersividade vertical [L]. 
ii) Dispersão hidrodinâmica

O processo de difusão molecular não pode ser separado da dispersão mecânica no fluxo de líquidos em meios porosos. Esses dois processos são combinados para definir um parâmetro chamado coeficiente de dispersão hidrodinâmica, $D$, o qual é representado nas Equações 22 a 24 (ELBACHÁ, 1989):

$$
\begin{array}{ll}
D_{L}=\alpha_{L} V_{x}+D^{*} & \text { Equação 22 } \\
D_{T}=\alpha_{T} V_{x}+D^{*} & \text { Equação 23 } \\
D_{Z}=\alpha_{Z} V_{x}+D^{*} & \text { Equação 24 }
\end{array}
$$

Onde $D_{L}$ é o coeficiente de dispersão hidrodinâmica longitudinal [ $\left.\mathrm{L}^{2} / T\right] ; D_{T}$ é o coeficiente de dispersão hidrodinâmica transversal $\left[\mathrm{L}^{2} / T\right] ; D_{Z}$ é o coeficiente de dispersão hidrodinâmica vertical $\left[\mathrm{L}^{2} / \mathrm{T}\right]$.

\subsection{Caminhamento de partículas}

A técnica de caminhamento de partículas é utilizada para a determinação das linhas de fluxo ou linhas de trajetórias, sendo útil para o entendimento do sistema de fluxo da água subterrânea e também para determinar as direções preferenciais de evolução de uma pluma de contaminação.

Neste trabalho, o caminhamento de partículas foi utilizado para determinar as direções preferenciais de fluxo da água subterrânea em situções com e sem o bombeamento dos poços de produção do município, visando um melhor entendimento do tempo de trânsito e das direções preferenciais de evolução da pluma de contaminação de nitrato.

Esta técnica consiste em acompanhar o caminhamento de partículas imaginárias, de tamanho infinitamente pequeno, colocadas no sistema de fluxo de água subterrânea, movimentando-se em função apenas de processo advectivo. Esta movimentação das partículas é calculada, em um domínio contínuo, com base nas velocidades da água subterrânea, sendo que estas velocidades são calculadas a partir de cargas hidráulicas obtidas em modelo numérico de fluxo. Dessa forma, os softwares utilizados para a determinação das linhas de trajetórias utilizando o caminhamento de partículas são denominados de pós-processadores dos modelos de fluxo de água subterrânea (IRITANI, 1998). 
As soluções analíticas para o caminhamento de partículas são restritas a modelos bidimensionais em estado estacionário, enquanto soluções numéricas permitem uma maior amplitude de cenários. Entretanto, este caminhamento de partículas pode apenas ser calculado utilizando-se softwares matemáticos específicos (ANDERSON \& WOESSNER, 1992).

A determinação da distribuição de velocidades, necessárias para o caminhamento de partículas, é calculada a partir de cargas hidráulicas obtidas nos modelos numéricos. Estas velocidades são calculadas com base nas taxas de fluxo entre uma célula e outra, em uma grade de diferenças finitas (Figura 4). Assim, calcula-se a velocidade inicial onde se encontra a partícula e a posição e a velocidade que esta deixa as células por onde caminha. Para isso, existem técnicas de interpolação aplicadas ao caminhamento de partículas, como linear e bilinear, mais frequentemente utilizadas, e distância reversa e bicúbica.

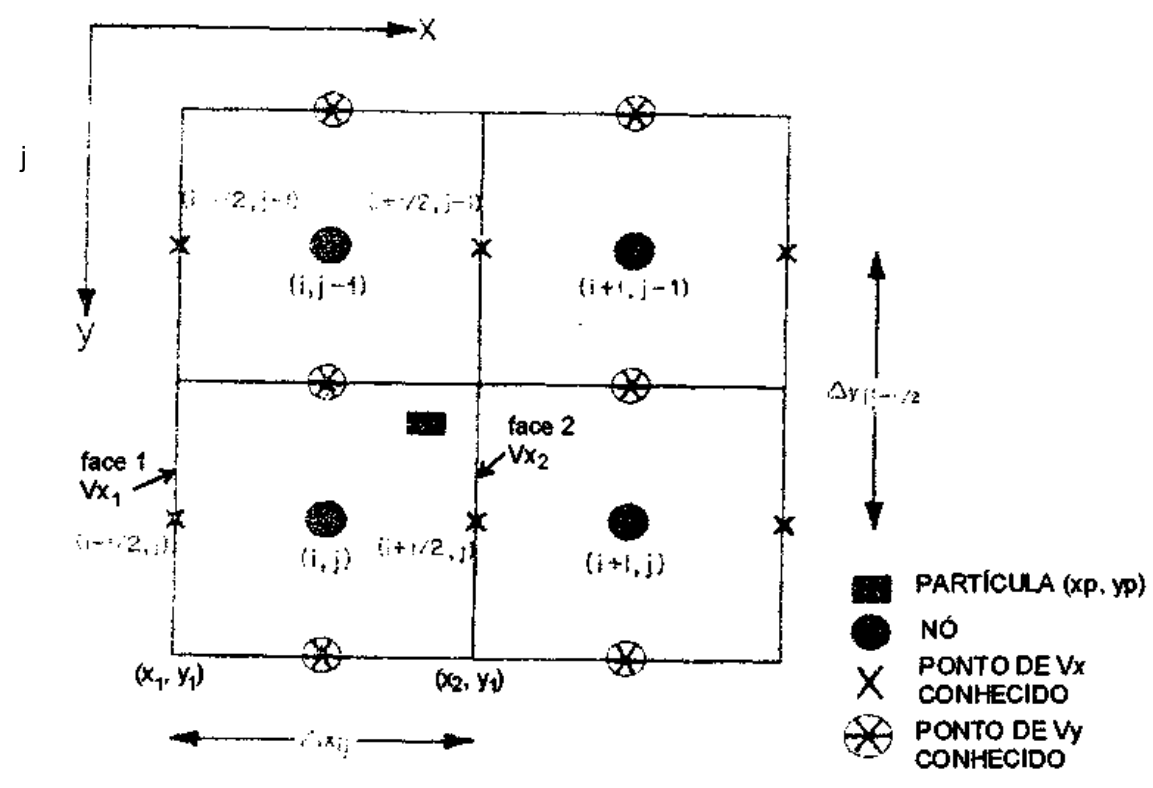

Figura 4. Localização dos pontos para cálculo de $v_{x} e v_{y}$ por interpolação linear para determinação do caminhamento de partículas e das linhas de trajetória (IRITANI, 1998)

A interpolação linear, aplicada pelo programa MODPATH (POLLOCK, 1989), utilizado neste trabalho, calcula a velocidade em cada eixo, $v_{x}, v_{y}$ e $v_{z}$, independentemente. Assim, a interpolação linear para $v_{x}$ é uma função das mudanças de velocidade somente na direção $x$ (Figura 4) e pode ser calculada por (ANDERSON \& WOESSNER, 1992) - Equações 25 e 26: 


$$
\begin{array}{cc}
\left.\left.v_{x}=\left(1-f_{x}\right) v_{x(i-1 / 2, j}\right)+f_{x} v_{x(i+1 / 2, j}\right) & \text { Equação 25 } \\
\left(x_{p}-x_{i-1 / 2, j}\right) & \text { Equação 26 }
\end{array}
$$

Onde $x_{p}$ é a coordenada $x$ da partícula. Esta mesma equação é usada para determinar $v_{y} \mathrm{e}$ $v_{z}$.

As linhas de trajetória percorridas pelas partículas são solucionadas por (ANDERSON \& WOESSNER, 1992) - Equações 27 a 29:

$$
\begin{aligned}
& \frac{d x}{d t}=v_{x} \\
& \frac{d y}{d t}=v_{y} \\
& \frac{d z}{d t}=v_{z}
\end{aligned}
$$

Equação 28

Equação 29

Cuja solução semi-analítica é dada por (Equação 30):

$$
x_{p}=x_{1}+\left(\frac{1}{A_{x}}\right)\left[\left(v_{x}\right) \exp \left(A_{x} \Delta t\right)-\left(v_{x}\right)_{1}\right]
$$

Equação 30

Onde (Equação 31):

$$
A_{x}=\frac{\left[\left(v_{x}\right)_{2}-\left(v_{x}\right)_{1}\right]}{\Delta x_{i, j}}
$$

Os parâmetros $\left(v_{x}\right)_{1}$ e $\left(v_{x}\right)_{2}$ representam as velocidades nos limites da célula no eixo $x$, e os termos $x_{1}$ e $x_{p}$ representam, respectivamente, a coordenada da face da célula e a coordenada da partícula no eixo $x$, como mostra a Figura 4.

POLLOCK (1989) usa a equação abaixo para calcular o tempo $\left(\Delta t_{x}\right)$ que a partícula leva, por exemplo no eixo $x$, para se movimentar de $x_{p}$ até a face da célula $\left(x_{2}\right)$ por onde esta partícula vai sair e passar para a célula vizinha (Equação 32).

$$
v_{x}=\left(1-f_{x}\right) v_{x(i-1 / 2, j)}+f_{x} v_{x(i+1 / 2, j)}
$$

Onde $v_{x}$ é a componente de velocidade da partícula. 
Esta solução semi-analítica amolda-se melhor para cenários em estado estacionário, onde a velocidade é constante no tempo.

O software MODPATH (POLLOCK, 1989), um pós-processador desenvolvido para delinear as linhas de trajetórias utilizando as saídas de carga hidráulica, em estado estacionário, do programa MODFLOW (MCDONALD \& HARBAUGH, 1988), usa a interpolação linear e uma solução semi-analítica para movimentar as partículas. Assim, dada a posição inicial das partículas colocadas em qualquer lugar na célula, o MODPATH, levando em conta somente a advecção e considerando que a componente da velocidade varia linearmente ao longo de cada eixo de coordenada, calcula o tempo de trânsito e a trajetória das partículas dentro do domínio do modelo matemático.

As partículas podem ser 'reversas' ou 'avante', isto é, elas podem caminhar para trás ou para frente, respectivamente, a partir da sua posição inicial dentro do domínio do modelo. Isto permite conhecer a origem ou o destino das linhas de trajetórias, ou da água subterrânea, sendo útil para a deteminação das áreas de captura de poços ou direções de caminhamento de eventuais plumas de contaminação, avaliando-se os riscos potenciais existentes (IRITANI, 1998).

Apesar de desenvolvido para ler e processar diretamente os arquivos gerados pelo MODFLOW, este software pode ser modificado para aceitar dados de distribuição de carga hidráulica gerados por qualquer outro programa tridimensional de fluxo, que utilize diferenças finitas centradas no bloco (WALTON, 1992).

\section{CARACTERIZAÇÃO DA ÁREA DE ESTUDO}

\subsection{Localização da área de estudo}

A área de estudo localiza-se no município de Urânia, região noroeste do Estado de São Paulo, cerca de $600 \mathrm{~km}$ da capital. Este município limita-se a norte com Santa Albertina e Paranapuã, a sul com São Francisco, a leste com Jales e a oeste com o município de Aspásia.

O acesso à área pode ser feito a partir da capital, pela Rodovia Anhanguera (SP 330) até a cidade de Limeira, ou pela Rodovia Bandeirantes, até a cidade de Campinas; seguindo pela Washington Luiz (SP 310) até Mirassol e, depois, pela Rodovia Euclides da Cunha (SP 320) até o município de Urânia.

A Figura 5 apresenta a localização do município de Urânia. 
Figura 5. Localização do município de Urânia
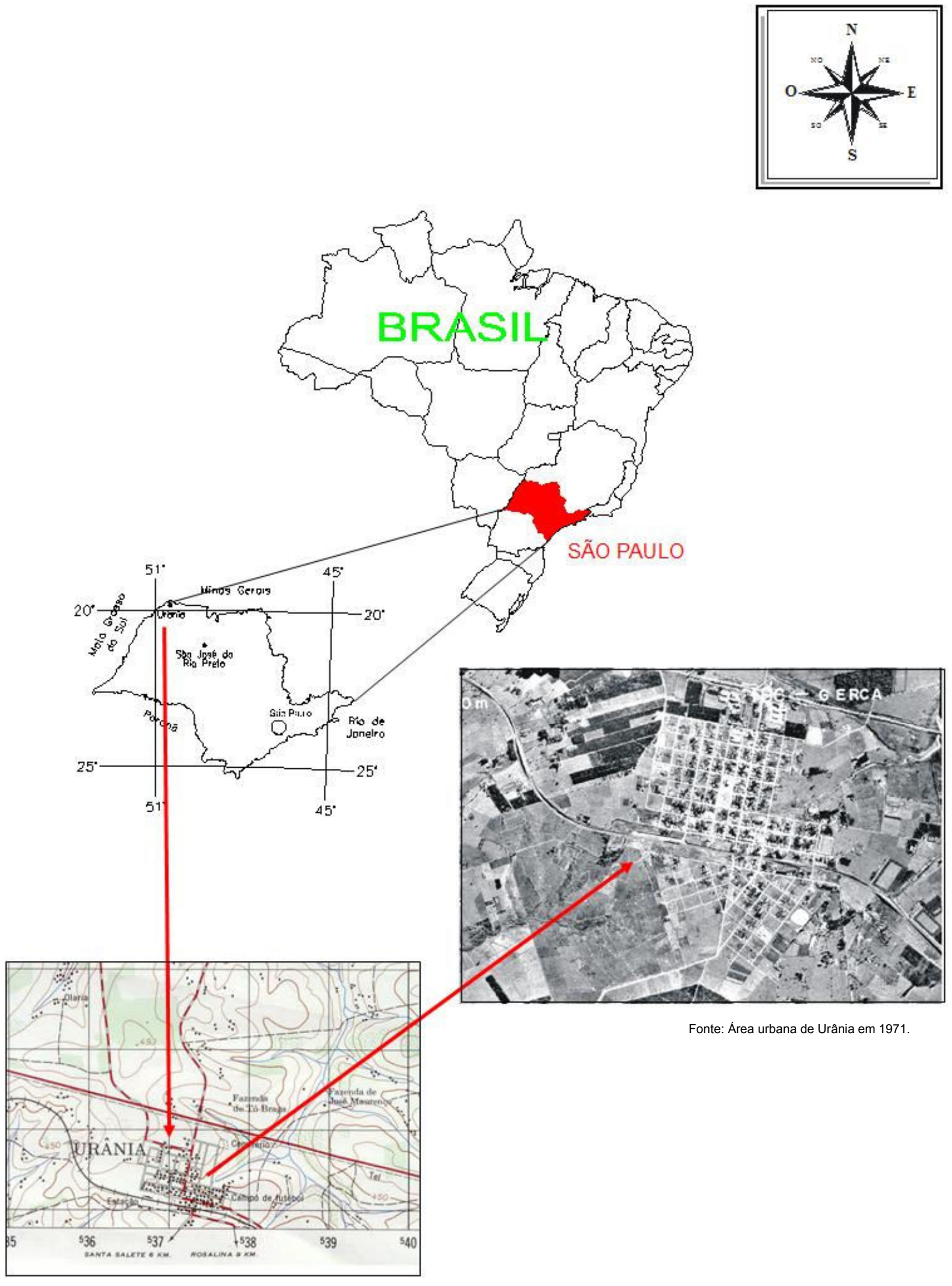


\subsection{Aspectos fisiográficos}

O município de Urânia encontra-se na unidade morfoestrutural do Planalto Centro Ocidental Paulista (ROSS \& MOROZ, 1997), que é caracterizado por colinas amplas e baixas com topos convexos e aplanados ou tabulares, entalhamento médio dos vales inferiores a $20 \mathrm{~m}$, interflúvios com dimensões médias entre 1750 e 3750 m, densidades de drenagem baixa, altimetria variando entre 400 a 700 m e declividades médias das vertentes entre 2 a 10\%. Com isso, o município de Urânia possui relevo monótono com a presença de pequenos morrotes, cujas cotas variam de 430 a 470 m. Situa-se sobre o divisor hidrográfico das unidades 18 (São José dos Dourados) e 15 (Turvo, Grande) (IGC-DAEE, 1996). No município de Urânia estão presentes as nascentes que fazem parte do Córrego da Porteira e do Ribeirão Comprido.

De acordo com o balanço hídrico do posto 8B-002, no Rio São José dos Dourados (DAEE, 1976), a chuva na região de estudo foi de $1430 \mathrm{~mm}$ em 1974, sendo que deste total, 83,6\% participou dos processos de evapotranspiração, 7,4 \% corresponderam ao escoamento superficial e apenas 9,0 \% compreenderam à recarga subterrânea.

Os solos da região são classificados como argilossolos vermelho-amarelos (ou podzólicos vermelho-amarelos) (EMBRAPA/IAC, 1999). São superficialmente arenosos com nítida diferenciação textural entre os horizontes A e B, apresentando sub-horizonte A2 e transição abrupta a clara entre os horizontes.

\subsection{Dados sócio-econômicos}

Segundo o IBGE (2000), a população do município de Urânia é de 8614 pessoas, residentes em uma área de $209 \mathrm{~km}^{2}$. Embora a Companhia de Saneamento Básico do Estado de São Paulo (SABESP) seja a responsável pela distribuição de água para o município de Urânia, há residências que possuem poços particulares dos tipos cacimba e/ou tubular para o consumo doméstico. De acordo com CAGNON (2003), no ano de 2002 havia no município 48 poços cacimba e 34 poços tubulares privados.

A SABESP possui sete poços distribuídos no município de Urânia, porém atualmente todos não são utilizados devido às concentrações anômalas de cromo na água subterrânea, tornando-a imprópria para o consumo humano. Desta forma, a água distribuída no município de Urânia povém de um poço de abastecimento situado em Jales (cidade vizinha), sendo extraída do Aquífero Guarani, que se refere a uma unidade sedimentar que se encontra confinada a $900 \mathrm{~m}$ de profundidade na região pelo Aquitarde Serra Geral. 
A SABESP também é responsável pelo gerenciamento da rede de esgoto no município. Segundo IPT (2000, apud VARNIER, 2007), o volume diário de efluente coletado em 1999 foi de $248 \mathrm{~m}^{3} /$ dia. Apesas da alta porcentagem da rede de esgoto, existem muitas fossas negras em operação no município (CAGNON, 2003). Tais fossas são bastante simples, compostas por buracos perfurados no solo, com dimensões médias de $1,5 \mathrm{~m}$ de diâmetro e 2,0 $\mathrm{m}$ de profundidade, geralmente sem qualquer tipo de impermeabilização em seu interior.

Mesmo se tratando de uma área urbanizada, há presença de atividades agrícolas (café, uva, manga, verduras e legumes) e pecuárias (bovinos, suínos e aves), principalmente nas porções noroeste e sul do município (VARNIER, 2007). Há alguma atividade industrial, representada pelo beneficiamento de arroz, construção de charretes e fábrica de móveis.

\subsection{Hidrogeologia regional}

Segundo IPT (1981), a região pesquisada está inserida na Bacia Vulcano-Sedimentar do Paraná, representada por uma complexa fossa tectônica encravada no escudo précambriano. Esta bacia encontra-se preenchida por sedimentos continentais e marinhos do Grupo Bauru, com predominância da Formação Adamantina, e lavas basálticas da Formação Serra Geral, do Grupo São Bento. O Grupo Bauru é composto pelas formações Caiuá, Pirapozinho, Santo Anastácio, Birigui, Araçatuba, Adamantina e Marília (IPT, 1981). A Figura 6 mostra a distribuição das unidades litoestratigráficas do Grupo Bauru no Estado de São Paulo.

O município de Urânia está assentado diretamente sobre a Formação Adamantina, a qual possui contato inferior discordante com os basaltos da Formação Serra Geral.

Segundo (IPT, 1981), a Formação Serra Geral, pertencente ao Grupo São Bento, é representada por um conjunto de derrames de lavas basálticas e de intrusões diabásicas, de natureza variada, composta por termos ácidos e básicos. Estes derrames são formados por rochas de cor cinza-escuro a preta, afaníticas. O topo da superfície da Formação Serra Geral, na região de estudo, foi encontrada em altitudes que variaram de 307 a 369 m (PALMÉR RIVERA, 2002). Essa formação consiste um aquitarde e, assim sendo, a produção de águas subterrâneas ocorre somente ao longo de falhas e fraturas das rochas e da intercalação com rochas mais permeáveis. Sua espessura varia desde poucos metros, aumentando para oeste do Estado, até $1000 \mathrm{~m}$. Desta forma, suas características hidrodinâmicas ficam demonstradas pelos valores de vazão específica que variam entre 0,1 e $50,0 \mathrm{~m}^{3} / \mathrm{h} / \mathrm{m}$, com valor médio de $1,0 \mathrm{~m}$ /h/m (CETESB on-line, acesso em 18 de julho de 2010). 


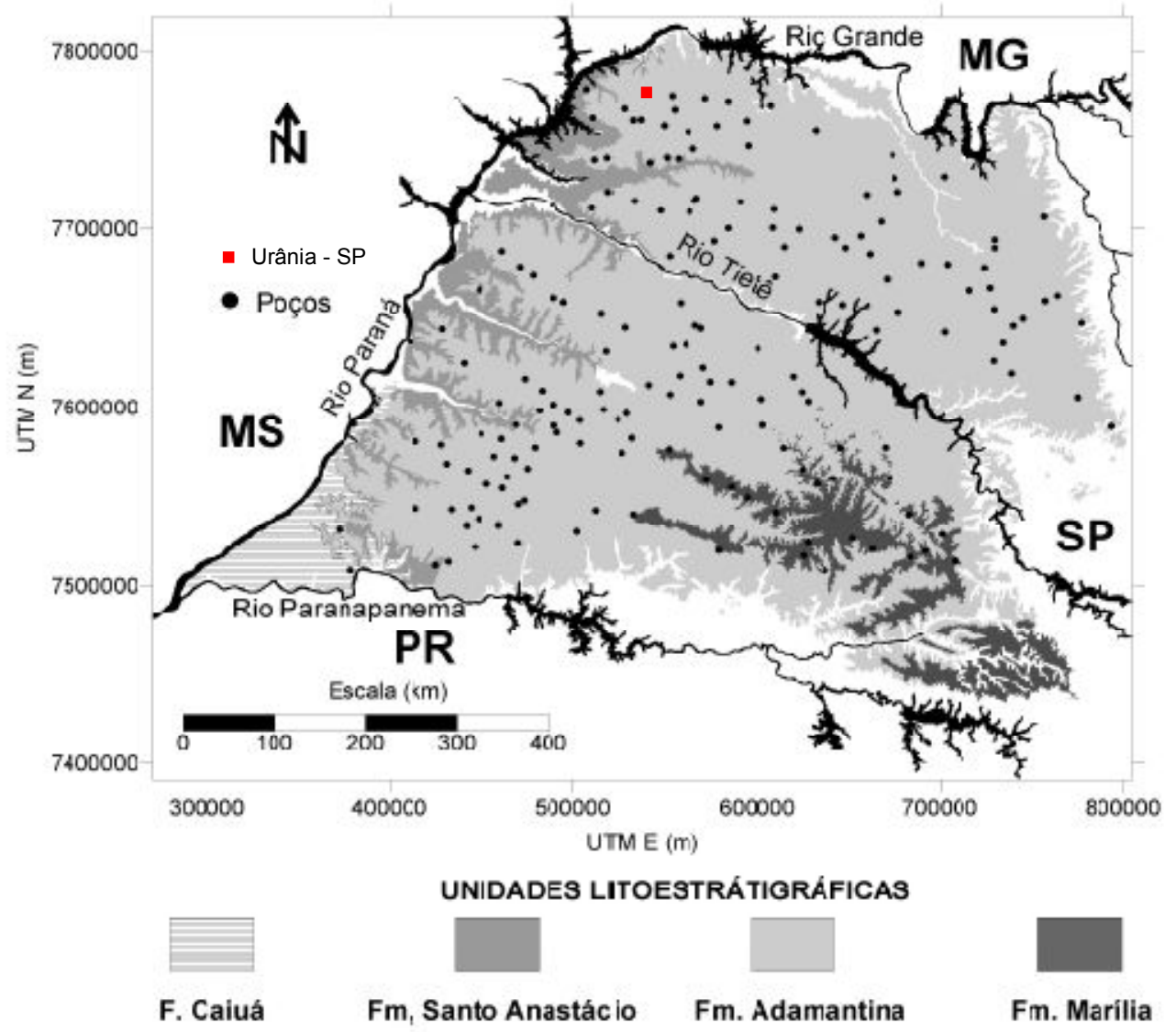

Figura 6. Configuração atual do substrato do Grupo Bauru no Estado de São Paulo

(PAULA E SILVA et al., 2003)

A recarga para este aquífero se dá através da precipitação pluvial sobre os solos basálticos, que vão atingir as regiões fissuradas da rocha matriz. Ocorre também um grande intercâmbio de água com o aquífero Bauru, localizado acima, e também com o aquífero inferior (Guarani), constituído pelos arenitos das formações Botucatu e Pirambóia (CETESB on-line, acesso em 18 de julho de 2010).

A Formação Adamantina foi formalmente proposta por SOARES et al. (1980) como um conjunto de fácies compostas por bancos de arenito portando estratificação cruzada, intercalados a bancos de lamitos, siltitos e arenitos lamíticos. Nessa proposta, os referidos autores justificaram, ainda, a manutenção de denominações regionais, como São José do Rio Preto, Taciba e Ubirajara, em razão da diversidade litofaciológica da unidade. FERNANDES (1998), em sua proposta de subdivisão estratigráfica dos sedimentos cretáceos suprabasálticos, sugere o abandono do nome Adamantina e a fragmentação da unidade nas formações Vale do Rio do Peixe, São José do Rio Preto e Presidente Prudente. 
Estudos realizados por PAULA E SILVA (2003) e PAULA E SILVA et al. (2003) retomam a designação Adamantina por entenderem que a característica principal dessa unidade é a variabilidade litofaciológica lateral e vertical.

A idade da Formação Adamantina, segundo DIAS-BRITO et al. (1998, apud SUAREZ, 1999), pelo estudo dos microfósseis calcários, estaria localizada no Cretáceo Inferior e o intervalo sugerido post-Cenomaniano ao pré-Campaniano (TuronianoSantoniano). SOARES \& LANDIM (1980, apud SUAREZ, 1999), atribuíram idade do Cretáceo Médio, Cenomaniano a Santoniano, havendo, assim, certa concordância entre esses autores.

SOARES et al. (1979, apud SOARES et al., 1980) relataram que a Formação Adamantina foi depositada em um extenso sistema fluvial meandrante dominantemente pelítico gradando para psamítico. SUAREZ (1999) indicou que o ambiente de deposição desta unidade é considerado como flúvio-lacustre, em um clima quente, úmido, com períodos áridos e semi-áridos.

Os fácies possuem como principal característica a presença de bancos de arenitos de granulação fina a muito fina e cor rósea a castanha com estratificação cruzada (SOARES et al., 1979, apud SOARES et al., 1980). Essa estratificação apresenta-se alternada com bancos de lamitos, siltitos e arenitos lamíticos, de cor castanha-avermelhada a cinza-acastanhada e estrutura maciça ou com acamamento plano-paralelo grosseiro, apresentando frequentemente marcas de onda e micro-estratificação cruzada (SUAREZ, 1999). Frequentemente os estratos de arenito estão cimentados com carbonato de cálcio, argila e, em outros casos, com cimento silicoso. Os afloramentos apresentam uma grande variação de estruturas sedimentares de natureza hidrodinâmica mostrando, às vezes, ritmicidade na sedimentação (SUAREZ, 1999).

As maiores espessuras da Formação Adamantina ocorrem geralmente nas porções ocidentais dos espigões, entre os grandes rios. Atinge $160 \mathrm{~m}$ entre o Rio São José dos Dourados e Rio do Peixe, 190 m entre o Rio Santo Anastácio e Rio Paranapanema, e 100 a 150 m entre o Rio do Peixe e Rio Turvo, adelgaçando-se destas regiões em direção a leste e nordeste (SOARES et al., 1980). A maior espessura, $208 \mathrm{~m}$, foi identificada na cidade de Guzolândia (ALMODOVAR, 1995). 
O Aquífero Adamantina apresenta extensão regional, sendo considerado livre a semiconfinado e contínuo (DAEE, 1976). O semiconfinamento é decorrente principalmente das variações de permeabilidade dos sedimentos em função do maior ou menor teor de argila da matriz, ou de camadas pelíticas que se intercalam aos corpos arenosos. A frequência das camadas lamíticas e as variações de argilosidade dos arenitos desta unidade hidroestratigráfica determinam seu comportamento hidráulico bastante heterogêneo e anisotrópico, mesmo em localidades relativamente próximas (PAULA E SILVA, 2003).

Graças à sua extensa área de ocorrência, responde por $50 \%$ do volume armazenado em todo sistema do Sistema Aquífero Bauru, o que demonstra sua grande importância estratégica, ainda que as vazões fornecidas mostrem-se extremamente variáveis (DAEE, 1976; 1979).

\section{METODOLOGIA}

\subsection{Levantamento de informações existentes}

Neste item são descritas as etapas e metodologias utilizadas para a construção do modelo conceitual da área, efetuada através da interpretação dos dados geológicos, hidrogeológicos, hidrológicos e de contaminação por nitrato. Cabe lembrar que este trabalho enfocou exclusivamente na interpretação de dados existentes, ressaltando a importância do tratamento e organização das informações já disponíveis, de forma a entender o sistema hidrogeológico, subsidiar o gerenciamento de recursos hídricos e direcionar as necessidades de trabalhos futuros, de forma previamente organizada, otimizando os recursos humanos e promovendo uma proteção efetiva da água subterrânea, conforme apresentado a seguir.

\section{a) Topografia superficial}

Os dados sobre a topografia superficial do município de Urânia foram retirados das Folhas Topográficas Santa Albertina e Jales, ambas em escala $1: 50000$ e com linhas espaçadas em 10 m (IGGSP, 1966a; IGGSP,1966b).

\section{b) Geologia e hidrogeologia local}

Os dados sobre a geologia e hidrogeologia do município de Urânia foram obtidos por meio de bibliografia de diversos autores (ALMODOVAR, 2000; GUTTIEREZ, 1999; DAEE, 1976; PALMÉR RIVERA, 2002; BERTOLO, 2001; HIRATA et al., 1997; ROSSATO, 1999). 
Foram utilizados também o Mapa geológico do Estado de São Paulo, escala 1:500000 (IPT, 1981), os dados de mapaeamento geológico e hidrogeológico realizados por PAULA E SILVA et al. (1994, 2003 e 2005) e os perfis litológico-construtivos, testes de bombeamento e vazão dos antigos poços de produção cadastrados na região de Urânia, Jales, Santa Albertina e Aspásia, contidas nas licenças de operação destes poços disponibilizadas pela SABESP (1979a; 1979b; 1979c; 1979d; 1979e; 1979f; 1979g; 1980; 1981; 1982a; 1982b; 1991; 1992), bem como do poço tubular existente no posto de combustível Garção (PT Garção) e nos resultados das Sondagens Elétricas Verticais (SEV1 a SEV14) realizadas por PALMÉR-RIVERA (2002).

Com este levantamento de dados foi possível definir as unidades hidroestratigráficas da área.

\section{c) Corpos d'água superficiais}

Os dados sobre vazão, espessura e profundidade dos córregos na área em estudo foram obtidos em CAGNON (2003) e PALMÉR RIVERA (2002). Estas autoras indicaram que estes corpos d'água superficiais são relativamente rasos e, em geral, a profundidade é inferior a $1 \mathrm{~m}$, e muitas vezes abaixo de $50 \mathrm{~cm}$.

\section{d) Precipitação, evapotranspiração e recarga}

Uma vez que não existem dados recentes disponíveis para o cálculo da precipitação média em Urânia, utilizaram-se os dados de monitoramento de precipitação mensal registrados no prefixo B7-006 em Urânia, disponíveis entre os anos de 1959 e 2003, em SIGRH (on line, acesso em 10 de janeiro de 2010). Assim, para estimativa da recarga na área rural, foram utilizadas as premissas expostas em BERTOLO (2001).

Já para a recarga na parte urbana de Urânia, que é mais difícil de estimar, uma vez que todas as famílias recebem água potável canalizada nas proximidades de Jales e que a fuga de abastecimento de água e tubulações de águas residuais constitui uma recarga extra para as águas subterrâneas, utilizou-se a estimativa proposta por RODRIGUES VERDELHO (2001, apud PALMÉR RIVERA, 2002).

Quanto à evapotranspiração, foram utilizadas as assunções de BERTOLO (2001). 


\section{e) Contaminação por nitrato}

A contaminação por nitrato foi avaliada por meio dos resultados analíticos de amostras de poços cacimba e tubulares cadastrados no município de Urânia, apresentados em CAGNON (2003).

Os dados apresentados nos itens "a" a "e" permitiram o entendimento da forma de ocorrência e comportamento do fluxo da água subterrânea, permitindo a criação do modelo conceitual para a área de interesse.

\subsection{Modelagem matemática}

Para a construção de um modelo matemático que represente um sistema real, os procedimentos são: desenvolvimento do modelo conceitual, citado acima, que envolve todo o levantamento e interpretação de dados e observações do sistema real; selecão do software a ser utilizado segundo as necessidades e os dados existentes; tradução do modelo conceitual para a linguagem matemática, construindo-se os diversos bancos de dados para a entrada das informações no software selecionado; e calibração do modelo matemático construído de forma a diminuir as incertezas inerentes a uma representação simplificada (modelo matemático) de um sistema real, em geral, complexo.

\subsubsection{Escolha do aplicativo matemático}

A escolha do aplicativo matemático fundamentou-se no objetivo de avaliar a aplicabilidade da modelagem matemática tridimensional para a determinação da evolução do nitrato para as porções mais profundas do aquífero livre do município de Urânia.

O software selecionado para fluxo de água subterrânea, como discutido anteriormente, foi o MODFLOW (MCDONALD \& HARBAUGH, 1988), contido no pacote comercial Visual MODFLOW (GUIGUER \& FRANZ, 1996), desenvolvido pelo U. S. Geological Survey, na versão 4.3. Este software resolve a equação de água subterrânea através do método de diferenças finitas e sua eficiência é plenamente reconhecida.

Para simulação do transporte do nitrato na zona saturada utilizou-se o software MT3DMS na versão 5.2. (ZHENG, 2006), e para simulação do caminhamento de partículas utilizou-se o MODPATH (POLLOCK, 1989), ambos contidos no pacote Visual MODFLOW (GUIGUER \& FRANZ, 1996). 
O pacote Visual MODFLOW é um pré e pós-processador para o MODFLOW, MODPATH e MT3DMS, permitindo a entrada de dados e a visualização dos resultados na forma gráfica, facilitando a construção e definição do modelo matemático.

O Visual MODFLOW lê os dados de entrada colocados graficamente e traduz para o formato ASCII exigido pelo MODFLOW, MT3DMS e MODPATH. Para os resultados, o Visual MODFLOW segue o caminho inverso, lendo os arquivos em ASCIl gerados pelo MODFLOW, MODPATH e MT3DMS e transforma para o formato de gráficos e mapas de isolinhas para facilitar a visualização.

Estes softwares são os mais utilizados nos Estados Unidos para a modelagem tridimensional do fluxo de água subterrânea, apresentando diversos pré e pósprocessadores que auxiliam na entrada de dados e na visualização dos resultados. Os softwares MODFLOW, MT3DMS e MODPATH foram escolhidos por atender os requisitos necessários para a construção do modelo matemático do sistema hidrogeológico e de transporte de contaminantes considerado, e também por apresentar uma documentação clara para sua utilização.

\subsubsection{Construção do modelo matemático}

Para a construção do modelo matemático é necessário traduzir o modelo conceitual da área, o qual foi definido no item 6.1., para a linguagem do software escolhido. Assim, os elementos para a definição do modelo foram introduzidos adequadamente de forma que o aplicativo matemático escolhido para a construção do modelo matemático represente as condições reais do sistema hidrogeológico, os quais foram:

- discretizacão da grade do modelo;

- delimitação das condições de contorno externas e internas;

- definição dos poços de injeção/extração e de observação;

- definição das condições iniciais;

- Grade do modelo.

No método das diferenças finitas, a área modelada é discretizada por uma grade ou malha, desenhada por linhas, colunas e camadas, que definem o conjunto de células onde serão colocadas as condições de contorno e também serão calculadas as cargas hidráulicas e velocidades das águas subterrâneas. Antes da discretização da malha é necessário definir o domínio do modelo, isto é, a área, dentro de sua região de interesse, que será modelada. 
A grade discretizada no modelo pode ser refinada nas áreas de maior interesse ou onde existem altos gradientes hidráulicos, como ao redor de poços, para aumentar a definição e precisão no cálculo das cargas hidráulicas e velocidades.

No MODFLOW é possível definir uma grade com espaçamento irregular, em todos os eixos $(x, y, z)$.

Com a grade discretizada na horizontal e na vertical, é necessário definir as propriedades hidráulicas de cada unidade hidrogeológica, para sua representação no modelo matemático. O MODFLOW aceita condições heterogêneas e anisotrópicas, sendo então necessário introduzir as condutividades hidráulicas das unidades para os três eixos de coordenadas $\left(K_{x}, K_{y}, K_{z}\right)$ e os parâmetros de armazenamento (Coeficiente de armazenamento $-S_{s}$, porosidade eficaz - $S_{y}$, porosidade efetiva - $n_{e}$ e porosidade total $-n$ ).

As condições de contorno para área foram definidas por meio do delineamento das microbacias atuantes na área de estudo.

Os poços de produção do município, nas simulações onde os mesmos foram considerados ativos, foram considerados como sumidouros de água, representados pelo termo $W(x, y, z, t)$ na equação de fluxo da água subterrânea. Os dados de vazão foram aqueles expressos nos documentos disponibilizados pela SABESP.

A condição inicial refere-se a distribuição tridimensional de carga hidráulica no domínio do modelo matemático no início da simulação, isto é, no tempo igual a zero. Deste modo, como condição inicial foram utilizadas as cargas hidráulicas calculadas a partir dos dados de nível d'água e cota topográfica dos poços cacimba e tubulares privados cadastrados no município de Urânia por CAGNON (2003) e PALMER RIVERA (2002).

\subsubsection{Calibração do modelo}

Após a entrada de dados, foi realizada a fase mais demorada, referente à calibração do modelo matemático de fluxo, onde os parâmetros de entrada foram mudados de forma que o sistema modelado representasse o sistema real. A metodologia do processo de calibração utilizada neste estudo foi a mais comum, ou seja, a de 'tentativa e erro'.

Adotou-se como critério de calibração um desvio padrão inferior a $1,5 \mathrm{~m}$, devido ao nível d'água na área em estudo variar em mais de 10,0 m. Outro critério adotado foi o relativo à diferença de carga hidráulica total $(\Delta \mathrm{H})$ no domínio do modelo, denominado neste trabalho de 'porcentagem de resíduo' e representado no (software por Normalized RMS), sendo que assumiu-se um valor inferior a 10\% como aceitável (GUIGUER, comunicação verbal). 


\subsubsection{Análise de sensibilidade}

A análise de sensibilidade, que objetiva mostrar as incertezas do modelo calibrado advindas das estimativas feitas para os parâmetros hidráulicos, condições de contorno e intervenções no sistema natural, como os poços de bombeamento, foi realizada para as condutividades hidráulicas e valores de recarga inseridos nos modelo.

Para tanto, os dados de entrada foram variados, sistematicamente, para verificar o seu efeito nas cargas hidráulicas calculadas pelo modelo matemático, para a identificação da sensibilidade desses parâmetros e seus efeitos no modelo calibrado.

\subsubsection{Transporte de contaminante}

A partir do modelo de fluxo calibrado foi simulado o transporte do contaminante nitrato no meio saturado, visando à avaliação da evolução da contaminação quanto à profundidade em um tempo de trânsito de 1 a 100 anos, considerando fontes contínuas e descontínuas de diferentes amplitudes, associadas ou não ao efeito da dispersão e do acionamento dos poços produção do município. Para tanto foram realizadas 16 simulações, conforme apresentado na Tabela 01.

Tabela 01 - Simulações de transporte

\begin{tabular}{|c|c|c|c|c|c|c|c|}
\hline \multirow{2}{*}{ Simulação } & \multicolumn{7}{|r|}{ Consideração } \\
\hline & A & $\mathrm{D}$ & PPI & PPA & FC & FD & Observação \\
\hline 1 & $x$ & & $\mathrm{x}$ & & $\mathrm{x}$ & & Avaliação da capacidade de diluição do aquífero \\
\hline 2 & $x$ & $x$ & $x$ & & $\mathrm{x}$ & & Avaliação do efeito da dispersão na simulação 1 \\
\hline 3 & $x$ & & & $\mathrm{x}$ & $\mathrm{x}$ & & Avaliação da capacidade de diluição do aquífero \\
\hline 4 & $x$ & $x$ & & $\mathrm{x}$ & $x$ & & Avaliação do efeito da dispersão na simulação 3 \\
\hline 5 & $x$ & & $\mathrm{x}$ & & & $x$ & Avaliação da capacidade de recuperação do aquífero \\
\hline 6 & $\mathrm{x}$ & $\mathrm{x}$ & $\mathrm{x}$ & & & $\mathrm{x}$ & Avaliação do efeito da dispersão na simulação 5 \\
\hline 7 & $x$ & & & $\mathrm{x}$ & & $\mathrm{x}$ & Avaliação da capacidade de recuperação do aquífero \\
\hline 8 & $x$ & $x$ & & $x$ & & $\mathrm{x}$ & Avaliação do efeito da dispersão na simulação 7 \\
\hline 9 & $x$ & & $\mathrm{x}$ & & $\mathrm{x}$ & & \multirow{2}{*}{$\begin{array}{l}\text { Avaliação da contribuição de outras fontes de contaminação, além } \\
\text { das fossas cadastradas no município }\end{array}$} \\
\hline 10 & $\mathrm{x}$ & & & $\mathrm{x}$ & $\mathrm{x}$ & & \\
\hline 11 & $x$ & & $\mathrm{x}$ & & $\mathrm{x}$ & & \multirow{2}{*}{$\begin{array}{c}\text { Avaliação do efeito de fontes aplicadas em áreas de } 65 \times 65 \text { metros } \\
\text { espaçadas por áreas de } 135 \times 135 \text { metros na área urbana }\end{array}$} \\
\hline 12 & $\mathrm{x}$ & & & $\mathrm{x}$ & $\mathrm{x}$ & & \\
\hline 13 & $x$ & & $x$ & & $x$ & & \multirow{2}{*}{$\begin{array}{l}\text { Avaliação do efeito de fontes aplicadas em áreas de } 65 \times 65 \text { metros } \\
\text { espaçadas por áreas de } 65 \times 65 \text { metros na área urbana }\end{array}$} \\
\hline 14 & $x$ & & & $x$ & $x$ & & \\
\hline 15 & $x$ & & & $x$ & $x$ & & \multirow{2}{*}{$\begin{array}{l}\text { Avaliação do efeito do bombeamento conjunto de poços com } \\
\text { seções filtrantes localizadas em porções distintas no aquífero }\end{array}$} \\
\hline 16 & $\mathrm{x}$ & & & $\mathrm{x}$ & $x$ & & \\
\hline A - Advecção. & & & & & & & PPA - Poços de Produção Ativos. \\
\hline D - Dispersão. & & & & & & & FC - Fonte Contínua. \\
\hline \multicolumn{4}{|c|}{ PPI - Poços de Produção Inativos. } & & & & FD - Fonte Descontínua. \\
\hline
\end{tabular}




\section{RESULTADOS OBTIDOS}

\subsection{Modelo conceitual}

\subsubsection{Topografia}

Para elaboração do modelo conceitual, primeiramente foi criado um mapa da região em estudo a partir da digitalização das Folhas Topográficas Santa Albertina e Jales, ambas em escala 1:50000 e com linhas espaçadas em 10 m (IGGSP, 1966a; IGGSP,1966b), no software $\operatorname{ArcGIS}^{\circledR}$ versão 9.3.1. Este software constitui um Sistema de Informações Geográficas e foi produzido pela ESRI (Environmental Systems Research Institute).

Neste mapa foi possível verificar que o município de Urânia situa-se sobre o divisor hidrográfico das unidades 18 (São José dos Dourados) e 15 (Turvo, Grande) (IGC-DAEE, 1996). Neste município estão presentes as nascentes que fazem parte do Córrego da Porteira e do Ribeirão Comprido. O relevo local é caracterizado por colinas amplas e baixas com topos convexos e aplanados ou tabulares, entalhamento médio dos vales inferiores a $20 \mathrm{~m}$, interflúvios com dimensões médias entre 1750 e 3750 m, densidades de drenagem baixa, altimetria variando entre 400 a 700 m e declividades médias das vertentes entre 2 a $10 \%$. Com isso, o município de Urânia possui relevo monótono com a presença de pequenos morrotes, cujas cotas variam de 400 a $490 \mathrm{~m}$.

\subsubsection{Unidades hidroestratigráficas}

No município de Urânia afloram as rochas sedimentares da Formação Adamantina (Grupo Bauru), que se depositaram sobre os basaltos da Formação Serra Geral.

ALMODOVAR (2000) descreveu e analisou amostras de calha de rochas basálticas da Formação Serra Geral em Urânia e classificou-as como melanocráticas, com textura fanerítica fina.

Segundo GUTIERREZ (1999), no município de Urânia, os sedimentos da Formação Adamantina são caracterizados por arenitos finos siltosos a muito argilosos, de cor marrom, variando as tonalidades de mais clara a escura e avermelhada. Os grãos são sub-arredondados e bem selecionados. A análise granulométrica realizada por ALMODOVAR (2000) em doze amostras do solo da área de estudo, concluiu que a faixa granulométrica presente no local era representada por areias, argilas e cascalhos. 
De acordo com PALMÉR RIVERA (2002) e ALMODOVAR (2000), a espessura da Formação Adamantina no município de Urânia varia entre 66 e 160 m, sendo as maiores espessuras localizadas do lado oeste do município de Urânia. No município, o contato inferior da Formação Adamantina se dá direta e discordantemente com os basaltos da Formação Serra Geral.

Assim, com base na geologia do município de Urânia, pode-se dividir em dois grandes grupos de unidades hidroestratigráficas: o Aquífero Adamantina (constituído pela Formação Adamantina) e o Aquitarde Serra Geral (constituído pela Formação Serra Geral).

O Aquitarde Serra Geral é classificado como do tipo fraturado, livre, anisotrópico e heterogêneo. Localmente, o intemperismo da rocha pode caracterizar um sistema limitado do tipo poroso. Sua espessura média é de 150 m (ALMODOVAR, 1995).

O topo do Aquífero Serra Geral pode ser definido a partir dos dados dos antigos poços de produção cadastrados na região de Urânia, Jales, Santa Albertina e Aspásia, contidas nas licenças de operação destes poços disponibilizadas pela SABESP (1979a; 1979b; 1979c; 1979d; 1979e; 1979f; 1979g; 1980; 1981; 1982a; 1982b; 1991; 1992), bem como do poço tubular existente no posto de combustível Garção (PT Garção) e nos resultados das Sondagens Elétricas Verticais (SEV1 a SEV14) realizadas por PALMÉR-RIVERA (2002), conforme expresso na Tabela 02.

O Aquífero Adamantina possui extensão regional e tem comportamento livre a semiconfimado, tendo as rochas basálticas da Formação Serra Geral como o seu limitante inferior (DAEE, 1976). De acordo com PALMÉR RIVERA (2002), este aquífero, no município de Urânia, apresenta espessura variando entre 60 e 120 m e, conforme ALMODOVAR (2000), pode ser considerado como livre, homogêneo e isotrópico, cujos níveis de água apresentam pouca variação entre os períodos seco e chuvoso.

Segundo BERTOLO (2001), a recarga natural do Aquífero Adamantina é dada diretamente pelas chuvas. A natureza essencialmente livre do aquífero faz surgir superfícies potenciométrícas com formas que acompanham a geometria da superfície do terreno, com linhas de fluxo de água subterrânea convergindo para as calhas dos rios, tendo desta forma um caráter efluente, e com os divisores das microbacias hidrogeológicas coincidindo com os divisores das microbacias hidrográficas. 
Tabela 02 - Profundidade da Formação Serra Geral em Urânia e região

\begin{tabular}{|c|c|c|c|c|c|}
\hline Poços & Coord. Oeste (m) & Coord. Norte (m) & Cota $(m)$ & $\begin{array}{l}\text { Prof. Form. Serra } \\
\text { Geral (m) }\end{array}$ & $\begin{array}{c}\text { Cota Form. Serra } \\
\text { Geral (m) }\end{array}$ \\
\hline PP01 & 536652 & 7761964 & 474,993 & 160,00 & 314,99 \\
\hline PP02 & 537020 & 7761774 & 462,276 & 155,00 & 307,28 \\
\hline PP03 & 537093 & 7761885 & 466,367 & 150,00 & 316,37 \\
\hline PP04 & 537347 & 7761277 & 437,095 & 102,60 & 334,50 \\
\hline PP05 & 538161 & 7761590 & 421,814 & 66,00 & 355,81 \\
\hline PP06 & 536551 & 7761369 & 455,081 & 117,00 & 338,08 \\
\hline PP08 & 536033 & 7762406 & 460,174 & 138,00 & 322,17 \\
\hline PP09 & 539250 & 7763400 & 420,000 & 67,60 & 352,40 \\
\hline PP01 SA & 524700 & 7781150 & 350,000 & 8,00 & 342,00 \\
\hline PP02 SA & 524400 & 7782400 & 330,000 & 0,00 & 330,00 \\
\hline PP01 A & 527600 & 7710000 & 380,000 & 26,00 & 354,00 \\
\hline PP02 A & 528500 & 7771000 & 410,000 & 67,00 & 343,00 \\
\hline PP01 J & 546500 & 7757850 & 433,000 & 117,00 & 316,00 \\
\hline PP02 J & 548800 & 7756600 & 430,000 & 85,00 & 345,00 \\
\hline PP01 SS & 532600 & 7761200 & 435,000 & 122,91 & 312,09 \\
\hline PT Garção & 535566 & 7762693 & 463,527 & 139,00 & 324,53 \\
\hline PT-30 & 538078 & 7762045 & 436,016 & 99,00 & 337,02 \\
\hline SEV1 & 537604 & 7762043 & 439,234 & 70,00 & 369,23 \\
\hline SEV2 & 536990 & 7762198 & 458,092 & 165,00 & 293,09 \\
\hline SEV3 & 536734 & 7761050 & 457,926 & 144,00 & 313,93 \\
\hline SEV4 & 536708 & 7760584 & 462,918 & 44,50 & 418,42 \\
\hline SEV5 & 537551 & 7760578 & 456,734 & 112,00 & 344,73 \\
\hline SEV6 & 537373 & 7760403 & 457,867 & 105,00 & 352,87 \\
\hline SEV7 & 536636 & 7761768 & 466,729 & 138,00 & 328,73 \\
\hline SEV8 & 538097 & 7761153 & 448,588 & 117,00 & 331,59 \\
\hline SEV9 & 536997 & 7760405 & 461,927 & 130,00 & 331,93 \\
\hline SEV10 & 537102 & 7761557 & 450,385 & 74,00 & 376,39 \\
\hline SEV11 & 536775 & 7760741 & 465,777 & 120,00 & 345,78 \\
\hline SEV12 & 536708 & 7760584 & 462,918 & 114,00 & 348,92 \\
\hline SEV13 & 536774 & 7760039 & 468,683 & 121,00 & 347,68 \\
\hline SEV14 & 537833 & 7760387 & 447,492 & 89,00 & 358,49 \\
\hline \multicolumn{3}{|c|}{ SA - Santa Albertina. } & J - Jales. & & \\
\hline \multicolumn{3}{|l|}{ A - Aspásia. } & SS - Santa & & \\
\hline
\end{tabular}

ROSSATO (1999) realizou o modelamento matemático preliminar do fluxo de água subterrânea do Aquífero Adamantina no município de Urânia e arredores. Os mapas potenciométricos, com e sem os poços profundos do município em funcionamento, demonstraram que a mancha urbana do município situa-se sobre um divisor de bacias hidrogeológicas, e que o bombeamento conjunto dos poços profundos da SABESP gera um único cone de rebaixamento sob o município. A mesma autora sugere que a área de recarga do aquífero corresponde a toda área de exposição dos sedimentos, enquanto que a descarga seria as calhas dos rios. 


\subsubsection{Hidrogeologia local}

Para avaliação da potenciometria local na área de interesse, primeiramente inseriuse no mapa topográfico os poços de produção (PP), tubulares (PT) e cacimba (PC) catalogados por CAGNON (2003) e PALMÉR-RIVERA (2002), por meio de suas coordenadas em UTM (Tabela 03).

Tabela 03 - Coordenadas em UTM dos poços cadastrados

\begin{tabular}{c|c|c}
\hline Poços & Coord. Oeste $(\mathbf{m})$ & Coord. Norte $(\mathbf{m})$ \\
\hline PP01 & 536650 & 7761960 \\
\hline PP02 & 537020 & 7761770 \\
\hline PP03 & 537090 & 7761890 \\
\hline PP04 & 537350 & 7761280 \\
\hline PP05 & 538160 & 7761590 \\
\hline PP06 & 536550 & 7761370 \\
\hline PP08 & 536030 & 7762410 \\
\hline PP09 & 539260 & 7763380 \\
\hline PC01 & 536730 & 7761500 \\
\hline PC02 & 536900 & 7761800 \\
\hline PC03 & 537220 & 7761640 \\
\hline PC04 & 537230 & 7761720 \\
\hline PC06 & 536660 & 7761480 \\
\hline PC07 & 536940 & 7761960 \\
\hline PC08 & 537310 & 7761250 \\
\hline PC09 & 536760 & 7761260 \\
\hline PC10 & 536880 & 7760610 \\
\hline PC13 & 537410 & 7761250 \\
\hline PC16 & 537420 & 7761210 \\
\hline PC17 & 537600 & 7761070 \\
\hline PC19 & 537140 & 7760750 \\
\hline PC22 & 537580 & 7760750 \\
\hline PC23 & 537220 & 7760350 \\
\hline PC24 & 537150 & 7760290 \\
\hline PC25 & 537050 & 7760960 \\
\hline PC26 & 536810 & 7760760 \\
\hline PC27 & 536840 & 7760870 \\
\hline PC28 & 537250 & 7760780 \\
\hline PC29 & 537650 & 7761570 \\
\hline - Coordenadas não disponiveis. & \\
\hline
\end{tabular}

\begin{tabular}{c|c|c}
\hline Poços & Coord. Oeste $(\mathbf{m})$ & Coord. Norte $(\mathbf{m})$ \\
\hline PC30 & 537790 & 7761530 \\
\hline PC32 & 537830 & 7761690 \\
\hline PC33 & 537660 & 7761290 \\
\hline PC34 & 537060 & 7760640 \\
\hline PC35 & 537120 & 7760670 \\
\hline PC37 & 537470 & 7760930 \\
\hline PC38 & 537520 & 7760920 \\
\hline PC40 & 537290 & 7760740 \\
\hline PC41 & 538300 & 7761030 \\
\hline PC43 & 536550 & 7761030 \\
\hline PC44 & 537660 & 7761330 \\
\hline PC45 & 537190 & 7760480 \\
\hline PC46 & 537970 & 7761200 \\
\hline PC48 & 538850 & 7761630 \\
\hline PC101 & - & - \\
\hline PT07 & 537810 & 7761160 \\
\hline PT12 & 536750 & 7760250 \\
\hline PT15 & 536950 & 7760950 \\
\hline PT16 & 537270 & 7760310 \\
\hline PT-19 & - & - \\
\hline PT20 & 537010 & 7761120 \\
\hline PT21 & 537170 & 7761070 \\
\hline PT22 & 537050 & 7760680 \\
\hline PT23A & - & - \\
\hline PT23 & 537460 & 7760600 \\
\hline PT24 & 537330 & 7761190 \\
\hline PT26 & 537690 & 7761140 \\
\hline PT29 & 538080 & 7762050 \\
\hline PT Garção & 535570 & 7762690 \\
\hline & & \\
\hline & & \\
\hline & & \\
\hline & & \\
\hline & & \\
\hline
\end{tabular}

Com os poços locados, para avaliação da potenciometria local foram levantados os dados de cota topográfica e nível d'água dos poços cadastrados, os quais foram adquiridos por meio de CAGNON (2003) e PALMÉR RIVERA (2002), para o cálculo de suas cargas hidráulicas, conforme apresentado na Tabela 04. 
Tabela 04 - Cotas topográficas e medidas de nível d'água dos poços cadastrados

\begin{tabular}{|c|c|c|c|c|}
\hline Poços & Cota $(\mathrm{m})$ & Data & N.A. $(\mathrm{m})$ & C.H. (m) \\
\hline PP01 & 474.99 & - & - & - \\
\hline PP02 & 462.28 & - & - & - \\
\hline PP03 & 466.37 & - & - & - \\
\hline PP04 & 437.1 & - & - & - \\
\hline PP05 & 421.81 & - & - & - \\
\hline PP06 & 455.08 & $06 / 11 / 01$ & 19.29 & 435.79 \\
\hline PP08 & 460.17 & - & - & - \\
\hline PP09 & 405.57 & - & - & - \\
\hline PC01 & 455.74 & - & - & - \\
\hline PC02 & 467.51 & $07 / 11 / 01$ & 14.67 & 452.84 \\
\hline $\mathrm{PCO} 3$ & 460.94 & - & - & - \\
\hline PC04 & 459.29 & $06 / 11 / 01$ & 16.00 & 443.29 \\
\hline PC06 & 455.62 & $31 / 10 / 01$ & 12.05 & 443.57 \\
\hline PC07 & 468.42 & $31 / 10 / 01$ & 14.76 & 453.66 \\
\hline PC08 & 439.19 & $30 / 10 / 01$ & 3.65 & 435.54 \\
\hline PC09 & 448.82 & $29 / 10 / 01$ & 7.10 & 441.72 \\
\hline PC10 & 458.93 & $29 / 10 / 01$ & 15.99 & 442.94 \\
\hline PC13 & 439.11 & $30 / 10 / 01$ & 4.20 & 434.91 \\
\hline PC16 & 442.36 & $29 / 10 / 01$ & 6.55 & 435.81 \\
\hline PC17 & 443.32 & $30 / 10 / 01$ & 6.86 & 436.46 \\
\hline PC19 & 452.23 & - & - & - \\
\hline PC22 & 453.9 & $29 / 10 / 01$ & 11.41 & 442.49 \\
\hline PC23 & 463.2 & $29 / 10 / 01$ & 15.78 & 447.42 \\
\hline PC24 & 463.81 & $29 / 10 / 01$ & 17.27 & 446.54 \\
\hline PC25 & 454.11 & 29/10/01 & 13.17 & 440.94 \\
\hline PC26 & 461.69 & 29/10/01 & 18.90 & 442.79 \\
\hline PC27 & 460.33 & $29 / 10 / 01$ & 17.16 & 443.17 \\
\hline PC28 & 444.16 & - & - & - \\
\hline PC29 & 441.55 & - & - & - \\
\hline
\end{tabular}

\begin{tabular}{c|c|c|c|c}
\hline Poços & Cota (m) & Data & N.A. (m) & C.H. (m) \\
\hline PC30 & 429.63 & $30 / 10 / 01$ & 6.60 & 423.03 \\
\hline PC32 & 436.5 & $30 / 10 / 01$ & 7.85 & 428.65 \\
\hline PC33 & 436.88 & - & - & - \\
\hline PC34 & 457.93 & $30 / 10 / 01$ & 11.80 & 446.13 \\
\hline PC35 & 448.79 & $30 / 10 / 01$ & 10.68 & 438.11 \\
\hline PC37 & 448.09 & $30 / 10 / 01$ & 4.98 & 443.11 \\
\hline PC38 & 447.94 & - & - & - \\
\hline PC40 & 443.03 & $29 / 10 / 01$ & 7.35 & 435.68 \\
\hline PC41 & 438.56 & - & - & - \\
\hline PC43 & 456.2 & $30 / 10 / 01$ & 15.58 & 440.62 \\
\hline PC44 & 428.16 & $29 / 10 / 01$ & 2.12 & 426.04 \\
\hline PC45 & 455.81 & $29 / 10 / 01$ & 13.80 & 442.01 \\
\hline PC46 & 443.25 & - & - & - \\
\hline PC48 & 427.38 & $07 / 11 / 01$ & 11.45 & 415.93 \\
\hline PC-101 & 455.08 & $06 / 11 / 01$ & 11.65 & 443.43 \\
\hline PT07 & 442.52 & - & - & - \\
\hline PT12 & 467.39 & - & - & - \\
\hline PT15 & 456.72 & - & - & - \\
\hline PT16 & 464.19 & - & - & - \\
\hline PT-19 & 446.25 & $29 / 10 / 01$ & 3.98 & 442.27 \\
\hline PT20 & 449.77 & - & - & - \\
\hline PT21 & 450.22 & $29 / 10 / 01$ & 10.19 & 440.03 \\
\hline PT22 & 456.79 & - & - & - \\
\hline PT23A & 457.62 & $31 / 10 / 01$ & 13.27 & 444.35 \\
\hline PT23 & 457.62 & $31 / 10 / 01$ & 13.28 & 444.34 \\
\hline PT24 & 440.93 & $29 / 10 / 01$ & 6.22 & 434.71 \\
\hline PT26 & 445.14 & $30 / 10 / 01$ & 10.29 & 434.85 \\
\hline PT29 & 436.02 & - & - & - \\
\hline Posto garção & 463.53 & - & - & - \\
\hline & & & & \\
\hline & & - & \\
\hline
\end{tabular}

A cota topográfica dos poços e os pontos ao longo dos córregos foram medidos por PALMÉR RIVEIRA (2002) com uma precisão Global Positioning System (GPS: Trimble Pathfinder PRO XR12). O software GPS Pathfinder Office (TRIMBLE, 2001, apud PALMÉR RIVEIRA, 2002) foi utilizado para os dados de correção diferencial, e os dados de correção foram registrados por uma antena localizada no escritório Santiago \& Cintra, em São Paulo.

Segundo PALMÉR RIVEIRA (2002), o nível da água nos poços selecionados foi medido utilizando um medidor elétrico comum. Os proprietários dos poços foram contatados no dia anterior às medidas para se certificar de que as bombas contidas nos poços não foram ligadas há pelo menos 12 horas antes das medições. 
Ao se avaliar os dados obtidos por PALMÉR RIVEIRA (2002) e os comparar com os obtidos por ROSSATO (1999), verificou-se que os níveis d'água na área de estudo não variam significantemente com o tempo, corroborando com as premissas expressas em ALMODOVAR (2000). Assim, foi possível utilizar os dados de nível d'água medidos em um intervalo de dez dias para elaboração do mapa de potenciometria local da porção rasa do aquífero livre, sem obter erros significativos (Figura 7). Salienta-se que para este mapa não foram utilizadas as cargas hidráulicas dos poços tubulares e de produção, devido ao posicionamento dos filtros dos mesmos.

Verifica-se neste mapa que existem três divisores de águas subterrâneas, um a norte, outro a sul-sudeste e ainda outro em parte da região sudoeste do município. O fluxo da água subterrânea apresenta sentido preferencial para nordeste, com linhas de fluxo convergindo para a calha do Ribeirão Comprido, considerado como área de descarga do aquífero livre na zona urbana do município de Urânia. O gradiente hidráulico calculado a partir do mapa de potenciometria local varia de 0,008 a $0,025 \mathrm{~m} / \mathrm{m}$.

Para obtenção dos valores de condutividade hidráulica, transmissividade e velocidade de fluxo da água subterrânea do aquífero Adamantina, foram utilizados os dados dos testes de bombeamento realizados no momento da construção dos poços de produção do município de Urânia (SABESP, 1979a; 1979b; 1979c; 1982a; 1991), os resultados de dois testes de bombeamento realizados por PALMÉR RIVERA (2002) nos poços tubulares PT-23 e PT-26, bem como os dados levantados por HIRATA (2000a), ROCHA et al. (1982) e HIRATA \& RODOLFI (1993), conforme apresentado na Tabela 05.

Tabela 05 - Sumário dos Parâmetros Hidrogeológicos para o Aquífero Adamantina

\begin{tabular}{|c|c|c|c|c|c|c|c|c|c|c|c|c|}
\hline \multirow[b]{2}{*}{ Zona } & \multicolumn{4}{|c|}{ Condutividade hidráulica (m/s) } & \multicolumn{2}{|c|}{ Grad. Hidráulico } & \multicolumn{2}{|c|}{$\begin{array}{c}\text { Velocidade de Fluxo } \\
(\mathrm{m} / \mathrm{s})\end{array}$} & \multicolumn{4}{|c|}{ Transmissividade $\left(\mathrm{m}^{2} / \mathrm{s}\right)$} \\
\hline & $\begin{array}{l}\text { HIRATA } \\
(2000 a)\end{array}$ & $\begin{array}{c}\text { ROCHA et al. } \\
\text { (1982) }\end{array}$ & $\begin{array}{c}\text { SABESP } \\
(1979 a-e ; \\
\text { 1982a; 1991) }\end{array}$ & $\begin{array}{c}\text { TB - nov/01 } \\
\text { (CAGNON, } \\
2003)\end{array}$ & $\begin{array}{l}\text { HIRATA } \\
\text { (2000a) }\end{array}$ & $\begin{array}{c}\text { Pot. } \\
\text { out/01 }\end{array}$ & $\begin{array}{l}\text { CAGNON } \\
(2003)\end{array}$ & $\begin{array}{l}\text { HIRATA } \\
(2000 a)\end{array}$ & $\begin{array}{c}\text { HIRATA \& } \\
\text { RODOLFI } \\
(1993)\end{array}$ & $\begin{array}{c}\text { SABESP } \\
(1979 a-e ; \\
\text { 1982a; } \\
1991)\end{array}$ & $\begin{array}{l}\text { ROCHA et } \\
\text { al. (1982) }\end{array}$ & $\begin{array}{c}\text { TB - nov/01 } \\
\text { (CAGNON, } \\
2003)\end{array}$ \\
\hline ZR & & & --- & $\begin{array}{r}7.17 \times 10^{-5} \mathrm{e} \\
8.54 \times 10^{-6}\end{array}$ & & $\begin{array}{c}0,008 \mathrm{a} \\
0,025\end{array}$ & $\begin{array}{c}1,20 \times 10^{-5} \mathrm{a} \\
6,26 \times 10^{-7}\end{array}$ & --- & --- & --- & --- & $\begin{array}{c}2,36 \times 10^{-4} \mathrm{e} \\
4,22 \times 10^{-4}\end{array}$ \\
\hline$Z P$ & $\begin{array}{c}1 \times 10^{-3} \mathrm{a} \\
1 \times 10^{-7}\end{array}$ & $\begin{array}{c}1,16 \times 10^{-5} a \\
1,16 \times 10^{-6}\end{array}$ & $\begin{array}{c}1.41 \times 10^{-6} \mathrm{a} \\
4.05 \times 10^{-7}\end{array}$ & --- & $\begin{array}{c}1,30 \mathrm{a} \\
3,42\end{array}$ & --- & --- & $\begin{array}{c}2.3 \times 10^{-2} \mathrm{a} \\
8.7 \times 10^{-7}\end{array}$ & $7,3 \times 10^{-5}$ & $\begin{array}{c}1.51 \times 10^{-4} \mathrm{a} \\
4.86 \times 10^{-5}\end{array}$ & $\begin{array}{c}3,5 \times 10^{-4} \mathrm{a} \\
5,8 \times 10^{-4}\end{array}$ & --- \\
\hline \multicolumn{13}{|c|}{ ZR - Zona rasa. } \\
\hline \multicolumn{13}{|c|}{ ZP - Zona profunda. } \\
\hline $\mathrm{TB}-\mathrm{T}$ & este de bon & nbeamento. & & & & & & & & & & \\
\hline
\end{tabular}




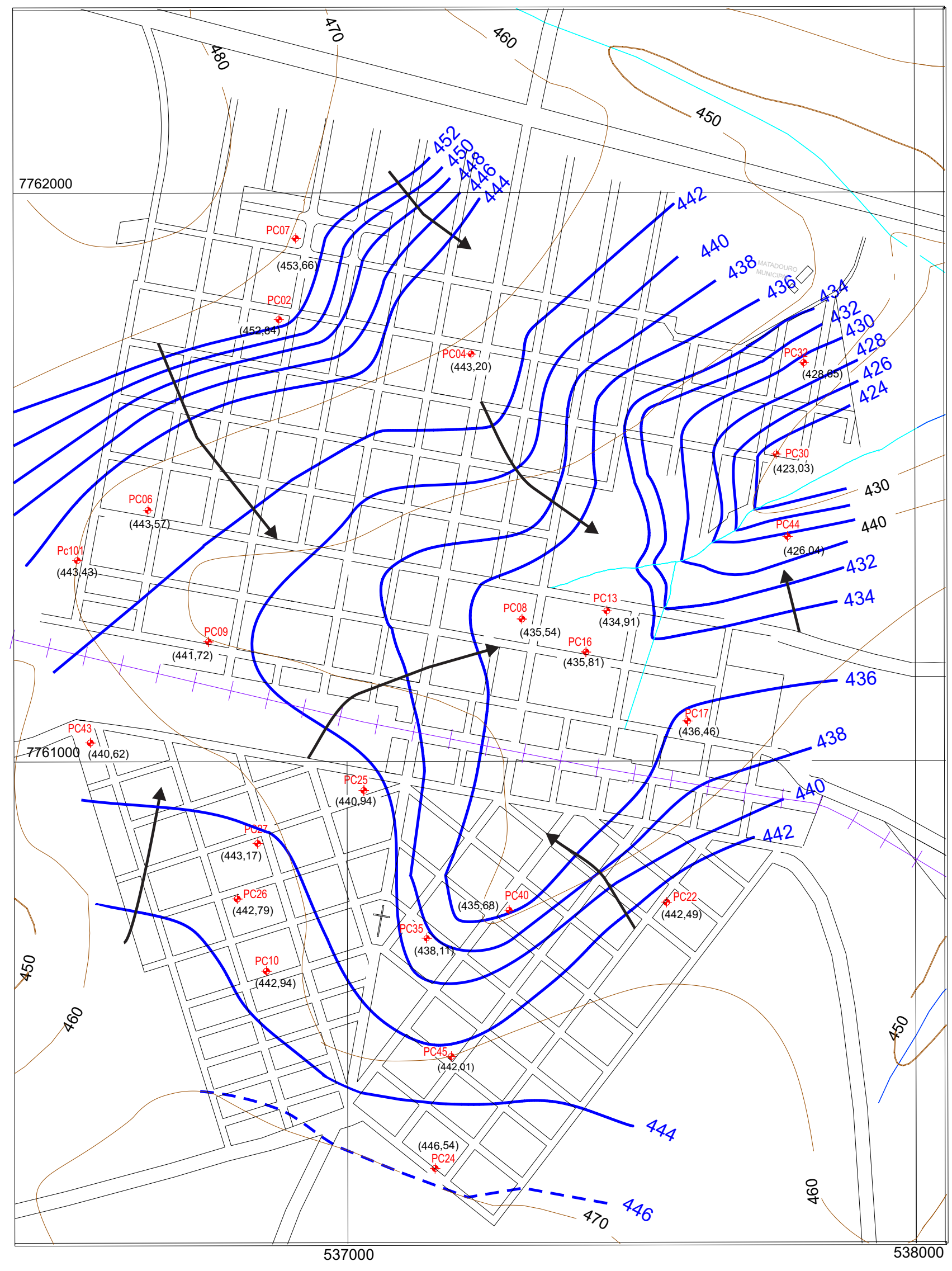

POTENCIOMETRIA LOCAL (OUTUBRO/2001)

水

LEGENDA

the curvas de nivel (m)

Drenagens

Rodovias principais

Estradas secundárias

++ Ferrovia

${ }_{450 m}$ Cota topográfica

PC44 Poço cacimba

(442,49) Carga hidráulica ( $\mathrm{m}$ )

- ${ }^{430}$ Linhas equipotenciométricas $(\mathrm{m}$ )

$\longrightarrow$ Linhas de Fluxo

$100200300 \mathrm{~m}$

Escala gráfica 
Através dos resultados apresentados na tabela acima, pode-se compartimentar a Formação Adamantina em duas unidades hidroestratigráficas, uma superior (zona rasa), menos permeável, e outra inferior (zona profunda), mais permeável. Este fato deve-se a diferença nos valores de condutividades hidráulicas verificada entre as zonas rasa e profunda do aquífero, onde o valor máximo de condutividade obtido para a unidade estratigráfica superior é de $7,17 \times 10^{-5} \mathrm{~m} / \mathrm{s}$ (CAGNON, 2003), enquanto que o obtido para a unidade hidroestratigráfica inferior é de $1,00 \times 10^{-3} \mathrm{~m} / \mathrm{s}$ (HIRATA, 2000a).

Tanto na unidade hidroestratigráfica superior quanto na inferior, adotaram-se menores valores de condutividade hidráulica nas regiões mais altas do modelo, pois foi assumido que estas regiões não foram intemperizadas ao longo do tempo, devido a sua constituição mais argilosa ou a sua cimentação.

O valor da porosidade efetiva $\left(n_{e}\right)$ utilizado foi de $15 \%$, pois, de acordo com HIRATA et al. (1997), a porosidade efetiva do Grupo Bauru varia entre $5 \%$ e $15 \%$.

\subsubsection{Precipitação, Evapotranspiração e Recarga}

Uma vez que os dados de nível d'água e de contaminação por nitrato foram coletados em 2001 (CAGNON, 2003; PALMÉR RIVERA, 2002), utilizou-se os dados de precipitação média em Urânia entre 1959 e 2003 (Tabela 06), de 1276 mm/ano (SIGRH on line, acesso em 10 de janeiro de 2010), para estimar a recarga. Segundo BERTOLO (2001), a recarga das águas subterrâneas em Urânia é de aproximadamente $15 \%$ da precipitação. Por isso, a recarga na área rural de Urânia foi estimada em 191 mm/ano.

A recarga na parte urbana de Urânia é mais difícil de estimar. Uma vez que toda a população recebe água potável canalizada oriunda das proximidades de Jales, a fuga das tubulações de abastecimento de água, de esgoto e de águas pluviais constitui uma recarga extra para as águas subterrâneas. De acordo com dados apresentados por RODRIGUES VERDELHO (2001, apud PALMÉR RIVERA, 2002), esta recarga adicional pode ser estimada em $47 \mathrm{~mm} / \mathrm{ano}$. Como a densidade habitacional é relativamente baixa em Urânia, e nem todas as ruas são pavimentadas, a diminuição da recarga devido ao aumento do escoamento superficial é suposta ser mínima. Desta forma a recarga total da área urbana é, portanto, estimada em $238 \mathrm{~mm} / \mathrm{ano}$. 
Tabela 06 - Precipitação mensal em Urânia (1959 a 2003)

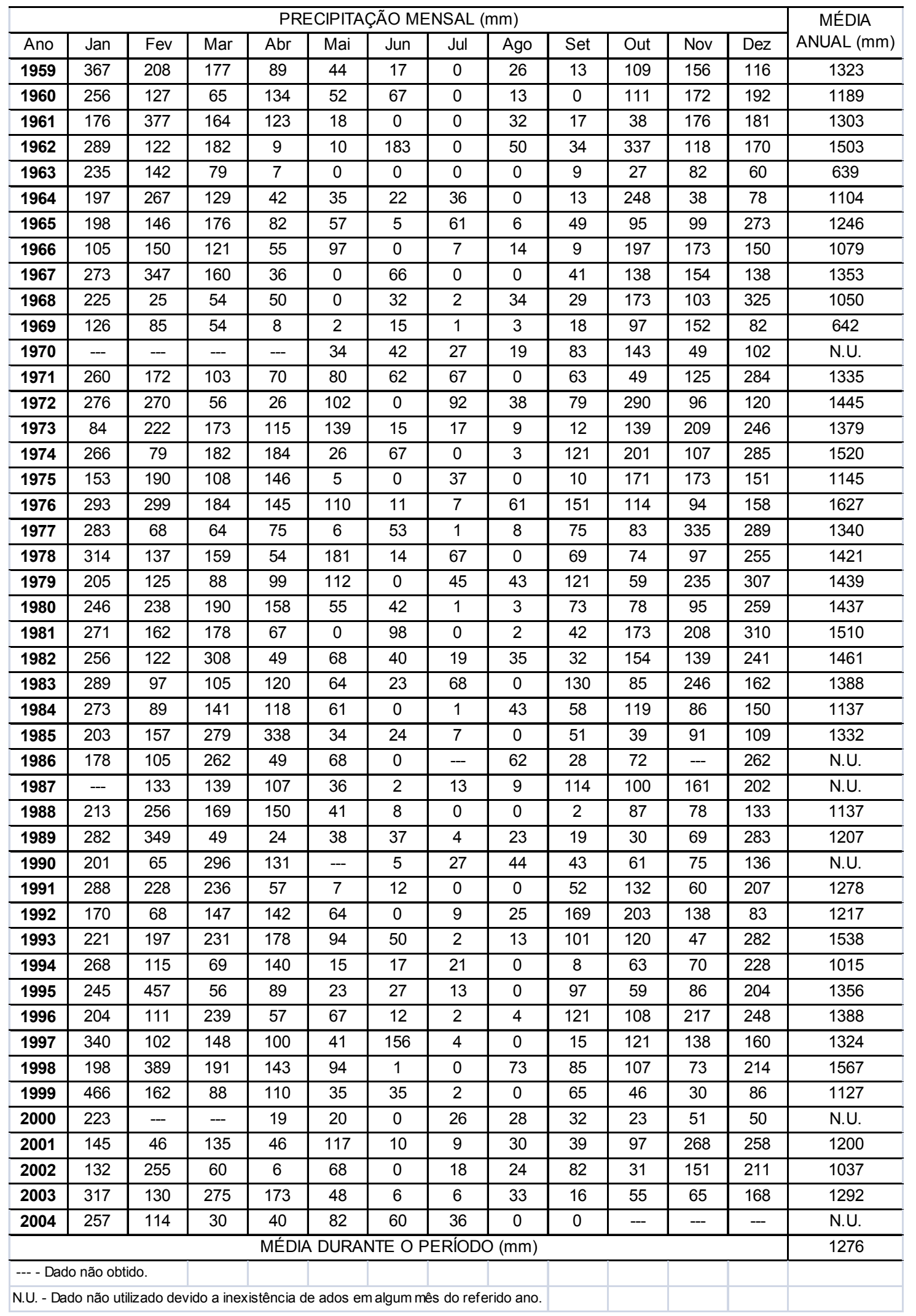


Em um estudo da zona não saturada realizado em Urânia, verificou-se que a influência da evapotranspiração é limitada a uma profundidade de vários metros acima do nível d'água (BERTOLO, 2001). Assim, a evapotranspiração da zona saturada é praticamente nula e não foi considerada no modelo conceitual. Salienta-se que a evapotranspiração da zona não saturada já está contabilizada nos valores de recarga, tanto da área urbana como da área rural.

\subsubsection{Corpos d'água superficiais}

Os córregos na área em estudo são relativamente rasos. Em geral, a profundidade é inferior a $1 \mathrm{~m}$, e muitas vezes abaixo de $50 \mathrm{~cm}$. Estes córregos foram considerados como sendo efluentes durante todo o ano, ou seja, eles recebem água do aquífero, uma vez que foi verificada por CAGNON (2003) a presença de corpos d'água tanto na estação chuvosa como na seca. A Tabela 07 apresenta as medidas de cota topográfica, carga hidráulica e profundidade, realizadas em alguns pontos dos córregos existentes na área em estudo por PALMÉR RIVERA (2002), e a Figura 8 apresenta a localização destes pontos.

Tabela 07 - Medidas de carga hidráulica dos córregos

\begin{tabular}{|c|c|c|c|c|c|}
\hline Ponto & Coord. Oeste (m) & Coord. Norte (m) & Cota $(m)$ & Cota do N.A. (m) & Prof. (m) \\
\hline r1 & 538492 & 7761720 & 418,67 & 416,67 & 0,20 \\
\hline r2 & 538332 & 7761689 & 417,25 & 416,25 & 0,10 \\
\hline r3 & 537499 & 7761054 & 438,57 & 434,18 & 0,90 \\
\hline $\mathrm{r} 4$ & 537370 & 7762263 & 448,88 & 446,21 & 0,30 \\
\hline r5 & 537635 & 7762185 & 441,75 & 440,25 & 1,50 \\
\hline r6 & 537603 & 7762193 & 441,42 & 439,92 & 1,50 \\
\hline $\mathrm{r} 7$ & 537597 & 7762177 & 438,36 & 436,86 & 1,50 \\
\hline r8 & 537607 & 7762211 & 439,88 & 438,38 & 1,50 \\
\hline r9 & 538991 & 7762829 & 405,19 & 403,44 & 0,30 \\
\hline r10 & 537383 & 7762970 & 448,96 & 447,96 & 0,03 \\
\hline r11 & 539147 & 7761204 & 424,22 & 421,24 & 3,00 \\
\hline $\mathrm{r} 12$ & 538995 & 7761158 & 421,47 & 420,47 & - \\
\hline r13 & 538680 & 7761430 & 420,31 & 419,31 & 0,40 \\
\hline r14 & 537689 & 7761411 & 428,89 & 425,89 & 0,45 \\
\hline r15 & 538612 & 7759012 & 451,43 & 450,43 & 0,00 \\
\hline $\mathrm{r} 16$ & 537885 & 7760358 & 445,27 & 443,72 & 0,90 \\
\hline $\mathrm{r} 17$ & 536402 & 7761125 & 452,07 & 449,27 & 0,00 \\
\hline r18 & 534912 & 7761227 & 410,12 & 408,12 & 0,40 \\
\hline $\mathrm{r} 19$ & 535577 & 7761635 & 429,17 & 428,17 & 0,00 \\
\hline $\mathrm{r} 20$ & 535044 & 7761944 & 424,78 & 423,78 & 0,05 \\
\hline $\mathrm{r} 21$ & 534848 & 7761862 & 429,90 & 427,45 & 0,74 \\
\hline $\mathrm{r} 22$ & 534579 & 7760324 & 400,12 & 396,42 & 0,40 \\
\hline $\mathrm{r} 23$ & 536369 & 7759212 & 433,57 & 432,57 & 0,10 \\
\hline $\mathrm{r} 24$ & 535079 & 7758387 & 419,31 & 418,31 & 0,50 \\
\hline
\end{tabular}




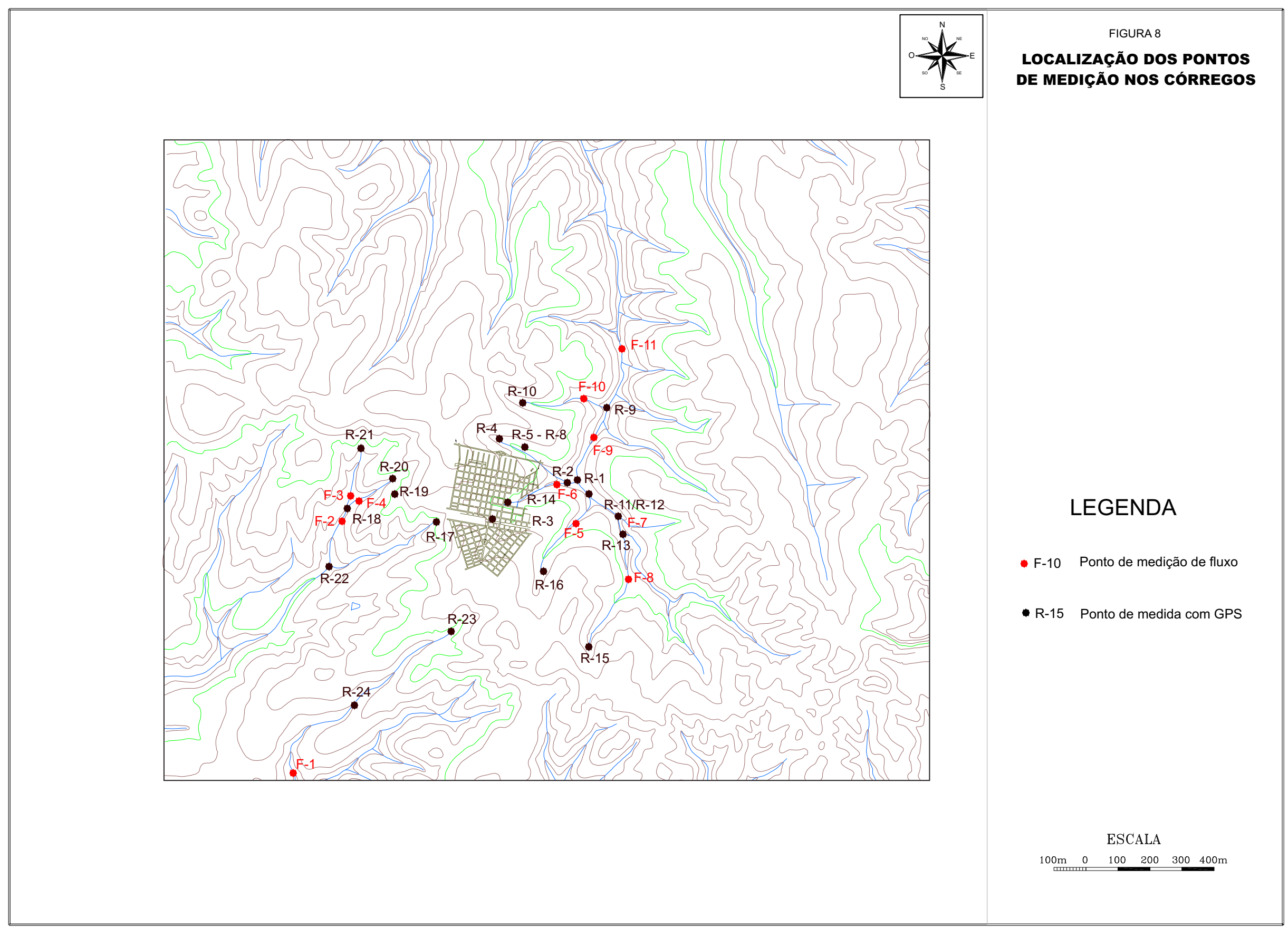


A vazão dos córregos foi medida por PALMÉR RIVERA (2002), obtendo-se valores entre 1290 e $17800 \mathrm{~m}^{3} /$ dia. No entanto, estas medições de vazão são muito incertas, o que fica claro quando se verifica uma diferença de vazão de até $300 \%$ entre pontos situados a apenas poucas centenas de metros de distância entre si.

Como seria de esperar, as vazões dos córregos são mais influenciadas pelas águas residuais na zona urbana (PALMÉR RIVERA, 2002). Entretanto esta influência não é grande o suficiente para ter um grande efeito sobre os fluxos medidos.

Outras massas de água superficiais encontrados na área em estudo são principalmente lagos artificiais usados para aquicultura. Eles são geralmente pequenos e não ultrapassam $3 \mathrm{~m}$ de diâmetro e, portanto, não foram considerados no modelo conceitual.

\subsubsection{Contaminação por nitrato}

Altas concentrações de nitrato, muitas veses excedendo os valores de potabilidade expressos na Portaria 518 (BRASIL, 2004), foram detectadas em poços tubulares pouco profundos (até $100 \mathrm{~m}$ ) e cacimbas (até $20 \mathrm{~m}$ ) no aquífero Adamantina, município de Urânia (HIRATA, 2000a; GUTIERREZ, 2003; HIRATA \& CAGNON, 2004). Este contaminante também foi detectado em elevadas concentrações na zona não saturada, conforme expresso em BERTOLO \& HIRATA (2000) e BERTOLO et al. (2006). Anterior a 1970, o município não dispunha de rede de esgoto e o efluente era lançado in natura no solo através de fossas negras. Segundo estimativas apresentadas por HIRATA \& CAGNON (2004), a área urbana possuía aproximadamente 1250 fossas $/ \mathrm{km}^{2}$ e densidade populacional de 5000 hab/km² (Tabela 08). As águas subterrâneas no município, segundo os autores, seriam vulneráveis à carga gerada pelas fossas.

Tabela 08 - Evolução do uso e ocupação do solo no município de Urânia

\begin{tabular}{|c|c|c|c|c|c|c|}
\hline Período & N. de hab. & $\begin{array}{c}\text { Área urbana } \\
\left(\mathrm{km}^{2}\right)\end{array}$ & $\begin{array}{c}\text { Dens.demográfica } \\
\text { urbana } \\
\left(\text { hab. } / \mathrm{km}^{2}\right)\end{array}$ & $\begin{array}{l}\text { Dens. urbana } \\
\text { de moradias } \\
\left(\text { moradias } / \mathrm{km}^{2}\right)\end{array}$ & $\begin{array}{c}\text { Dens. urbana } \\
\text { de fossas } \\
\text { (fossas } / \mathrm{km}^{2} \text { ) }\end{array}$ & $\begin{array}{l}\text { Sistem de } \\
\text { tratamento } \\
\text { de efluente }\end{array}$ \\
\hline década de 60 & 18.000 & 0,72 & 5.000 & 1.250 & 1.250 & fossas \\
\hline década de 70 & 16.829 & 1,19 & 4.315 & 1.079 & -- & $59 \%$ coletado \\
\hline década de 80 & 13.510 & 1,47 & 4.421 & 1.105 & -- & $64 \%$ coletado \\
\hline década de 90 & 12.280 & 1,65 & 4.582 & 1.146 & -- & $89 \%$ coletado \\
\hline hoje & 8.824 & 2,14 & 3.301 & 825 & -- & $95,9 \%$ coletado \\
\hline
\end{tabular}

Fonte: Modif. de HIRATA \& CAGNON, 2004. 
Com o processo de urbanização, as fossas negras foram desativadas e, atualmente, a rede cobre $96 \%$ do município. Embora a rede de esgoto já tenha sido implementada há mais de 30 anos, o nitrogênio remanescente no solo continua em grande volume nas zonas não saturada e saturada. A Figura 9 apresenta a localização das fossas na área em estudo cadastradas por CAGNON (2003).

$\mathrm{Na}$ Tabela 09 estão apresentadas as concentrações de nitrato obtidas por ALMODOVAR (2000) e CAGNON (2003) nos poços cacimba (PC), tubulares (PT) e de produção (PP) do município de Urânia - SP.

Verificam-se nesta tabela concentrações médias de nitrato de aproximadamente $63 \mathrm{mg} / \mathrm{L}, 30 \mathrm{mg} / \mathrm{L}$ e $17 \mathrm{mg} / \mathrm{L}$ nos poços cacimba (em média $14 \mathrm{~m}$ de profundidade e seção filtrante plena), tubulares (em média $80 \mathrm{~m}$ de profundidade) e de produção (em média $140 \mathrm{~m}$ de profundidade e $35 \mathrm{~m}$ de seção filtrante), respectivamente. Salienta-se que embora tenha sido constatada concentrações de nitrato na porção profunda do aquífero livre, até a presente data não se tem conhecimento se esta contaminação foi ocasionada pelo bombeamento dos poços de produção.

Também é importante informar que devido à detecção de cromo em concentrações superiores ao limite para potabilidade expresso na Portaria 518 (BRASIL, 2004), todos os poços de produção do município de Urânia foram desativados, sendo atualmente o município abastecido por poço de captação da água subterrânea do Aquífero Guarani, situado na cidade de Jales.

A fim de identificar as causas da origem do cromo nas águas subterrâneas, ALMODOVAR (2000) realizou um estudo de maior detalhe em Urânia. Como resultado, identificou que a origem do cromo é natural e não está ligada a nenhum evento de poluição de origem antrópica, que os sedimentos apresentam elevadas concentrações do elemento em relação a outros contextos geológicos e que as águas de circulação mais profunda e de maior tempo de trânsito no aquífero são aquelas que apresentam as maiores concentrações de cromo. A utilização de modelos de equilíbrio químico pela autora ressaltaram, inclusive, na existência de ambiente hidroquímico favorável à dissolução de minerais com cromo. 


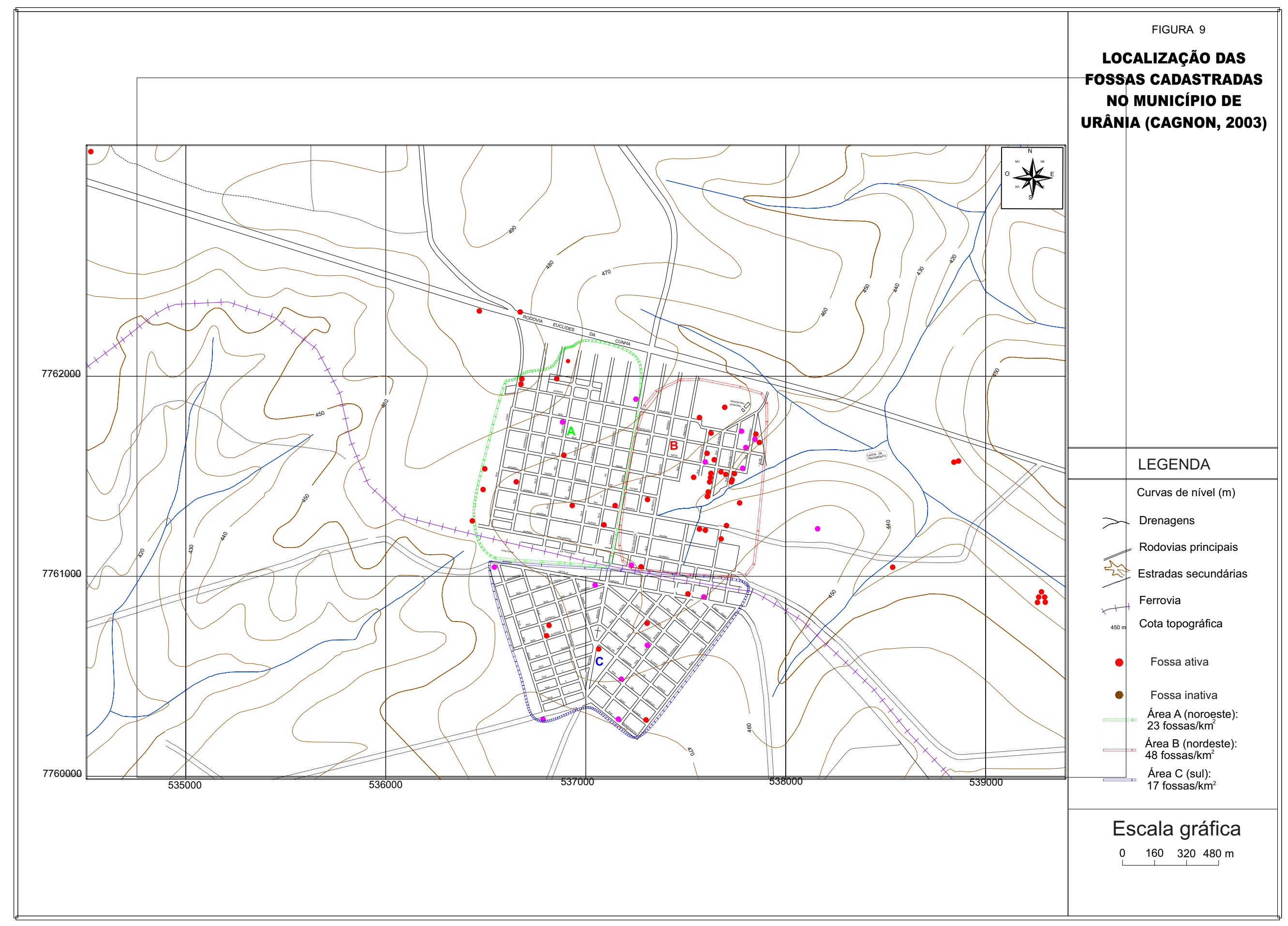


Tabela 09 - Concentrações de nitrato nos poços em Urânia - SP

\begin{tabular}{|c|c|c|c|c|c|c|c|c|c|c|c|c|c|c|}
\hline Fonte & \multicolumn{4}{|c|}{ ALMODOVAR (2000) } & \multicolumn{10}{|c|}{ CAGNON (2003) } \\
\hline Data & jun-98 & nov-98 & mar-99 & jun-99 & Abr-00 (C) & Abr-00 (L) & Ago-00 (C) & Ago-00 (L) & Fev-01 (C) & Fev-01 (L) & Ago-01 (C) & Ago-01 (L) & Set-01 (C) & Set-01 (L) \\
\hline Poços & $(\mathrm{mg} / \mathrm{L})$ & $(\mathrm{mg} / \mathrm{L})$ & $(\mathrm{mg} / \mathrm{L})$ & $(\mathrm{mg} / \mathrm{L})$ & $(\mathrm{mg} / \mathrm{L})$ & (mg/L) & $(\mathrm{mg} / \mathrm{L})$ & $(\mathrm{mg} / \mathrm{L})$ & (mg/L) & $(\mathrm{mg} / \mathrm{L})$ & $(\mathrm{mg} / \mathrm{L})$ & $(\mathrm{mg} / \mathrm{L})$ & $(\mathrm{mg} / \mathrm{L})$ & (mg/L) \\
\hline$\overline{P C}-02$ & 63.07 & 66.29 & 69.41 & 85.31 & 81.00 & 63.07 & 67.00 & 84.03 & 57.00 & 39.09 & 88.00 & 122.25 & 93.00 & 66.63 \\
\hline PC-04 & 116.41 & 113.24 & 99.65 & 126.12 & N.E. & 90.81 & 73.00 & N.E. & 58.00 & N.E. & 49.00 & 64.69 & 59.00 & N.E. \\
\hline PC-06 & 38.26 & N.E. & 55.81 & 51.64 & 68.00 & 69.40 & 50.00 & N.E. & 41.00 & N.E. & 59.00 & 76.52 & 47.00 & 73.37 \\
\hline PC-07 & 48.21 & 48.29 & 46.40 & 50.29 & 43.00 & 51.03 & N.E. & N.E. & N.E. & N.E. & N.E. & N.E. & N.E. & N.E. \\
\hline PC-08 & 68.56 & 55.72 & 65.11 & 68.78 & 81.00 & N.E. & 68.00 & 59.65 & N.E. & 28.53 & 50.00 & 65.91 & N.E. & N.E. \\
\hline PC-10 & 35.31 & 27.92 & 37.35 & 37.22 & 30.00 & 35.03 & N.E. & N.E. & N.E. & N.E. & N.E. & N.E. & N.E. & N.E. \\
\hline PC-11 & 154.83 & N.E. & 163.19 & 160.45 & N.E. & 172.87 & N.E. & N.E. & N.E. & N.E. & N.E. & N.E. & N.E. & N.E. \\
\hline PC-12 & 54.78 & 78.83 & 67.78 & 78.64 & 88.00 & 80.10 & N.E. & N.E. & N.E. & N.E. & N.E. & N.E. & N.E. & N.E. \\
\hline PC-16 & 113.66 & N.E. & 78.80 & 87.21 & 87.00 & 53.97 & N.E. & N.E. & N.E. & N.E. & N.E. & N.E. & N.E. & N.E. \\
\hline PC-17 & 87.43 & 83.54 & 94.74 & 116.38 & N.E. & N.E. & 99.00 & 113.86 & 72.00 & 64.56 & 85.00 & 124.25 & 97.00 & 99.81 \\
\hline PC-18 & 134.86 & N.E. & N.E. & 81.35 & 61.00 & 63.59 & N.E. & N.E. & N.E. & N.E. & N.E. & N.E. & N.E. & N.E. \\
\hline PC-19 & N.E. & N.E. & N.E. & N.E. & 55.00 & N.E. & N.E. & N.E. & N.E. & N.E. & N.E. & N.E. & N.E. & N.E. \\
\hline PC-21 & N.E. & N.E. & N.E. & N.E. & 35.00 & N.E. & N.E. & N.E. & N.E. & N.E. & N.E. & N.E. & N.E. & N.E. \\
\hline PC-22 & 58.78 & N.E. & N.E. & N.E. & N.E. & 150.25 & N.E. & N.E. & N.E. & N.E. & N.E. & N.E. & N.E. & N.E. \\
\hline PC-23 & N.E. & N.E. & N.E. & N.E. & 112.00 & N.E. & 73.00 & N.E. & 34.00 & N.E. & 27.00 & N.E. & N.E. & N.E. \\
\hline PC-24 & N.E. & N.E. & N.E. & N.E. & 0.00 & N.E. & 3.00 & N.E. & 0.00 & N.E. & 0.00 & N.E. & N.E. & N.E. \\
\hline PC-25 & N.E. & N.E. & N.E. & N.E. & 74.00 & N.E. & 75.00 & N.E. & 51.00 & N.E. & 77.00 & N.E. & 87.00 & 111.70 \\
\hline PC-26 & N.E. & N.E. & N.E. & N.E. & 0.00 & N.E. & 3.00 & N.E. & 0.00 & N.E. & 0.00 & N.E. & 13.00 & 4.34 \\
\hline PC-27 & N.E. & N.E. & N.E. & N.E. & 90.00 & N.E. & 50.00 & N.E. & 31.00 & N.E. & 41.00 & N.E. & N.E. & N.E. \\
\hline PC-28 & N.E. & N.E. & N.E. & N.E. & N.E. & N.E. & 39.00 & N.E. & 26.00 & N.E. & 39.00 & N.E. & N.E. & N.E. \\
\hline PC-29 & N.E. & N.E. & N.E. & N.E. & 140.00 & N.E. & 90.00 & 144.80 & 93.00 & 77.20 & 76.00 & 104.51 & N.E. & N.E. \\
\hline PC-30 & N.E. & N.E. & N.E. & N.E. & 41.00 & N.E. & 37.00 & 0.00 & 28.00 & N.E. & 33.00 & N.E. & N.E. & N.E. \\
\hline PC-31 & N.E. & N.E. & N.E. & N.E. & 72.00 & N.E. & N.E. & N.E. & N.E. & N.E. & N.E. & N.E. & 61.00 & 48.89 \\
\hline PC-32 & N.E. & N.E. & N.E. & N.E. & 69.00 & N.E. & 58.00 & N.E. & 52.00 & N.E. & 56.00 & N.E. & 58.00 & 75.87 \\
\hline PC-33 & N.E. & N.E. & N.E. & N.E. & 116.00 & N.E. & 60.00 & 61.22 & 45.00 & 23.63 & 43.00 & 53.00 & N.E. & N.E. \\
\hline PC-34 & N.E. & N.E. & N.E. & N.E. & 21.00 & N.E. & 26.00 & 33.00 & 21.00 & 10.43 & 24.00 & 28.18 & 25.00 & 32.04 \\
\hline PC-35 & N.E. & N.E. & N.E. & N.E. & 25.00 & N.E. & 39.00 & N.E. & 24.00 & N.E. & 37.00 & N.E. & N.E. & N.E. \\
\hline PC-36 & N.E. & N.E. & N.E. & N.E. & 68.00 & N.E. & N.E. & N.E. & N.E. & N.E. & N.E. & N.E. & N.E. & N.E. \\
\hline PC-37 & N.E. & N.E. & N.E. & N.E. & 58.00 & N.E. & N.E. & N.E. & N.E. & N.E. & N.E. & N.E. & N.E. & N.E. \\
\hline PC-38 & N.E. & N.E. & N.E. & N.E. & 88.00 & N.E. & 77.00 & 88.41 & 61.00 & 38.56 & 68.00 & 84.43 & 60.00 & 82.49 \\
\hline PC-39 & N.E. & N.E. & N.E. & N.E. & 9.00 & N.E. & N.E. & N.E. & N.E. & N.E. & N.E. & N.E. & N.E. & N.E. \\
\hline PC-40 & N.E. & N.E. & N.E. & N.E. & 76.00 & N.E. & N.E. & N.E. & 25.00 & N.E. & 59.00 & N.E. & N.E. & N.E. \\
\hline PC-41 & N.E. & N.E. & N.E. & N.E. & 24.00 & N.E. & 32.00 & N.E. & 23.00 & N.E. & 27.00 & N.E. & N.E. & N.E. \\
\hline PC-42 & N.E. & N.E. & N.E. & N.E. & 0.00 & N.E. & 10.00 & N.E. & 0.00 & N.E. & 0.00 & N.E. & N.E. & N.E. \\
\hline PC-43 & N.E. & N.E. & N.E. & N.E. & 80.00 & N.E. & 75.00 & 76.37 & 46.00 & 35.74 & 50.00 & 62.46 & N.E. & N.E. \\
\hline PC-44 & N.E. & N.E. & N.E. & N.E. & N.E. & N.E. & 3.00 & N.E. & 0.00 & N.E. & N.E. & N.E. & 0.00 & 1.74 \\
\hline PC-45 & N.E. & N.E. & N.E. & N.E. & N.E. & N.E. & 71.00 & N.E. & 49.00 & N.E. & N.E. & N.E. & 61.00 & 76.66 \\
\hline PC-46 & N.E. & N.E. & N.E. & N.E. & N.E. & N.E. & 39.00 & N.E. & N.E. & N.E. & 35.00 & N.E. & N.E. & N.E. \\
\hline PC-47 & N.E. & N.E. & N.E. & N.E. & N.E. & N.E. & N.E. & N.E. & 43.00 & N.E. & 5.00 & N.E. & N.E. & N.E. \\
\hline PC-48 & N.E. & N.E. & N.E. & N.E. & N.E. & N.E. & N.E. & N.E. & N.E. & N.E. & 11.00 & 7.25 & N.E. & N.E. \\
\hline PT-01 & 59.67 & 46.19 & 61.32 & 67.06 & 60.00 & 36.78 & N.E. & N.E. & N.E. & N.E. & N.E. & N.E. & N.E. & N.E. \\
\hline $\begin{array}{l}\text { PT-02 } \\
\text { nat }\end{array}$ & 13.23 & N.E. & 18.44 & 18.60 & N.E. & 19.23 & 15.00 & N.E. & 10.00 & N.E. & 17.00 & N.E. & 21.00 & 22.87 \\
\hline PT-05 & 22.12 & N.E. & 35.07 & 34.81 & N.E. & 32.59 & N.E. & N.E. & N.E. & N.E. & N.E. & N.E. & N.E. & N.E. \\
\hline PT-07 & N.E. & N.E. & N.E. & N.E. & N.E. & N.E. & 39.00 & N.E. & 29.00 & N.E. & 32.00 & N.E. & N.E. & N.E. \\
\hline PT-08 & 70.39 & 35.41 & 60.10 & 65.36 & 81.00 & 67.66 & N.E. & N.E. & N.E. & N.E. & N.E. & N.E. & N.E. & N.E. \\
\hline PT-11 & 57.59 & N.E. & 60.25 & 61.41 & 54.00 & 59.51 & 51.00 & 61.39 & 28.00 & 49.44 & 46.00 & N.E. & 44.00 & 52.07 \\
\hline PT-12 & 2.24 & N.E. & 1.46 & N.E. & 0.00 & 3.09 & 5.00 & N.E. & 0.00 & N.E. & 0.00 & 54.89 & 6.00 & 3.36 \\
\hline PT-13 & 21.53 & 24.86 & 17.31 & 24.59 & 21.00 & 24.74 & N.E. & N.E. & N.E. & N.E. & N.E. & N.E. & N.E. & N.E. \\
\hline PT-14 & 55.58 & 69.31 & 69.04 & 69.40 & 67.00 & 71.55 & N.E. & N.E. & N.E. & N.E. & N.E. & N.E. & N.E. & N.E. \\
\hline PT-16 & 2.12 & N.E. & 2.56 & N.E. & 0.00 & 2.84 & 1.00 & N.E. & 0.00 & N.E. & 0.00 & N.E. & N.E. & N.E. \\
\hline PT-18 & N.E. & N.E. & N.E. & N.E. & 20.00 & N.E. & 19.00 & N.E. & 15.00 & N.E. & 19.00 & N.E. & N.E. & N.E. \\
\hline PT-19 & N.E. & N.E. & N.E. & N.E. & 67.00 & N.E. & 59.00 & N.E. & 49.00 & N.E. & 46.00 & N.E. & 48.00 & N.E. \\
\hline PT-21 & N.E. & N.E. & N.E. & N.E. & 21.00 & N.E. & 21.00 & N.E. & 10.00 & N.E. & N.E. & N.E. & N.E. & N.E. \\
\hline PT-22 & N.E. & N.E. & N.E. & N.E. & 0.00 & N.E. & 3.00 & N.E. & 1.00 & N.E. & 0.00 & N.E. & N.E. & N.E. \\
\hline PT-23 & N.E. & N.E. & N.E. & N.E. & 55.00 & N.E. & 34.00 & N.E. & 22.00 & N.E. & 35.00 & N.E. & N.E. & N.E. \\
\hline PT-24 & N.E. & N.E. & N.E. & N.E. & 0.00 & N.E. & 8.00 & N.E. & N.E. & N.E. & N.E. & N.E. & N.E. & N.E. \\
\hline PT-25 & N.E. & N.E. & N.E. & N.E. & 0.00 & N.E. & N.E. & N.E. & 0.00 & N.E. & 0.00 & N.E. & N.E. & N.E. \\
\hline PT-26 & N.E. & N.E. & N.E. & N.E. & 39.00 & N.E. & N.E. & N.E. & N.E. & N.E. & N.E. & N.E. & N.E. & N.E. \\
\hline PT-27 & N.E. & N.E. & N.E. & N.E. & 52.00 & N.E. & 44.00 & 45.42 & 33.00 & 32.26 & 37.00 & 47.90 & N.E. & N.E. \\
\hline PT-28 & N.E. & N.E. & N.E. & N.E. & 0.00 & N.E. & 3.00 & 0.53 & 13.00 & 0.13 & 0.00 & 0.19 & 0.00 & 0.10 \\
\hline PT-29 & N.E. & N.E. & N.E. & N.E. & 43.00 & N.E. & 22.00 & N.E. & 0.00 & N.E. & 12.00 & N.E. & N.E. & N.E. \\
\hline PT-30 & N.E. & N.E. & N.E. & N.E. & N.E. & N.E. & 28.00 & 29.94 & 34.00 & N.E. & 22.00 & N.E. & 24.00 & 13.45 \\
\hline PT-31 & N.E. & N.E. & N.E. & N.E. & 34.00 & N.E. & N.E. & N.E. & N.E. & 5.78 & 27.00 & 25.95 & N.E. & N.E. \\
\hline PT-32 & N.E. & N.E. & N.E. & N.E. & N.E. & N.E. & 28.00 & N.E. & N.E. & N.E. & N.E. & N.E. & N.E. & N.E. \\
\hline PT-33 & N.E. & N.E. & N.E. & N.E. & N.E. & N.E. & 45.00 & N.E. & 32.00 & N.E. & 41.00 & N.E. & N.E. & N.E. \\
\hline PT-34 & N.E. & N.E. & N.E. & N.E. & N.E. & N.E. & 3.00 & N.E. & 0.00 & N.E. & 0.00 & 26.05 & N.E. & N.E. \\
\hline PT-35 & N.E. & N.E. & N.E. & N.E. & N.E. & N.E. & 19.00 & N.E. & 18.00 & N.E. & 22.00 & N.E. & 27.00 & 21.42 \\
\hline PP-02 & 2.86 & 6.94 & 30.43 & 38.01 & N.E. & 29.01 & N.E. & N.E. & N.E. & N.E. & N.E. & N.E. & N.E. & N.E. \\
\hline PP-03 & 23.50 & 26.70 & 25.88 & 51.47 & N.E. & 41.53 & N.E. & N.E. & N.E. & N.E. & N.E. & N.E. & N.E. & N.E. \\
\hline PP-04 & N.E. & N.E. & 6.77 & 7.18 & N.E. & 5.89 & N.E. & N.E. & N.E. & N.E. & N.E. & N.E. & N.E. & N.E. \\
\hline PP-05 & N.E. & N.E. & 0.12 & 0.02 & N.E. & 0.01 & N.E. & N.E. & N.E. & N.E. & N.E. & N.E. & N.E. & N.E. \\
\hline édia Cacimba & 81.18 & 67.69 & 77.82 & 85.76 & 59.73 & 83.01 & 50.71 & 73.48 & 36.67 & 39.72 & 41.56 & 72.13 & 55.08 & 61.23 \\
\hline Média Tubular & 33.83 & 43.94 & 36.17 & 48.75 & 32.32 & 35.33 & 23.53 & 34.32 & 16.33 & 21.90 & 19.78 & 31.00 & 24.29 & 18.88 \\
\hline Média Profundo & 13.18 & 16.82 & 15.80 & 24.17 & N.E. & 19.11 & N.E. & N.E. & N.E. & N.E. & N.E. & N.E. & N.E. & N.E. \\
\hline
\end{tabular}




\subsubsection{Discretização da área modelada}

A área modelada neste estudo compreendeu duas microbacias hidrográficas devido o município de Urânia estar situado sobre um divisor de águas subterrâneas, perfazendo uma área de aproximadamente $4,7 \mathrm{~km}$ por $5,5 \mathrm{~km}$, conforme pode se observar na Figura 10. A área mais escura nesta figura indica a região externa às midrobacias em estudo.

A ocupação urbana de Urânia deu-se principalmente a sul da Rodovia Euclides da Cunha. $\mathrm{Na}$ porção norte da rodovia e em todo entorno do município predominam propriedades rurais e loteamentos de sítios e chácaras, sendo que a maioria é abastecida por água superficial ou pela rede da SABESP. Todos os poços cacimba e tubulares cadastrados por CAGNON (2003) e PALMÉR RIVERA (2002) encontram-se na área urbana de Urânia.

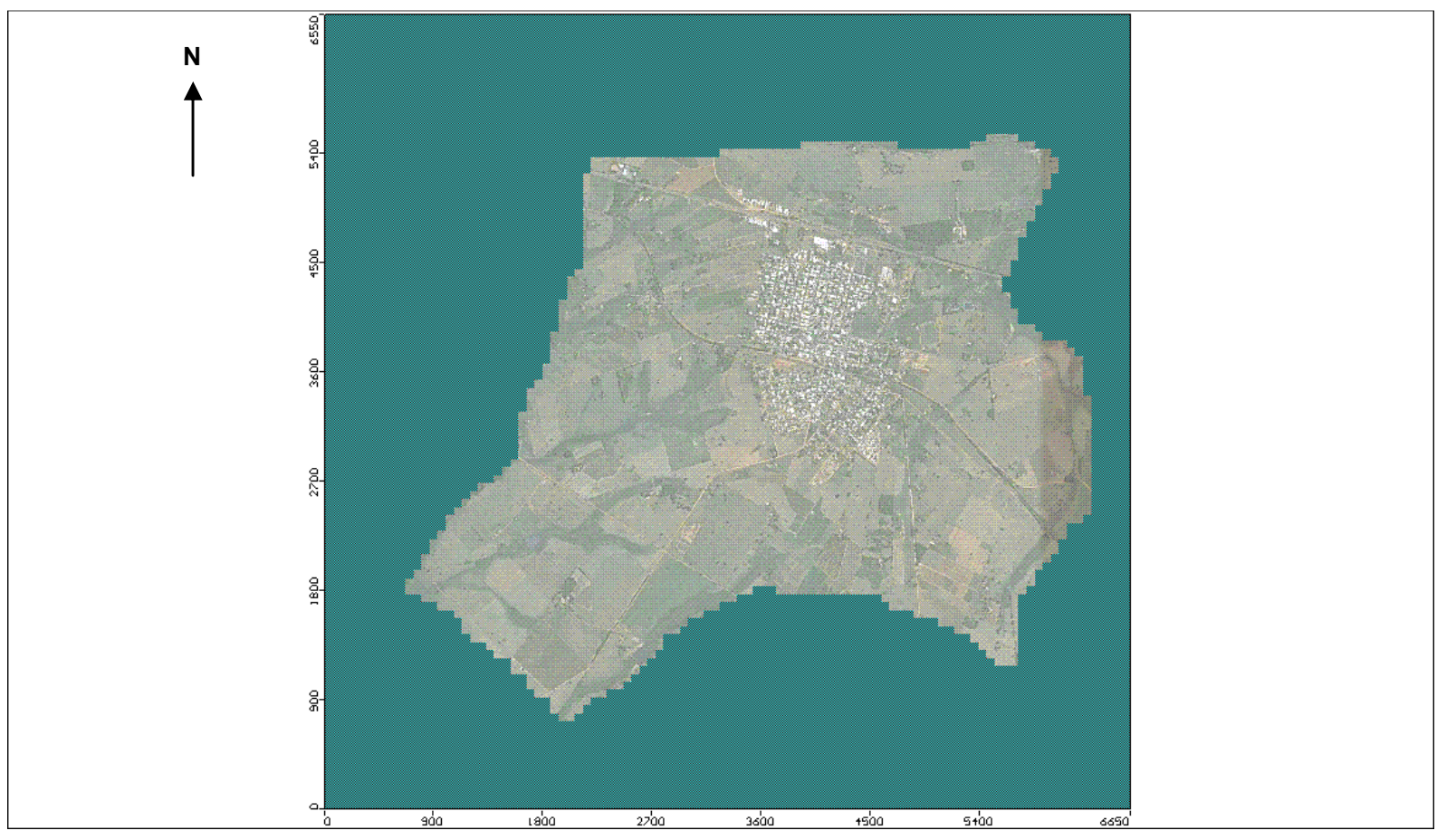

Figura 10. Região modelada

Salienta-se que as coordenadas das figuras apresentadas neste estudo estão como coordenadas estabelecidas pelo modelo matemático, onde 100 m no eixo x (direção leste oeste) corresponde a 533128E m em Universal Transversa Mercator (UTM) e $100 \mathrm{~m}$ no eixo y (direção norte - sul) a $7757489 \mathrm{~N}$ m em UTM. 
Inicialmente foi definida uma grade para a área modelada com espaçamento constante de $130 \mathrm{~m}$, tanto para o eixo x como para o eixo y. Esta grade foi refinada nas microbacias de interesse para um espaçamento $(\Delta x=\Delta y)$ de $65 \mathrm{~m}$. Desta forma a grade do modelo foi discretizada em 89 linhas por 93 colunas, totalizando 8277 células (Figura 11).

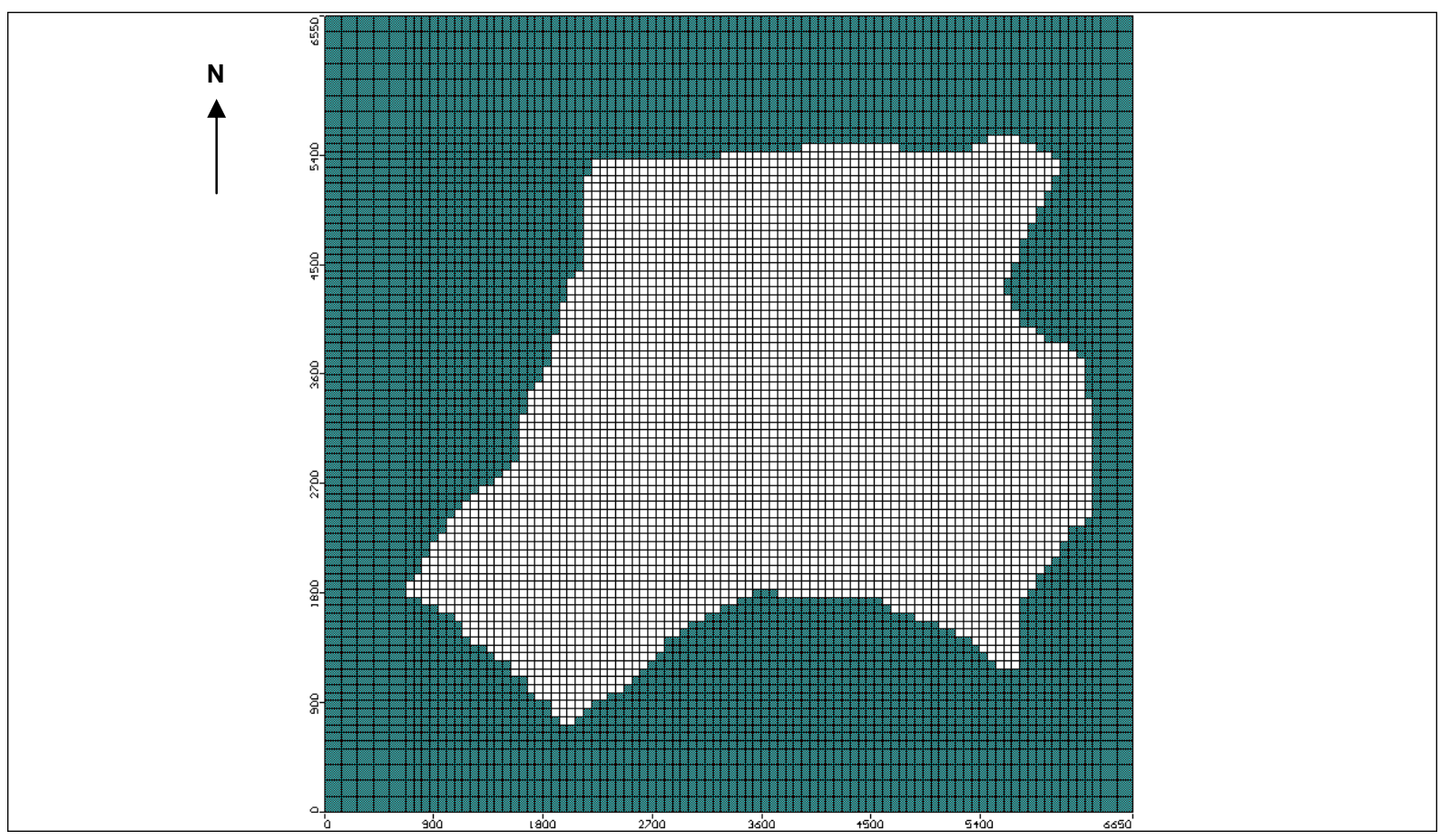

Figura 11. Grade do modelo

O número de camadas do modelo matemático foi inicialmente definido com base nas unidades hidroestratigráficas determinadas no modelo conceitual, sendo, portanto, de três camadas. Para obter uma redução do desvio padrão no cálculo do fluxo entre camadas, realizado célula a célula no modelo de elementos finitos (GUIGUER, comunicação verbal), foram inseridas camadas adicionais dentro de cada unidade hidroestratigráfica (Figura 12).

Deste modo foram definidas sete camadas. A primeira, segunda e terceira camadas representam a unidade hidroestratigráfica superior da Formação Adamantina, que possui espessura média de $67 \mathrm{~m}$. A quarta, quinta e sexta camadas representam a unidade hidroestratigráfica inferior da Formação Adamantina, a qual representa a principal unidade aquífera da área e possui aproximadamente $53 \mathrm{~m}$ de espessura. A sétima camada representa a unidade hidroestratigráfica referente a alteração do basalto da Formação Serra Geral, com aproximadamente $10 \mathrm{~m}$ de espessura. 


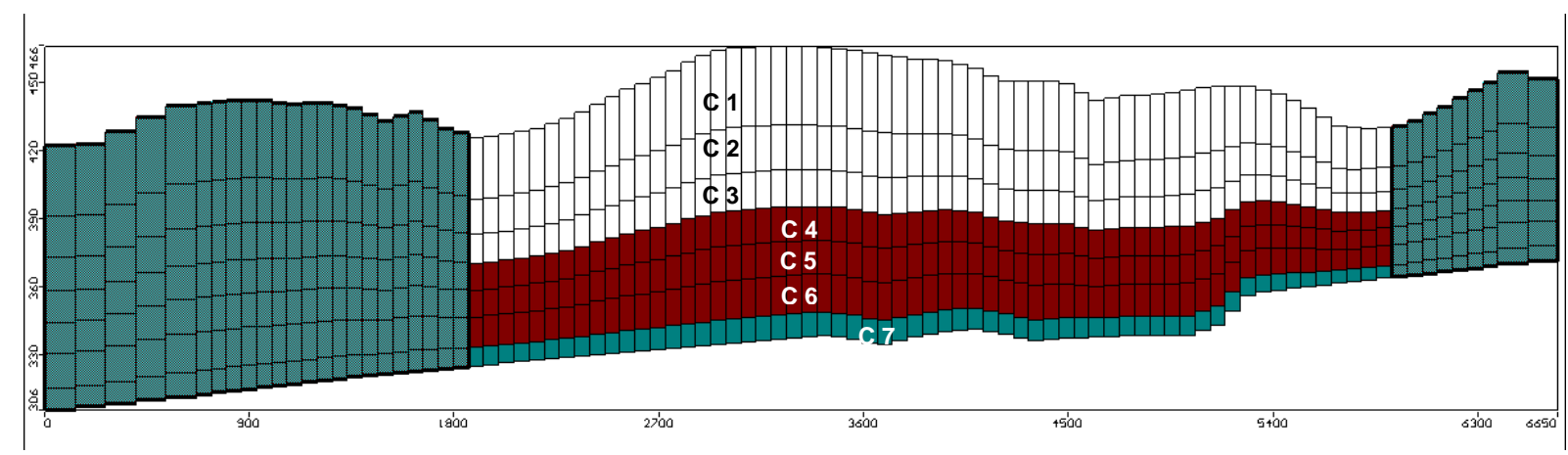

Legenda:

Unidade hidroestratigráfica superior da Formação Adamantina - em branco

Unidade hidroestratigráfica inferior da Formação Adamantina - em vermelho

Unidade hidroestratigráfica da Formação Serra Geral - em azul claro

C - Camada

\section{Figura 12. Número de camadas do modelo}

As superfícies que limitam as camadas foram definidas com base nas unidades hidroestratigráficas do modelo conceitual. As superfícies foram digitalizadas e importadas para o modelo matemático, permitindo uma representação mais próxima da espessura real do aquífero.

O topo da primeira unidade hidroestratigráfica, que também se refere ao topo da primeira camada,representa a superfície do terreno, como pode ser visualizado na Figura 13.

A base da primeira unidade hidroestratigráfica (base da terceira camada do modelo) representa a separação entre os sedimentos mais finos, englobados na unidade hidrogeológica superior, e os sedimentos mais grosseiros (topo da quarta camada do modelo), que representam o principal aquífero na área (Figura 14). A base da segunda unidade refere-se ao topo da unidade representada pela alteração de basalto (base da sexta ou topo da sétima camada do modelo) e sua superfície foi baseada no Mapa de Contorno Estrutural (Figura 15).

A base da terceira unidade (base da sétima camada do modelo), que representa 0 contato entre o basalto alterado e o basalto são da Formação Serra Geral, foi colocado como fluxo zero, pois acredita-se que, além de possuir baixa permeabilidade, este aquífero não apresenta contribuição a grandes profundidades devido ao fechamento das fraturas (Figura 16). 


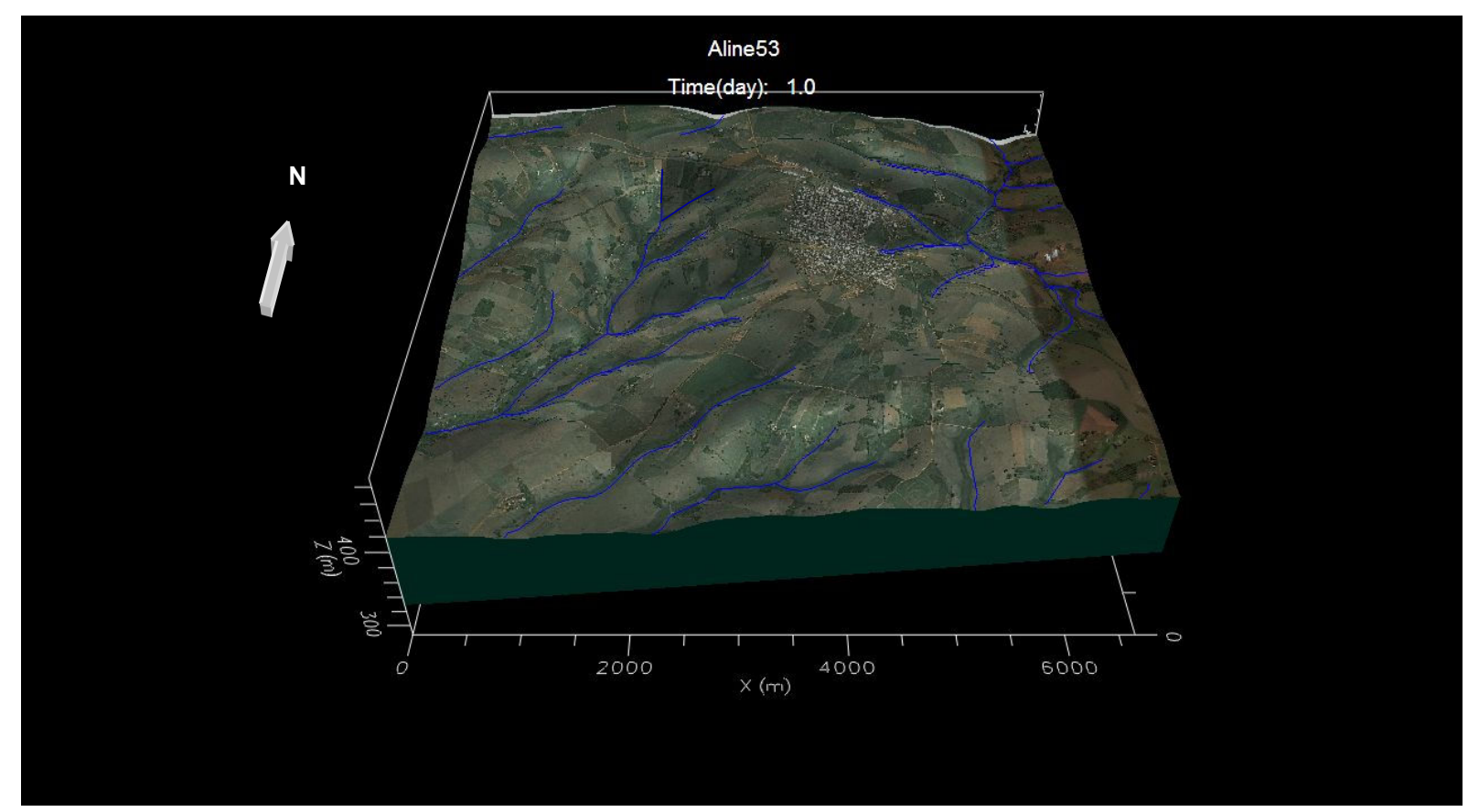

Figura 13. Superfície da primeira camada do modelo

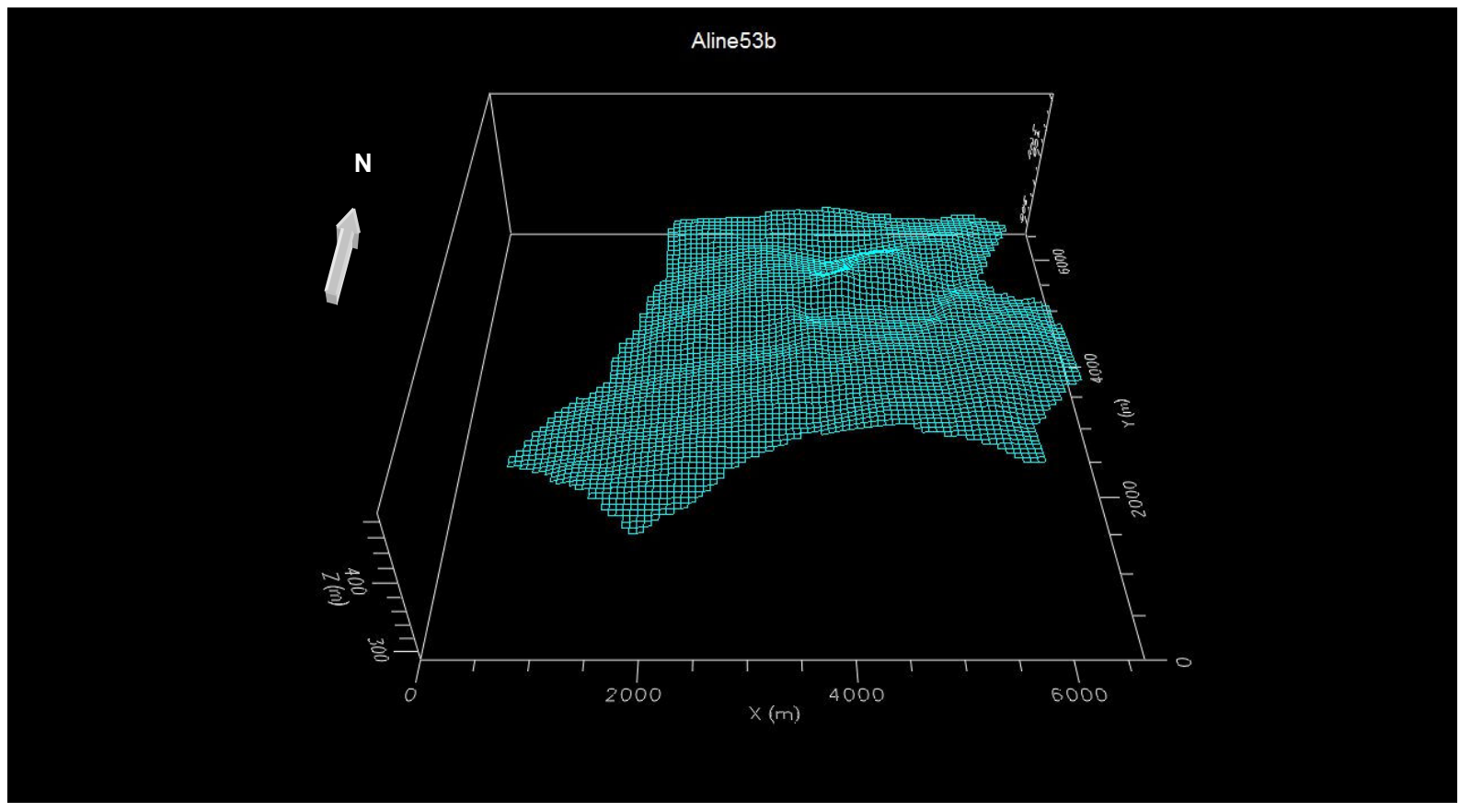

Figura 14. Visualização espacial da superfície de contato entre a primeira e a segunda unidade hidroestratigráfica 


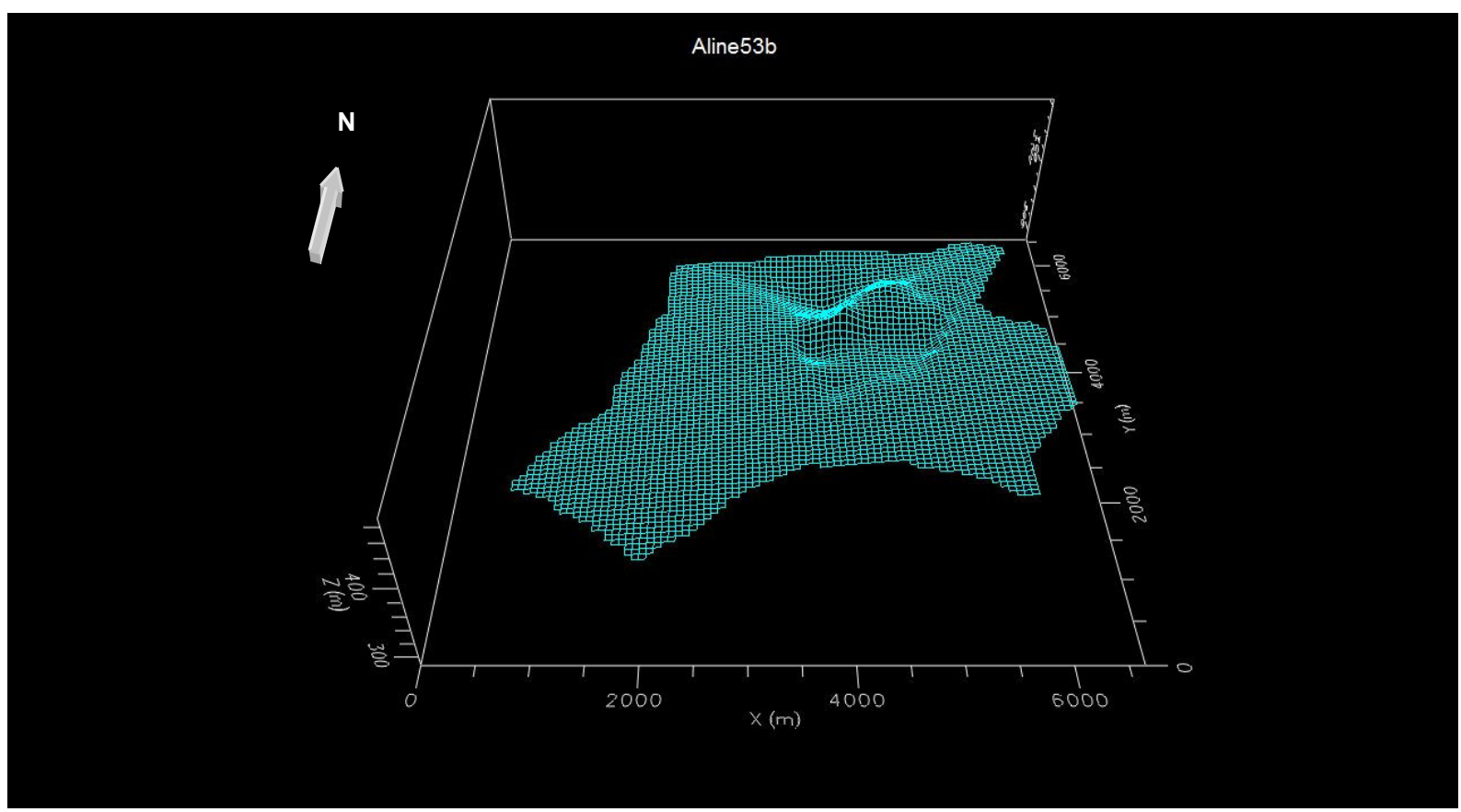

Figura 15. Visualização espacial da superfície de contato entre a segunda e a terceira unidade hidroestratigráfica

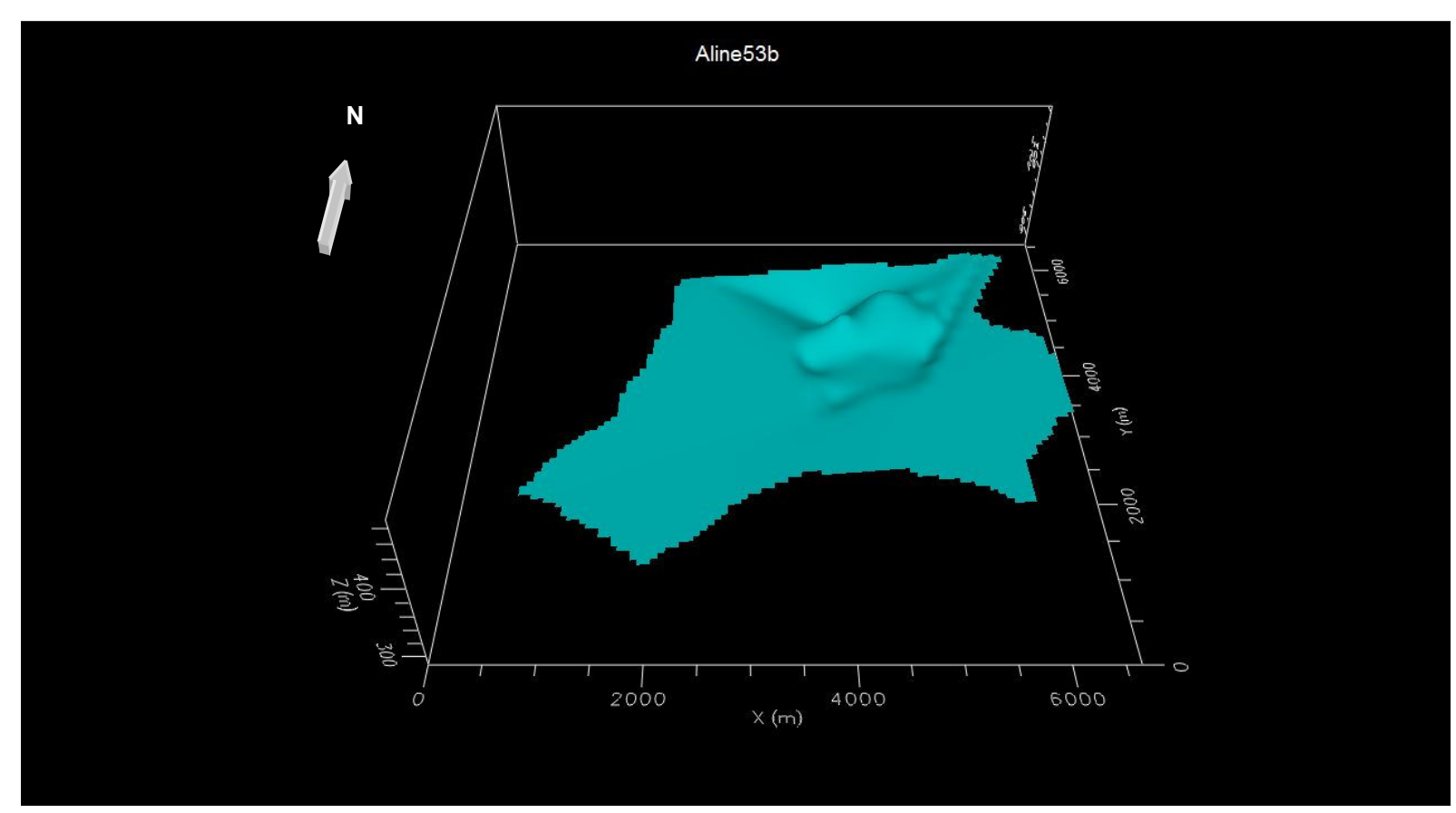

Figura 16. Visualização espacial da base da terceira unidade hidroestratigráfica 


\subsubsection{Definição das condições de contorno}

A área modelada é limitada a norte, sul-sudeste e parte sudoeste por células inativas, indicando uma condição de contorno de "não fluxo", simulando os três divisores de águas existentes a norte, a sul-sudeste e parte da região sudoeste do município (em verde claro nas Figuras 17 e 18. Esta condição de contorno foi assumida para todas as camadas do modelo matemático. A base da última camada, no seu limite inferior, representado pelo topo do basalto são da Formação Serra Geral, também foi assumida como células inativas, indicando uma condição de contorno de "não fluxo".

Os limites nordeste, leste, noroeste, oeste e parte sudoeste do modelo são definidos por condição de contorno do tipo "rio" para a primeira camada da primeira unidade hidroestratigráfica do modelo (Figura 17 - linhas em azul escuro), devido aos córregos que limitam as microbacias de interesse constatados nestes locais, os quais correspondem às áreas de descarga do aquífero livre local, como pode ser notado no mapa potenciométrico elaborado para a área urbana de Urânia. Para as demais camadas do modelo assumiu-se uma condição de contorno de "não fluxo" nestes limites.

Os valores de cota, carga hidráulica, profundidade e largura dos córregos foram obtidos a partir das medições realizadas por PALMÉR RIVERA (2002). A condutância do rio $\left(C_{\text {rio }}\right)$ foi calculada pelo MODFLOW, seguindo a Equação 10 (item 4.3.).

Para tanto, os dados de condutividade hidráulica vertical $\left(K^{\prime}\right)$ foram estimados em aproximadamente uma ordem de magnitude inferior à média da condutividade hidráulica do aquífero, num valor de $1,0 \times 10^{-7} \mathrm{~m} / \mathrm{s}$; a espessura do material do leito dos córregos $(M)$ foi estimada em $0,5 \mathrm{~m}$; e para as larguras dos córregos $(W)$ foram assumidos os valores obtidos pelas medições de PALMÉR RIVERA (2002), conforme demonstrado anteriormente. Salienta-se que os valores de $K^{\prime}$ e $M$ foram estimados, pois não há referências bibliográficas sobre os mesmos para a área.

Importante informar que os valores de comprimento dos córregos $(L)$ foram calculados diretamente pelo software durante a digitalização dos córregos no modelo matemático. 


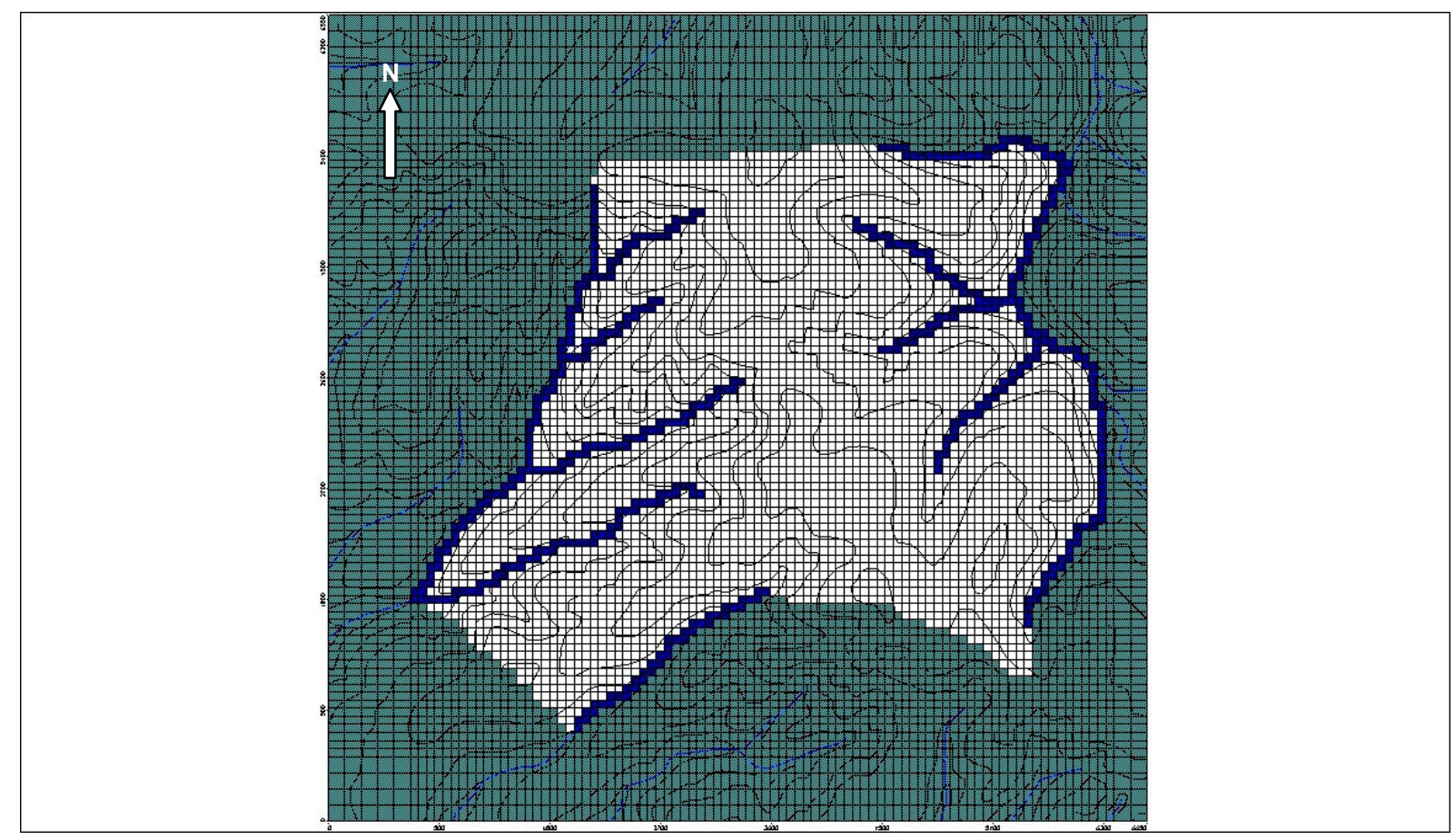

Figura 17. Condições de contorno estabelecidas para a primeira camada do modelo

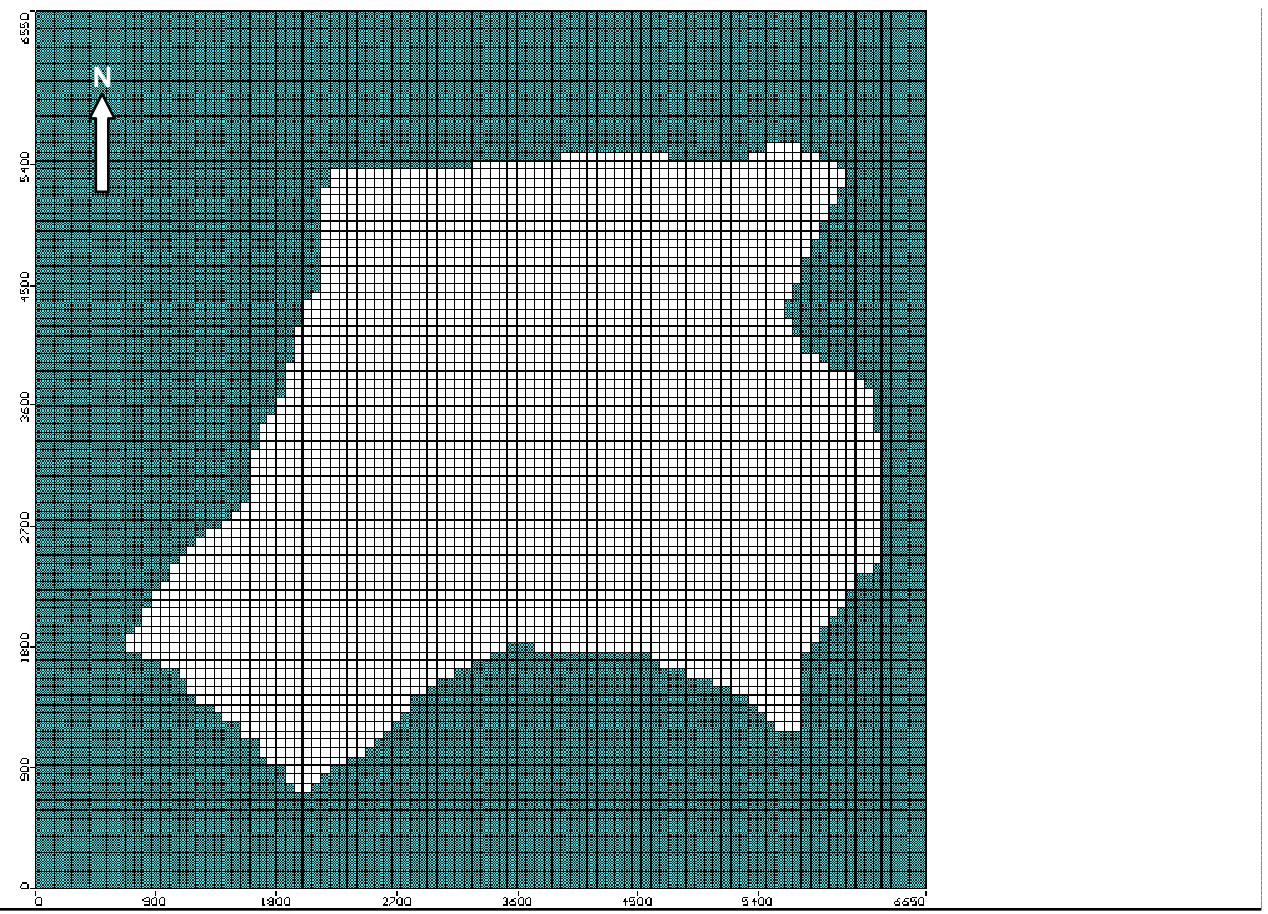

Figura 18. Condições de contorno estabelecidas para as demais camadas do modelo 
No limite superior do modelo foi assinalada uma condição de contorno do Tipo 2, de fluxo especificado, utilizando o módulo de recarga do MODFLOW. Definiram-se duas zonas distintas de recarga com base nas características de uso e ocupação do solo nas microbacias de interesse. Uma delas (em azul na Figura 19) abrange a zona urbana do município de Urânia, com valor de recarga calculado pelo método de 'tentativa e erro' em $230 \mathrm{~mm} / \mathrm{ano}$; a outra a zona rural (em branco na Figura 19), com valor de recarga calculado pelo método de 'tentativa e erro' em $183 \mathrm{~mm} / \mathrm{ano}$. Os valores citados são do modelo já calibrado e não divergem significativamente dos cálculados no modelo conceitual em 238 mm/ano e 191 mm/ano, respectivamente.

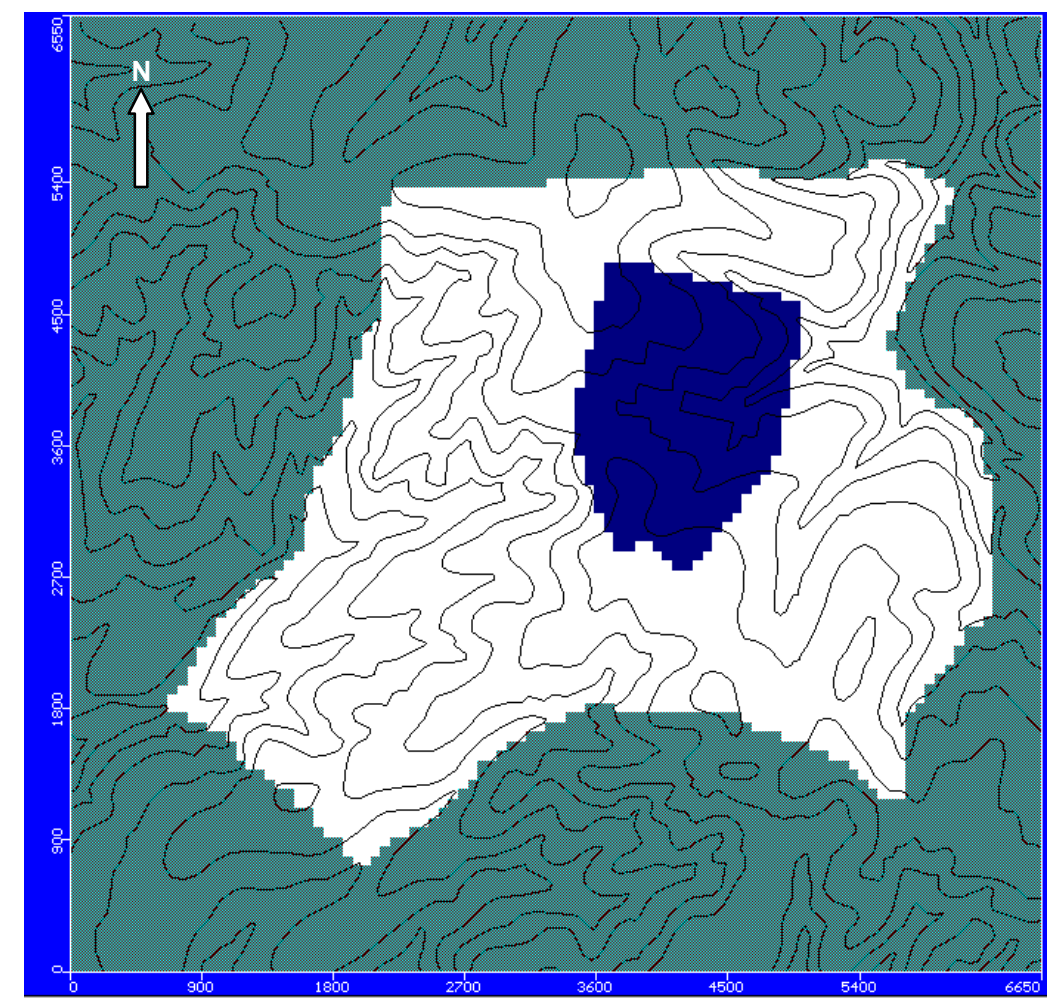

Figura 19.Zonas de recarga: urbana e rural

Estas zonas de recarga foram assumidas considerando a interferência antrópica no regime hidrológico, devido a ocupação urbana afetar o processo de infiltração, alterando as taxas de recarga do aquífero através da impermeabilização do terreno e perdas da rede de água e esgoto. 


\subsubsection{Definição das unidades hidráulicas e seus parâmetros hidrogeológicos}

As zonas hidráulicas do modelo matemático foram definidas com base nas unidades hidroestratigráficas do modelo conceitual e na avaliação dos parâmetros hidráulicos obtidos por meio dos testes de bombeamento realizados no momento da construção dos poços de produção, dos resultados de dois testes de bombeamento nos poços tubulares, bem como dos dados bibliográficos, como comentado anteriormente.

Os parâmetros de armazenamento foram adotados como homogêneos para todas as unidades hidráulicas, baseando-se em dados bibliográficos, pois não foi possível determiná-los a partir dos testes de vazão. Os valores adotados para os parâmetros hidráulicos estão ilustrados na Tabela 10, sendo que representam os valores obtidos após a calibração do modelo. Assim, os valores de coeficiente de armazenamento específico $\left(S_{s}\right)$, porosidade eficaz $\left(S_{y}\right)$, porosidade efetiva para fluxo $\left(n_{e}\right)$ e porosidade total $(n)$ para todas as camadas do modelo matemático foram fixados em $1,00 \times 10^{-5} \mathrm{~m}^{-1}$, $0,15,0,15$ e 0,30 , respectivamente.

Tabela 10 - Parâmetros hidráulicos adotados no modelo matemático

\begin{tabular}{c|c|c|c|c|c|c|c}
\hline Zonas & $\mathrm{Kx}(\mathrm{m} / \mathrm{s})$ & $\mathrm{Ky}(\mathrm{m} / \mathrm{s})$ & $\mathrm{Kz}(\mathrm{m} / \mathrm{s})$ & $\mathrm{S}_{\mathrm{s}}\left(\mathrm{m}^{-1}\right)$ & $\mathrm{S}_{\mathrm{y}}$ & $\mathrm{n}_{\mathrm{e}}$ & $\mathrm{n}$ \\
\hline 1 & $6.00 \mathrm{E}-08$ & $6.00 \mathrm{E}-08$ & $6.00 \mathrm{E}-09$ & $1.00 \mathrm{E}-05$ & 0.15 & 0.15 & 0.30 \\
\hline 2 & $2.50 \mathrm{E}-07$ & $2.50 \mathrm{E}-07$ & $2.50 \mathrm{E}-08$ & $1.00 \mathrm{E}-05$ & 0.15 & 0.15 & 0.30 \\
\hline 3 & $5.50 \mathrm{E}-06$ & $5.50 \mathrm{E}-06$ & $5.50 \mathrm{E}-07$ & $1.00 \mathrm{E}-05$ & 0.15 & 0.15 & 0.30 \\
\hline 4 & $3.00 \mathrm{E}-05$ & $3.00 \mathrm{E}-05$ & $3.00 \mathrm{E}-06$ & $1.00 \mathrm{E}-05$ & 0.15 & 0.15 & 0.30 \\
\hline 5 & $6.00 \mathrm{E}-05$ & $6.00 \mathrm{E}-05$ & $6.00 \mathrm{E}-06$ & $1.00 \mathrm{E}-05$ & 0.15 & 0.15 & 0.30 \\
\hline 6 & $7.00 \mathrm{E}-07$ & $7.00 \mathrm{E}-07$ & $7.00 \mathrm{E}-08$ & $1.00 \mathrm{E}-05$ & 0.15 & 0.15 & 0.30 \\
\hline 7 & $2.50 \mathrm{E}-07$ & $2.50 \mathrm{E}-07$ & $2.50 \mathrm{E}-08$ & $1.00 \mathrm{E}-05$ & 0.15 & 0.15 & 0.30 \\
\hline 8 & $5.00 \mathrm{E}-05$ & $5.00 \mathrm{E}-05$ & $5.00 \mathrm{E}-06$ & $1.00 \mathrm{E}-05$ & 0.15 & 0.15 & 0.30 \\
\hline 9 & $7.00 \mathrm{E}-05$ & $7.00 \mathrm{E}-05$ & $7.00 \mathrm{E}-06$ & $1.00 \mathrm{E}-05$ & 0.15 & 0.15 & 0.30 \\
\hline 10 & $6.00 \mathrm{E}-10$ & $6.00 \mathrm{E}-10$ & $6.00 \mathrm{E}-11$ & $1.00 \mathrm{E}-05$ & 0.15 & 0.15 & 0.30 \\
\hline
\end{tabular}

\footnotetext{
$\mathrm{Kx}, \mathrm{Ky}, \mathrm{K}_{\mathrm{z}}=$ condutividade hidráulica nos eixos $\mathrm{x}, \mathrm{y}, \mathrm{z}$

$\mathrm{S}_{\mathrm{S}}=$ coeficiente de armazenamento específico

$\mathrm{S}_{\mathrm{y}}=$ porosidade eficaz

$\mathrm{n}_{\mathrm{e}}$, = porosidade efetiva para fluxo

$\mathrm{n}=$ porosidade total
} 
A relação de anisotropia das zonas de condutividade hidráulica não foi possível definir, pois os testes de bombeamento interpretados não foram executados utilizando poços de observação. Dessa forma, adotou-se que as zonas de condutividade hidráulica são isotrópicas nos eixos $x$ e $y$, entretanto anisotrópicas em relação ao eixo $z$, pois assume-se que a sedimentação de camadas arenosas e argilosas imprimem uma condutividade hidráulica inferior no sentido vertical. Dessa forma, adotou-se a relação de $K_{x}=K_{y}=0,1 K_{z}$.

A configuração das zonas de condutividade hidráulicas nas unidades hidroestratigráficas referentes a Formação Adamantina obedeceu a disposição da topografia das mesmas, como mostram as Figuras 20 e 21. Já para a unidade hidroestratigráfica representada pela alteração do basalto da Formação Serra Geral, adotou-se uma condição homogênea (Figura 22).

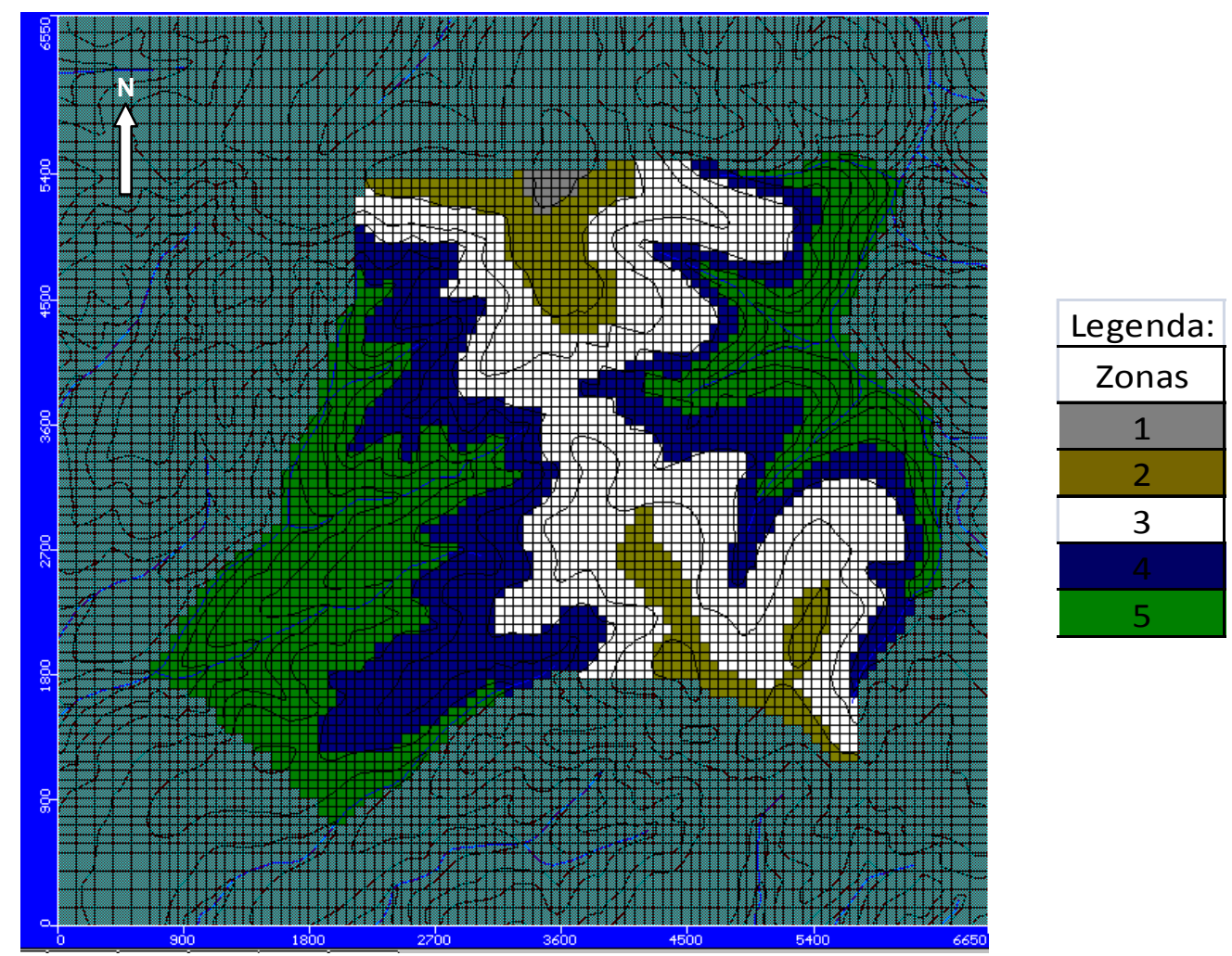

Figura 20.Zonas hidráulicas da unidade hidroestratigráfica superior da Formação Adamantina 


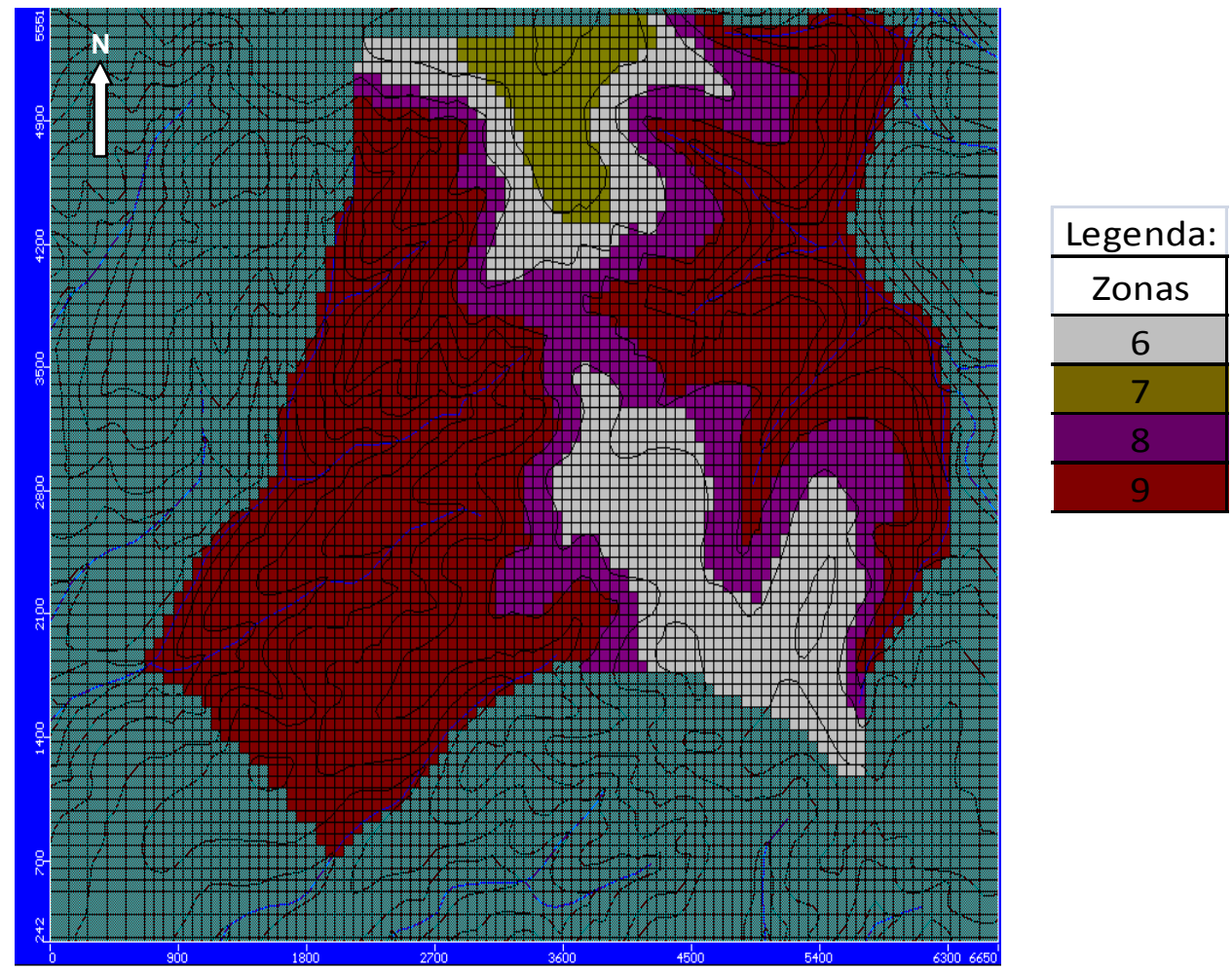

Figura 21.Zonas hidráulicas da unidade hidroestratigráfica inferior da Formação Adamantina

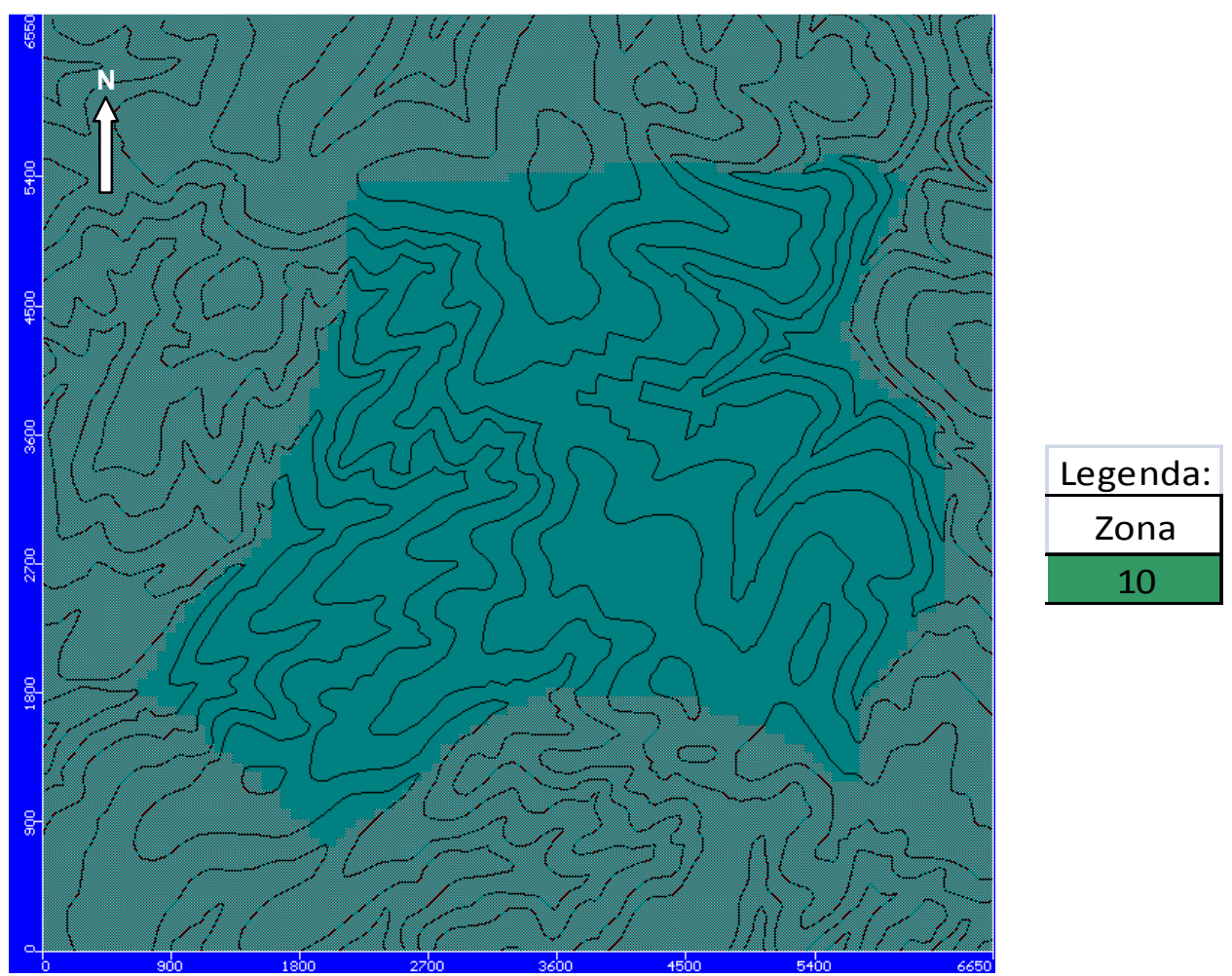

Figura 22.Zona hidráulica da unidade hidroestratigráfica da alteração do basalto da Formação Serra Geral 
Verifica-se na unidade hidroestratigráfica da porção superior da Formação Adamantina (Camadas 1 a 3 ) a existência de cinco zonas de condutividades hidráulicas distintas (Zonas 1 a 5). Para as porções mais elevadas do terreno, com cotas acima de $490 \mathrm{~m}$ (Zona 1) e entre 475 a 490 m (Zona 2), adotou-se valores de condutividade hidráulica na direção dos eixos $x\left(K_{x}\right)$ e $y\left(K_{y}\right)$ menores, com valores variando entre $2,5 \times 10^{-7}$ e $6,0 \times 10^{-8} \mathrm{~m} / \mathrm{s}$. Já para as porções mais baixas do terreno, com cotas variando entre 400 e $440 \mathrm{~m}$ (Zona 5), 440 e $460 \mathrm{~m}$ (Zona 4) e 460 e $475 \mathrm{~m}$ (Zona 3), os valores adotados para $K_{x}$ e $K_{y}$ foram entre $6,0 \times 10^{-5}$ e $5,5 \times 10^{-6} \mathrm{~m} / \mathrm{s}$.

$\mathrm{Na}$ unidade hidroestratigráfica referente à porção inferior da Formação Adamantina (camadas 4 a 6) existem quatro zonas de condutividade hidráulica distintas (Zonas 6 a 9). Para as áreas mais elevadas desta unidade, com cotas acima de $400 \mathrm{~m}$ (Zona 6) e entre 385 e $400 \mathrm{~m}$ (Zona 7) adotou-se valores de $K_{x}$ e $K_{y}$ menores, com valores variando entre $7,0 \times 10^{-7}$ e $2,5 \times 10^{-7} \mathrm{~m} / \mathrm{s}$. Já para as porções mais baixas do terreno, com cotas variando entre 355 e $375 \mathrm{~m}$ (Zona 9) e 375 e $385 \mathrm{~m}$ (Zona 8), os valores adotados para $K_{x}$ e $K_{y}$ foram entre $7,0 \times 10^{-5}$ e $5,0 \times 10^{-5} \mathrm{~m} / \mathrm{s}$.

Para a alteração do basalto da Formação Serra Geral (camada 7) adotou-se um valor de $K_{x}$ e $K_{y}$ de $6,0 \times 10^{-10} \mathrm{~m} / \mathrm{s}$, visto que o mesmo, devido à sua constituição essencialmente argilosa, apresenta menores valores de condutividade hidráulica que a Formação Adamantina (mais arenosa).

A Figura 23 mostra uma seção realizada na linha 34 do modelo, com as zonas de condutividade hidráulica nas diferentes unidades hidroestratigráficas.

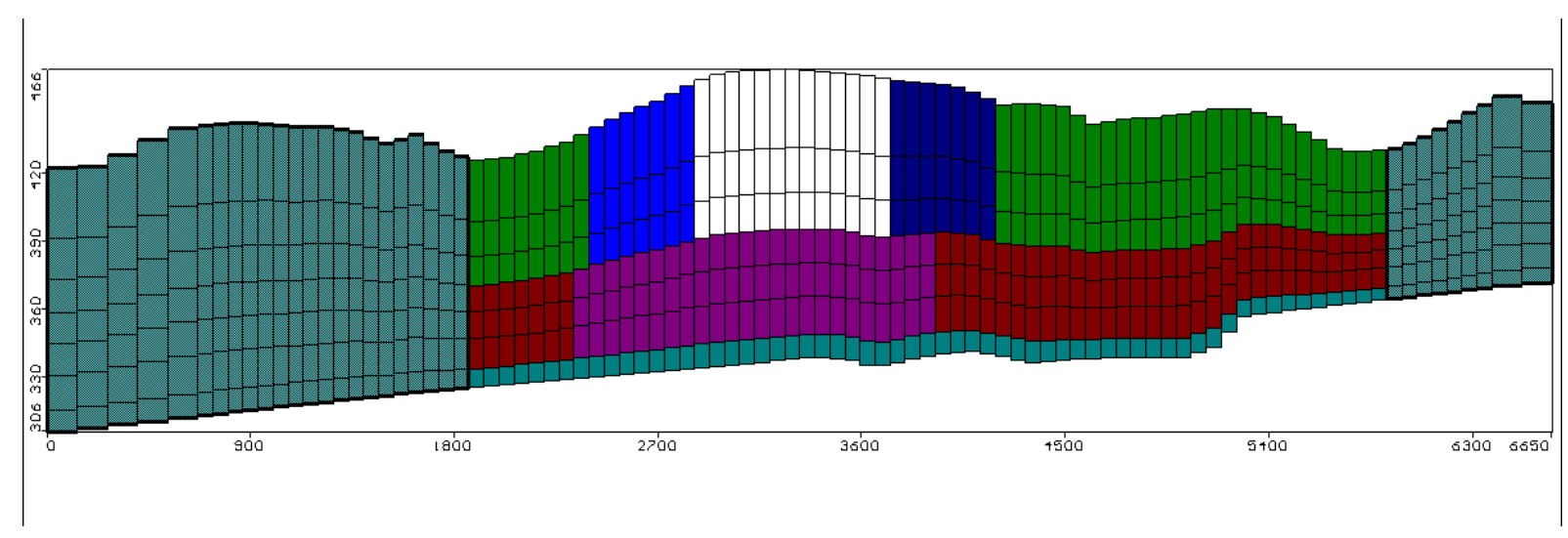

Figura 23. Seção realizada na linha 34 do modelo mostrando as diferentes zonas de condutividade hidráulica 


\subsubsection{Poços de bombeamento}

A modelagem matemática de fluxo foi conduzida em duas situações para possibilitar a verificação do modelo calibrado. Na primeira situação modelada foi considerado o sistema hidrogeológico 'sem bombeamento', assumindo que nenhum poço de produção do município estava ativo, o que representa o cenário real; e no segundo cenário, consideraram-se os poços em funcionamento, denominada de situação 'com bombeamento'.

Ressalta-se que todas as condições de contorno apresentadas anteriormente foram consideradas tanto para a modelagem matemática 'sem bombeamento' como a 'com bombeamento'.

As características construtivas e hidráulicas dos poços inseridas no modelo matemático foram: intervalo dos filtros, vazão e período de bombeamento (Tabela 11), obtidas a partir dos dados disponibilizados pela SABESP. Salienta-se que os intervalos dos filtros dos poços PP-01, PP-02 e PP-03 foram estimados, pois há dados bibliográficos sobre os mesmos. Os poços considerados ativos para o modelo matemático estão ilustrados na Figura 24.

Tabela 11 - Dados dos poços de bombeamento no município de Urânia

\begin{tabular}{|c|c|c|c|c|c|c|}
\hline \multirow{2}{*}{$\begin{array}{c}\text { Identificação } \\
\text { do poço }\end{array}$} & \multicolumn{2}{|c|}{ Coordenadas em UTM $(\mathrm{m})$} & $\begin{array}{c}\text { Início do } \\
\text { filtro }(\mathrm{m})\end{array}$ & $\begin{array}{c}\text { Final do } \\
\text { filtro }(\mathrm{m})\end{array}$ & $\begin{array}{c}\text { Tempo de } \\
\text { operação }\end{array}$ & $\begin{array}{c}\text { Vazão } \\
\left(\mathrm{m}^{3} / \text { dia }\right)\end{array}$ \\
\hline PP01 & 536650 & 7761960 & 434.72 & 317.46 & 36500 & -192.0 \\
\hline PP02 & 537020 & 7761770 & 422.24 & 325.78 & 36500 & -360.0 \\
\hline PP03 & 537090 & 7761890 & 436.73 & 325.00 & 36500 & -192.0 \\
\hline PP04 & 537350 & 7761280 & 370.88 & 338.00 & 36500 & -432.0 \\
\hline PP05 & 538160 & 7761590 & 379.61 & 355.91 & 36500 & -326.4 \\
\hline PP06 & 536550 & 7761370 & 395.30 & 338.08 & 36500 & -384.0 \\
\hline PP08 & 536030 & 7762410 & 387.87 & 322.17 & 36500 & -211.2 \\
\hline
\end{tabular}

No modelo na situação 'com bombeamento', as vazões dos poços foram estimadas para um tempo de bombeamento de 24 horas e por 36500 dias (100 anos).

O MODFLOW assume que os poços PP-01 a PP-06 e PP-08 possuem filtro em toda a camada numérica, contudo, para os poços em que há essas informações, colocou-se o intervalo considerando o topo e a base da secão filtrante conforme documentos disponibilizados pela SABESP. A maior parte dos poços possui filtro a partir da segunda unidade hidroestratigráfica, onde predominam as porções mais arenosas do pacote sedimentar. Alguns poços possuem o nível dinâmico abaixo da primeira seção filtrante, deixando partes secas. 


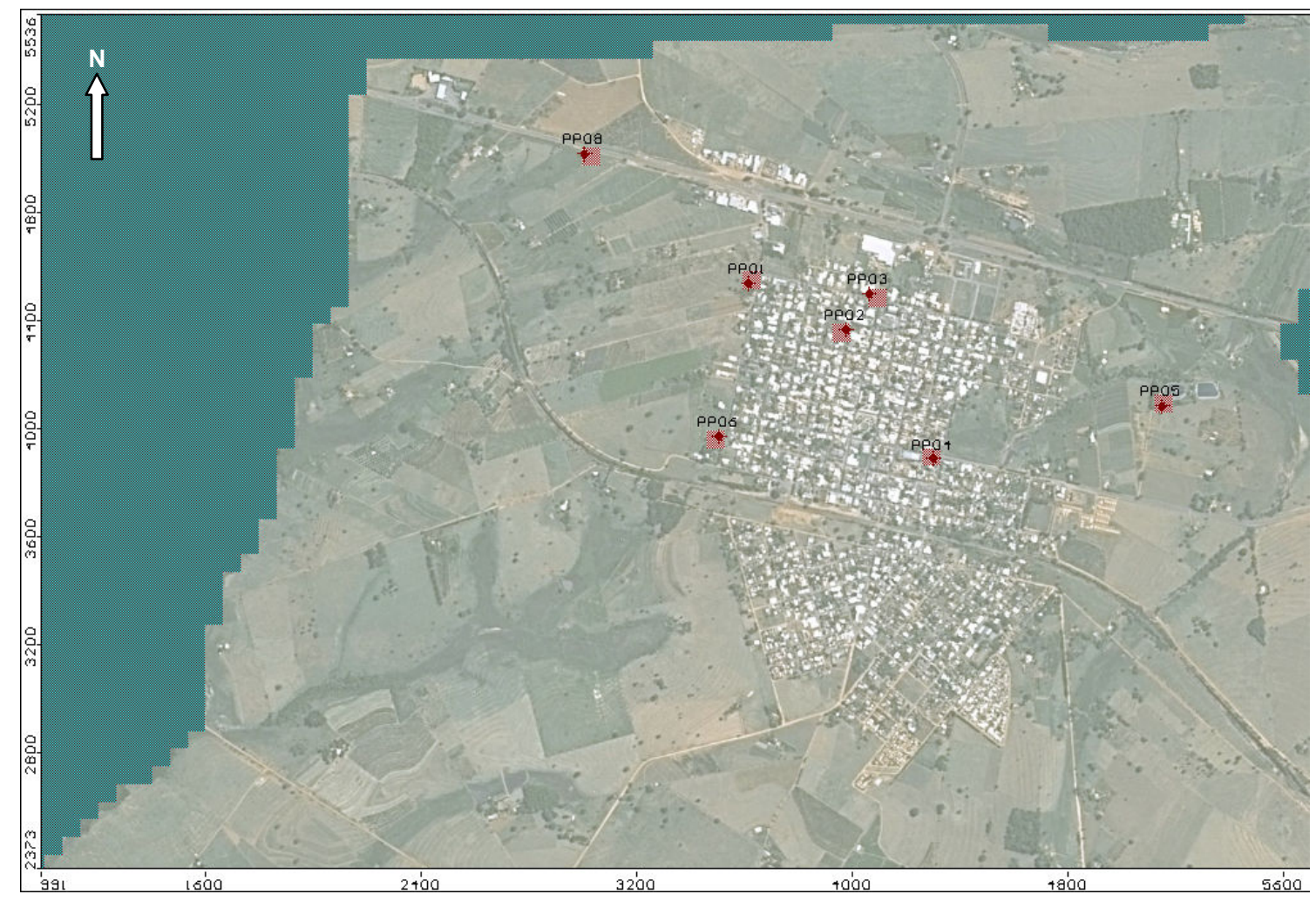

Figura 24. Localização dos poços de bombeamento no modelo matemático

\subsubsection{Parâmetros de calibração}

Para maior confiabilidade, a calibração do modelo matemático foi efetuada considerando-se duas situações distintas do sistema hidrogeológico.

$\mathrm{Na}$ primeira situação, denominada de 'sem bombeamento', que se refere ao cenário real, simulou-se o sistema hidrogeológico sem a interferência dos poços de produção do município, em estado estacionário. Para esta situação utilizou-se como parâmetros de calibração, os níveis estáticos de 21 poços cacimba e tubulares cadastrados no município de Urânia por CAGNON (2003) e PALMÉR RIVERA (2002), cujas medições foram efetuadas em outubro de 2001. O mapa potenciométrico, considerando o nível estático natural da água subterrânea (Figura 7), serviu de base para a visualização do comportamento do fluxo sem o bombeamento dos poços. Os poços utilizados para a calibração no modelo 'sem bombeamento' e 'com bombeamento', bem como os não utilizados, são mostrados na Figura 25. 


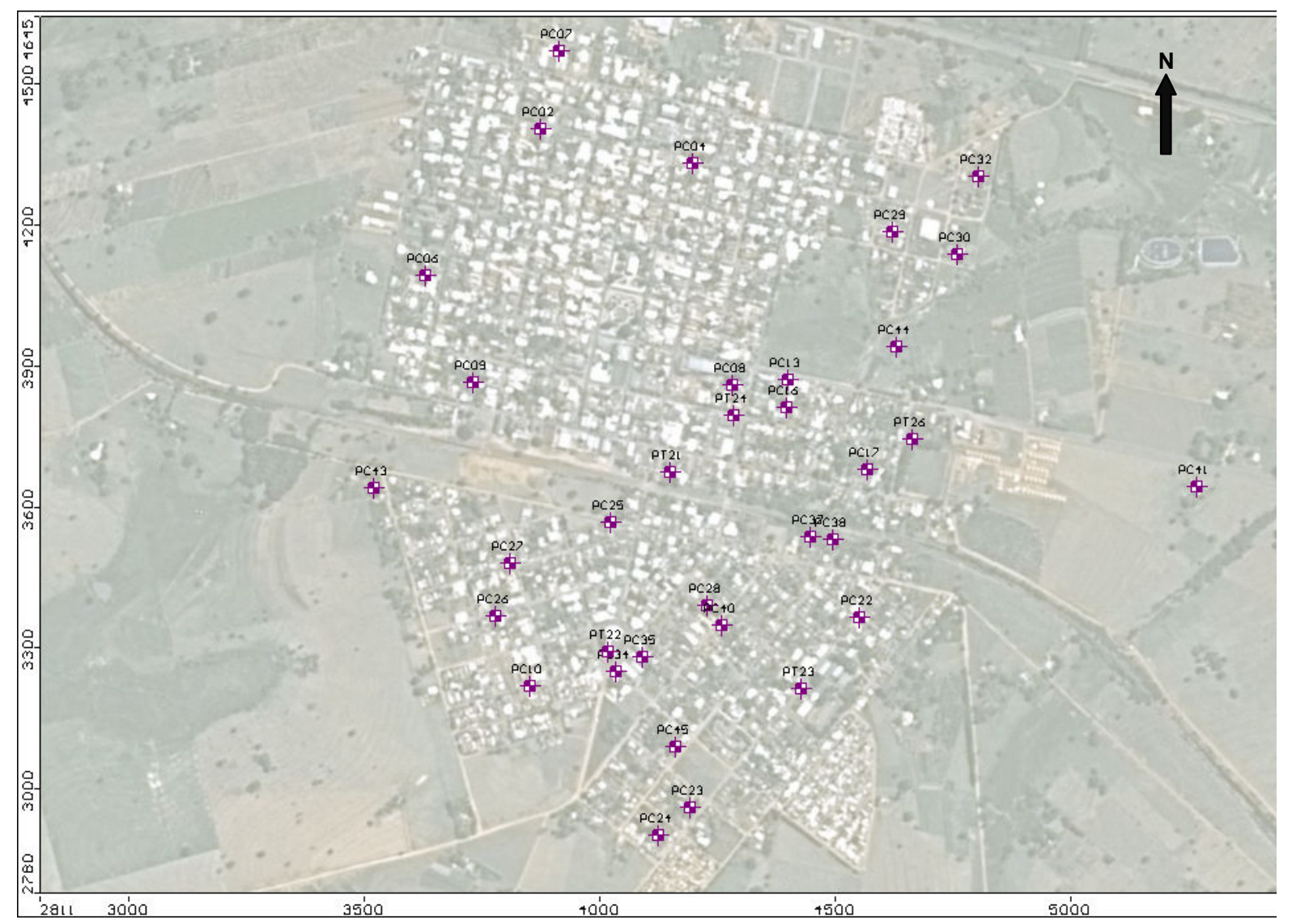

Figura 25. Localização dos poços de observação

Foram selecionados 21 poços cacimba e tubulares para servirem de poços de observação de carga hidráulica e auxilarem na tarefa de calibração. Estes poços foram escolhidos pela distribuição geométrica, consistência dos dados em relação aos demais e a ausência de poços próximos em regime de bombeamento.

\subsubsection{Calibração do modelo matemático}

Como foi dito anteriormente, a calibracão do modelo matemático deu-se em duas situações: a primeira considerando o sistema hidrogeológico real, sem o bombeamento dos poços de produção (situação 'sem bombeamento'); e uma segunda etapa de calibracão considerando os poços funcionando, denominada de situação 'com bombeamento'. 
O processo de calibracão do modelo 'sem bombeamento', que se configura como cenário real, consistiu em variar os parâmetros, principalmente de condutividade hidráulica e recarga, de forma a obter um valor aceitável entre a diferença do nível d'água calculado pelo modelo e o observado no campo. A condutância dos rios não foi alterada por ter sido calculada a partir de dados medidos em campo por PALMÉR RIVERA (2002), o que levou o processo de calibração a concentrar a atenção nos parâmetros de condutividade hidráulica e recarga do modelo.

Para a calibração adotou-se a porcentagem (\%) do resíduo (Normalized RMS) como parâmetro de avaliação, isto é, a média raiz quadrada do resíduo proporcional entre as diferenças das cargas hidráulicas calculadas e observadas (RMS) em relação à máxima diferença dos valores de carga hidráulica observados no sistema. Dessa forma, procurou-se chegar a um valor inferior a $10 \%$.

Este valor não foi atingido para situação 'com bombeamento', pois o único parâmetro modificado para averiguação da calibração do modelo foi o acionamento dos poços de produção do município, portanto obviamente ocorreu um rebaixamento do nível d'água em todos os poços cacimba e tubulares quando comparados como os níveis d'água observados no modelo conceitual, que reflete a situação 'sem bombeamento'. Cabe informar que os níveis dinâmicos dos 07 poços de produção existentes no município não puderam ser utilizados para calibração do modelo na situação 'com bombeamento', devido à inexistência de dados sobre o início e final da seção filtrante dos poços PP-01, PP-02 e PP-03, cujo posicionamento ocasiona uma variação significativa no nível dinâmico dos mesmos. Desta forma, justifica-se que com somente quatro dados conhecidos de nível dinâmico e de posiciamento da seção filtrante (poços de produção PP-04, PP-05, PP-06 e PP-08) não são suficientes para avaliar a calibração desse modelo.

Assim, a calibração do modelo matemático na situação 'sem bombeamento' atingiu valores menores para a 'média dos resíduos' (ME), 'média absoluta dos resíduos' (MAE), desvio padrão (RMS) e porcentagem do resíduo (i.e. porcentagem do desvio padrão normalizado $=$ Normalized $R M S$ ) em relação à situação 'com bombeamento', como mostra a Tabela 12, devido ao rebaixamento provocado pelo funcionamento dos poços. 
Tabela 12 - Resíduos calculados entre as cargas hidráulicas observadas e determinadas pelo modelo matemático

\begin{tabular}{l|c|c|}
\hline \multirow{2}{*}{ Resíduo } & \multicolumn{2}{c}{ Situação } \\
\cline { 2 - 3 } & com bombeamento' & sem bombeamento' \\
\hline ME $(m)$ & -5.481 & -0.016 \\
\hline MAE $(m)$ & 5.481 & 0.918 \\
\hline RMS $(m)$ & 5.722 & 1.328 \\
\hline RMS Normalizado (\%) & 37.894 & 8.797 \\
\hline
\end{tabular}

As Figuras 26 e 27 mostram, graficamente, a relação das cargas hidráulicas observadas com as cargas hidráulicas calculadas pelo modelo na situação 'sem bombeamento' e 'com bombeamento', respectivamente. A reta, com inclinação de $45^{\circ}$, indica a calibracão ideal. Os valores dos resíduos calculados estão ilustrados na base dos gráficos. Nota-se que, na situação 'com bombeamento', apesar dos pares de dados de carga hidráulica observada e calculada não estarem exatamente sobre a reta, eles acompanham aproximadamente a sua inclinação, o que levou a considerar o modelo como calibrado.

Em relação ao balanço de água total, tanto na situação 'sem bombeamento', como na situação 'com bombeamento', a diferença entre o volume de água que entra e o volume que sai do sistema modelado é praticamente o mesmo (Tabela 13), indicando que o programa está calculando corretamente as equações parciais de fluxo do modelo matemático (ANDERSON \& WOESSNER, 1992). As Figuras 28 e 29 apresentam os histogramas de balanço de água total para as situações sem e com bombeamento dos poços de produção do município, respectivamente.

Tabela 13 - Balanço total de água no modelo matemático

\begin{tabular}{|c|c|c|c|c|}
\hline \multirow{2}{*}{ Valores em m³/dia } & \multicolumn{4}{|c|}{ Situação } \\
\cline { 2 - 5 } & \multicolumn{2}{|c|}{ 'Com bombeamento' } & \multicolumn{2}{c|}{ 'Sem bombeamento' } \\
\cline { 2 - 5 } & Entrada de água & Saída de água & Entrada de água & Saída de água \\
\hline Armazenamento & 0.00 & 0.00 & 0.00 & 0.00 \\
\hline Carga constante & 0.00 & 0.00 & 0.00 & 0.00 \\
\hline Poços & 0.00 & 1977.01 & 0.00 & 0.00 \\
\hline Drenança dos rios & 64.36 & 7288.69 & 35.07 & 9236.67 \\
\hline Recarga & 9201.42 & 0.00 & 9201.42 & 0.00 \\
\hline Total & 9265.77 & 9265.70 & 9236.49 & 9236.67 \\
\hline Entrada - Saída & \multicolumn{3}{|c|}{0.07} & \multicolumn{2}{c}{0.0 .18} \\
\hline Discrepância (\%) & 0.00 & & \multicolumn{2}{c}{0} \\
\hline
\end{tabular}




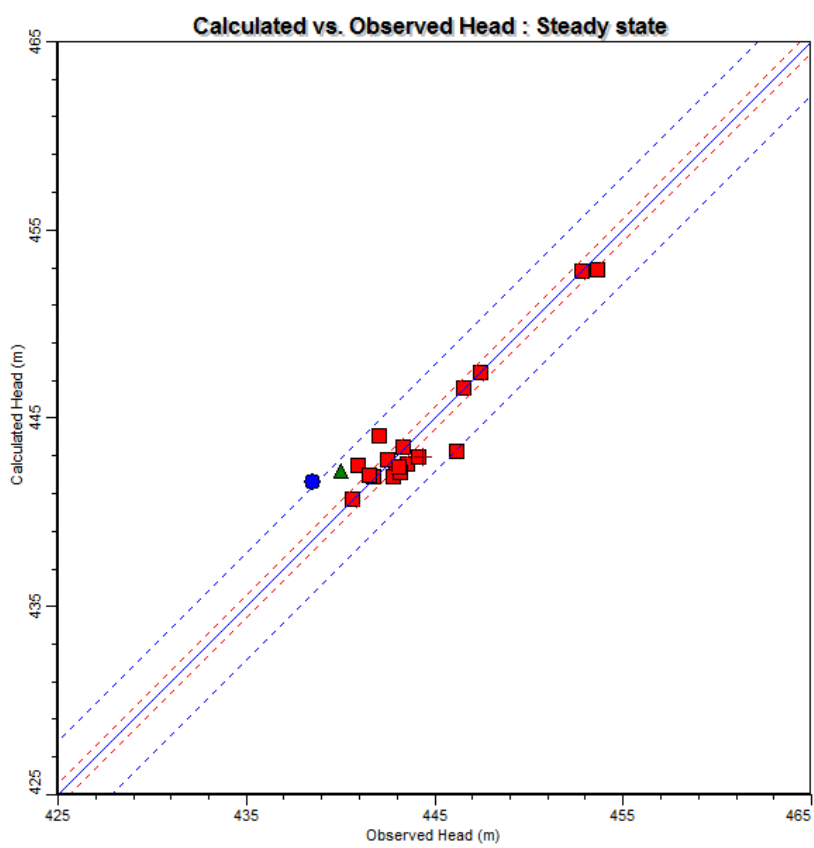

Figura 26. Calibração do modelo matemático - situação 'sem bombeamento'

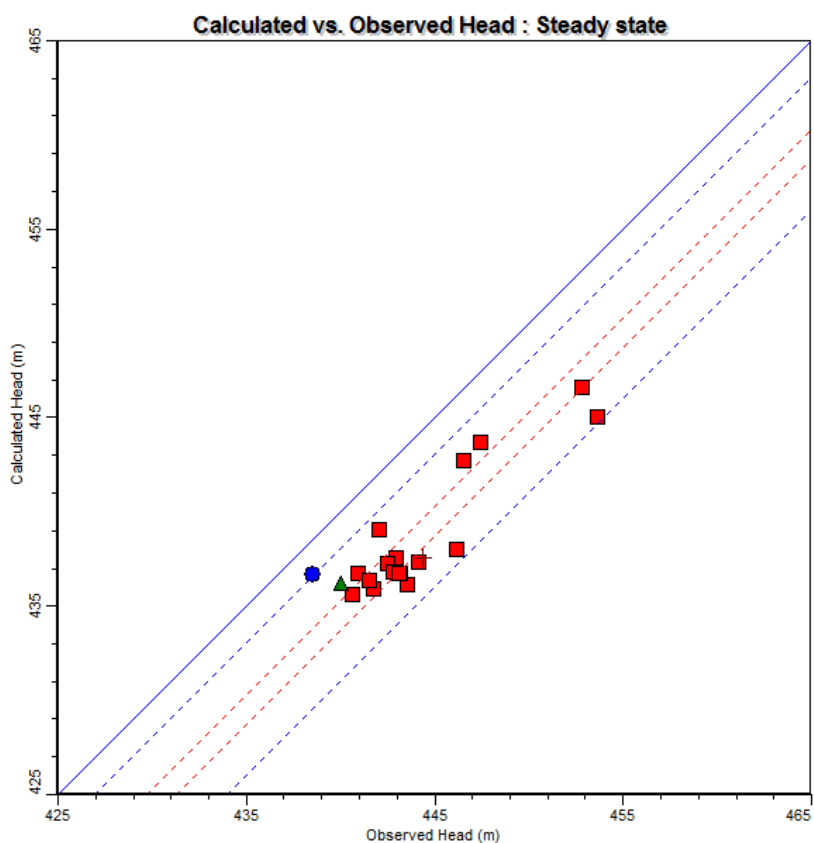

Figura 27. Calibração do modelo matemático - situação 'com bombeamento' 


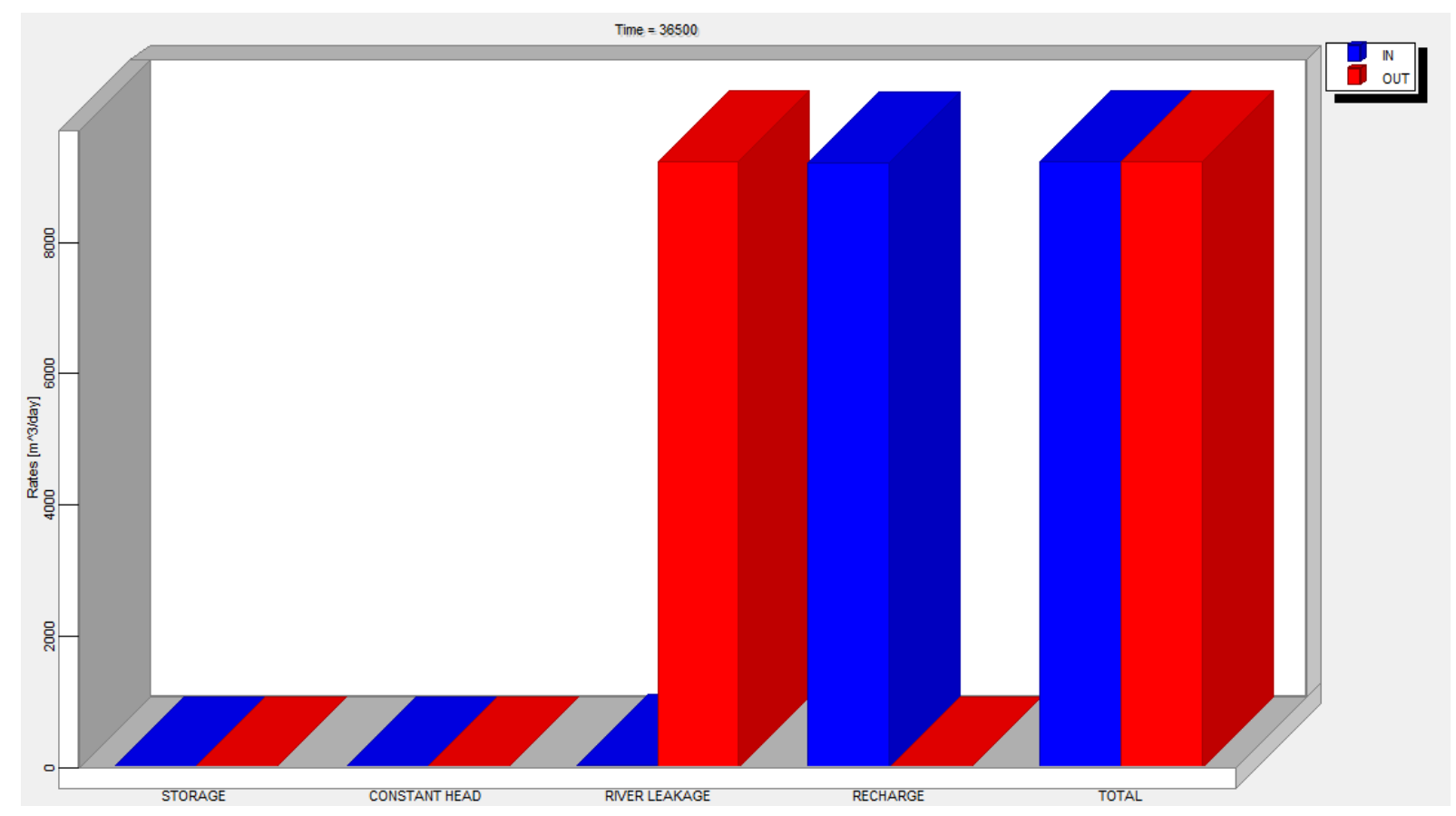

Figura 28. Balanço de água total - situação 'sem bombeamento'

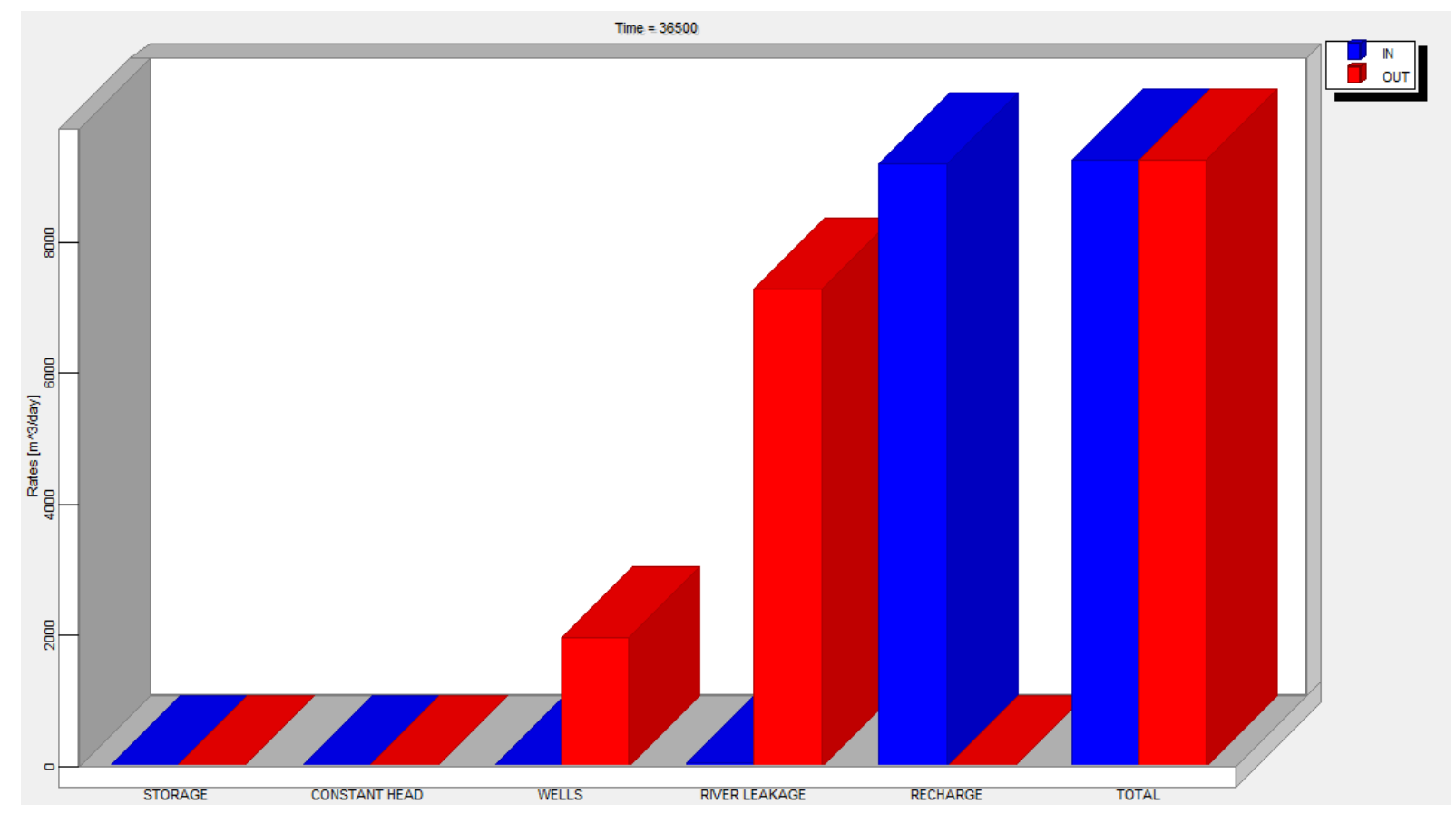

Figura 29. Balanço de água total - situação 'com bombeamento' 
É importante ponderar que o bombeamento dos poços ocasiona uma menor drenança dos rios, indicando que o mesmo influencia nos corpos d'água superficiais.

A Tabela 14 apresenta as cargas hidráulicas observadas e as calculadas para o modelo calibrado nas situações sem e com o bombeamento os poços de produção do município. O mapa potenciométrico elaborado a partir das cargas hidráulicas calculadas para a situação 'sem bombeamento' (Tabela 14) é apresentado na Figuras 30 . Nesse, efetuado para a primeira camada do modelo, pode se verificar a concordância com os sentidos de fluxo da água subterrânea verificados no mapa elaborado durante o modelo conceitual, e a influência dos córregos (zonas de descarga do aquífero livre) e dos divisores de águas subterrâneas (zonas de recarga do aquífero livre).

A Figura 31 apresenta o mapa potenciométrico calibrado realizado a partir das cargas hidráulicas calculadas para situação 'com bombeamento' (Tabela 14). Neste mapa, elaborado para a primeira camada do modelo, já é possível verificar a influência dos cones de rebaixamento de alguns poços de produção do município nos sentidos de fluxo das águas subterrâneas, porém não há divergência quanto aos sentidos de fluxo preferenciais verificados no mapa de potenciometria local elaborado para situação 'sem bombeamento'. No perfil apresentado na Figura 31 referente a linha 33 do modelo, observa-se a siginificativa influência do cone de rebaixamento do PP-06 no fluxo das camadas próximas a seção filtrante deste poço.

O resultado dessa simulação indicou um rebaixamento médio de $5,5 \mathrm{~m}$ nos poços cacimba e tubulares na situação 'com bombeamento' quando camparada com a situação sem o bombeamento dos poços de produção do município, porém não foram verificados poços de observação secos, como se pode visualizar na Tabela 14. 
Tabela 14 - Resultados dos valores de carga hidráulica calculados para a condição observada e para as situações modeladas

\begin{tabular}{|c|c|c|c|c|c|c|c|c|c|c|c|c|c|}
\hline \multirow{2}{*}{$\begin{array}{c}\text { Poços de } \\
\text { observação }\end{array}$} & \multirow{2}{*}{\multicolumn{2}{|c|}{$\begin{array}{c}\text { Coordenadas do } \\
\text { modelo }(\mathrm{m})\end{array}$}} & \multirow{2}{*}{\multicolumn{2}{|c|}{$\begin{array}{c}\text { Coordenadas em } \\
\text { UTM }(\mathrm{m})\end{array}$}} & \multirow{2}{*}{$\frac{\operatorname{Cota}(\mathrm{m})}{\mathrm{Z}}$} & \multicolumn{2}{|c|}{ Condição observada } & \multicolumn{3}{|c|}{ Situação 'sem bombeamento' } & \multicolumn{3}{|c|}{ Situação 'com bombeamento' } \\
\hline & & & & & & $\begin{array}{l}\text { N.A. } \\
(\mathrm{m})\end{array}$ & $\begin{array}{c}\text { Carga } \\
\text { hidráulica (m) }\end{array}$ & $\begin{array}{l}\text { N.A. } \\
(\mathrm{m})\end{array}$ & $\begin{array}{c}\text { Carga hidráulica } \\
\text { calculada }(\mathrm{m})\end{array}$ & Calc.-Obs. & $\begin{array}{l}\text { N.A. } \\
\text { (m) }\end{array}$ & $\begin{array}{c}\text { Carga hidráulica } \\
\text { calculada }(\mathrm{m})\end{array}$ & Calc.-Obs \\
\hline $\mathrm{PC} 02$ & 3874.149 & 4405.780 & 536902 & 7761795 & 467.51 & 14.67 & 452.84 & 14.70 & 452.81 & -0.03 & 20.87 & 446.64 & -6.20 \\
\hline PC06 & 3630.149 & 4093.780 & 536658 & 7761483 & 455.62 & 12.05 & 443.57 & 13.05 & 442.57 & -1.00 & 19.45 & 436.17 & -7.40 \\
\hline PC07 & 3912.149 & 4571.780 & 536940 & 7761961 & 468.42 & 14.76 & 453.66 & 15.51 & 452.91 & -0.75 & 23.41 & 445.01 & -8.65 \\
\hline PC09 & 3729.149 & 3865.780 & 536757 & 7761255 & 448.82 & 7.09 & 441.72 & 6.89 & 441.92 & 0.20 & 12.90 & 435.92 & -5.80 \\
\hline PC23 & 4191.149 & 2961.780 & 537219 & 7760351 & 463.20 & 15.78 & 447.42 & 15.76 & 447.44 & 0.02 & 19.53 & 443.67 & -3.75 \\
\hline PC24 & 4123.149 & 2902.780 & 537151 & 7760292 & 463.81 & 17.27 & 446.54 & 17.22 & 446.59 & 0.05 & 21.05 & 442.76 & -3.79 \\
\hline $\mathrm{PC} 25$ & 4022.149 & 3568.780 & 537050 & 7760958 & 454.11 & 13.17 & 440.94 & 11.58 & 442.53 & 1.59 & 17.38 & 436.73 & -4.21 \\
\hline $\mathrm{PC} 26$ & 3779.149 & 3369.780 & 536807 & 7760759 & 461.69 & 18.90 & 442.79 & 19.81 & 441.88 & -0.91 & 24.87 & 436.82 & -5.97 \\
\hline $\mathrm{PC} 27$ & 3808.149 & 3481.780 & 536836 & 7760871 & 460.33 & 17.16 & 443.17 & 18.23 & 442.10 & -1.07 & 23.62 & 436.71 & -6.46 \\
\hline PC28 & 4226.149 & 3389.780 & 537254 & 7760779 & 444.16 & 0.00 & 444.16 & 1.22 & 442.95 & -1.21 & 6.84 & 437.32 & -6.84 \\
\hline PC43 & 3520.149 & 3640.780 & 536548 & 7761030 & 456.20 & 15.58 & 440.62 & 15.47 & 440.73 & 0.11 & 20.56 & 435.64 & -4.98 \\
\hline PC45 & \begin{tabular}{|l|l|}
4161.149 \\
\end{tabular} & 3089.780 & 537189 & 7760479 & 455.81 & 13.80 & 442.01 & 11.76 & 444.05 & 2.04 & 16.73 & 439.08 & -2.93 \\
\hline PT21 & 4149.028 & 3674.839 & 537176.9 & 7761064 & 450.22 & 10.19 & 440.03 & 8.03 & 442.19 & 2.16 & 14.01 & 436.21 & -3.82 \\
\hline PT23 & \begin{tabular}{|l|}
4427.149 \\
\end{tabular} & 3213.780 & 537455 & 7760603 & 457.62 & 13.28 & 444.34 & 14.67 & 442.94 & -1.40 & 20.07 & 437.55 & -6.79 \\
\hline
\end{tabular}



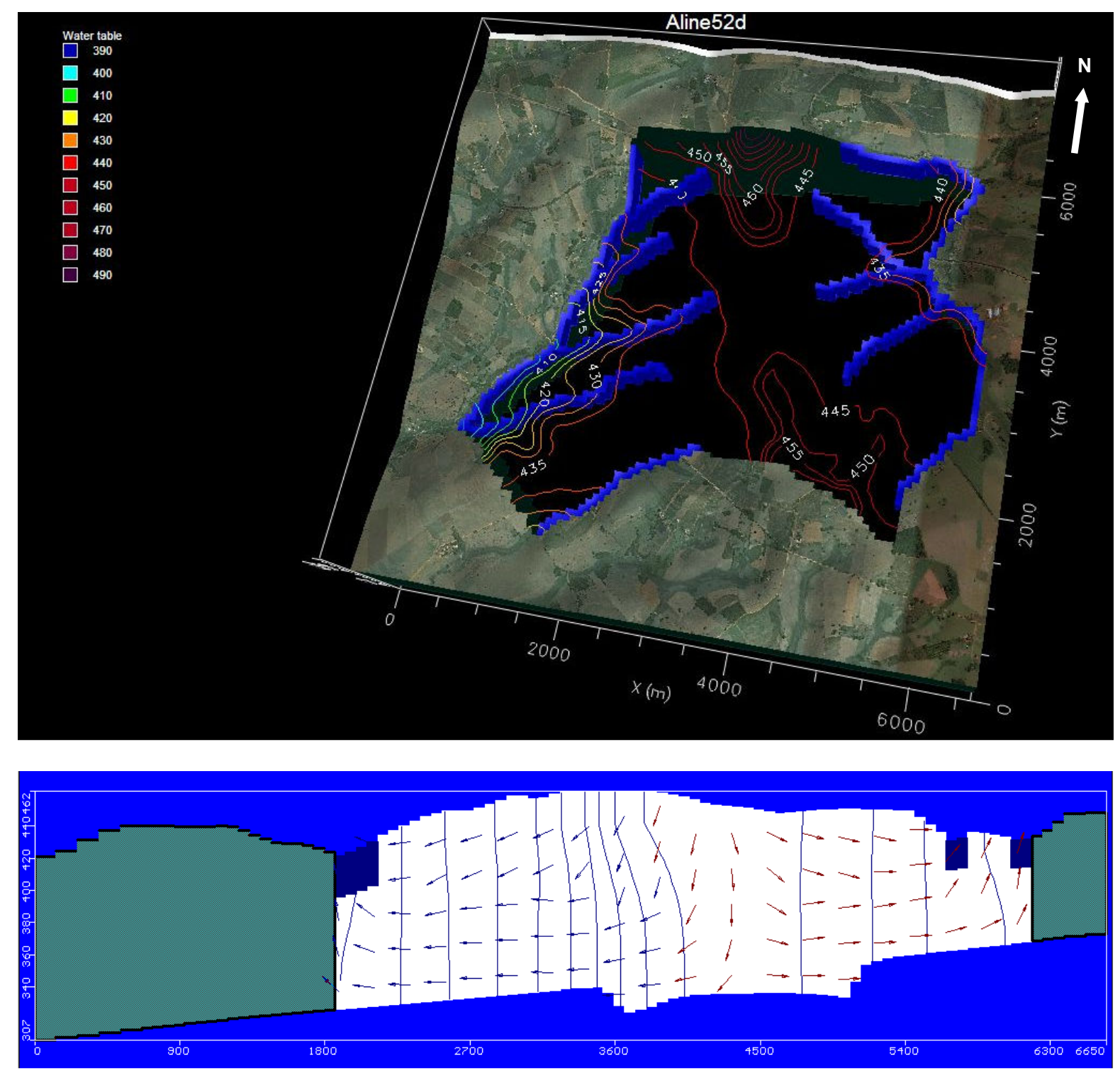

Figura 30. Mapa potenciométrico - situação 'sem bombeamento' (planta e perfil da linha 36) 

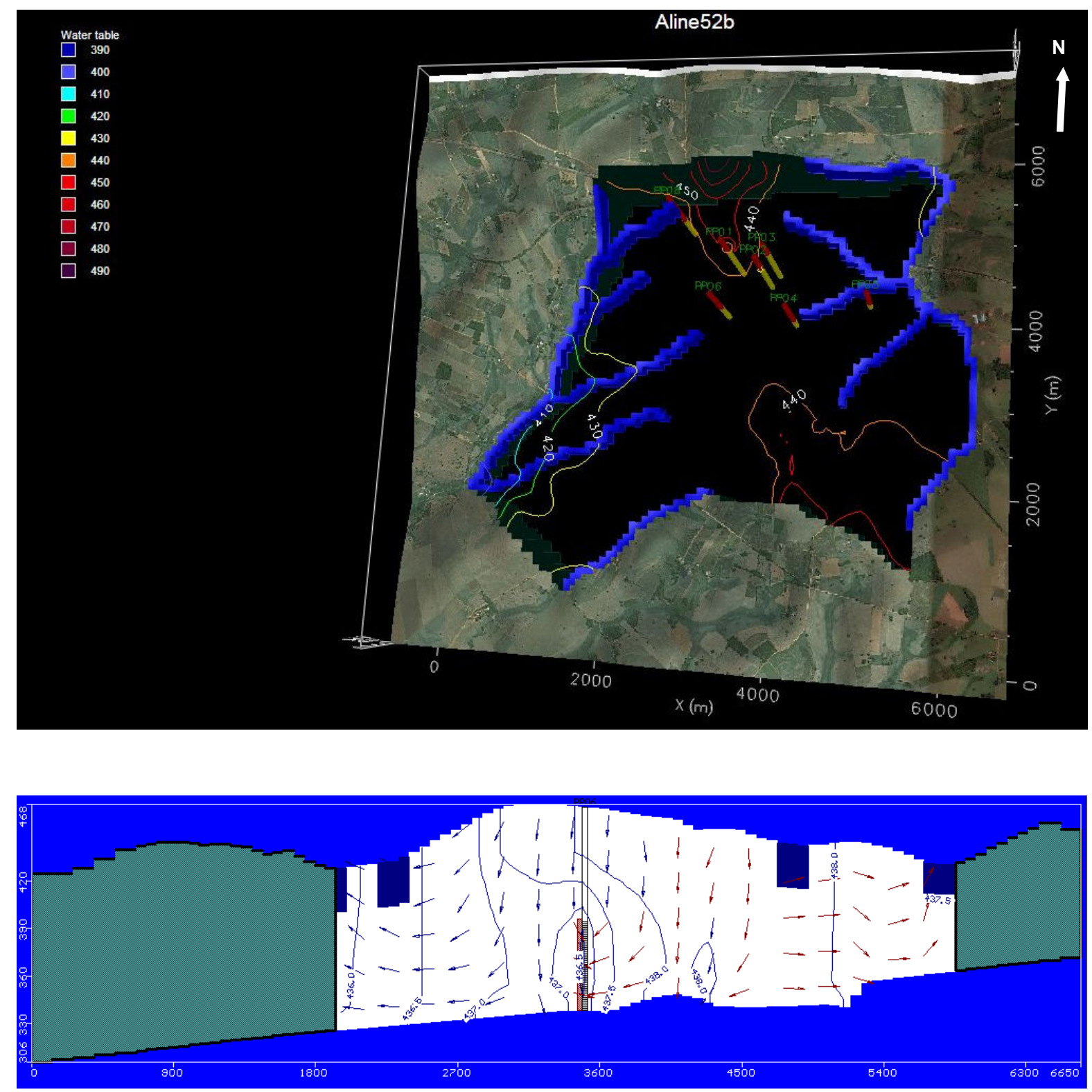

Figura 31. Mapa potenciométrico - situação ‘com bombeamento' (planta e perfil da linha 33) 


\subsubsection{Análise de sensibilidade}

A análise de sensibilidade foi desenvolvida para avaliar os parâmetros que mais afetam as cargas hidráulicas calculadas pelo modelo matemático. Para tanto, variou-se os valores das condutividades hidráulicas das unidades hidroestratigráficas e as taxas de recarga. Segundo ANDERSON \& WOESSNER (1992), a análise de sensibilidade é feita, tipicamente, variando-se um parâmetro de cada vez para verificar seu reflexo nos resíduos calculados.

A análise de sensibilidade foi efetuada para a situação 'sem bombeamento', a qual reflete o cenário atual. Observou-se que as taxas de recarga não apresentam grande influência no modelo matemático, sendo que os resíduos, representados pela diferença entre as cargas hidráulicas observadas e calculadas pelo modelo, mostraram pequenas diferenças em relação ao valor calibrado (p. ex. uma variação média de 0,27 \% para o parâmetro RMS Normalized), como mostra a Tabela 15.

Tabela 15 - Análise de sensibilidade do modelo matemático construído.

\begin{tabular}{c|c|c|c|c|c|c|}
\hline Situação & Parâmetro & Variação & ME $(\mathrm{m})$ & MAE $(\mathrm{m})$ & RMS $(\mathrm{m})$ & RMS Normalized (\%) \\
\hline \multirow{4}{*}{$\begin{array}{c}\text { 'Sem } \\
\text { bombeamento' }\end{array}$} & $\begin{array}{c}\text { Condutividade } \\
\text { hidráulica (K) em m/s }\end{array}$ & $0.5 \mathrm{~K}$ & -0.483 & 1.235 & 1.516 & 10.037 \\
\cline { 2 - 7 } & $\begin{array}{c}\text { Recarga (R) em } \\
\mathrm{mm} / \text { ano }\end{array}$ & -1.189 & 1.745 & 2.099 & 13.900 \\
\cline { 3 - 7 } & & $1.5 \mathrm{R}$ & 0.142 & 0.999 & 1.333 & 8.792 \\
\hline
\end{tabular}

Os gráficos apresentados nas Figuras 32 a 35, mostram, respectivamente, a relação das cargas hidráulicas observadas com as cargas hidráulicas calculadas pelo modelo nas análises de condutividade com variação de $0,5 \mathrm{~K}, 1,5 \mathrm{~K}$ e de recarga de $0,5 \mathrm{R}$ e $1,5 \mathrm{R}$.

A variação nas condutividades hidráulicas afeta o modelo matemático com maior intensidade que as taxas de recarga, como refletem os valores dos resíduos calculados. Observa-se que o aumento de $0,5 \mathrm{~m} / \mathrm{s}$ nas condutividades hidráulicas de todas as unidades hidroestratigráficas eleva o parâmetro RMS Normalized para aproximadamente $10 \%$ (Tabela 15 - Figura 32), obtendo-se assim uma variação de $14 \%$ do valor desse parâmetro calculado para o modelo calibrado. Já o aumento de $1,5 \mathrm{~m} / \mathrm{s}$ nas condutividades hidráulicas de todas as unidades hidroestratigráficas eleva o parâmetro RMS Normalized para aproximadamente $14 \%$ (Tabela 15 - Figura 33), obtendo-se assim uma variação de $58 \%$ do valor deste parâmetro calculado para o modelo calibrado. 

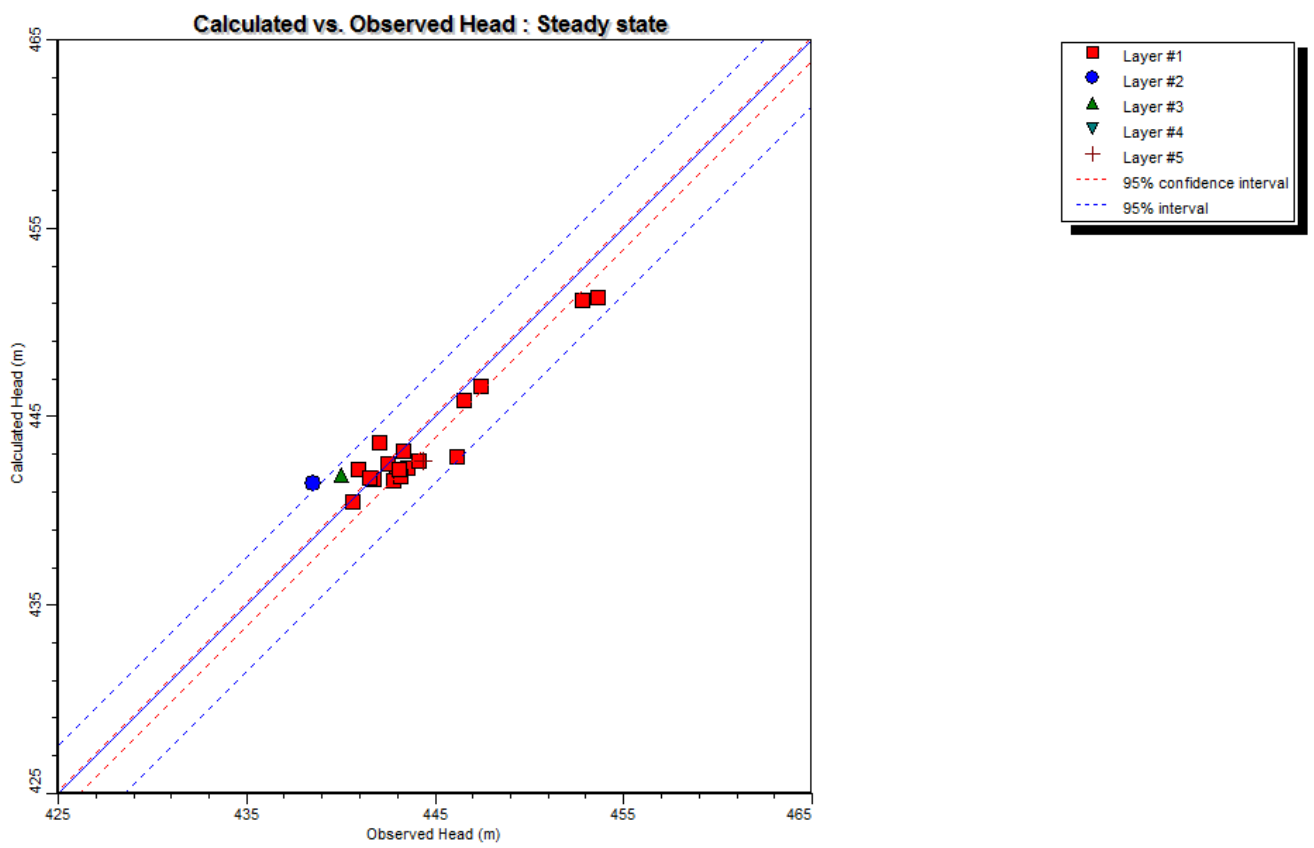

Residual Mean : : $0.483(\mathrm{~m})$
Abs. Residual Mean : $1.235(\mathrm{~m})$

the Estimate : $0.321(\mathrm{~m}$

Cormalized RMS : 10.037 ( \%)

Figura 32. Análise de sensibilidade do modelo matemático - situação 'sem bombeamento'

(variação $0,5 \mathrm{~K}$ )
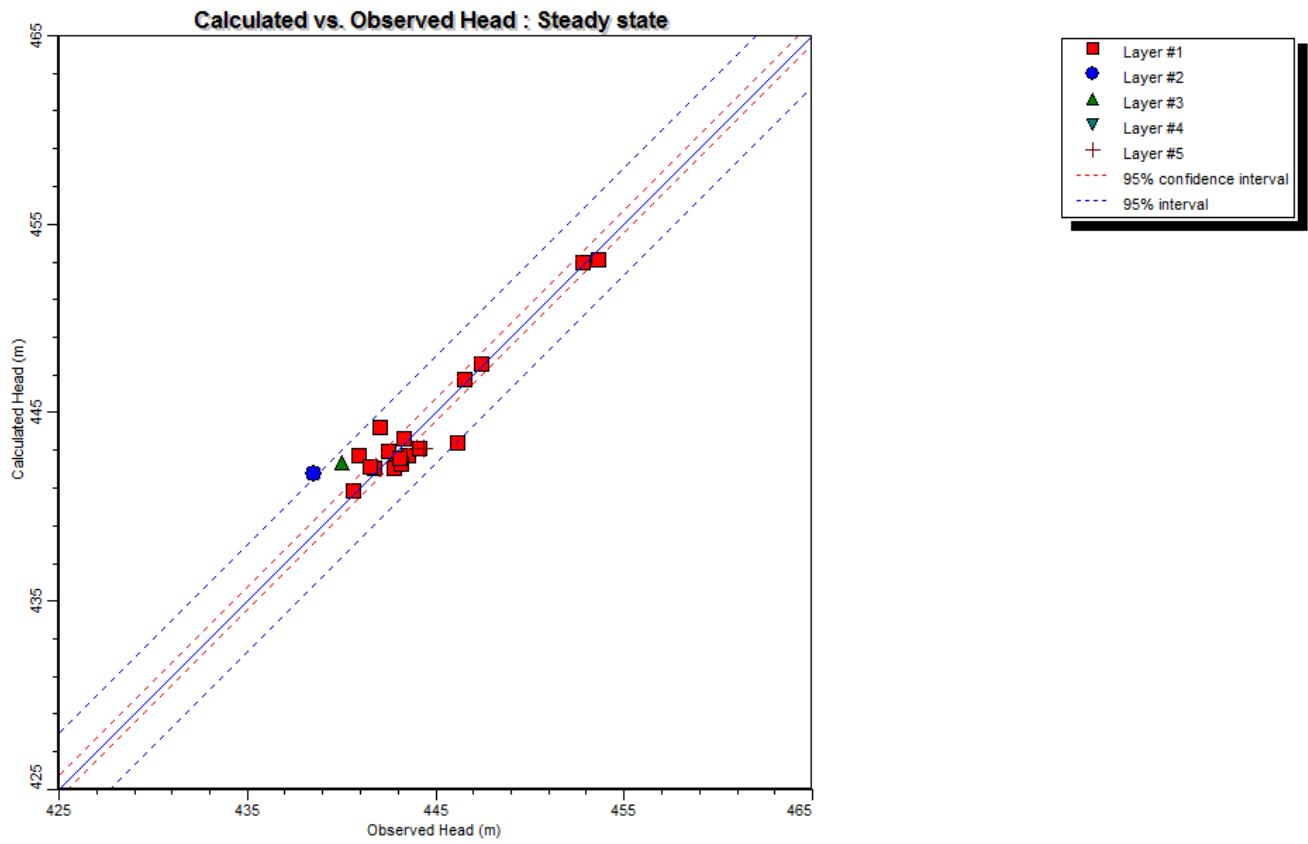

$95 \%$ interval

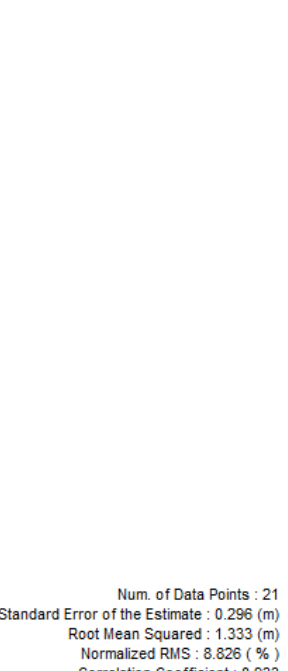

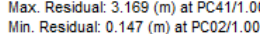

Residual Mean : $0.142(\mathrm{~m})$

(10

Figura 33. Análise de sensibilidade do modelo matemático - situação 'sem bombeamento' (variação 1,5 K) 


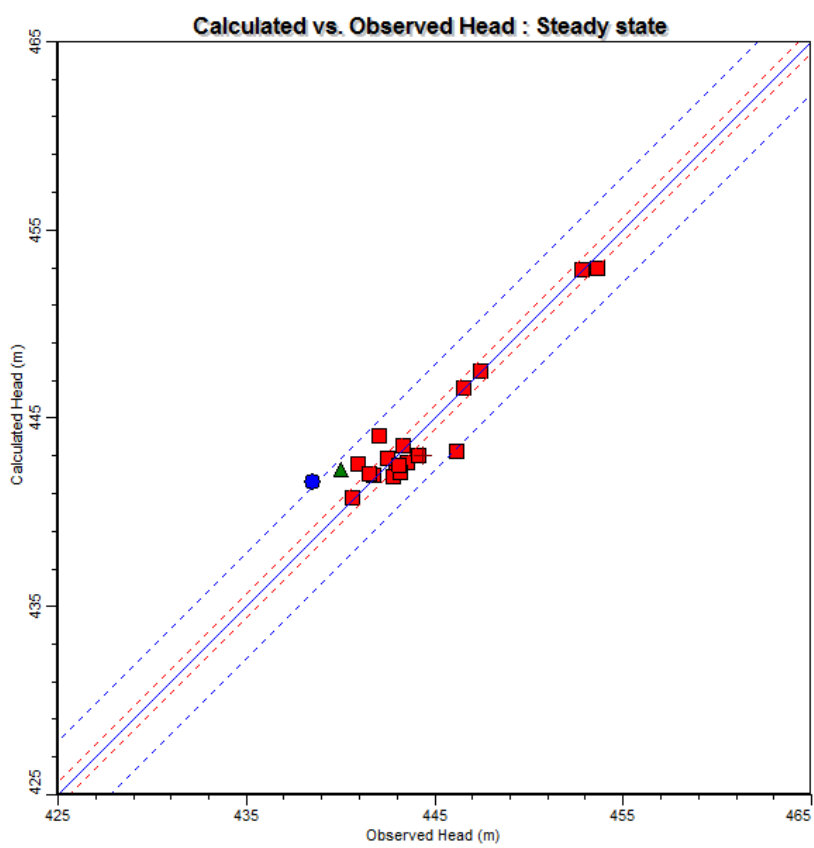

Figura 34. Análise de sensibilidade do modelo matemático - situação 'sem bombeamento' (variação 0,5 R)
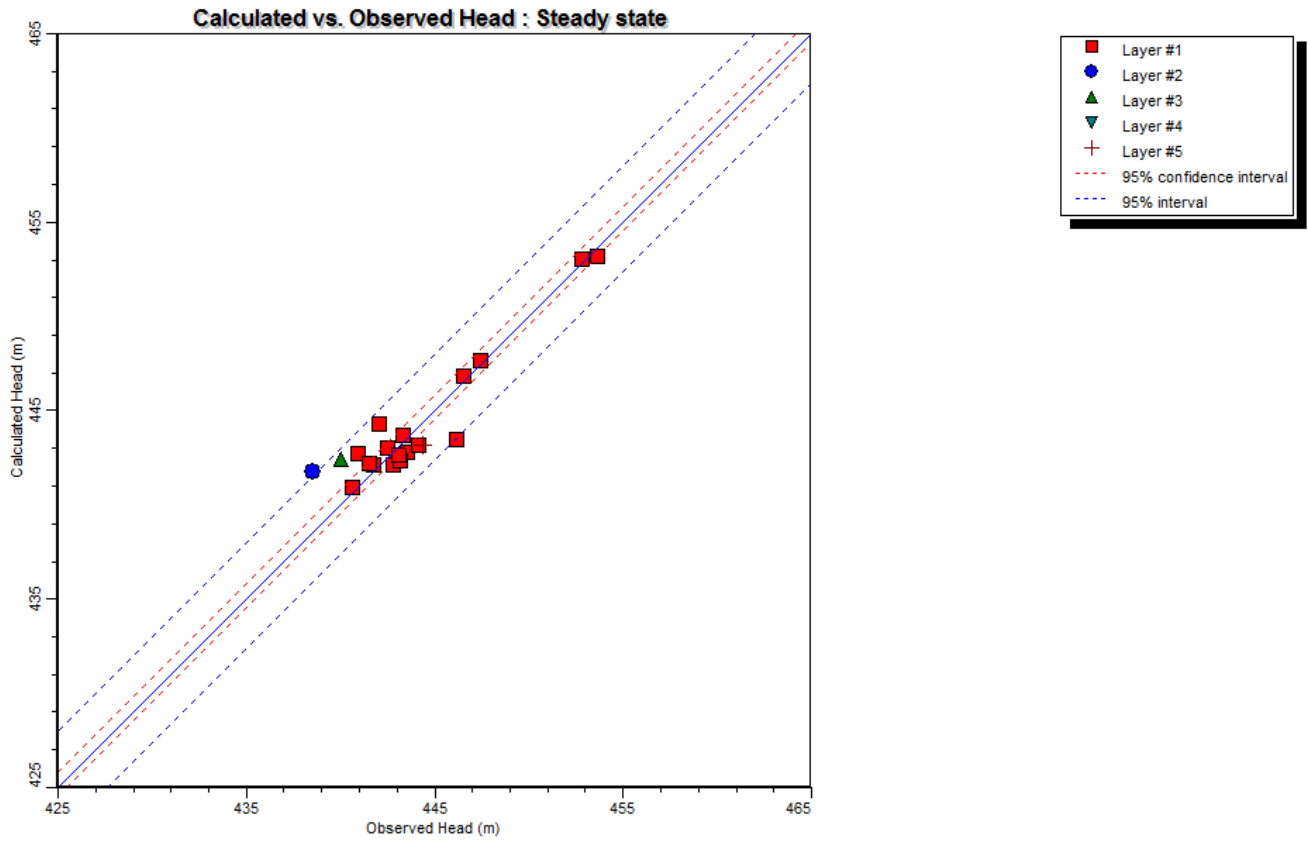

Figura 35. Análise de sensibilidade do modelo matemático - situação 'sem bombeamento' (variação 1,5 R) 
Dessa forma, é possível observar que o modelo matemático construído é mais sensível em relação aos valores de condutividade hidráulica, sendo necessário um levantamento mais preciso desses parâmetros. Os valores de recarga apresentam pouca influência no sistema modelado, o que mostra que sua estimativa com base bibliográfica não induzirá grandes erros no modelo matemático.

\subsection{Modelagem de Transporte}

A partir do modelo de fluxo de água subterrânea calibrado para as situações 'sem bombeamento' e 'com bombeamento' foi utilizado o software MT3DMS para a avaliação da evolução das concentrações de nitrato no aquífero por um período de 100 anos. Para tanto foram simulados 16 cenários, conforme especificado no item 6.2.5.

A técnica de resolução da equação de transporte adotada neste estudo foi a de diferenças finitas - implícita progressiva.

\section{Simulação 1}

No primeiro cenário buscou-se avaliar a fração de um determinado valor de referência de concentração que atingiria a porção inferior do aquífero livre em relação ao tempo, sem o bombeamento dos poços de produção. Assim, considerou-se um cenário bastante restritivo, no qual foi inserida uma carga constante com concentração de $100 \mathrm{mg} / \mathrm{L}$ de nitrato em toda a zona urbana na primeira camada do modelo (espessura de $35 \mathrm{~m}$ ), referente à primeira camada da unidade hidroestratigráfica superior da Formação Adamantina, sem considerar o bombeamento dos poços de extração do município e sem considerar a dispersão (Figura 36), por um período de 100 anos.

Para avaliar a evolução da contaminação, foram inseridos três poços de observação na linha 34 do modelo, com o posicionamento de seus filtros em diferentes porções do aquífero (Figura 37). O poço de observação inserido na porção rasa do aquífero livre, denominado de $\mathrm{PO}-102$, possui sua seção filtrante na unidade hidroestratigráfica superior da Formação Adamantina, na segunda camada do modelo, a $40 \mathrm{~m}$ de profundidade. Já o inserido na porção intermediária do aquífero livre, denominado PO-101, possui sua seção filtrante na unidade hidroestratigráfica inferior da Formação Adamantina, na quarta camada do modelo, a $65 \mathrm{~m}$ de profundidade. $\mathrm{O}$ poço inserido na porção profunda do aquífero livre também possui sua seção filtrante na unidade hidroestratigráfica inferior da Formação Adamantina, porém na sexta camada do modelo, a $100 \mathrm{~m}$ de profundidade.

A concentração inicial de nitrato nestes poços foi considerada como nula, ou seja, inicialmente os mesmos não estavam contaminados. 


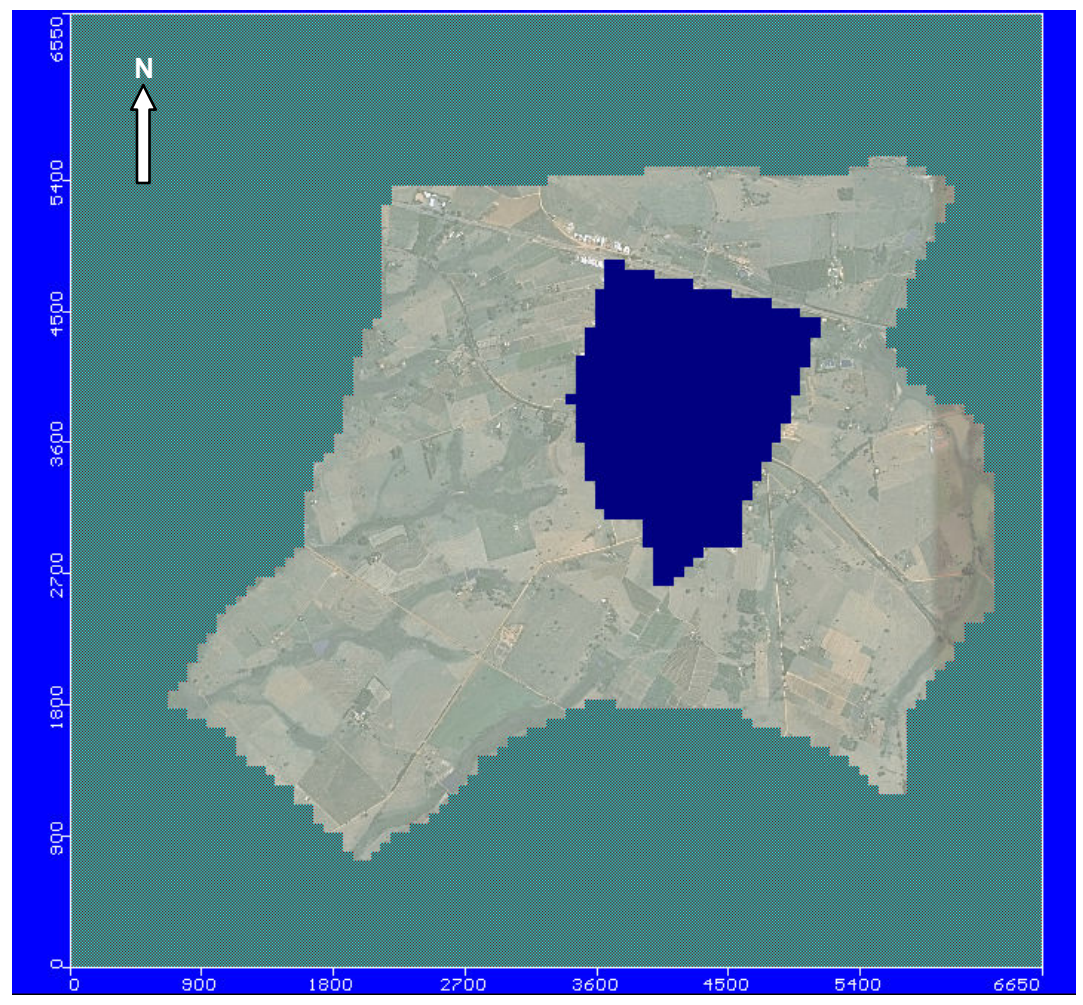

Figura 36. Área urbana de Urânia com concentração constante de nitrato na primeira camada do modelo por todo o tempo simulado (100 anos)

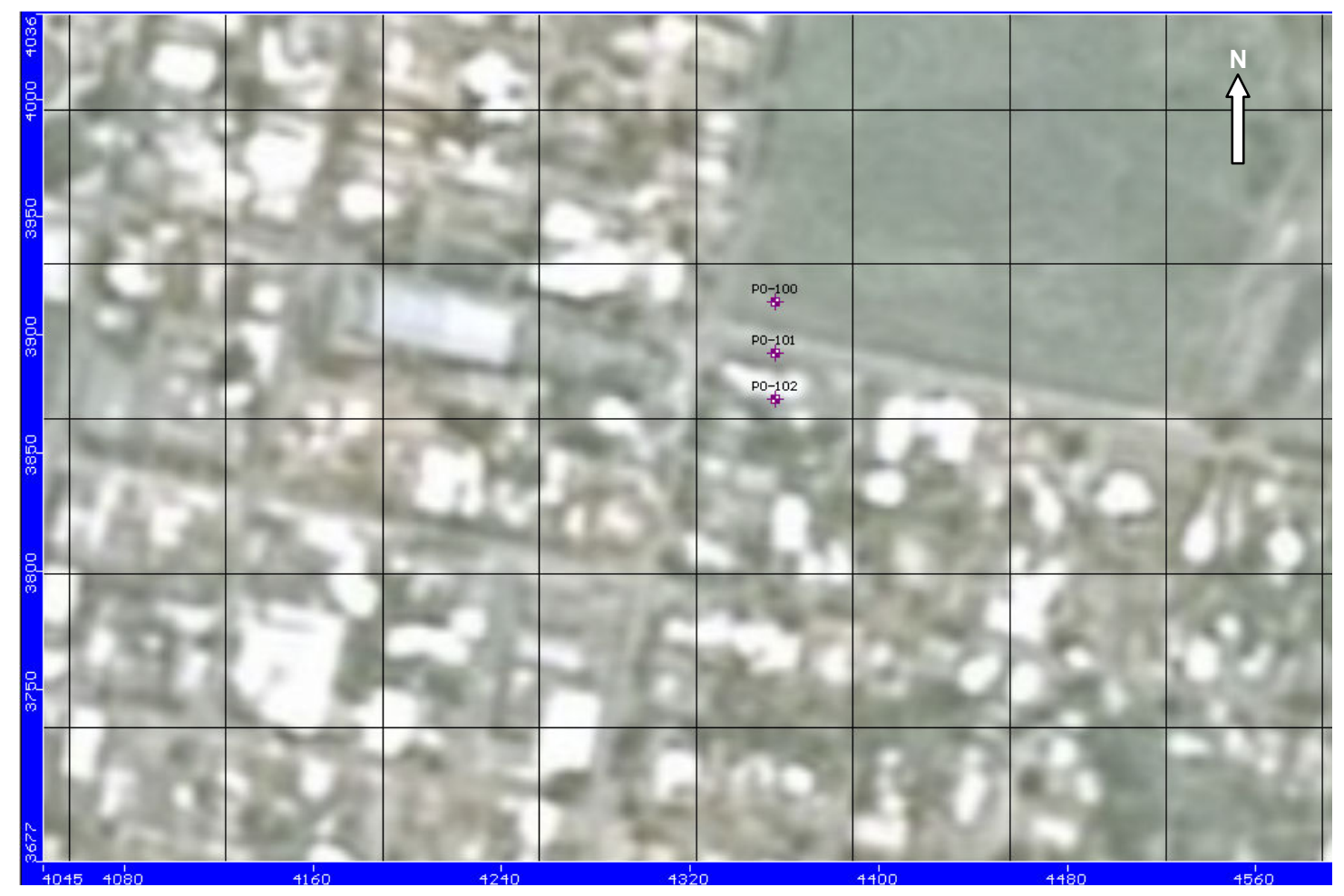

Figura 37. Localização dos poços de observação PO-100, PO-101 e PO-102 
Os resultados desta simulação indicaram que, para o período considerado, $70 \%$ da contaminação estimada para a primeira camada do modelo atingirá a porção profunda, 98 \% atingirá a porção intermediária e 100 \% a porção rasa do aquífero livre (Figura 38). Desta forma, o aquífero livre tem capacidade de diluir somente $30 \%$ de uma contaminação lançada em toda área urbana na primeira camada do modelo até atingir sua sexta camada (base da Formação Adamantina).

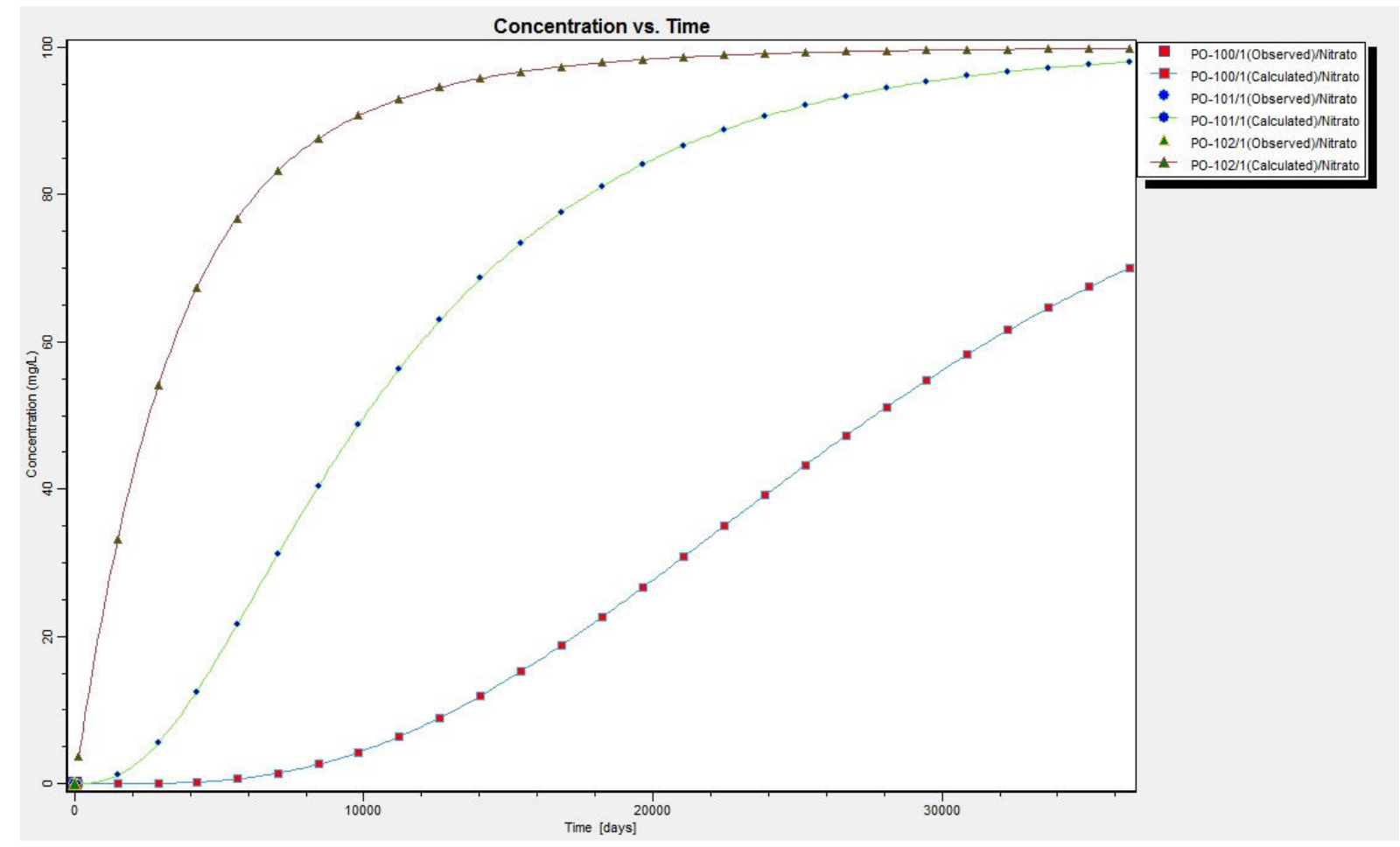

Figura 38. Simulação 1 - Concentração $x$ tempo

A legenda da Figura 38 indica as concentrações nos poços de observação calculadas pelo modelo e as observadas. Como no modelo somente foram inseridas as concentrações iniciais nos poços, os resultados das concentrações observadas se propõem os resultados das concentrações calculadas pelo modelo.

A evolução da contaminação no aquífero com o tempo pode ser verificada na Figura 40, a qual apresenta as seções para os tempos de 1, 10, 20, 40, 60, 80 e 100 anos, na linha 34 do modelo matemático. Verifica-se que a frente de contaminação de nitrato atinge a porção profunda do aquífero (sexta camada do modelo) em 10 anos de simulação. Já a segunda e quarta camadas do modelo são atingidas, respectivamente, em 1 e 5 anos de simulação. 

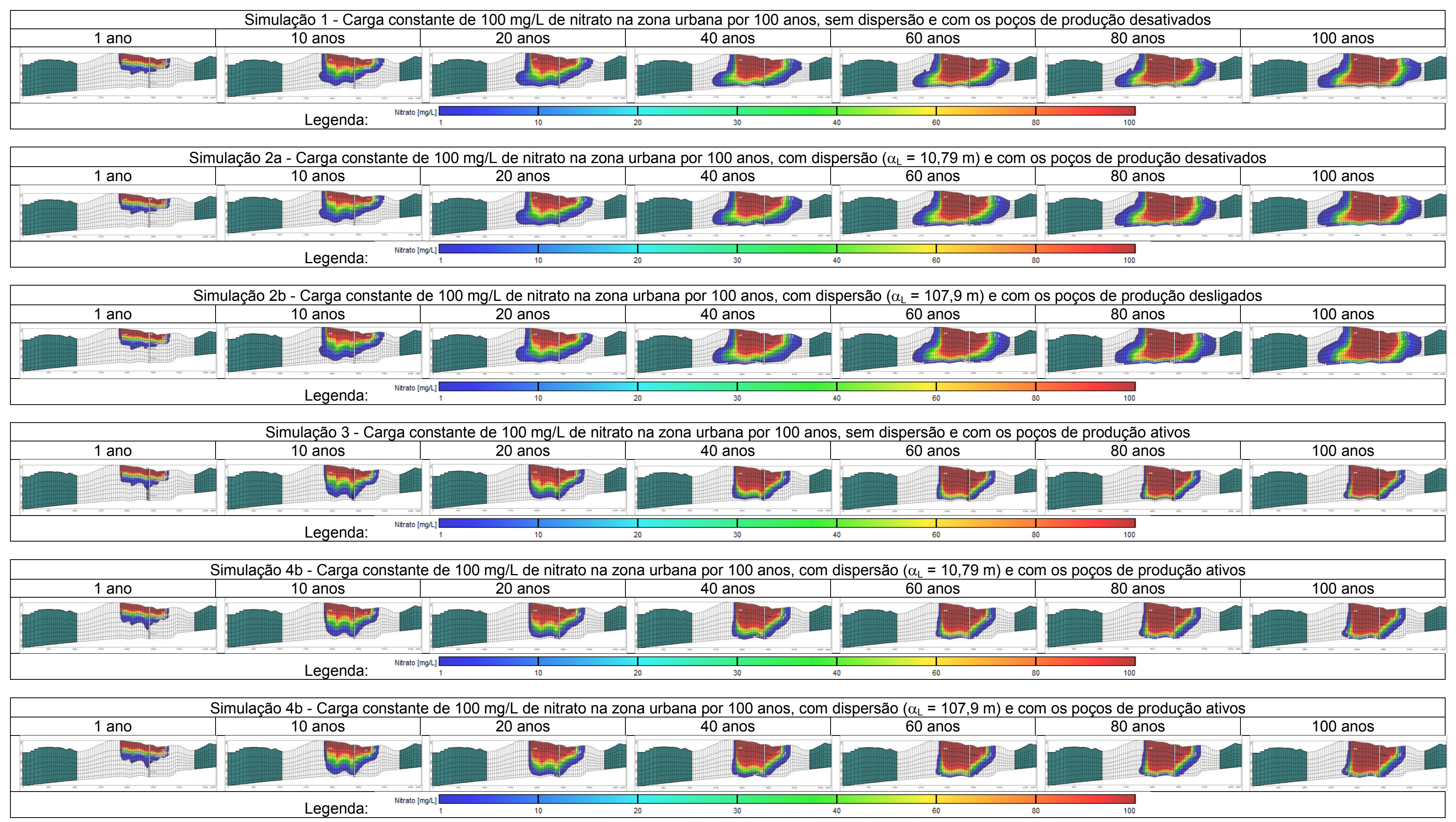

Figura 39. Resultados das simulações da contaminação por nitrato no aquifero urbano (Simulações 1 a 4) 


\section{Simulação 2}

No segundo cenário buscou-se avaliar a ação da dispersão na evolução do contaminante na zona saturada, sem considerar o bombeamento dos poços de produção. Assim, utilizaram-se todas as assunções realizadas para a Simulação 1 e adicionou-se a dispersão hidrodinâmica.

A advecção é calculada pelo software com a equação diferencial parcial tridimensional (Equação 1, item 4.1.). A dispersão hidrodinâmica foi calculada através dos termos de advecção e dispersividade longitudinal, transversal e vertical (Equações 22 a 24, item 4.9.). O termo de difusão, por ser representado por um valor muito pequeno, foi desprezado das equações. A dispersividade longitudinal $\left(\alpha_{L}\right)$ foi calculada utilizando-se a equação de XU \& ECKSTEIN (1995) - Equação 33:

$$
\alpha_{L}=0,83\left[\log _{10}\left(L_{p}\right)\right]^{2,414} \quad \text { Equação } 33
$$

Onde $L p$ é o comprimento da pluma de contaminação no sentido do fluxo d'água subterrânea [ft]. Para tanto, constatou-se que as concentrações de nitrato abrangem toda a área urbana de Urânia, assim sendo, efetuou-se a medida em planta da pluma de contaminação em 2000 m (i.e. 6560 ft). Assim, obteve-se um valor de 10,79 m para $\alpha_{\mathrm{L}}$.

Os valores de dispersividade transversal $\left(\alpha_{T}\right)$ e dispersividade vertical $\left(\alpha_{V}\right)$ para as unidades hidroestratigráficas referentes à Formação Adamantina foram estimados em $0,1 \alpha_{L}$ e 0,01 $\alpha_{L}$, respectivamente, seguindo as orientações da NEWWEL et al. (1997). Para a camada referente à alteração do basalto da Formação Serra Geral, $\alpha_{T}$ e $\alpha_{V}$ foram estimados em 0,01 $\alpha_{L}$ e 0,001 $\alpha_{L}$, respectivamente, devido à sua constituição essencialmente argilosa.

Os resultados desta simulação indicaram que, para o período considerado, $71 \%$ da contaminação estimada para a primeira camada do modelo atingirá a porção profunda, $98 \%$ atingirá a porção intermediária e $100 \%$ a porção rasa do aquífero livre (Figura 40). Dessa forma, o aquífero livre tem capacidade de diluir somente $29 \%$ de uma contaminação lançada em toda área urbana na primeira camada do modelo até atingir sua sexta camada (base da Formação Adamantina). Portanto, avaliando os resultados obtidos na Simulação 1 e os comparando com os obtidos na Simulação 2, observa-se que a dispersão não afeta significantemente os resultados obtidos no transporte do nitrato. A evolução da contaminação no aquífero com o tempo apresentada na Figura 40 (Simulação 2a), também corrobora com esta informação, onde não se verifica disparidades entre as plumas de contaminação modeladas para os tempos de 1, 10, 20, 40, 60, 80 e 100 anos, na linha 34 do modelo matemático, nas Simulações 1 e 2. 


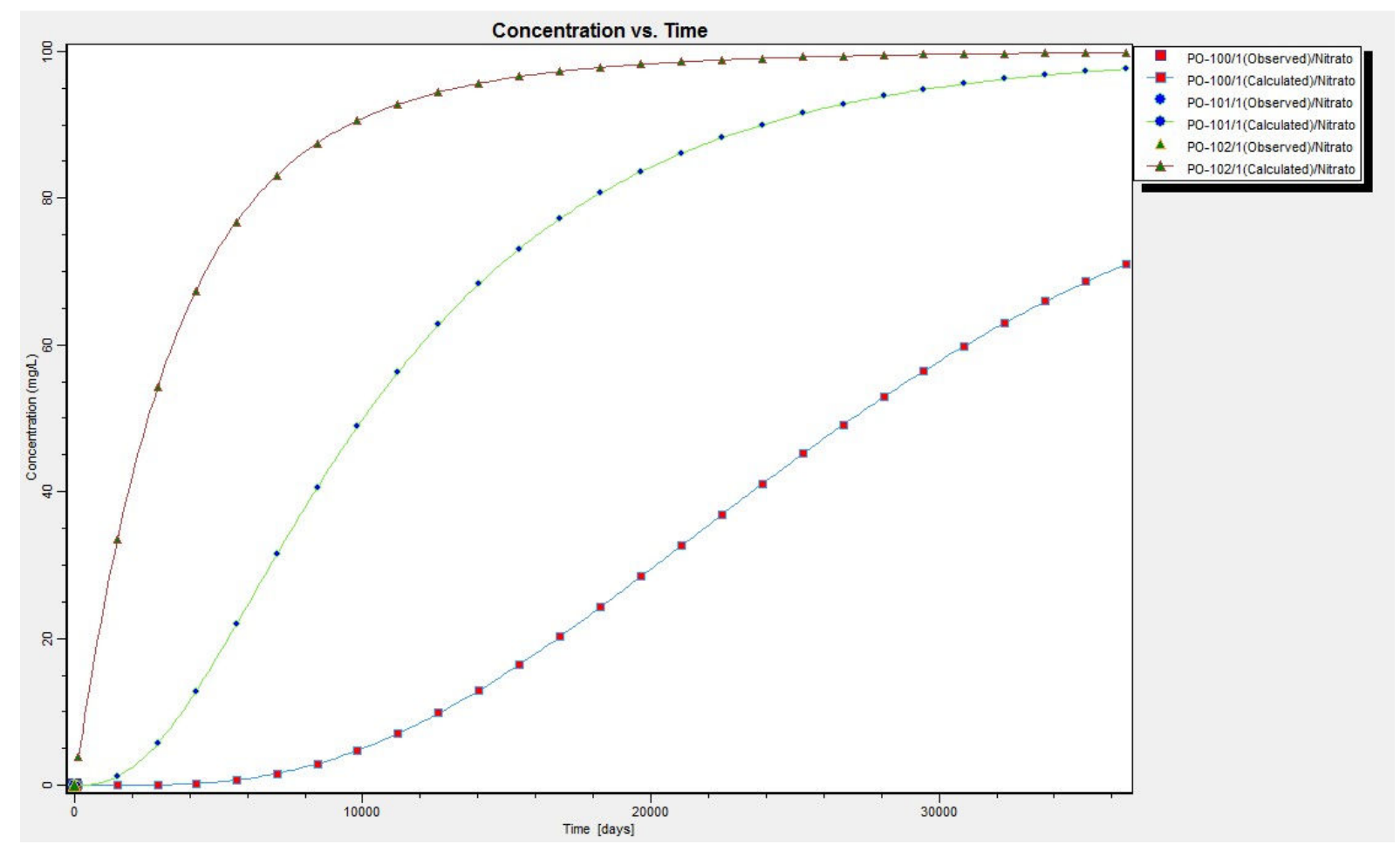

Figura 40. Simulação 2a - Concentração $x$ tempo

Para avaliar a sensibilidade deste parâmetro, realizou-se uma nova simulação com o aumento de uma ordem de grandeza no valor de $\alpha_{L}$ (i.e. para 107,9 m). Esta simulação foi denominada de Simulação $2 b$.

Os resultados desta simulação também indicaram que, para o período considerado, $71 \%$ da contaminação estimada para a primeira camada do modelo atingirá a porção profunda, $98 \%$ atingirá a porção intermediária e $100 \%$ a porção rasa do aquífero livre (Figura 41). Assim, como se pode verificar na Figura 39, confirma-se se que a dispersão não afeta significantemente os resultados obtidos no transporte do nitrato.

$\underline{\text { Simulação } 3}$

No terceiro cenário buscou-se avaliar a influência do bombeamento dos poços de produção na porcentagem de nitrato que atinge a porção inferior do aquífero livre em relação ao tempo. Assim, consideraram-se os poços de produção do município ativos e uma carga constante com concentração de $100 \mathrm{mg} / \mathrm{L}$ de nitrato em toda a zona urbana na primeira camada do modelo (espessura de $35 \mathrm{~m}$ ), sem considerar a dispersão (Figura 42), por um período de 100 anos. 


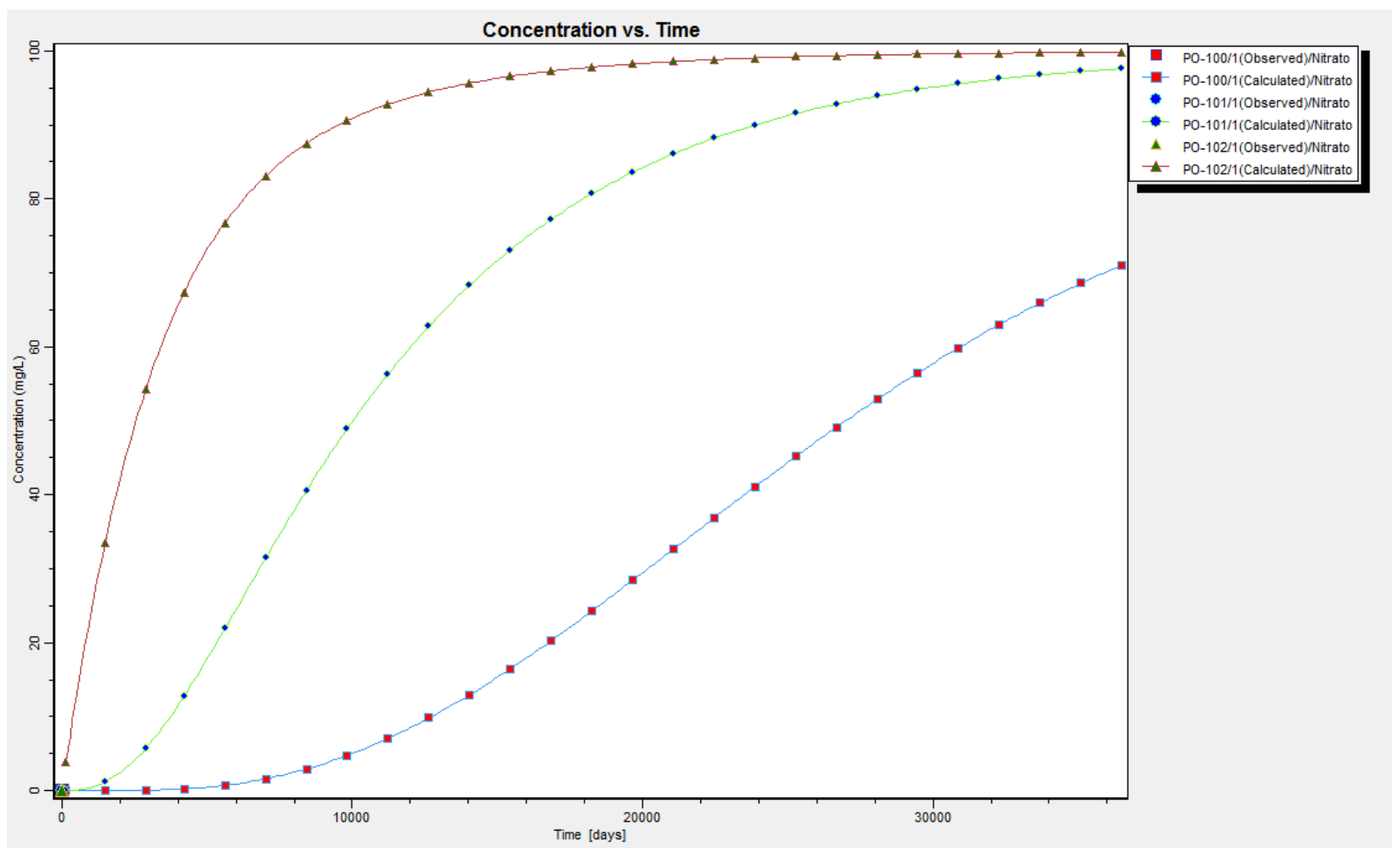

Figura 41. Simulação $2 b$ - Concentração $x$ tempo

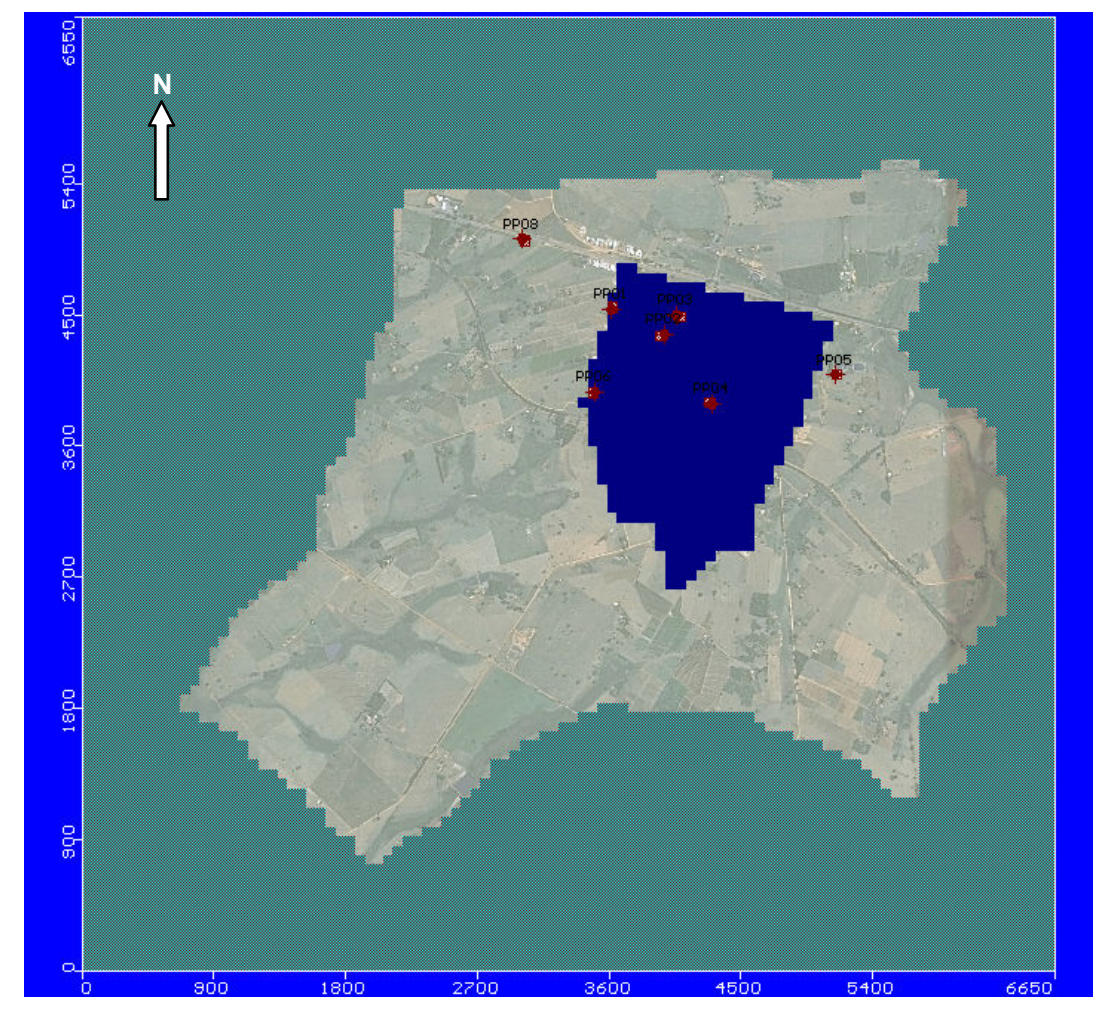

Figura 42. Área urbana de Urânia com concentração constante de nitrato na primeira camada do modelo por todo o tempo simulado (100 anos), com os poços de produção ativos 
É importante ressaltar que no MT3DMS não é possível avaliar qual a concentração de nitrato que está sendo extraída pelos poços de produção. Assim, para avaliar a evolução da contaminação, foram considerados os três poços de observação inseridos em uma mesma célula do modelo, com posicionamento da seção filtrante em diferentes profundidades do aquífero: rasa (PO-102); intermediária (PO-101); e profunda (PO-100), na linha 34 do modelo, na célula ao lado da qual se encontra o poço de produção PP-04 do município, conforme ilustra a Figura 43.

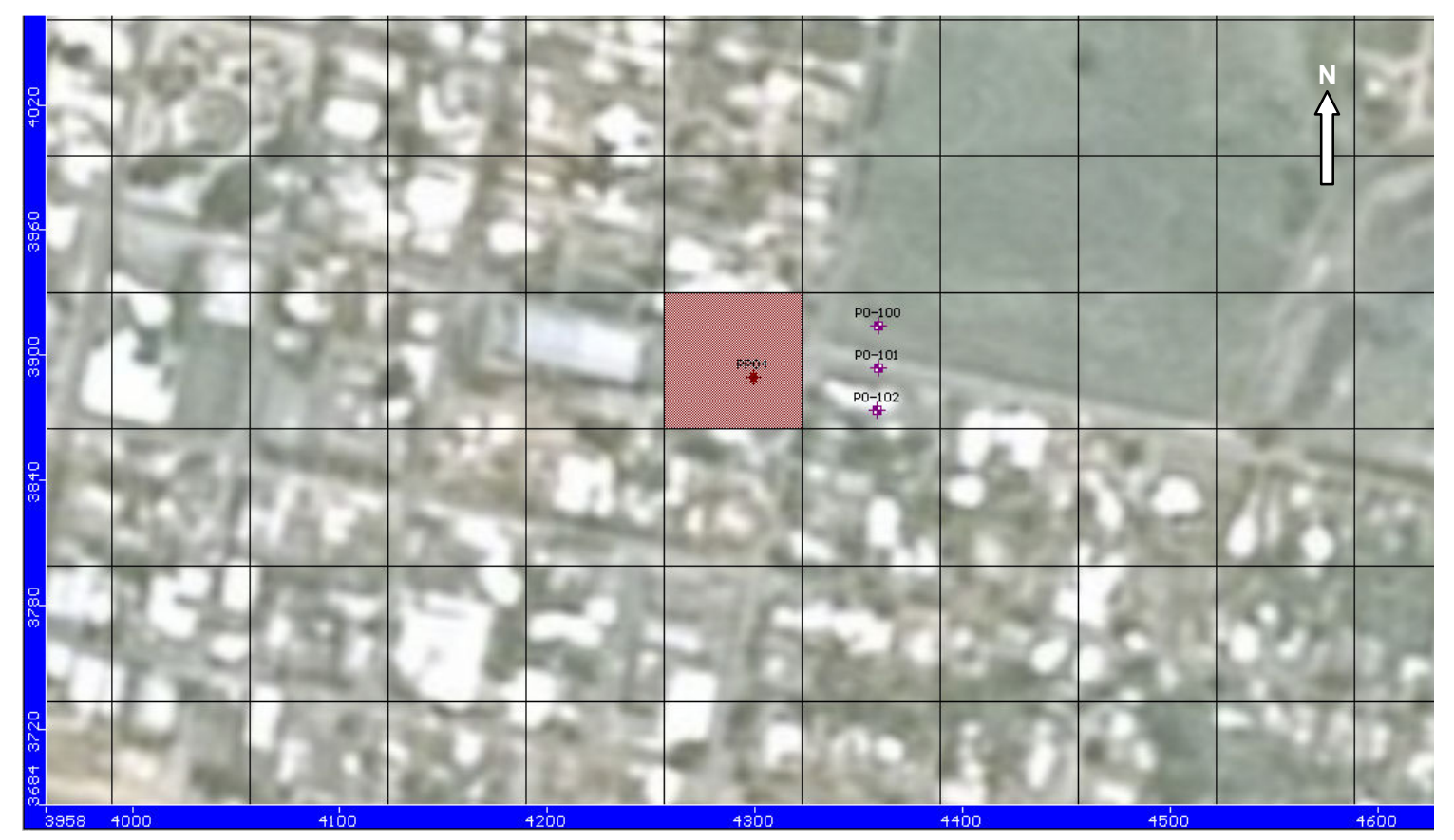

Figura 43. Localização dos poços de observação PO-100 a PO-102 em relação ao poço de produção PP-04

Dessa forma, com o PP-04 ativo, verificou-se que, para o período considerado, $36 \%$ da contaminação estimada para a primeira camada do modelo atingirá a porção profunda, 88 \% atingirá a porção intermediária e 100 \% a porção rasa do aquífero livre (Figura 44). Portanto, nessa simulação o aquífero livre tem capacidade de diluir $64 \%$ de uma contaminação lançada em toda área urbana na primeira camada do modelo até atingir sua sexta camada (base da Formação Adamantina), com os poços de produção do município ativos. 


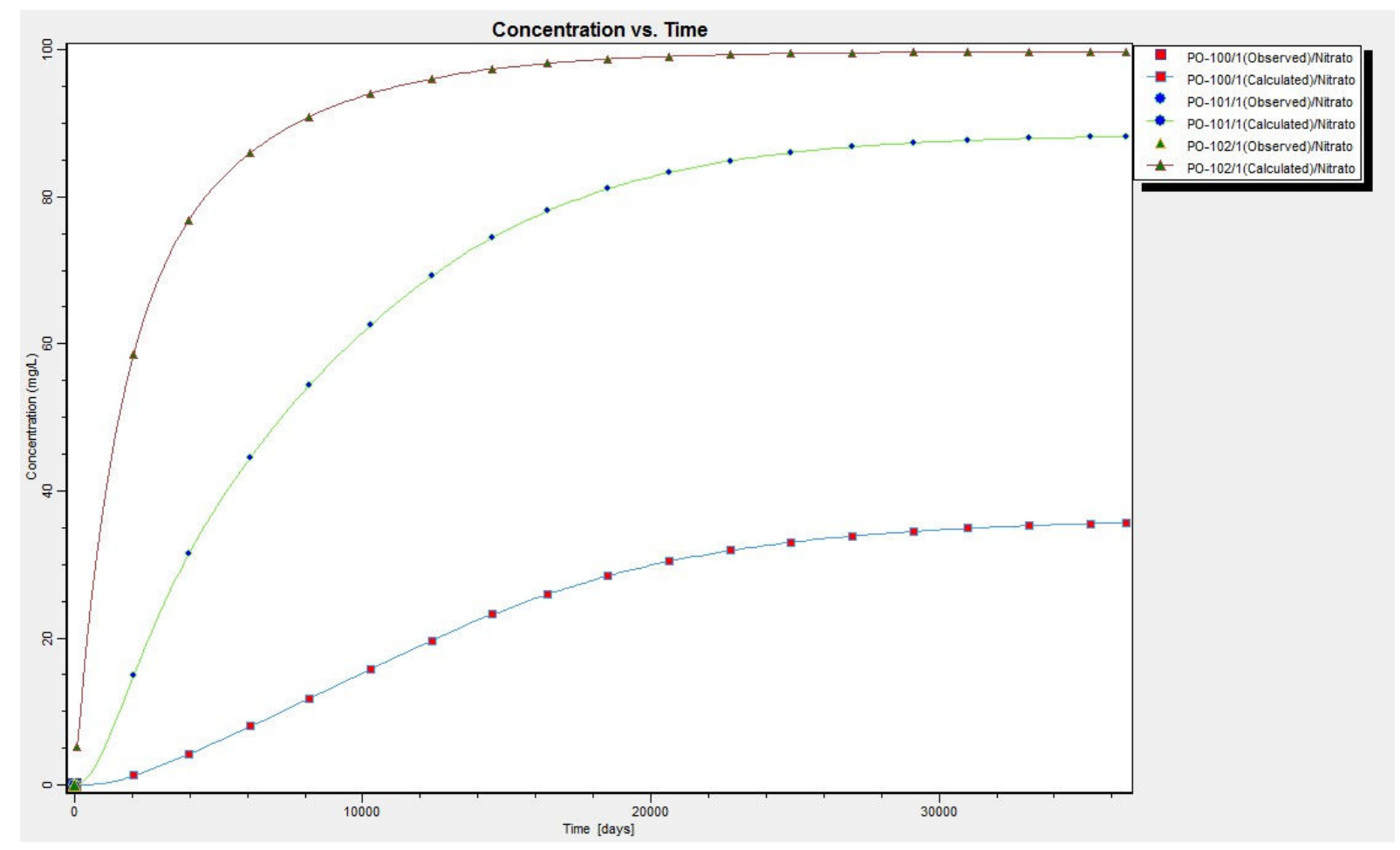

Figura 44. Simulação 3 - Concentração $x$ tempo

Assim, em relação à Simulação 1, verifica-se um aumento superior a $100 \%$ na capacidade de diluição do contaminante pelo aquífero, como também uma diminuição da extensão da pluma de contaminação, devido ao bombeamento dos poços. Contudo, observa-se na Figura $\mathbf{4 0}$ que o contaminante atingiu em um menor intervalo de tempo as porções mais profundas do aquífero. A segunda e a quarta camadas do modelo foram atingidas em 1 ano de simulação e a sexta camada em 5 anos. Estes fatores ocorreram devido ao aumento da capacidade de diluição do aquífero e do gradiente vertical, proporcionados pelo bombeamento dos poços.

Para avaliar o efeito do aumento do gradiente vertical provocado pelo bombeamento dos poços de produção, foi utilizado o software MODPATH para exprimir a trajetórias de partículas, somente considerando a advecção. Essas partículas (em verde) foram inseridas ao redor do poço de produção PP-04, situado na linha 34 / coluna 60 do modelo matemático, conforme ilustra a Figura 45.

Para esse objetivo foram realizadas duas simulações para avaliação da trajetória das partículas, uma delas considerando os poços de produção ativos e, a outra, com eles desativados. Os resultados destas simulações em planta e para linha 34 do modelo matemático podem ser visualizados na Figuras 46 e 47. 


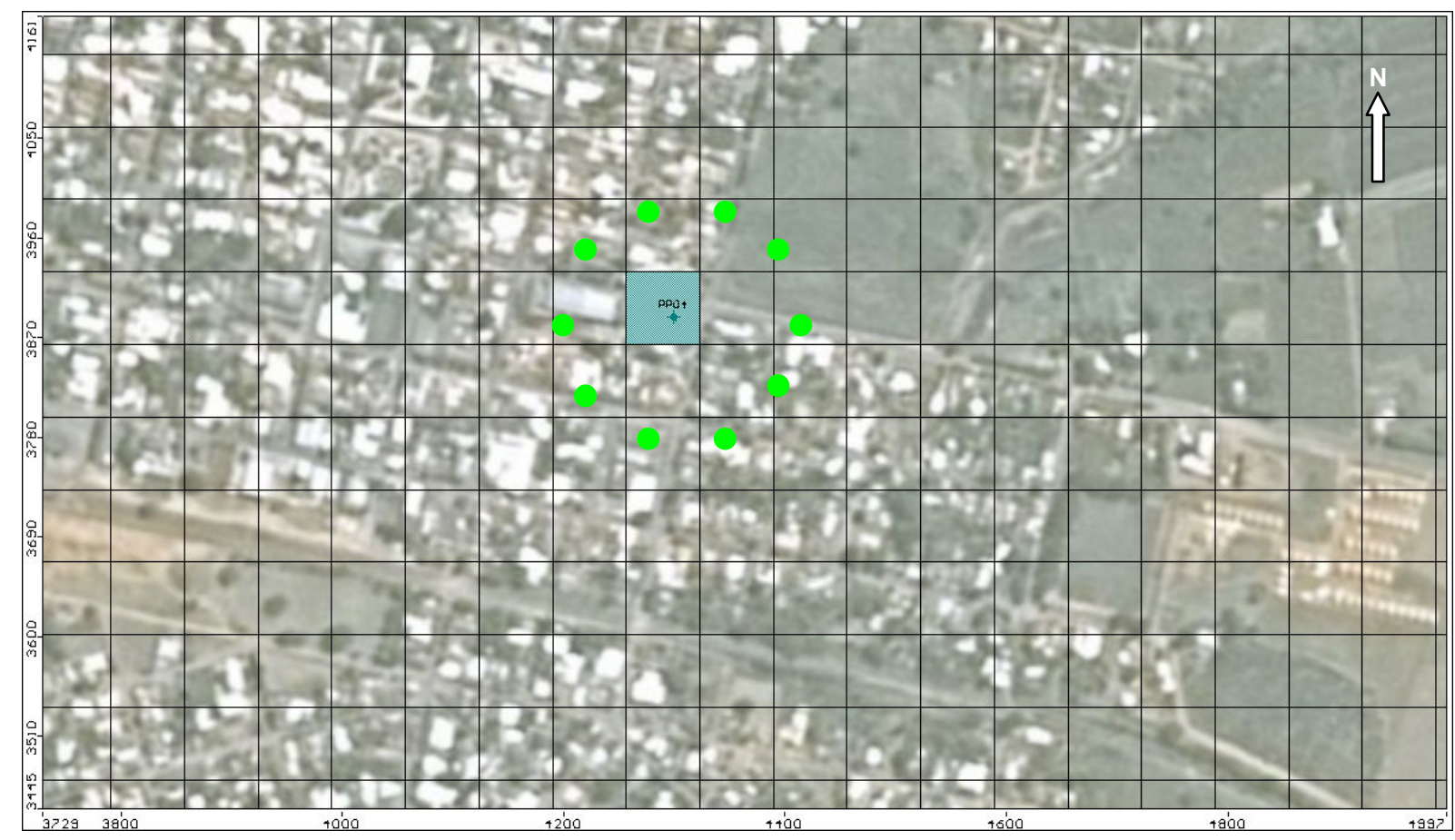

Figura 45. Localização das partículas (em verde) inseridas ao redor do PP-04

A simulação com o MODPATH indicou que, embora para o município de Urânia esta situação seja atualmente hipotética, o acionamento dos poços de produção do município faz com que a frente de uma contaminação existente na porção rasa do aquífero alcance as porções profundas em um menor intervalo de tempo do que com os poços inativos (em aproximadamente 20 anos a menos). Este fato deve-se ao aumento do gradiente vertical proporcionado pelo bombeamento dos poços. Todavia é importante salientar que o bombeamento dos poços proporcionou como benefício, o aumento de $100 \%$ da capacidade de diluição do aquífero quando comparado com as simulações anteriores.

Simulação 4

No quarto cenário buscou-se avaliar o efeito da ação da dispersão na evolução do contaminante na zona saturada, com os poços de produção ativos. Assim, utilizou-se todas as assunções realizadas para a Simulação 3 e adiciou-se a dispersão hidrodinâmica. A dispersão hidrodinâmica considerada nessa simulação (4a) foi a mesma utilizada na Simulação $2 a$, sendo o valor de $\alpha_{L}$ igual a 10,79 m. Os poços de observação inseridos para Simulação 1 também foram considerados.

A partir destes dados, a modelagem indicou que, para o período considerado, $41 \%$ da contaminação estimada para a primeira camada do modelo atingirá a porção profunda, 85 \% atingirá a porção intermediária e 99 \% a porção rasa do aquífero livre (Figura 48). 


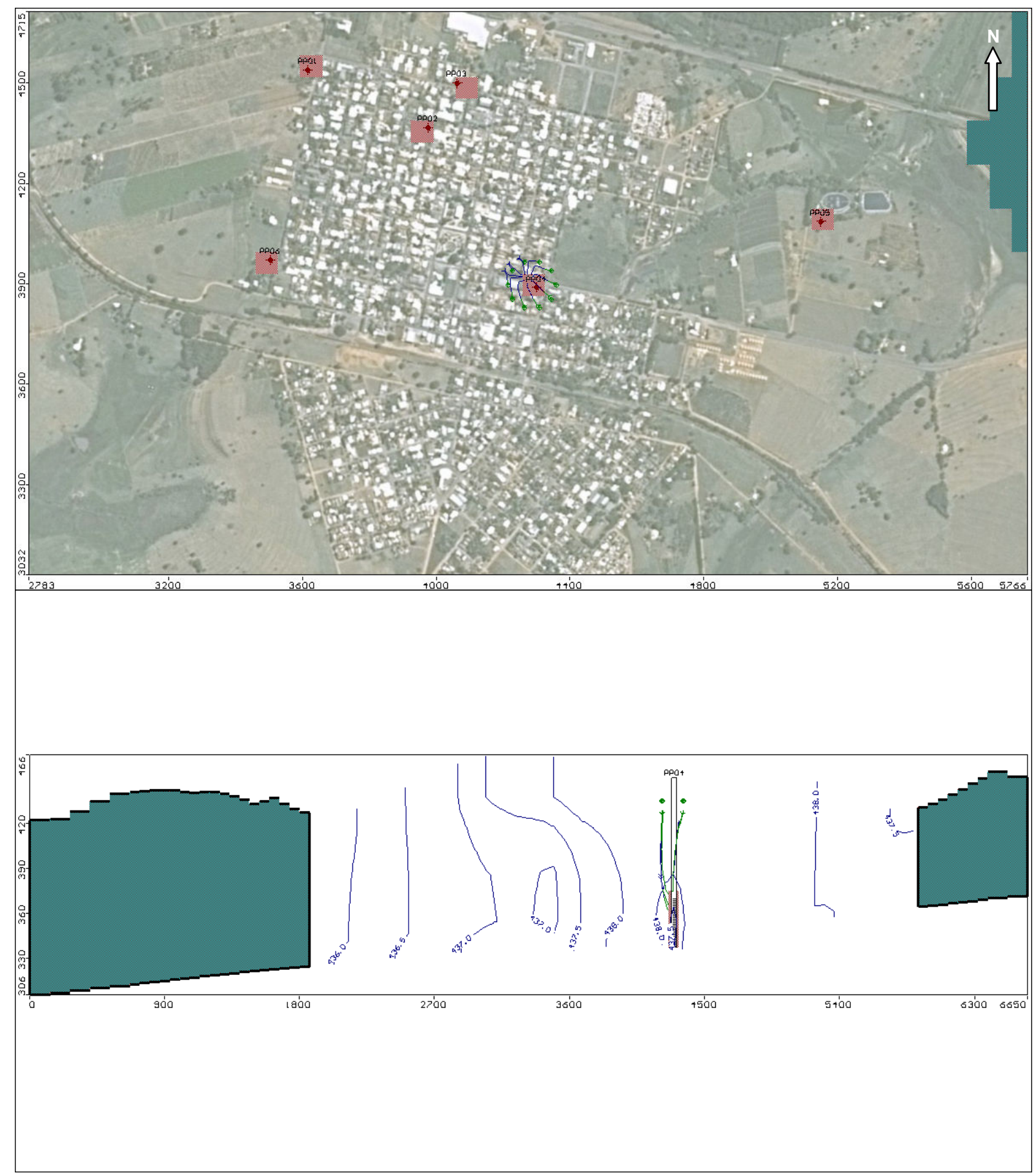

Figura 46. Trajetória das partículas - poços de produção ativos (planta e perfil) 

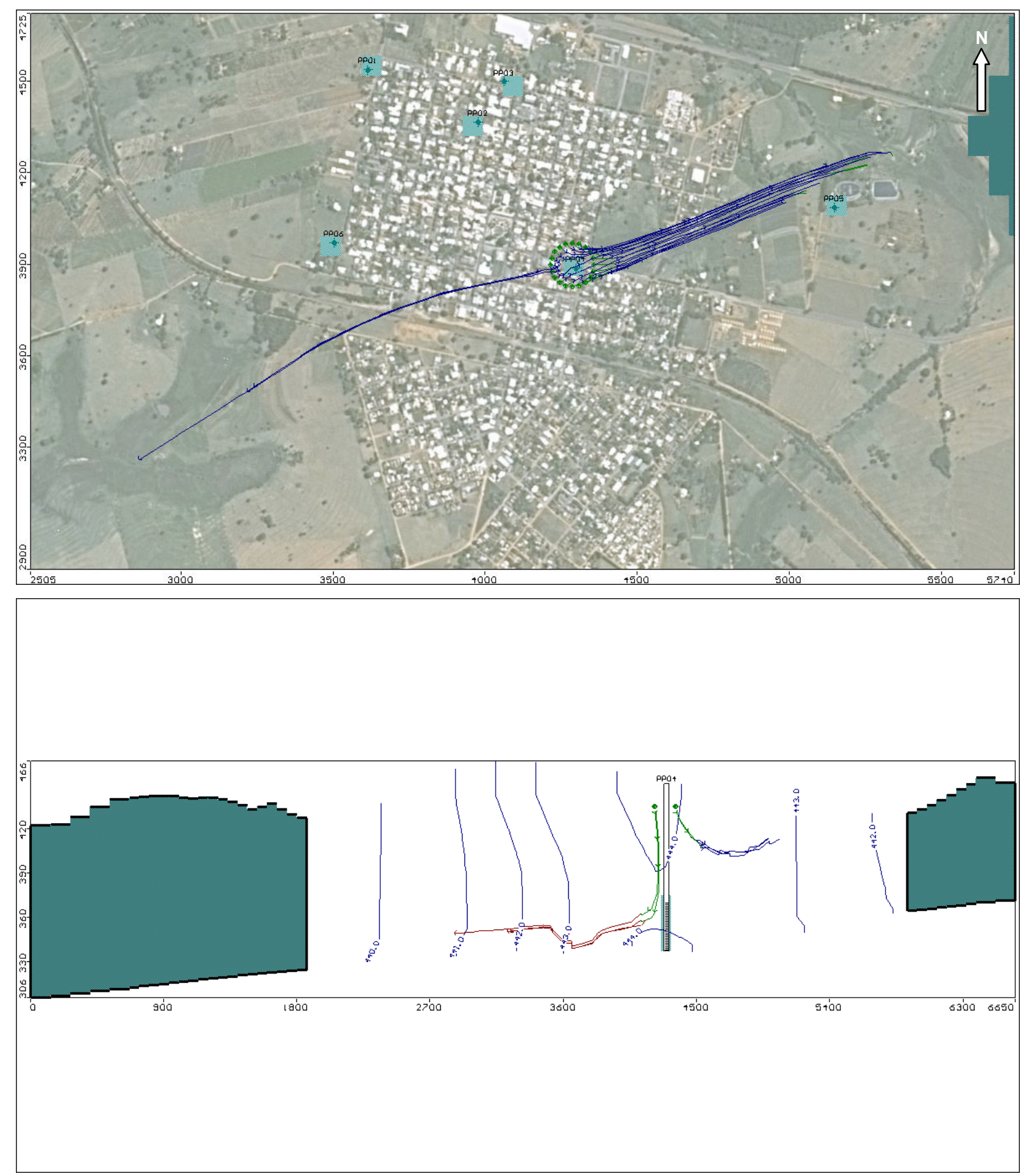

Figura 47. Trajetória das partículas - poços de produção inativos (planta e perfil) 


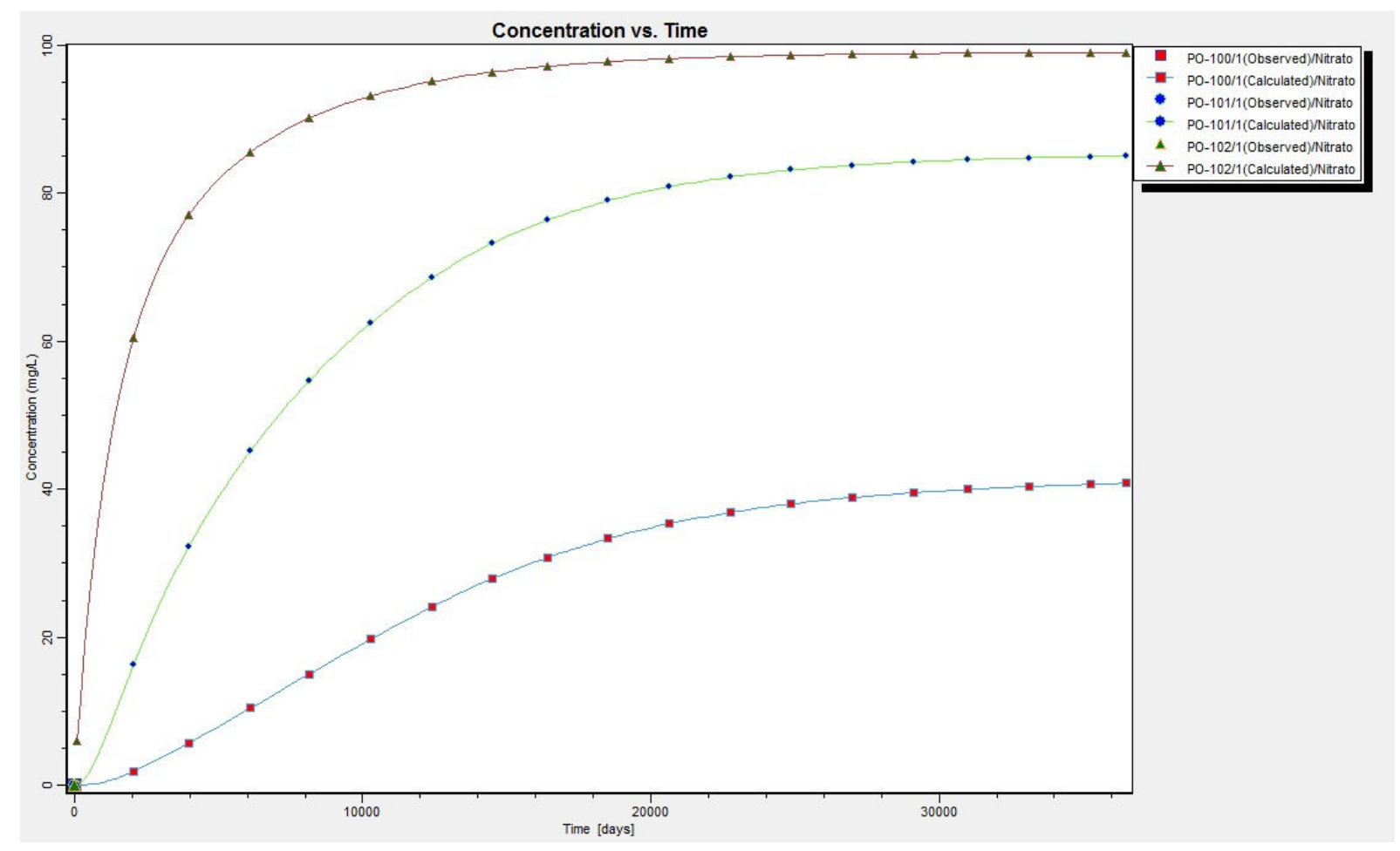

Figura 48. Simulação 4a - Concentração x tempo

Dessa forma, o aquífero livre tem capacidade de diluir $39 \%$ de uma contaminação lançada em toda área urbana na primeira camada do modelo até atingir sua sexta camada (base da Formação Adamantina). Portanto, avaliando os resultados obtidos na Simulação 3 e os comparando com os obtidos na Simulação $4 a$, observa-se que embora a dispersão afete um pouco mais significantemente os resultados obtidos no transporte do nitrato quando comparado com as Simulações 1 e 2, a mesma ainda não apresenta grande impacto. As diferenças entre os resultados obtidos nas Simulações 3 e 4 a variaram entre 1 e $3 \%$.

Para avaliar a sensibilidade deste parâmetro com os poços de produção ativos, realizou-se uma nova simulação com o aumento de uma ordem de grandeza no valor de $\alpha_{L}$ (i.e. para 107,9 m). Esta simlação foi denominada de Simulação 4b. Os resultados desta simulação também indicaram que, para o período considerado, $41 \%$ da contaminação estimada para a primeira camada do modelo atingirá a porção profunda, $85 \%$ atingirá a porção intermediária e 99 \% a porção rasa do aquífero livre (Figura 49).

Assim, mesmo com o aumento de uma ordem de grandeza no valor de dispersividade longitudinal, não há alterações nos resultados obtidos na Simulação 4a e 4b. 


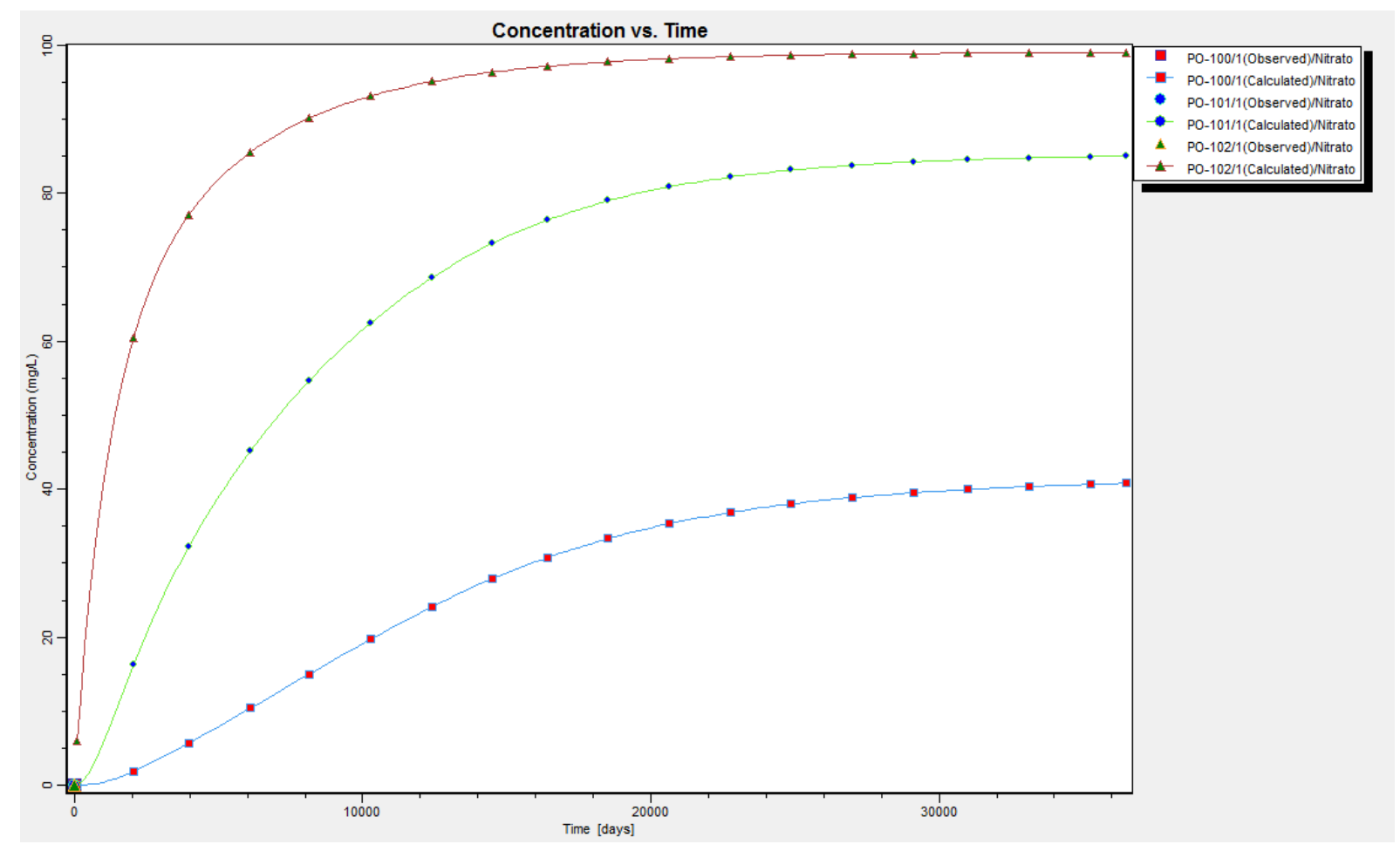

Figura 49. Simulação $4 b$ - Concentração $x$ tempo

Desta forma, como se pode verificar na Figura 40, a contaminação atinge as porções mais profundas do aquífero em um mesmo período de tempo que o observado na Simulação 3 e, poranto, confirma-se que a dispersão não afeta significantemente os resultados obtidos no transporte do nitrato.

\section{Simulação 5}

No quinto cenário buscou-se avaliar em quanto tempo o aquífero se recuperaria após o cessamento da fonte de contaminação de nitrato, ou seja, simulando a introdução de uma rede de esgoto $100 \%$ eficiente no município. Para tanto, foi verificada a porcentagem de nitrato que atingiria a porção inferior do aquífero livre em relação ao tempo, com os poços de produção inativos e sem a ação da dispersão do contaminante na zona saturada, considerando uma carga constante com concentração de $100 \mathrm{mg} / \mathrm{L}$ de nitrato em toda a zona urbana na primeira camada do modelo (espessura de $35 \mathrm{~m}$ ) por um período de 10 anos. Os poços de observação inseridos para Simulação 1 também foram considerados.

Os resultados desta simulação indicaram que a porção rasa do aquífero (segunda camada do modelo) apresentará uma concentração máxima de $65 \%$ da concentração inicial em 10 anos e de $0 \%$ em 100 anos, a porção intermediária apresentará uma concentração máxima de $27 \%$ em 23 anos e de $1 \%$ em 100 anos, e a porção profunda apresentará uma concentração máxima de 15 \% em 72 anos e de 11 \% em 100 anos (Figura 50). 


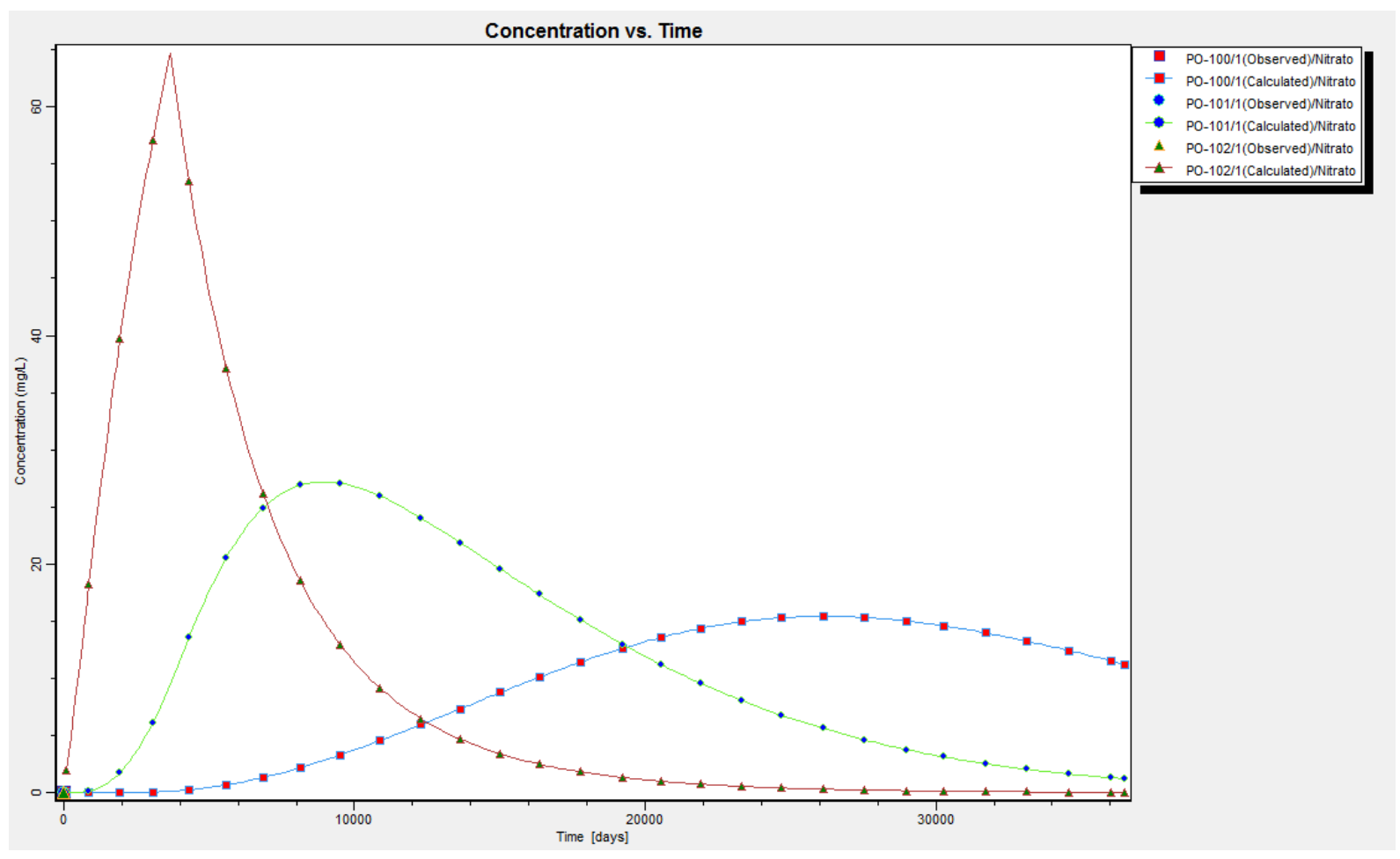

Figura 50. Simulação 5 - Concentração $x$ tempo

A evolução da contaminação no aquífero com o tempo pode ser verificada na Figura 51, a qual apresenta as seções para os tempos de 1, 10, 20, 40, 60, 80 e 100 anos, na linha 34 do modelo matemático. Verifica-se que após a interrupção da fonte de contaminação (10 anos) ocorre uma redução significativa das concentrações de nitrato até seu quase desaparecimento em 100 anos, corroborando com a informação supracitada.

Com base nesta informação, pode-se constatar que se fosse possível cessar todas as fontes de contaminação de nitrato no município, como fossas e vazamentos de tubulações de esgoto, em 10 anos o problema de contaminação de nitrato na porção rasa e intermediária do aquífero estaria sanado. Já para a porção mais profunda, a contaminação perduraria por um período de 90 anos após o cessamento da fonte, com uma fração de $11 \%$ de sua concentração inicial.

\section{Simulação 6}

No sexto cenário buscou-se avaliar a ação da dispersão na porcentagem de nitrato que atingiria a porção inferior do aquífero livre em relação ao tempo, sem considerar o bombeamento dos poços e com a ação da dispersão do contaminante na zona saturada. Para tanto, utilizou-se todos os dados inseridos na Simulação 5, e adicionou-se os valores de dispersão determinados para a Simulação 2a. Os poços de observação inseridos para Simulação 1 também foram considerados. 


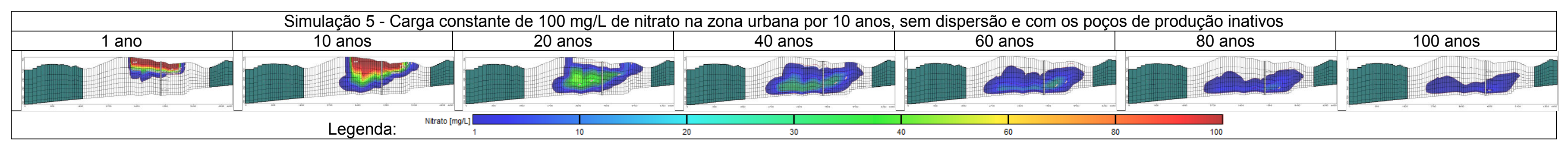

Legenda:

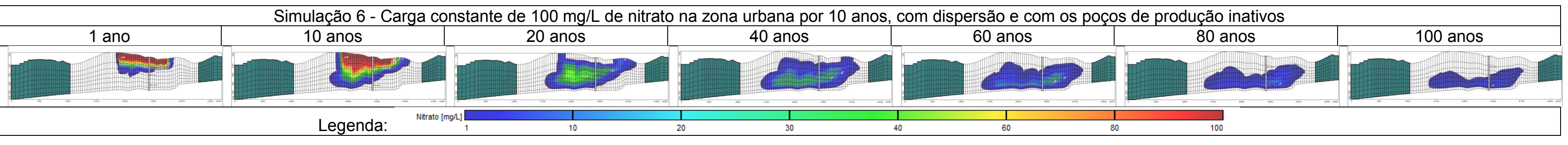

Legenda:

Simulação 7 - Carga constante de $100 \mathrm{mg} / \mathrm{L}$ 40

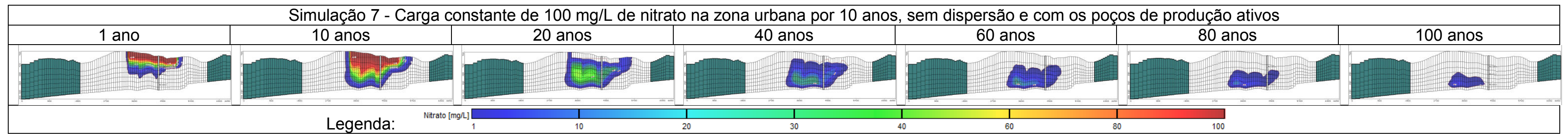

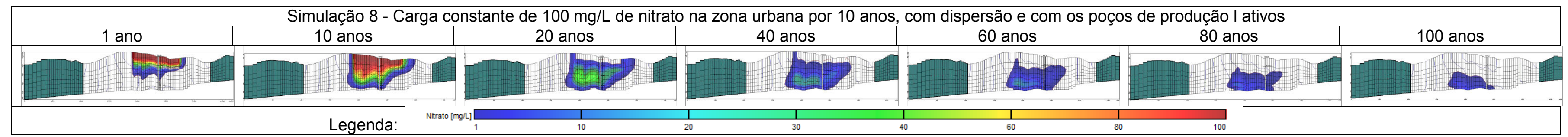

Figura 51. Resultados das simulações da contaminação por nitrato no aquífero urbano (Simulações 5 a 8) 
Os resultados desta simulação indicaram que a porção rasa do aquífero (segunda camada do modelo) apresentará uma concentração máxima de $65 \%$ em 10 anos e de $0 \%$ em 100 anos, a porção intermediária apresentará uma concentração máxima de 27 \% em 23 anos e de 1 \% em 100 anos, e a porção profunda apresentará uma concentração máxima de $15 \%$ em 73 anos e de $11 \%$ em 100 anos (Figura 52). Assim, como também se pode verificar na Figura 51, não há diferença entre os resultados obtidos para as Simulações 5 e 6, mas uma vez indicando que a dispersão não altera os resultados da modelagem.

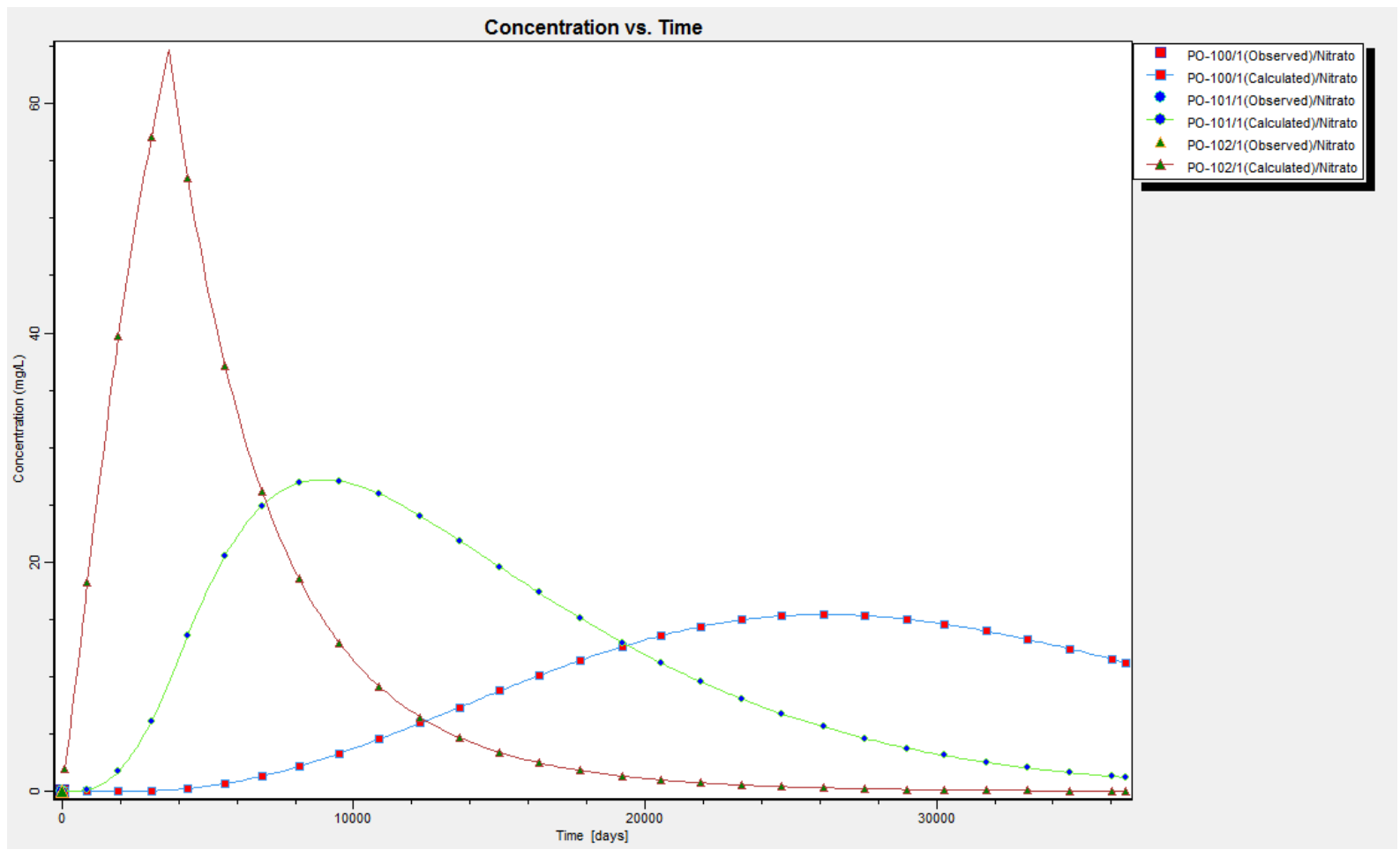

Figura 52. Simulação 6 - Concentração x tempo

\section{Simulação 7}

No sétimo cenário buscou-se avaliar a porcentagem de nitrato que atingiria a porção inferior do aquífero livre em relação ao tempo, com o bombeamento dos poços e sem a ação da dispersão do contaminante na zona saturada, considerando uma carga constante com concentração de $100 \mathrm{mg} / \mathrm{L}$ de nitrato em toda a zona urbana na primeira camada do modelo (espessura de $35 \mathrm{~m}$ ) por um período de 10 anos. Os poços de observação inseridos para Simulação 1 também foram considerados. 
Os resultados dessa simulação indicaram que a porção rasa do aquífero (segunda camada do modelo) apresentará uma concentração máxima de $84 \%$ em 10 anos e de $0 \%$ em 100 anos, a porção intermediária apresentará uma concentração máxima de 41 \% em 12 anos e de $1 \%$ em 100 anos, e a porção profunda apresentará uma concentração máxima de $11 \%$ em 29 anos e de $1 \%$ em 100 anos (Figura 53).

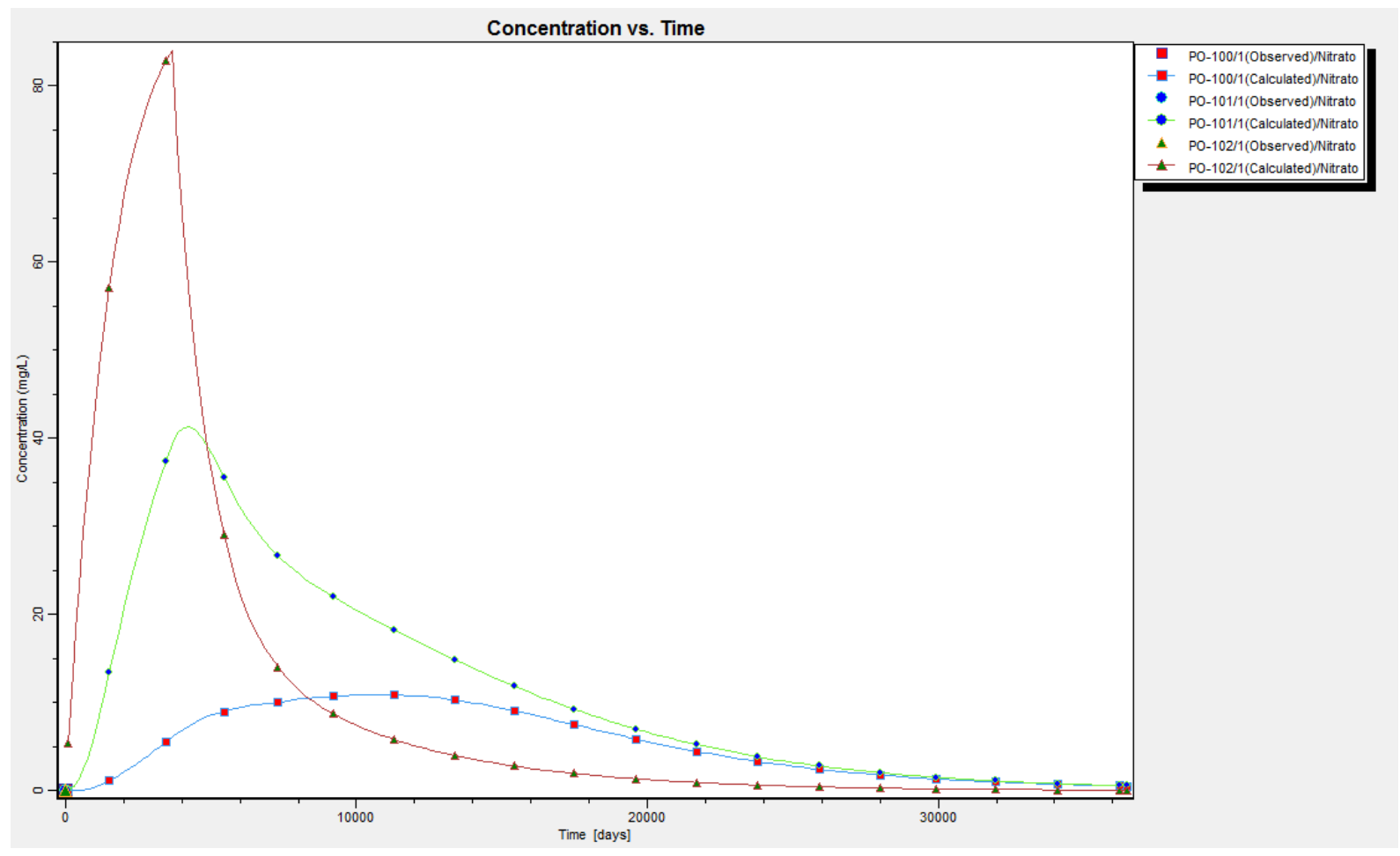

Figura 53. Simulação 7 - Concentração $x$ tempo

A evolução da contaminação no aquífero com o tempo pode ser verificada na Figura 51, a qual apresenta as seções para os tempos de 1, 10, 20, 40, 60, 80 e 100 anos, na linha 34 do modelo matemático. Verifica-se que após a interrupção da fonte constante de contaminação (10 anos) ocorre uma redução significativa das concentrações de nitrato até seu quase desaparecimento em 100 anos, corroborando com a informação supracitada.

Em relação à Simulação 5 , na qual não se considerou o bombeamento dos poços do município, verificou-se um maior aprofundamento da pluma de contaminação, resultando em um aumento de cerca de $20 \%$ nas concentrações verificadas nos poços de observação instalados na porção rasa e intermediária do aquífero livre (PO-102 e PO-101, respectivamente), ainda, para este último, em um menor intervalo de tempo do que o verificado na Simulação 5. 
Outro fato importante notado foi uma redução mais expressiva nas concentrações de nitrato após a interrupção da fonte de contaminação (após 10 anos) em relação à Simulação 5 .

Estes fatores devem-se ao aumento do gradiente vertical e da diluição do contaminante no aquífero livre ocasionado pela ativação dos poços de produção.

\section{$\underline{\text { Simulação } 8}$}

No oitavo cenário buscou-se avaliar a ação da dispersão na porcentagem de nitrato que atingiria a porção inferior do aquífero livre em relação ao tempo. Para tanto, utilizou-se todos os dados inseridos na Simulação 7 e adiciou-se os valores de dispersão determinados para a Simulação 2a. Os poços de observação inseridos para Simulação 1 também foram considerados.

Os resultados desta simulação indicaram que a porção rasa do aquífero apresentará uma concentração máxima de $84 \%$ da concentração inicial em 10 anos e de $0 \%$ em 100 anos, a porção intermediária apresentará uma concentração máxima de 41 \% em 12 anos e de $1 \%$ em 100 anos, e a porção profunda apresentará uma concentração máxima de $11 \%$ em 29 anos e de $1 \%$ em 100 anos (Figura 54). Assim, como também se pode verificar na Figura 51, não há diferença entre os resultados obtidos para as Simulações 7 e 8 , mas uma vez indicando que a dispersão não altera os resultados da modelagem.

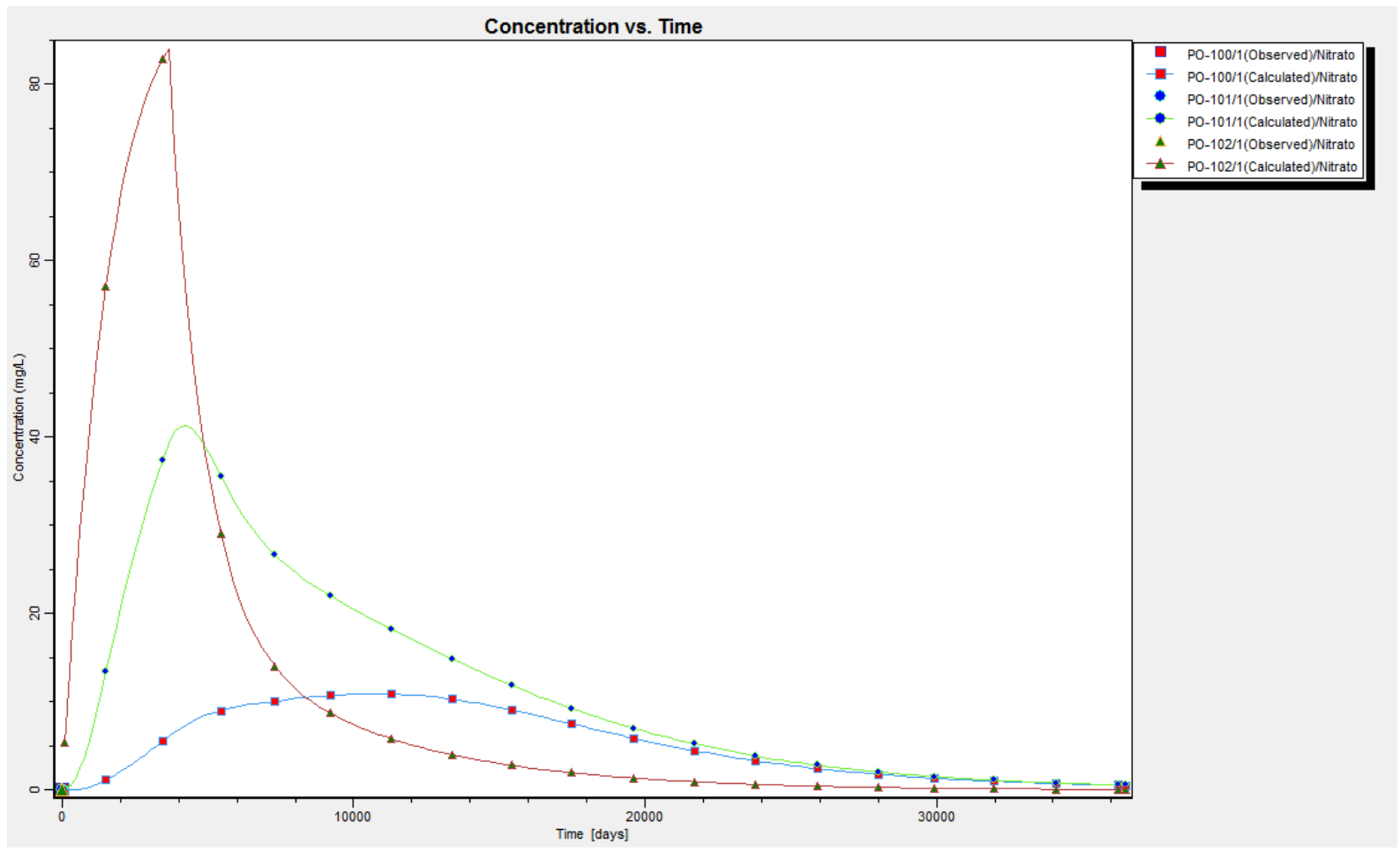

Figura 54. Simulação 8 - Concentração $x$ tempo 


\section{Simulação 9}

No nono cenário buscou-se avaliar a porcentagem de nitrato que atingiria a porção inferior do aquífero livre em relação ao tempo, sem o bombeamento dos poços de produção e sem a ação da dispersão do contaminante na zona saturada, considerando uma carga constante com concentração de $100 \mathrm{mg} / \mathrm{L}$ de nitrato advinda da lixiviação da zona não saturada em todas as células onde foram cadastradas fossas ativas e inativas por CAGNON (2003) - acima da primeira unidade hidroestratigráfica do modelo - por um período de 100 anos. Os poços de observação inseridos para Simulação 1 também foram considerados.

A Figura 55 apresenta a localização das fossas (em rosa) cadastradas por CAGNON (2003), conforme mostrado anteriormente na Figura 9.

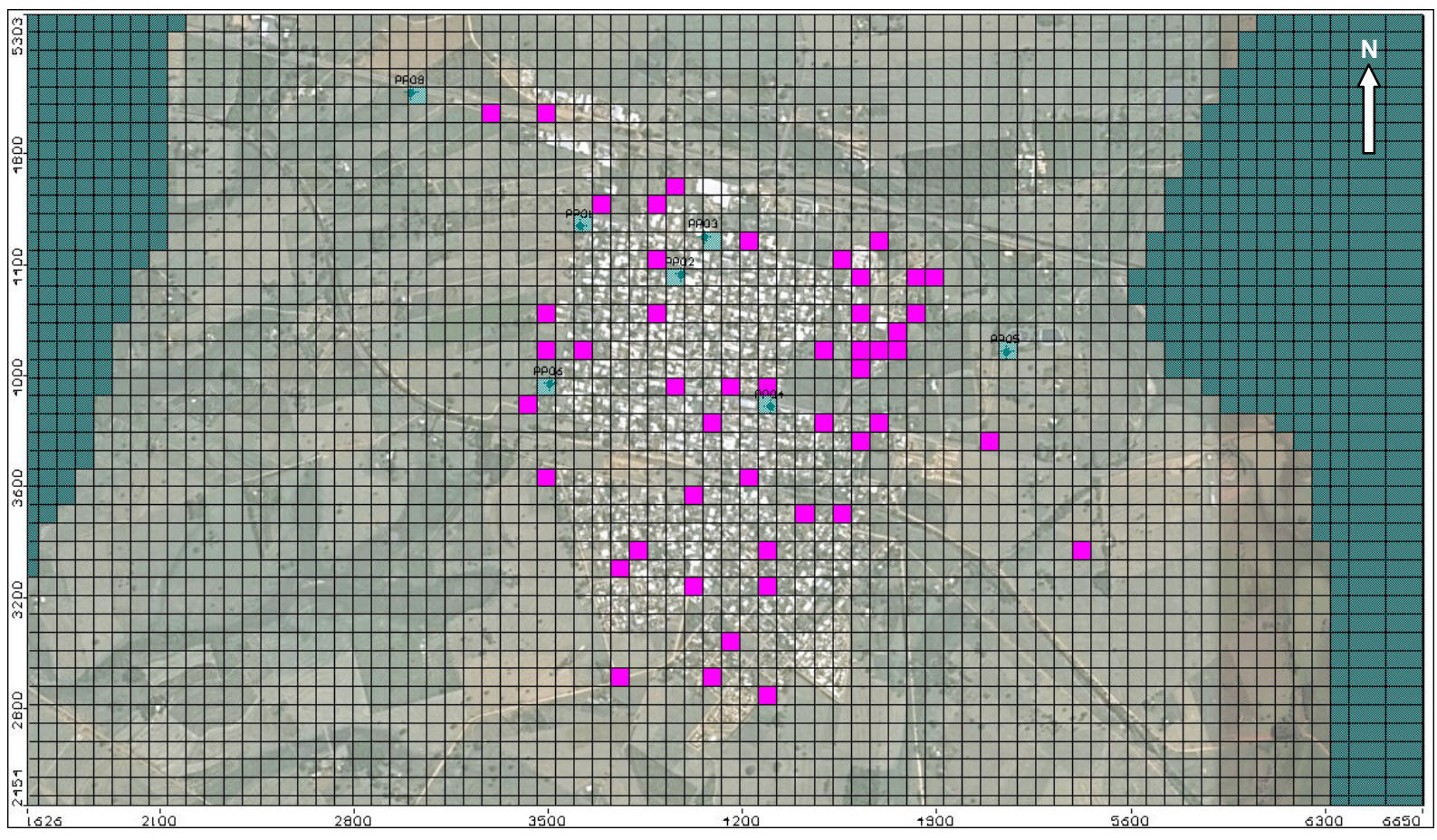

Figura 55. Localização das fossas cadastradas em Urânia - SP (em rosa)

Os resultados desta simulação indicaram que, para o período considerado, $6 \%$ da contaminação estimada para as fossas atingirá a porção profunda e $13 \%$ atingirá tanto a porção intermediária quanto a porção rasa do aquífero livre (Figura 56).

A evolução da contaminação no aquífero com o tempo pode ser verificada na Figura 57. Nela verifica-se que somente considerando as fossas ativas e inativas cadastradas no município como fontes constantes de contaminação, para o tempo avaliado não haverá incremento das concentrações de nitrato no aquífero livre em uma fração superior a $13 \%$ da contaminação inicial. 


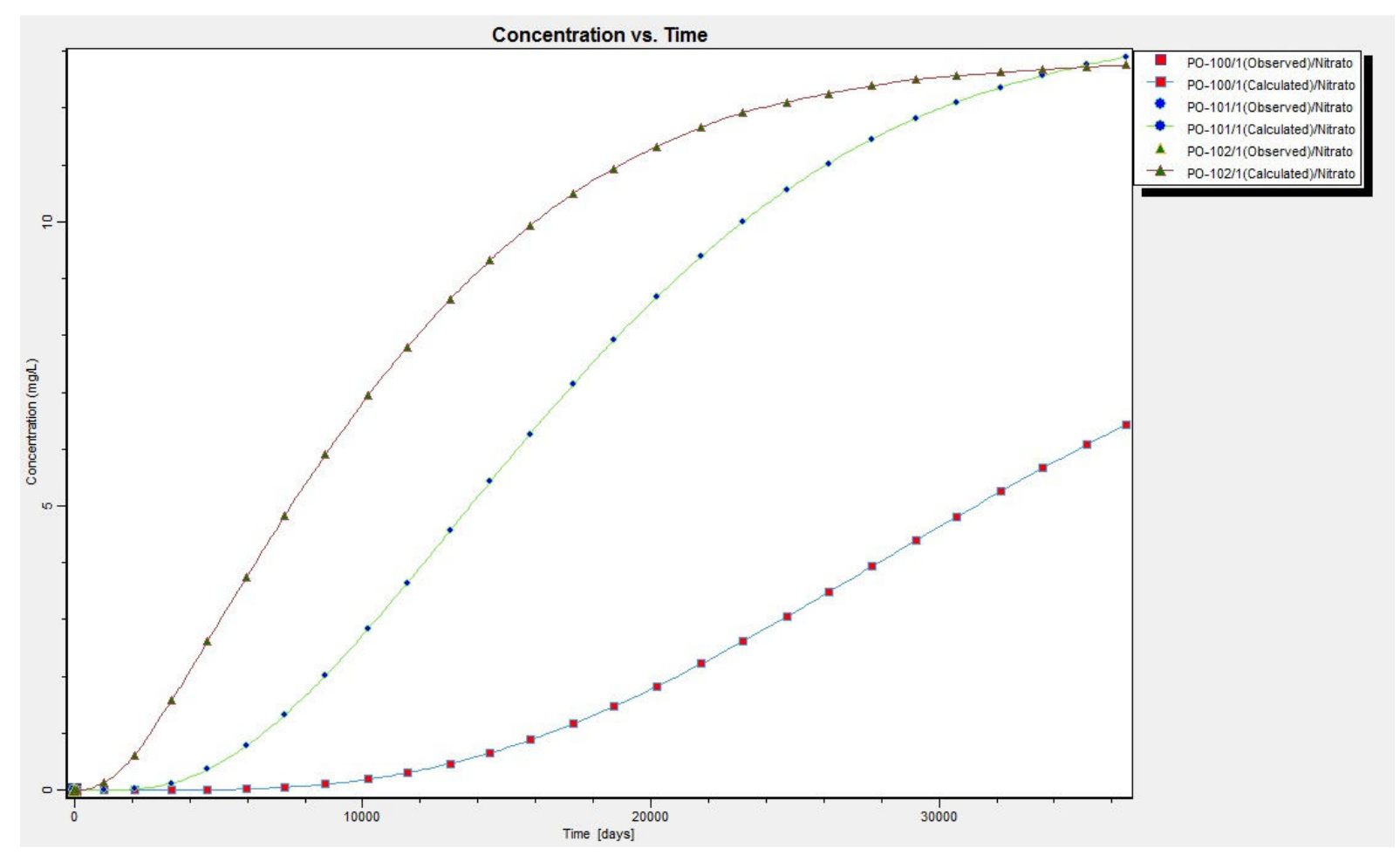

Figura 56. Simulação 9 - Concentração $x$ tempo

\section{Simulação 10}

No décimo cenário buscou-se avaliar a porcentagem de nitrato que atingiria a porção inferior do aquífero livre em relação ao tempo, se os poços de bombeamento considerados como inativos na Simulação 9, fossem ligados.

Os resultados desta simulação indicaram que, para o período considerado, $4 \%$ da contaminação estimada para as fossas atingirá a porção profunda, $6 \%$ atingirá a porção intermediária e $5 \%$ atingirá a porção rasa do aquífero livre (Figura 58). A porcentagem de nitrato que atinge a porção intermediária do aquífero livre é um pouco maior do que as demais, devido à unidade hidroestratigráfica inferior da Formação Adamantina apresentar uma maior condutividade hidráulica do que as demais unidades.

A evolução da contaminação no aquífero com o tempo pode ser verificada na Figura 57, a qual apresenta as seções para os tempos de 1, 10, 20, 40, 60, 80 e 100 anos, na linha 34 do modelo matemático. Verifica-se que somente considerando as fossas ativas e inativas cadastradas no município como fontes constantes de contaminação, e também considerando os poços de produção do município como ativos, para o tempo avaliado não haverá incremento das concentrações de nitrato no aquífero livre para valores superiores $6 \%$ da concentração inicial. 


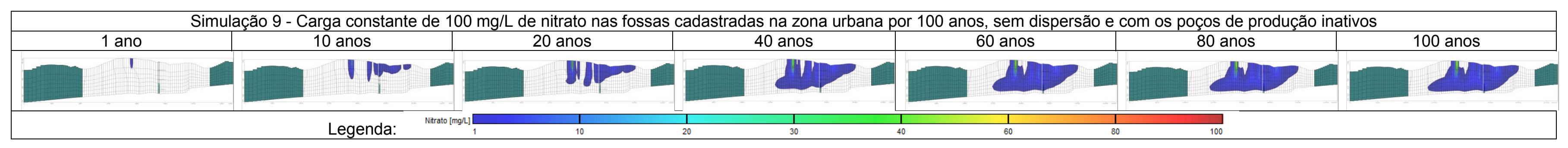

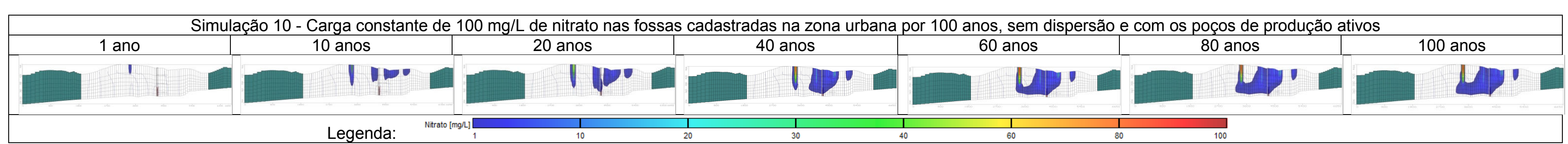
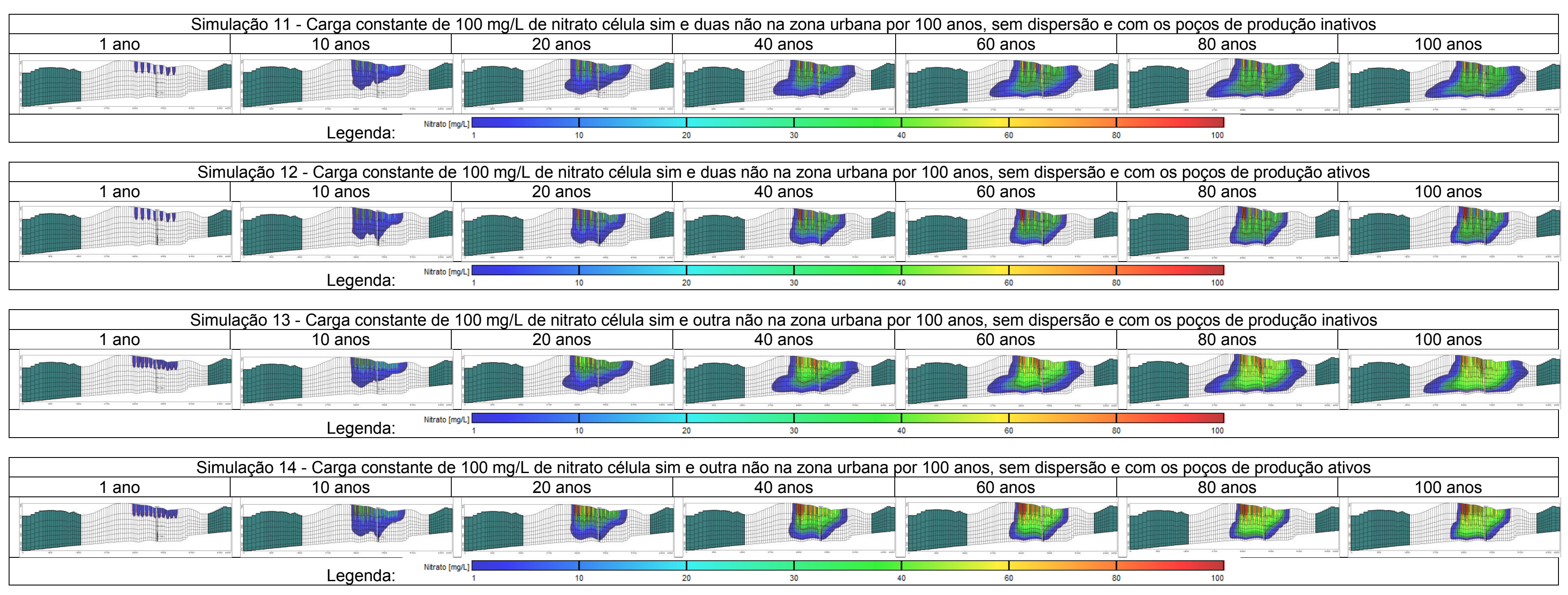

Figura 57. Resultados das simulações da contaminação por nitrato no aquífero urbano (Simulações 9 a 14) 


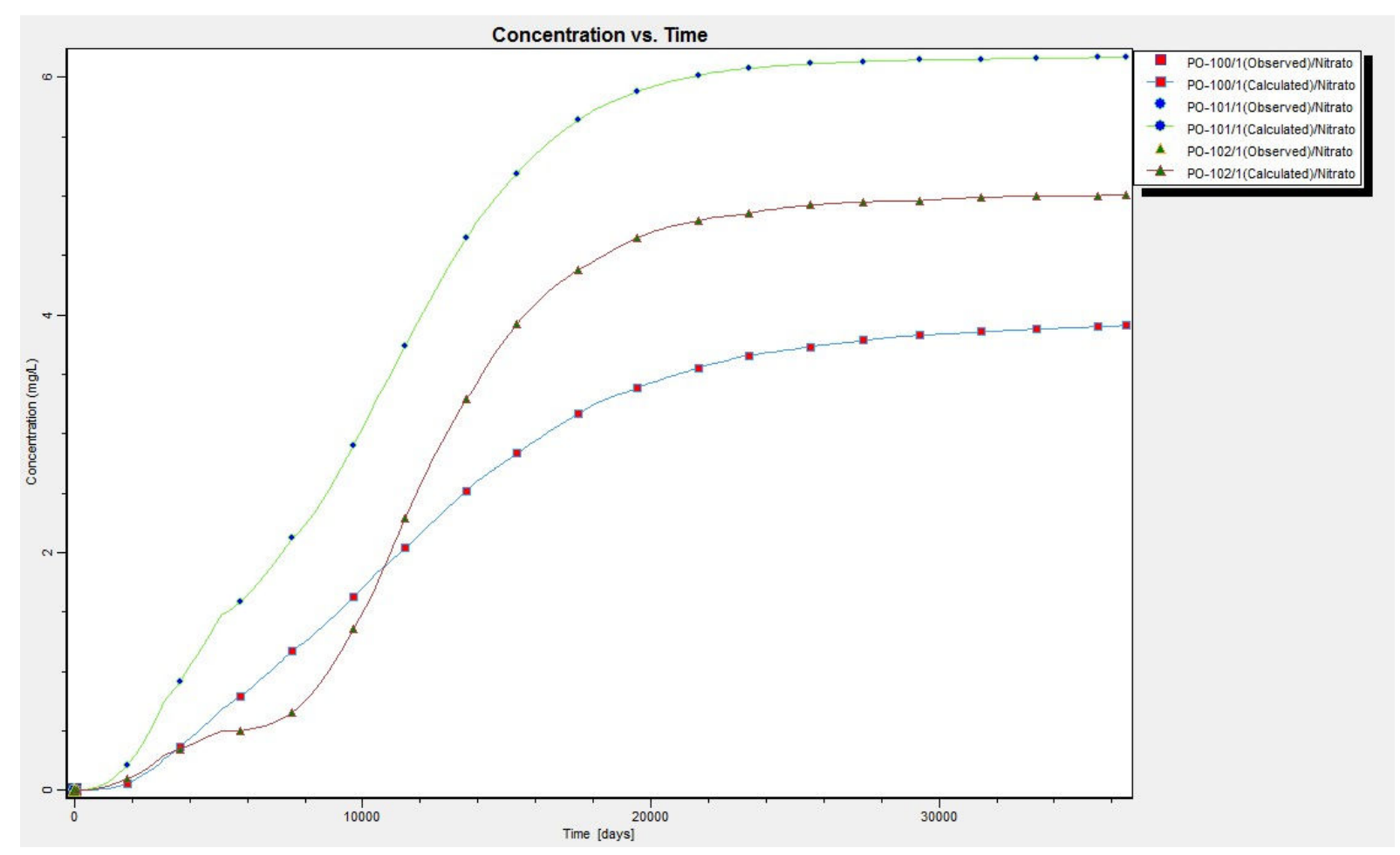

Figura 58. Simulação 10 - Concentração $x$ tempo

\section{$\underline{\text { Simulação } 11}$}

No décimo primeiro cenário foi avaliada a porcentagem de nitrato que atingiria a porção inferior do aquífero livre em relação ao tempo, sem o bombeamento dos poços de produção e sem introdução da dispersão no modelo, considerando uma carga constante com concentração de $100 \mathrm{mg} / \mathrm{L}$ de nitrato em áreas de $65 \mathrm{~m} \times 65 \mathrm{~m}$ espaçadas por áreas de $130 \mathrm{~m} \times 130 \mathrm{~m}$ (i.e. uma célula como fonte e outras duas não), advinda da lixiviação da zona não saturada na área urbana de Urânia - acima da primeira unidade hidroestratigráfica do modelo - por um período de 100 anos. Os poços de observação inseridos para Simulação 1 também foram considerados. Esse cenário foi considerado para avaliar a capacidade limite de diluição do aquífero livre. A Figura 59 apresenta a localização das áreas fontes de contaminação.

Os resultados dessa simulação indicaram que, para o período considerado, $22 \%$ da contaminação estimada para as fossas atingirá a porção profunda, $36 \%$ atingirá a porção intermediária e 33 \% atingirá a porção rasa do aquífero livre (Figura 60). A porcentagem de nitrato que atinge a porção intermediária do aquífero livre é um pouco maior do que a que atinge a porção rasa, pois a unidade hidroestratigráfica inferior da Formação Adamantina, na qual está situada a seção filtrante do poço de observação intermediário PP-101, apresenta uma maior condutividade hidráulica. 


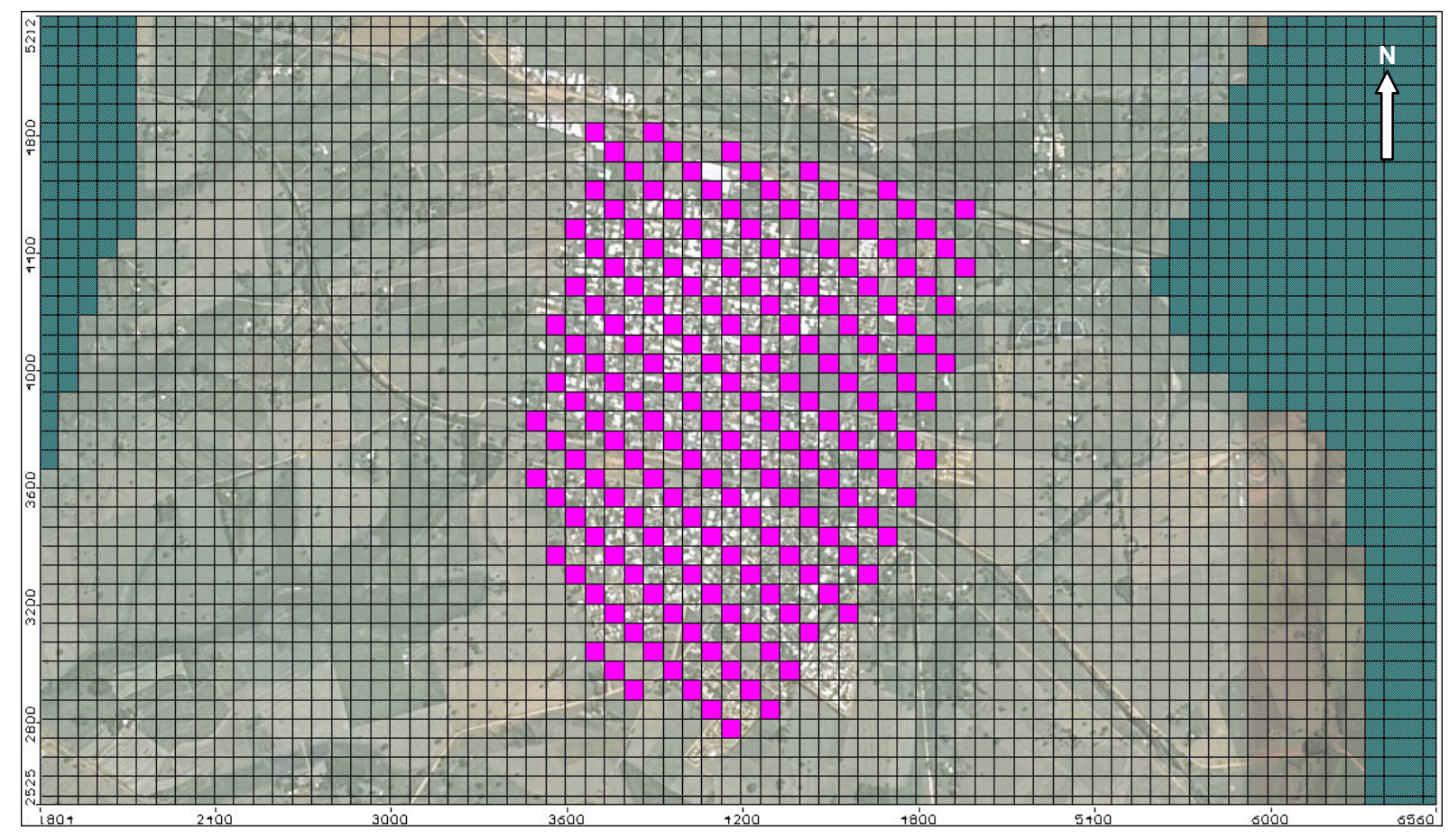

Figura 59. Fontes de contaminação em área de $65 \times 65 \mathrm{~m}$ espaçadas por áreas de $130 \times 130 \mathrm{~m}$ na zona urbana de Urânia

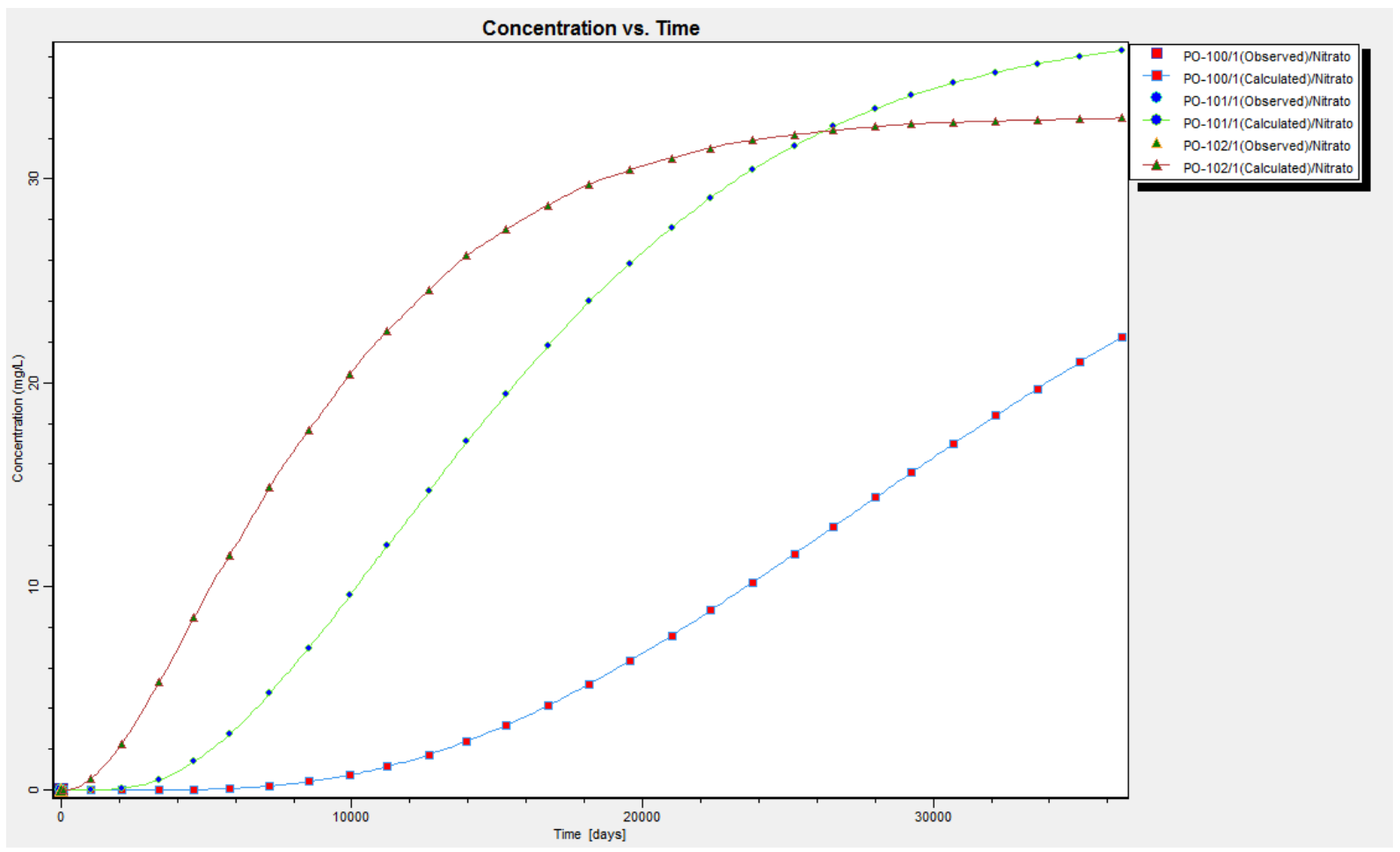

Figura 60. Simulação 11 - Concentração x tempo 
A evolução da contaminação no aquífero com o tempo pode ser verificada na Figura 57. Comparando-se os resultados obtidos nesta simulação com os obtidos na Simulação 9 , verifica-se um incremento das concentrações, na ordem de $28 \%$ para porção rasa e de $18 \%$ para a porção profunda do aquífero.

\section{Simulação 12}

Visando à avaliação do efeito do bombeamento na Simulação 11 em relação à porcentagem de nitrato que atingiria a porção inferior do aquífero livre em relação ao tempo, foram utilizados os resultados obtidos na Simulação 9, onde se considerou os poços de produção do município ativos e não se considerou a ação da dispersão. Os poços de observação inseridos para Simulação 1 também foram considerados.

Os resultados desta simulação indicaram que, para o período considerado, $17 \%$ da contaminação estimada para as fossas atingirá a porção profunda, 30 \% atingirá a porção intermediária e 31 \% atingirá a porção rasa do aquífero livre (Figura 61).

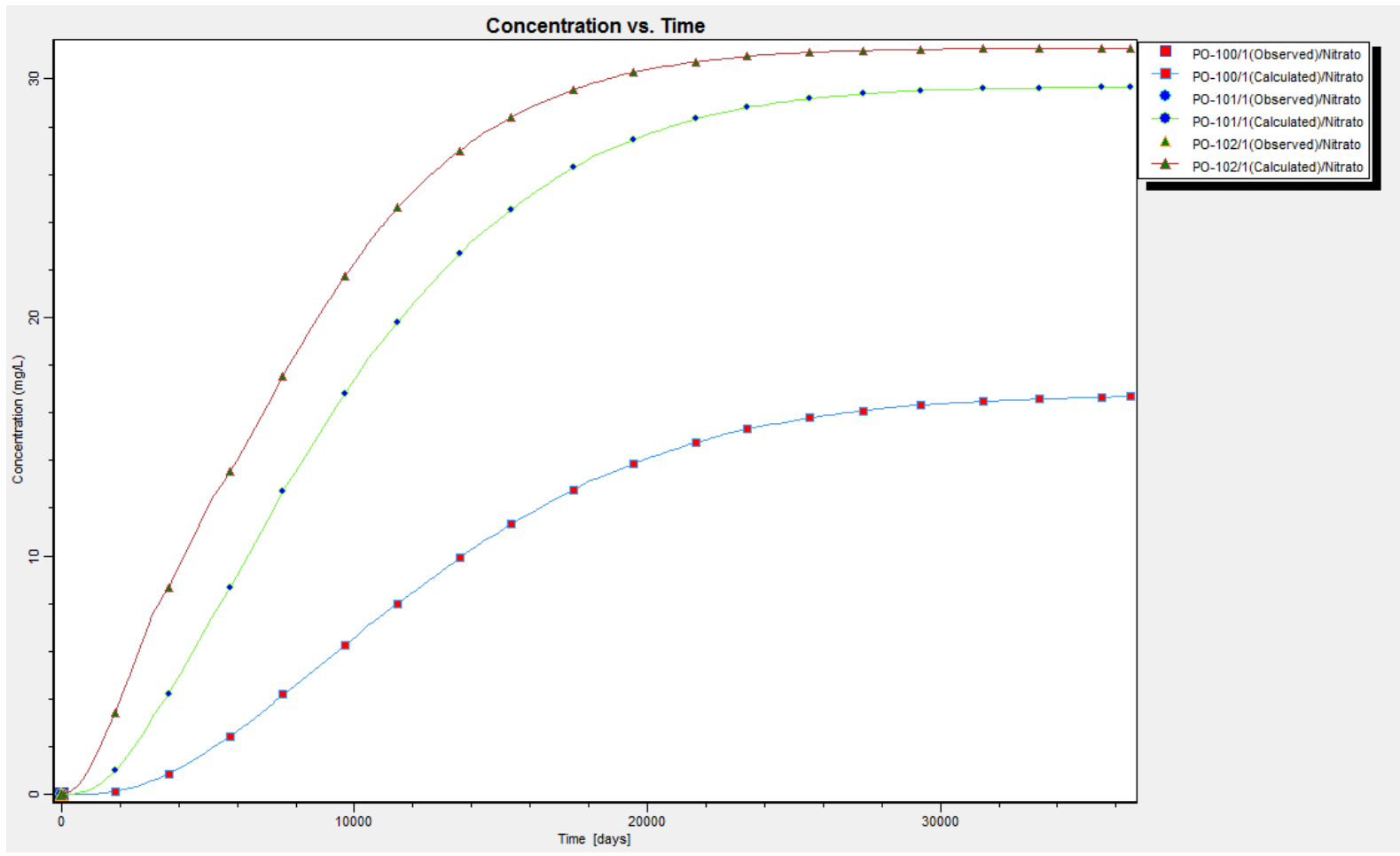

Figura 61. Simulação 12 - Concentração $x$ tempo

A evolução da contaminação no aquífero com o tempo pode ser verificada na Figura 57, na qual se verifica um incremento das concentrações nessa simulação, quando comparada com a Simulação 10. 
Em relação à Simulação 11, verifica-se uma redução de 2 a 5 \% das concentrações nos poços de observação. Embora a frente da pluma de contaminação atinja as camadas do aquífero livre em um menor intervalo de tempo, o bombeamento dos poços de produção impede uma maior dispersão dos contaminantes. Ambos os fatos devem-se ao aumento do gradiente vertical e da diluição provocado pelo bombeamento dos poços de produção.

Simulação 13

No décimo terceiro cenário buscou-se avaliar a porcentagem de nitrato que atingiria a porção inferior do aquífero livre em relação ao tempo, sem o bombeamento dos poços de produção e sem a ação da dispersão do contaminante na zona saturada, considerando uma carga constante com concentração de $100 \mathrm{mg} / \mathrm{L}$ de nitrato em uma área de $65 \mathrm{~m} \times 65 \mathrm{~m}$, espaçada por uma área de $65 \mathrm{~m}$ x $65 \mathrm{~m}$ (i.e. célula como fonte e outra não), advinda da lixiviação da zona não saturada na área urbana de Urânia - acima da primeira unidade hidroestratigráfica do modelo - por um período de 100 anos. Os poços de observação inseridos para Simulação 1 também foram considerados. Esse cenário foi considerando visando avaliar a capacidade limite de diluição do aquífero livre. A Figura 62 apresenta a localização das fontes de contaminação consideradas nessa simulação.

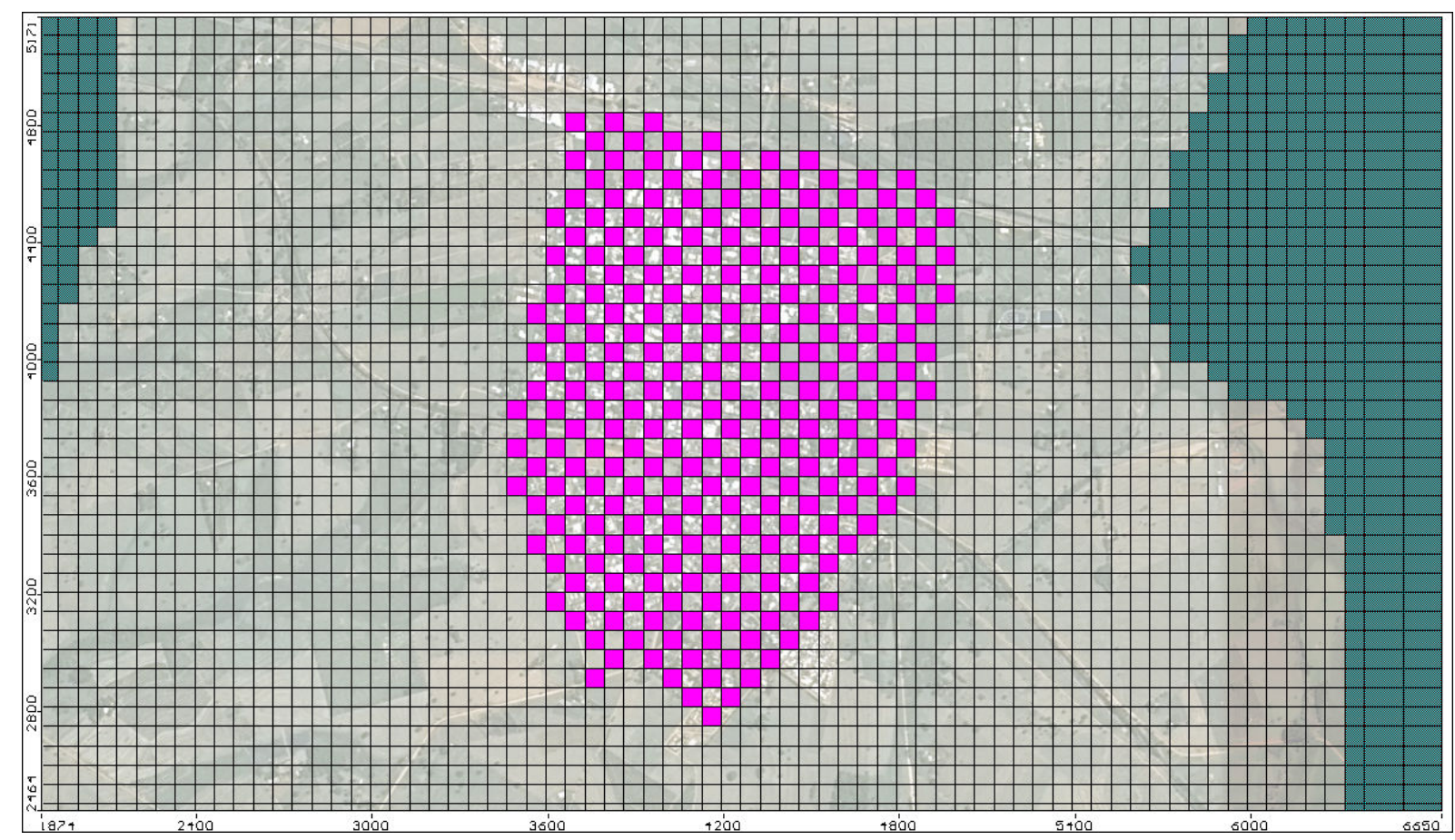

Figura 62. Fontes de contaminação em área de $65 \times 65 \mathrm{~m}$ espaçadas por áreas de $65 \times 65 \mathrm{~m}$ na zona urbana de Urânia 
Os resultados desta simulação indicaram que, para o período considerado, $31 \%$ da contaminação estimada para as fossas atingirá a porção profunda, $48 \%$ atingirá a porção intermediária e $44 \%$ atingirá a porção rasa do aquífero livre (Figura 63). A porcentagem de nitrato que atinge a porção intermediária do aquífero livre é um pouco maior do que a que atinge a porção rasa, pois a unidade hidroestratigráfica inferior da Formação Adamantina, na qual está situada a seção filtrante do poço de observação intermediário PP-101, apresenta uma maior condutividade hidráulica.

A evolução da contaminação no aquífero com o tempo pode ser verificada na Figura 57. Comparando os resultados obtidos nesta simulação com os obtidos na Simulação 11, verifica-se um incremento das concentrações na ordem de $11 \%$ para a porção rasa do aquífero e de $8 \%$ para a porção profunda.

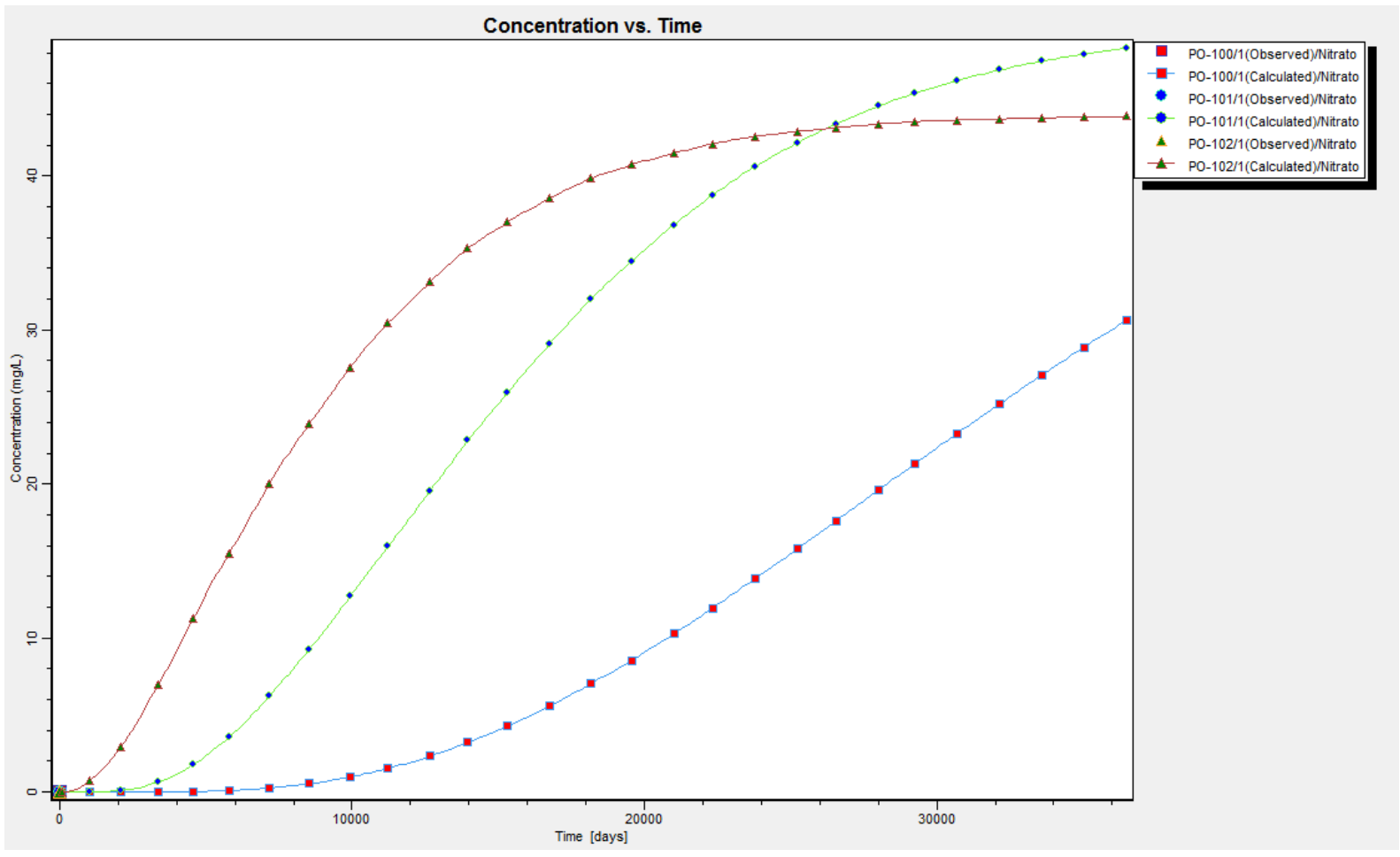

Figura 63. Simulação 13 - Concentração x tempo

\section{Simulação 14}

Visando à avaliação do efeito do bombeamento na Simulação 13 em relação à porcentagem de nitrato que atingiria a porção inferior do aquífero livre em relação ao tempo, foram utilizados os resultados obtidos na Simulação 13 e foram considerados os poços de produção do município ativos, porém a ação da dispersão não foi considerada. Os poços de observação inseridos para Simulação 1 também foram considerados. 
Os resultados desta simulação indicaram que, para o período considerado, $25 \%$ da contaminação estimada para as fossas atingirá a porção profunda, $47 \%$ atingirá a porção intermediária e $44 \%$ atingirá a porção rasa do aquífero livre (Figura 64). A porcentagem de nitrato que atinge a porção intermediária do aquífero livre é um pouco maior do que a que atinge a porção rasa, devido à unidade hidroestratigráfica inferior da Formação Adamantina apresentar uma maior condutividade hidráulica do que a unidade superior.

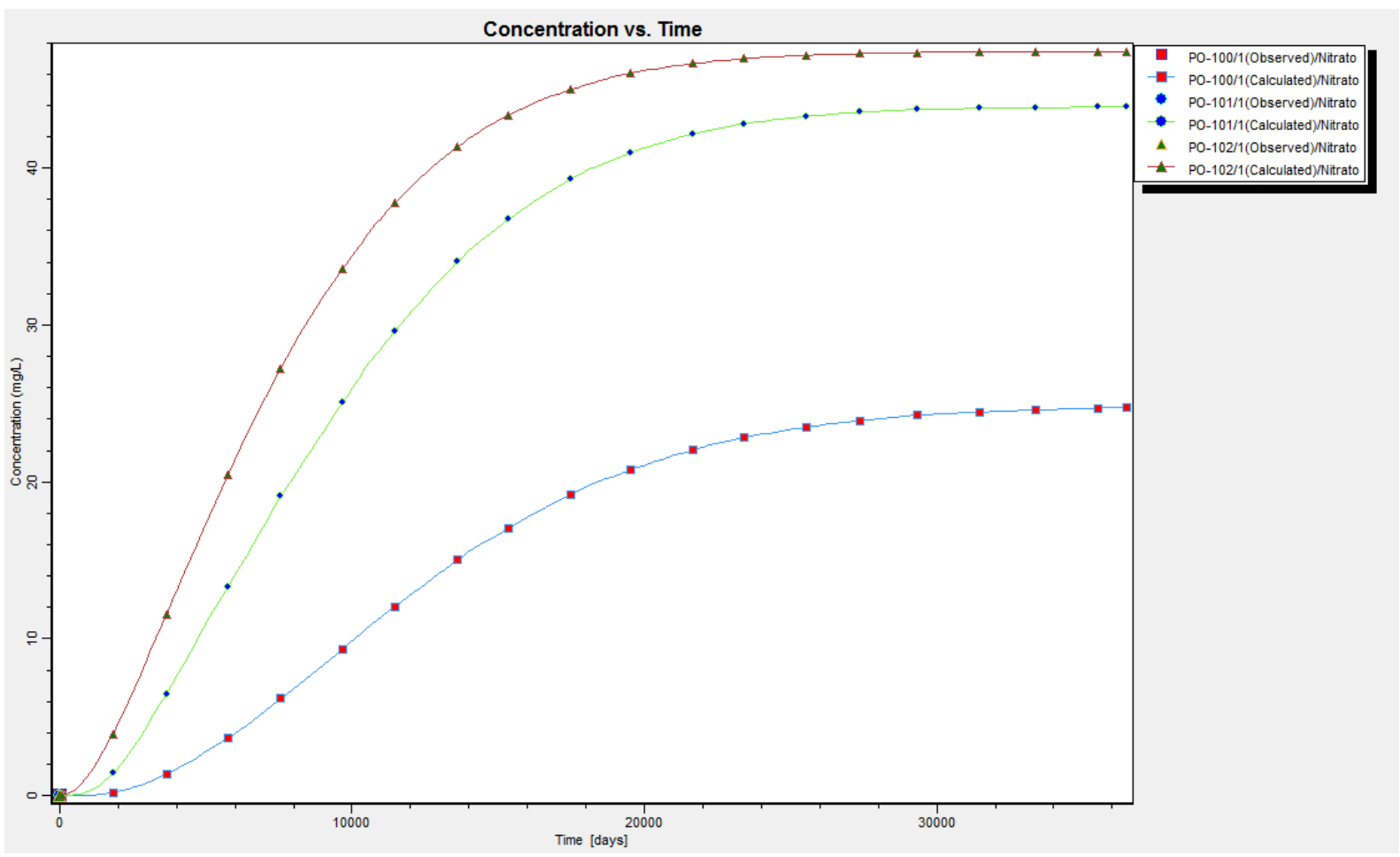

Figura 64. Simulação 14 - Concentração x tempo

A evolução da contaminação no aquífero com o tempo pode ser verificada na Figura 57. Comparando os resultados obtidos nesta simulação com os obtidos na Simulação 12 , verifica-se um incremento das concentrações de $8 \%$ para a porção profunda e de $17 \%$ para a porção intermediária do aquífero livre.

Em relação à Simulação 13, verifica-se uma redução de $1 \%$ e 6 \% das concentrações nos poços de observação com seção filtrante posicionadas na porção intermediária e profunda do aquífero livre, respectivamente. Embora a frente da pluma de contaminação atinja as camadas do aquífero livre em um menor intervalo de tempo, o bombeamento dos poços de produção impede uma maior dispersão dos contaminantes. Ambos os fatos devem-se ao aumento do gradiente vertical e da diluição provocado pelo bombeamento dos poços de produção. 


\section{Simulação 15}

No décimo quinto cenário foi avaliada a porcentagem de nitrato que atingiria a porção inferior do aquífero livre em relação ao tempo, considerando a operação de dois poços de bombeamento hipotéticos, sendo um com seção filtrante posicionada na porção rasa e outro com seção filtrante posicionada na porção profunda do aquífero livre. Uma carga constante com concentração de $100 \mathrm{mg} / \mathrm{L}$ de nitrato foi estimada para toda a zona urbana na primeira camada do modelo (espessura de $35 \mathrm{~m}$ ), por um período de 100 anos. Desse modo, os poços de produção do município e a dispersão não foram considerados.

Este cenário foi realizado visando à possibilidade de utilização da água subterrânea da porção rasa do aquífero para usos menos nobres (p.ex. lavagem de veículos) e da porção profunda para consumo humano.

O poço de bombeamento hipotético inserido na porção rasa do aquífero livre foi denominado de PP-09, sendo sua seção filtrante locada na primeira camada do modelo, representada pela unidade hidroestratigráfica superior da Formação Adamantina. O poço de bombeamento hipotético inserido na porção profunda do aquífero livre foi denominado de PP-10, sendo sua seção filtrante locada na sexta camada do modelo, representada pela unidade hidroestratigráfica inferior da Formação Adamantina.

A vazão estimada para os dois poços de bombeamento foi de $200 \mathrm{~m}^{3} /$ dia, e o tempo de operação de ambos foi de 24 horas por dia durante 100 anos. Estes poços foram inseridos na linha 34 do modelo matemático.

Para avaliar a evolução da contaminação foram inseridos seis poços de observação (PO-100 a PO-105). Três deles (PO-102 a PO-100) foram inseridos em uma mesma célula do modelo, junto ao PP-09, com posicionamento da seção filtrante em diferentes profundidades do aquífero: rasa; intermediária; profunda, respectivamente. Os outros três (PO-105 a PO-103) foram inseridos em uma mesma célula do modelo, junto ao PP-10, com posicionamento da seção filtrante em diferentes profundidades do aquífero: rasa; intermediária; profunda, respectivamente. A Figura 65 apresenta a disposição destes poços no modelo (as células em vermelho indicam que os poços de bombeamento estão ativos).

Os poços de observação inseridos na porção rasa do aquífero livre (PO-102 e PO-105) possuem sua seção filtrante na unidade hidroestratigráfica superior da Formação Adamandina, na segunda camada do modelo, a $40 \mathrm{~m}$ de profundidade. Já os inseridos na porção intermediária do aquífero livre, denominados PO-101 e PO-104, possuem sua seção filtrante na unidade hidroestratigráfica inferior da Formação Adamandina, na quarta camada do modelo, a $65 \mathrm{~m}$ de profundidade. 


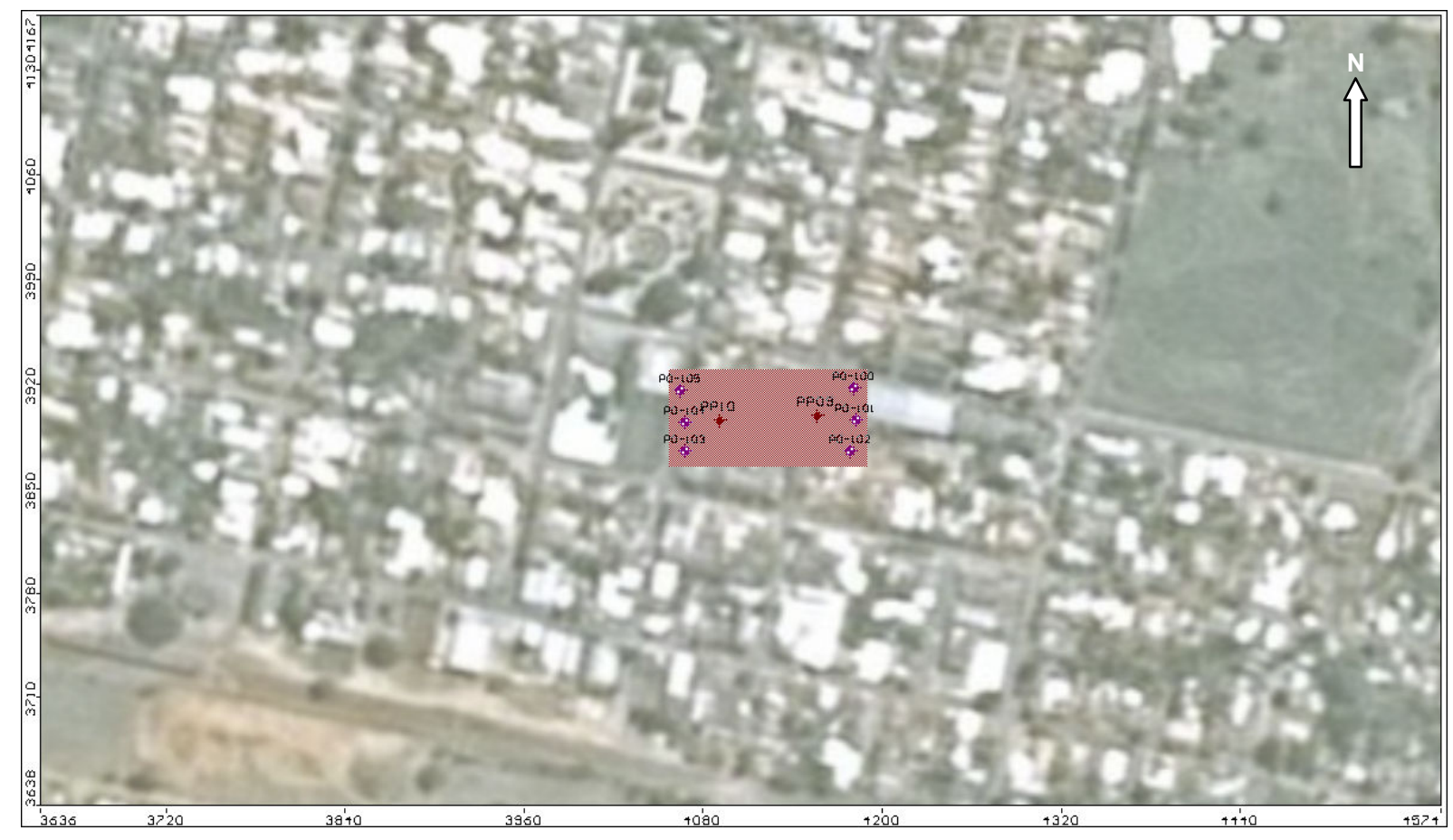

Figura 65. Localização dos poços de bombeamento e de observação hipotéticos na área urbana de Urânia (Simulação 15)

Os poços inseridos na porção profunda do aquífero livre (PO-100 e PO-105) também possuem sua seção filtrante na unidade hidroestratigráfica inferior da Formação Adamandina, porém na sexta camada do modelo, a $100 \mathrm{~m}$ de profundidade. A concentração inicial de nitrato nestes poços foi considerada como nula, ou seja, inicialmente os mesmos não estavam contaminados.

Os resultados dessa simulação indicaram que, para o período considerado, entre 64 e $79 \%$ da contaminação estimada para a zona urbana na primeira camada do aquífero atingirá a porção profunda (PO-100 e PO-103, respectivamente), entre 90 e 91 \% atingirá a porção intermediária (PO-101 e PO-104, respectivamente) e entre 98 e 99 \% atingirá a porção rasa do aquífero livre (PO-102 e PO-105, respectivamente) (Figura 66). A legenda da Figura 66 indica as concentrações nos poços de observação calculadas pelo modelo e as observadas. Como no modelo somente foram inseridas as concentrações iniciais nos poços, os resultados das concentrações observadas se propõem as calculadas pelo modelo.

A discrepância verificada entre as porcentagens do contaminante que atingem os poços de observação inseridos na porção profunda do aquífero livre junto aos poços de produção PP-09 e PP-10 deve-se ao bombeamento do poço com seção filtrante mais profunda (PP-10) ocasionar o aumento do gradiente vertical do aquífero, sendo este mais proeminente na célula onde o mesmo encontra-se inserido. 


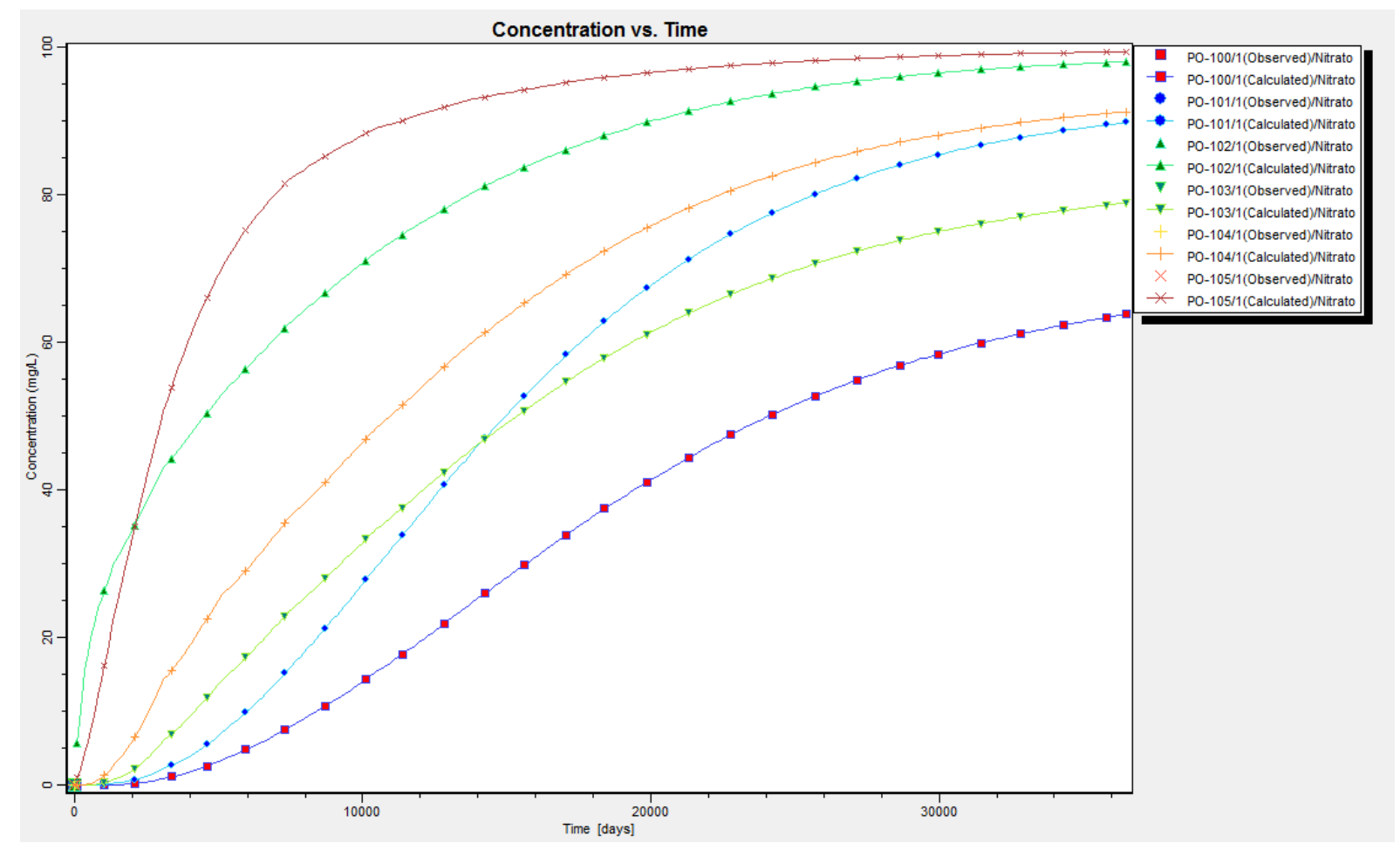

Figura 66. Simulação 15 - Concentração $x$ tempo

Verifica-se que a solução contemplada pela instalação de poços de produção na porção profunda e na porção rasa para o uso mais e menos nobre das águas do aquífero, respectivamente, é interessante, desde que as concentrações originais sejam para o nitrato inferior a $56 \mathrm{mg} / \mathrm{L}$, pois, desse modo, a capacidade de diluição de $21 \%$ do aquífero fará com que a concentração em água seja inferior a $44 \mathrm{mg} / \mathrm{L}$ de $\mathrm{NO}_{3}{ }^{-}$, ou seja, inferior ao limite de potabilidade expresso na Portaria 518 (BRASIL, 2004).

A evolução da contaminação no aquífero com o tempo pode ser verificada na Figura 67. Nela nota-se que em 10 anos as concentrações de nitrato já começam atingir a porção profunda do aquífero livre.

\section{Simulação 16}

Neste cenário utilizou inicialmente os dados obtidos na Simulação 15 para se verificar, pela técnica de tentativa e erro, quantos poços de produção na porção rasa do aquífero seriam necessários para que o contaminante não atingisse a porção profunda do aquífero livre com concentrações superiores ao padrão de potabilidade de $44 \mathrm{mg} / \mathrm{L}$ de $\mathrm{NO}_{3}$.

Todos os poços de produção hipotéticos adicionados têm vazão de $200 \mathrm{~m}^{3} / \mathrm{dia}$, e o tempo de operação dos mesmos foi de 24 horas por dia durante 100 anos. 

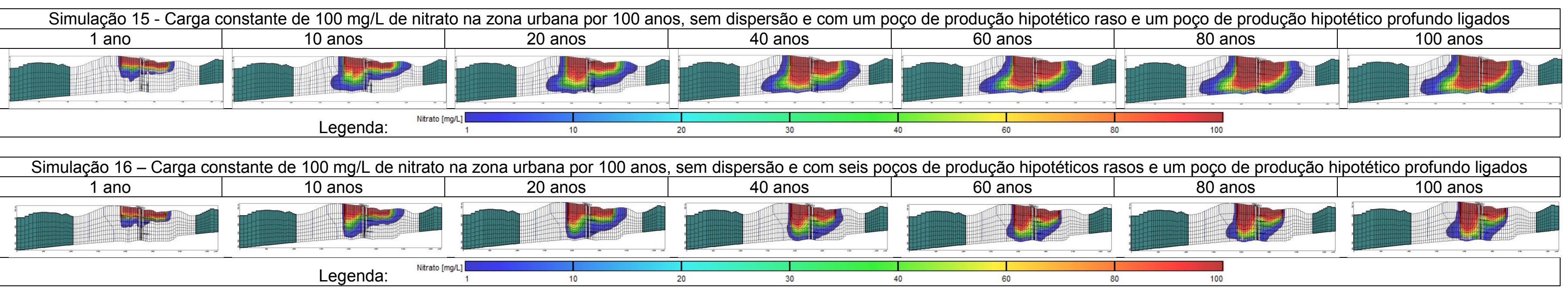

Figura 67. Resultados das simulações da contaminação por nitrato no aquífero urbano (Simulações 15 e 16) 
Como resultado, obteve-se que seriam necessários seis poços de produção na porção superior do aquífero livre (PP-09, e PP-11 a PP-15), ao redor do poço de produção inserido na porção profunda (PP-10), para que a contaminação não ultrapassasse os padrões de potabilidade na porção profunda do aquíro. A disposição destes poços no modelo está apresentada na Figura 68 e os resultados obtidos em função do tempo estão apresentados na Figura 69. A evolução da contaminação no aquífero com o tempo pode ser verificada na Figura 67.

Na Figura 67 também é possível observar que a concentração que atinge a porção profunda do aquífero com esta configuração de poços de produção é de $38 \mathrm{mg} / \mathrm{L}$, ou seja, inferior ao padrão para potabilidade para este composto.

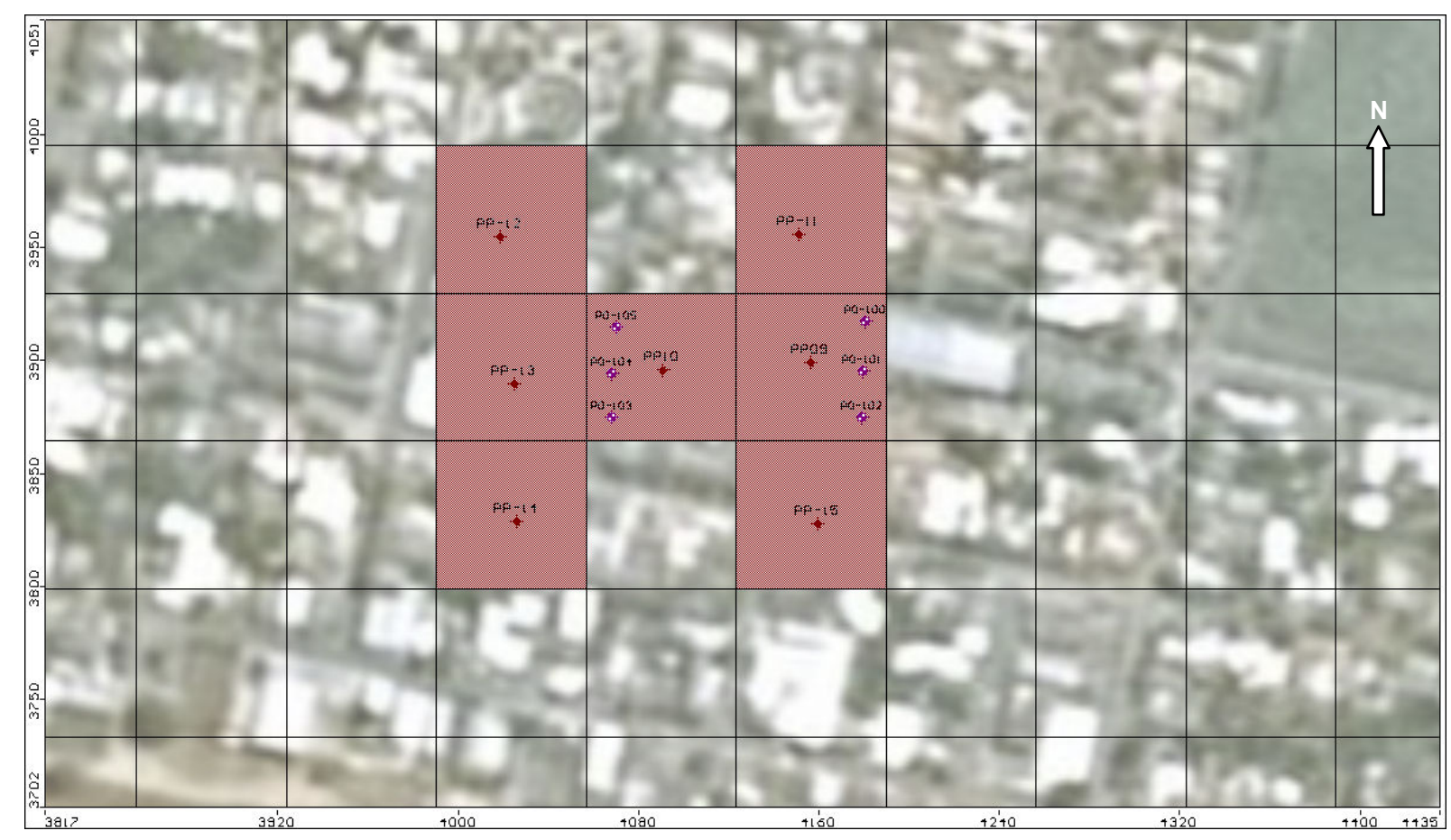

Figura 68. Localização dos poços de bombeamento e de observação hipotéticos na área urbana de Urânia (Simulação 16) 


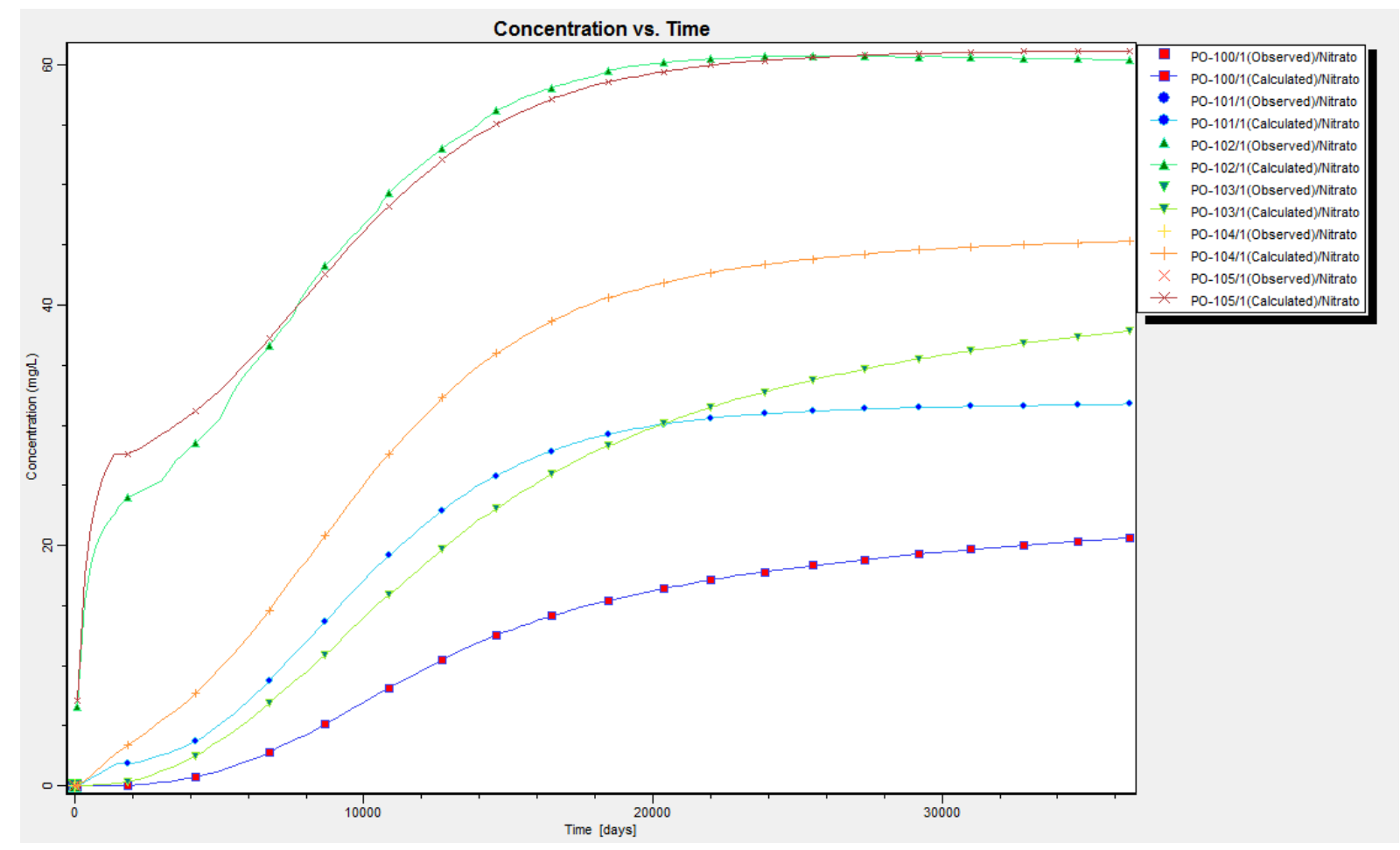

Figura 69. Simulação 16 - Concentração x tempo

Como resultado das 16 simulações executadas, nota-se que a melhor solução para o gerecianmento da contaminação de nitrato na área em estudo seria o cessamento da fonte de contaminação por meio da implantação de uma rede de esgoto $100 \%$ eficiente. Enquanto que a pior solução para o problema seria mitigar a área por meio de atenuação natural, pois, dessa forma, devido à persistência e à mobilidade do nitrato, verifica-se que a contaminação irá atingir as porções mais profundas do aquífero em um curto intervalo de tempo (inferior a 10 anos), podendo comprometer a qualidade de suas águas.

A Tabela 16 apresenta os resultados obtidos a partir das simulações. 
Tabela 16 - Resultados das 16 simulações efetuadas

\begin{tabular}{|c|c|c|c|c|c|c|c|c|c|c|c|}
\hline \multirow{2}{*}{ Simulação } & \multicolumn{6}{|c|}{ Consideração } & \multicolumn{3}{|c|}{$\%$ da Conc. de $\mathrm{NO}_{3}{ }^{-}$em 100 anos } & \multirow{2}{*}{ Principal resultado } & \multirow{2}{*}{$\begin{array}{l}\text { Melhor / pior } \\
\text { por situação }\end{array}$} \\
\hline & A & $\mathrm{D}$ & PPI & PPA & FC & FD & PO-100 & PO-101 & PO-102 & & \\
\hline 1 & $\mathrm{x}$ & & $\mathrm{x}$ & & $\mathrm{x}$ & & 70 & 98 & 100 & $\begin{array}{l}\text { O aquifero tem capacidade de diluição de } 30 \% \text {. O contaminante atinge as } \\
\text { porçôes mais profundas do aquifero em aproximadamente } 60 \text { anos. }\end{array}$ & 1a pior \\
\hline $2 a$ & $\mathrm{x}$ & $x$ & $\mathrm{x}$ & & $\mathrm{x}$ & & 71 & 98 & 100 & \multirow{2}{*}{ A dispersão não afeta a evolução do contaminante nitrato no aquifero live. } & - \\
\hline $2 b$ & $x$ & $x$ & $x$ & & $x$ & & 71 & 98 & 100 & & - \\
\hline 3 & $\mathrm{x}$ & & & $\mathrm{x}$ & $\mathrm{x}$ & & 36 & 88 & 100 & $\begin{array}{l}\text { O aquifero tem capacidade de diluição de } 64 \% \text {. O contaminante atinge as } \\
\text { porçôes mais profundas do aquifero em aproximadamente } 20 \text { anos. }\end{array}$ & 3a pior \\
\hline $4 a$ & $x$ & $x$ & & $x$ & $x$ & & 41 & 85 & 99 & \multirow{2}{*}{ A dispersão não afeta a evolução do contaminante nitrato no aquifero live. } & - \\
\hline $4 \mathrm{~b}$ & $\mathrm{x}$ & $\mathrm{x}$ & & $x$ & $\mathrm{x}$ & & 41 & 85 & 99 & & - \\
\hline 5 & $\mathrm{x}$ & & $\mathrm{x}$ & & & $\mathrm{x}$ & 11 & 1 & 0 & $\begin{array}{l}\text { A porção rasa do aquifero se recupera em } 10 \text { anos. A porção profunda } \\
\text { permanece com uma fração de } 11 \% \text { da carga inicial após } 90 \text { anos do } \\
\text { cessamento da fonte. }\end{array}$ & $2^{\text {a }}$ melhor \\
\hline 6 & $\mathrm{x}$ & $\mathrm{x}$ & $\mathrm{x}$ & & & $\mathrm{x}$ & 11 & 1 & 0 & A dispersão não afeta a evolução do contaminante nitrato no aquifero liver. & - \\
\hline 7 & $\mathrm{x}$ & & & $\mathrm{x}$ & & $\mathrm{x}$ & 1 & 1 & 0 & $\begin{array}{l}\text { A porção rasa do aquifero se recupera em } 10 \text { anos. As porções intermediária } \\
\text { e profunda também se recuperam, mas permanecem com uma fração de } \\
1 \% \text { da carga inicial a partir de } 70 \text { anos do cessamento da fonte. }\end{array}$ & 1a melhor \\
\hline 8 & $\mathrm{x}$ & $\mathrm{x}$ & & $\mathrm{x}$ & & $\mathrm{x}$ & 1 & 1 & 0 & A dispersão não afeta a evolução do contaminante nitrato no aquifero live. & - \\
\hline 9 & $\mathrm{x}$ & & $\mathrm{x}$ & & $\mathrm{x}$ & & 6 & 13 & 13 & \multirow{2}{*}{$\begin{array}{l}\text { Somente considerando as fossas cadastradas como fontes, é possivel que } \\
\text { as mesmas sejam fonte de } 100 \mathrm{mg} / \mathrm{L} \text { e o aquifero se mantenha dentro dos } \\
\text { padrões de potabilidade. }\end{array}$} & 4a melhor \\
\hline 10 & $\mathrm{x}$ & & & $\mathrm{x}$ & $\mathrm{x}$ & & 5 & 6 & 4 & & 3a melhor \\
\hline 11 & $\mathrm{x}$ & & $\mathrm{x}$ & & $\mathrm{x}$ & & 22 & 36 & 33 & \multirow{2}{*}{$\begin{array}{l}\text { Considerando fontes com concentração de } 100 \mathrm{mg} / \mathrm{L} \text { aplicadas em áreas de } \\
65 \times 65 \text { metros espaçadas por áreas de } 135 \times 135 \text { metros na zona urbana, o } \\
\text { aquifero terá capacidade de manter as concentraçôes em valores inferiores } \\
\text { ao de potabilidade. }\end{array}$} & - \\
\hline 12 & $\mathrm{x}$ & & & $\mathrm{x}$ & $\mathrm{x}$ & & 17 & 30 & 31 & & - \\
\hline 13 & $\mathrm{x}$ & & $\mathrm{x}$ & & $\mathrm{x}$ & & 31 & 48 & 44 & $\begin{array}{l}\text { Considerando fontes com concentração de } 100 \mathrm{mg} / \mathrm{L} \text { aplicadas em áreas de } \\
65 \times 65 \text { metros espaçadas por áreas de } 65 \times 65 \text { metros na zona urbana, o } \\
\text { aquifero não terá capacidade de manter as concentrações em valores } \\
\text { inferiores ao de potabilidade. }\end{array}$ & - \\
\hline 14 & $\mathrm{x}$ & & & $\mathrm{x}$ & $\mathrm{x}$ & & 17 & 30 & 31 & $\begin{array}{l}\text { Com o bombeamento dos poços de pordução, considerando fontes com } \\
\text { concentração de } 100 \mathrm{mg} / \mathrm{L} \text { aplicadas em áreas de } 65 \times 65 \text { metros } \\
\text { espaçadas por áreas de } 65 \times 65 \text { metros na zona urbana, o aquifero terá } \\
\text { capacidade de manter as concentraçốes em valores inferiores ao de } \\
\text { potabilidade. }\end{array}$ & - \\
\hline 15 & $\mathrm{x}$ & & & $\mathrm{x}$ & $\mathrm{x}$ & & 64 & 90 & 98 & $\begin{array}{l}\text { Considerando poços de extração na porção rasa e profunda do aquifero e } \\
\text { uma fonte de } 70 \mathrm{mg} / \mathrm{L} \text {, as concentrações no aquifero se manterão em valores } \\
\text { inferiores ao de potabilidade. }\end{array}$ & $2^{\text {a }}$ pior \\
\hline 16 & $\mathrm{x}$ & & & $\mathrm{x}$ & $\mathrm{x}$ & & 21 & 32 & 60 & $\begin{array}{l}\text { Considerando } 06 \text { poços de extração rasos e um profundo e considerando } \\
\text { uma donte constante de } 100 \mathrm{mg} / \mathrm{L} \text {, o aquifero em sua porção profunda } \\
\text { apresentará concentraçôes inferiores ao limite de potabilidade. }\end{array}$ & $4^{a}$ pior \\
\hline A - Advecção & & & & & & & & & & PPA - Poços de Produçāo Ativos. & \\
\hline D - Dispersão & & & & & & & & & & FC - Fonte Continua. & \\
\hline PPI- Poços de P & & & & & & & & & & FD - Fonte Descontinua. & \\
\hline
\end{tabular}




\section{CONCLUSÕES E RECOMENDAÇÕES}

A execução deste trabalho comprovou a viabilidade de aplicação da modelagem matemática tridimensional para a determinação da evolução da contaminação de compostos persistentes e móveis, como o nitrato, em aquíferos urbanos, auxiliando também no gerenciamento geral dos recursos hídricos subterrâneos.

O município de Urânia, situado sobre um divisor de águas subterrâneas, abrange duas microbacias. Estas estão limitadas a norte, sul-sudeste e parte sudoeste por três divisores de águas e a nordeste, leste, noroeste, oeste e parte sudoeste por córregos constatados nestes locais. Os córregos correspondem às áreas de descarga do aquífero livre local. Estes limitantes das microbacias foram selecionados como condições de contorno do modelo.

A recarga da área urbana de Urânia foi calculada em $230 \mathrm{~mm} / \mathrm{ano}$, enquanto que a da rural foi em $183 \mathrm{~mm} /$ ano. O Aquífero Adamantina pôde ser dividido em duas unidades hidroestratigráficas, uma inferior, mais permeável, e outra superior, menos permeável. Dentro destas duas unidades, as porções com cotas topográficas mais elevadas mostraramse menos permeáveis que as porções próximas aos córregos, estando condizentes com os dados bibliográficos. As rochas alteradas do aquitarde Serra Geral, consideradas como uma camada de $10 \mathrm{~m}$ de espessura correspondem à unidade hidroestatigráfica inferior do modelo. Já o basalto são do aquitarde Serra Geral foi considerado como "não fluxo", devido a sua insignificante contribuição no sistema aquífero em estudo, sendo este o limitante vertical das microbacias em estudo.

Os poços cacimba e tubulares privados cadastrados no município serviram como poços de observação para calibração do modelo matemático de fluxo das águas subterrâneas. Já os poços de bombeamento da SABESP serviram como sumidouros de água subterrânea nas simulações em que os mesmos foram considerados.

Os resultados da modelagem de fluxo permitiram identificar que o Aquífero Adamantina na área de estudo não é homogêneo e isotrópico, bem como não há contribuição de outras microbacias para as águas subterrâneas modeladas, senão das microbacias em estudo. O mapa potenciométrico elaborado pelo modelo mostrou-se condizente com o efetuado durante a criação do modelo conceitual, validando os resultados obtidos. O tempo de trânsito das águas subterrâneas entre sua área de recarga e a porção inferior do Aquífero Adamantina (120 m da superfície), sem a operação de poços de produção, é de aproximadamente 60 anos. Este tempo diminui para menos de 40 anos quando estes poços estão bombeando. 
Caso a contaminação por nitrato seja de uma fonte constante em toda a área urbana, os resultados da modelação mostram que o aquífero tem capacidade de diluir somente $30 \%$ da contaminação inicial. Considerando a construção de uma rede de esgoto totalmente eficiente, o modelo indicou que o tempo de recuperação das porções rasa e intermediária do aquífero é de 10 anos. Já na porção mais profunda, a contaminação perduraria por um período de 90 anos após o encerramento da fonte, com uma fração de $11 \%$ de sua concentração inicial, após 10 anos. Assim, conclui-se que a efetividade de estender a rede de esgoto no município em um período de 10 anos é uma medida interessante para mitigação do aquífero frente à contaminação por nitrato.

A dispersão não é um parâmetro determinante na evolução da contaminação de nitrato no aquífero em estudo, devido à inserção no modelo das anisotropias e heterogeneidades do meio físico, corroborando com as assunções verificadas por ROBERTSON et al. (1991).

A capacidade máxima de diluição do contaminante pelo aquífero na área urbana de Urânia corresponde a fontes de contaminação de até $100 \mathrm{mg} / \mathrm{L}$ de nitrato oriundas de áreas de $65 \mathrm{~m} \times 65 \mathrm{~m}$ na zona urbana do município, com um espaçamento de $130 \mathrm{~m} \times 130 \mathrm{~m}$ entre elas.

Embora para o município de Urânia essa situação seja atualmente hipotética, o acionamento dos poços de produção do município faz com que a frente de uma contaminação alcance as porções profundas do aquífero em um menor intervalo de tempo do que com os poços inativos, porém aumenta em praticamente $100 \%$ a capacidade de diluição do contaminante pelo aquífero e diminui a extensão da pluma de contaminação. Este fato deve-se ao aumento da capacidade de diluição do aquífero e do gradiente vertical proporcionado pelo bombeamento dos poços. Dessa forma, a utilização de água subterrânea por meio de poços que imprimam grandes vazões, como no caso dos poços de produção de Urânia, é uma alternativa para redução das concentrações de nitrato.

A alternativa de contenção da contaminação para porções inferiores do aquífero por meio da existência de poços de produção com seção filtrante inserida na porção rasa do aquífero, visando à utilização desta água bombeada para usos menos nobres, enquanto os poços de produção destinados ao consumo humano, cujos filtros estariam posicionados na porção profunda, permaneceriam protegidos, somente se mostrou interessante quando as concentrações originais de nitrato forem inferior a $56 \mathrm{mg} / \mathrm{L}$, pois, desse modo, a capacidade de diluição do aquífero faria com que a concentração em água da porção profunda fosse inferior ao limite de potabilidade. 
À medida que novos dados forem coletados, o modelo matemático deve ser revisado. Este aprimoramento técnico a partir de novos dados não é um processo inerente somente à modelagem matemática. Em qualquer método o processo aplicado para a proteção e o gerenciamento dos aquíferos é necessário revisar e aprimorar os resultados à medida que surgem novas informações do meio físico ou que ocorram alterações das interferências antrópicas no sistema hidrogeológico. 


\section{REFERÊNCIAS BIBLIOGRÁFICAS}

ALMODOVAR, M. L. N. (1995). Estudo da anomalia de cromo nas águas subterrâneas da região noroeste do Estado de São Paulo. São Paulo, 101 p. (Dissertação Mestrado) - Instituto de Geociências, Universidade de São Paulo.

ALMODOVAR, M. L. N. (2000). A origem natural da poluição por cromo no aquífero Adamantina, município de Urânia (SP). São Paulo, 199 p. (Tese - Doutorado) Instituto de Geociências, Universidade de São Paulo.

ANDERSON, M. P. \& WOESSNER, W. W. (1992) Applied groundwater modeling: simulation of flow and agvective transport. Academic Press. San Diego, U. S. 381 p.

BARCHA, S.F. (1980). Aspectos geológicos e províncias hidrogeológicas da Formação Bauru na região norte-ocidental do Estado de São Paulo. São José do Rio Preto, 1980. 209 p. Tese (Livre Docência) - Instituto de Biociências, Letras e Ciências Exatas, Universidade Estadual Paulista de São José do Rio Preto.

BEAR, J. (1972). Dynamics of fluids in porous media. U.S.A: American Elsevier Publishing Company, 764p.

BEAR, A.V.; VERRUIJT, A. (1987). Modeling Groundwater Flow and Pollution, Theory and Applications of Transport in Porous Media; D. Reidel Publishing Co. Boston, MA.

BERTOLO, R. A.; HIRATA, R. (2000). Monitoramento da zona não saturada: um estudo da hidráulica e hidroquímica na estação experimental de Urânia, São Paulo, Brasil. In: CONGRESSO MUNDIAL INTEGRADO DE ÁGUAS SUBTERRÂNEAS, 1. Fortaleza, 2000. Anais. Fortaleza, ABAS. (CD-ROM).

BERTOLO, R. A. (2001). Hidrodinâmica e hidrogeoquímica da zona não saturada do aquífero Adamantina em Urânia (SP). São Paulo, 218p. (Tese-Doutorado) -Instituto de Geociências, Universidade de São Paulo.

BERTOLO, R. A.; HIRATA, R.; SRACEK, O. (2006). Geochemistry and geochemical modeling of unsatured zone in a tropical region in Urânia, São Paulo State, Brazil. Journal of Hidrology, v. 329, p- 49-62.

BRASIL - MINISTÉRIO DA SAÚDE (2004) Portaria n¹518 Controle e Vigilância da Qualidade da Água para Consumo Humano e seu Padrão de Potabilidade. Brasil, $32 \mathrm{p}$. 
CAGNON, F. A. (2003). Origem e hidroquímica do nitrato nas águas subterrâneas do aquífero Adamantina em Urânia, SP. 148 p. (Dissertação de Mestrado) - Instituto de Geociências da Universidade de São Paulo.

CAMPOS, H. C. N. S.; HIRATA, R. A.; ROCHA, G.; MISTRETA, G. (1994). Origem e ocorrência de nitrato nos aquíferos do Estado de São Paulo, Brasil. In: CONGRESSO LATINOAMERICANO DE HIDROGEOLOGIA SUBTERRÂNEA. Santiago, Alhsud. 1994. Anais. Santiago, ALHSUD. 20 p.

CAMPOS, H. C. N. S. (1987). Contribuição do estudo hidrogeoquímico do Grupo Bauru no Estado de São Paulo. São Paulo, 158 p. (Dissertação - Mestrado) - Instituto de Geociências da Universidade de São Paulo.

CANTER, L. W. (1997). Nitrates in Groundwater. Boca Raton, Lewis Publication. 263 p.

CANTER, L. W.; KNOX, R. C. (1988). Septic tank system effects on ground water quality. $3^{\text {a }}$ ed. Michigan, Lewis Publishers. $336 \mathrm{p}$.

CESARINO, A. (2002). Seleção de materiais para remediação de aquíferos contaminados por nitrato através de barreiras reativas. São Paulo, 88 p. (Dissertação - Mestrado) - Instituto de Geociências da Universidade de São Paulo.

CHIESSI, C. M. (2000). Estudo Hidrogeoquímico da zona não saturada do Aquífero Adamantina. São Paulo. Iniciação Científica - Instituto de Geociências da Universidade de São Paulo, Fundação de Amparo à Pesquisa do Estado de São Paulo.

CLEARY, R. W. (1989). Hidrologia de águas subterrâneas. In: RAMOS et al. 1989. Engenharia hidrológica. ABRH e Ed. UFRJ. Rio de Janeiro. p. 293-404.

CLEARY, R. W. (1991). Qualidade das águas subterrâneas. In: PORTO et al. 1991. Hidrologia Ambiental. ABRH e EDUSP. São Paulo. p. 211-293.

COMPANHIA DE TECNOLOGIA DE SANEAMENTO AMBIENTAL - CETESB. (2010). Disponível em http://www.cetesb.sp.gov.br/ Acesso em 18 de julho de 2010.

DEPARTAMENTO DE ÁGUAS E ENERGIA DO ESTADO DE SÃO PAULO - DAEE (1976). Estudo de águas subterrâneas; regiões administrativas 7, 8 e 9 (Bauru, São José do Rio Preto e Araçatuba). São Paulo, ENCO. 4v.

DEPARTAMENTO DE ÁGUAS E ENERGIA ELÉTRICA - DAEE. (1979). Estudo de águas subterrâneas, regiões administrativas 10 e 11: Presidente Prudente e Marília. São Paulo: v.1 e v.2, 1979.

DOMENICO, P.A; SCHWARTZ (1998) Physical and Chemical Hydrogeology. John Wiley and Sons Inc., New York, EUA, $2^{\mathrm{a}}$ ed. 506 p. 
ELBACHÁ, A.T. (1989). Estudo da Influência de Alguns Parâmetros no Transporte de Massa em Solos Argilosos. Rio de Janeiro, 1989.178 p. Dissertação (Mestrado em Engenharia Civil) - Departamento de Engenharia Civil, PUC-RIO.

EMBRAPA / IAC (1999). Mapa Pedológico do Estado de São Paulo. Escala: 1:500.000. São Paulo.

FERNANDES, L. A. (1998). Estratigrafia e evolução geológica da parte oriental da Bacia Bauru (Ks, Brasil). São Paulo, 1998. 216 p. Tese (Doutorado em Geociências) Instituto de Geociências, Universidade de São Paulo.

FERREIRA, L; HIRATA, R. (1993). Determinação dos riscos de contaminação das águas subterrâneas por sistemas de saneamento in situ. Estudo de caso: município de Campinas. In: SIMPÓSIO BRASILEIRO DE RECURSOS HÍDRICOS, 10., Gramado., 1993./4na/s. Gramado, IPH/ABRH, n. 4, p.443-452.

FERREIRA, L. M. R. (1999). A prática de Disposição de Efluentes Domiciliares "in situ" e os Impactos nas Águas Subterrâneas. Estudo de Caso no Município de Campinas. São Paulo, 136 p. (Dissertação - Mestrado) - Instituto de Geociências da Universidade de São Paulo.

FETTER, C. W. (1988). Applied Hydrogeology. Merril Publishing Company, EUA, $2^{\mathrm{a}}$ ed. $592 \mathrm{p}$.

FOSTER, S. S. D.; VENTURA, M.; HIRATA, R. (1987). Groundwater pollution: an executive overview of Latin America - Caribbean situation in relation to potable water-supply. CEPISTech. Report (WHO-PAHO-CEPIS). Lima, Peru.

FOSTER, S. S. D.; HIRATA, R. (1988). Determination del risco del contamination de aguas subterráneas: uma metodologia basada en datos existentes. $2^{a}$ ed. Peru., Centro Panamericano de Ingenieria Sanitária y Ciências del Ambiente -CEPIS-PAHOMHO. $81 \mathrm{p}$.

FREEZE, R.A.; CHERRY, J.A. (1979). Groundwater. New Jersey: Prentice-Hall, 1979. $604 \mathrm{p}$.

GUIGUER, N.; FRANZ, T. (1996). Visual MODFLOW. User's Manual. WHI, Waterloo, Canadá. $231 \mathrm{p}$.

GUTIERREZ, A. S. (1999): A Hidroquímica do Sistema Aquífero Bauru na cidade de Urânia SP. São Paulo, 45 p. (Projeto de iniciação científica) - Instituto de Geociências da Universidade de São Paulo, Fundação de Amparo à Pesquisa do Estado de São Paulo. 
GUTIERREZ, A. S. (2003): Modelo hidrogeoquímico do aquífero Adamantina em Urânia - SP. São Paulo, 130 p. (Dissertação de Mestrado) - Instituto de Geociências da Universidade de São Paulo.

HIRATA, R. (1994). Fundamentos e estratégias de proteção e controle da qualidade das águas subterrâneas: estudo de casos no Estado de São Paulo. 195 p. (Tese de Doutoramento) Instituto de Geociências da Universidade de São Paulo.

HIRATA, R.; BASTOS, C.; ROCHA, G. (1997). Mapeamento da vulnerabilidade das águas subterrâneas no Estado de São Paulo. São Paulo, Secretaria do Meio Ambiente do Estado de São Paulo. 95p.

HIRATA, R. (2000a). A origem da poluição por cromo no Aquífero Adamantina, município de Urânia (SP). São Paulo, FAPESP/IGc-USP. 333p. (Relatório final-Processo $\mathrm{n}^{\circ}$ 97/13879-6).

HIRATA, R. (2000b). Estudo da contaminação por nitrato no Distrito de Tibiriçá, Bauru. São Paulo, DAE/IGc-USP. 2v. (Relatório técnico).

HIRATA, R. (2000c). Nitrogênio nas águas subterrâneas: fontes antrópicas, comportamento hidrogeoquímico e manejo. São Paulo, FAPESP/IGc-USP. 150p. (Relatório final Processo $n^{\circ}$ 97/6950-6).

HIRATA, R.; RODOLFI, G. (1993). Presença de cromo nas águas subterrâneas em Urânia. São Paulo, Secretaria de Meio Ambiente - Instituto Geológico. (Relatório técnico). $24 \mathrm{p}$.

HIRATA, R.; CAGNON, F. A. (2004). Source of nitrate in the groundwater of Adamantina aquifer in Urânia, SP - Brazil. In: XXXIII IAH Congress / VII ALHSUD, 2004, Zacatecas City, 2004.

INSTITUTO BRASILEIRO DE GEOGRAFIA E ESTATÍSTICA - IBGE (2002). Pesquisa Nacional de Saneamento Básico - 2000. Rio de Janeiro, Brasil. 397 p.

INSTITUTO BRASILEIRO DE GEOGRAFIA E ESTATÍSTICA (2000). Censo demográfico do Brasil. http:Ilwww.ibge.gov.

INSTITUTO GEOGRÁFICO E GEOLÓGICO DE SÃO PAULO - IGGSP (1966a) Mapa Topográfico: Região sul do Brasil 1:50000, folha Santa Albertina.

INSTITUTO GEOGRÁFICO E GEOLÓGICO DE SÃO PAULO - IGGSP (1966b) Mapa Topográfico: Região sul do Brasil 1:50000, folha Jales. 
INSTITUTO GEOGRÁFICO E CARTOGRÁFICO - DEPARTAMENTO DE ÁGUAS E ENERGIA DO ESTADO DE SÃO PAULO (1996). Plano estadual de recursos hídricos/Plano Cartográfico do Estado de São Paulo. Unidades Hidrográficas De Gerenciamento de Recursos Hídricos do Estado de São Paulo. Mapa 1:100000.

INSTITUTO DE PESQUISAS TECNOLÓGICAS DO ESTADO DE SÃO PAULO - IPT (1981). Mapa Geológico do Estado de São Paulo. Escala 1:500000. São Paulo, IPT. v. 2, (Monografias, 6).

IRITANI, M. A. (1998). Modelação matemática tridimensional para a proteção das captações de água subterrânea. São Paulo, 200 p. (Dissertação de Mestrado) - Instituto de Geociências da Universidade de São Paulo.

KONIKOW, L. F. \& BREDEHOEFT, J. D. (1992). Ground-water models canoot be validated. Advances in Water Resources, 15 (1): 75 - 83.

LEWIS, W.; FOSTER, S.; DRASAR, B. (1982). O risco de poluição do lençol freático por sistemas de disposição local de esgotos. Local, MDU, PNUMA. 92 p.

MARQUES, J. P. P. (2000). Os mecanismos controladores da partição do Cromo no sistema rocha-solo-água no Aquífero Bauru, Noroeste do Estado de São Paulo. São Paulo, Orientação de outra natureza - Instituto de Geociências da Universidade de São Paulo, Fundação de Amparo à Pesquisa do Estado de São Paulo.

MCDONALD, M. G. \& HARBAUGH, A. W. (1988). MODFLOW - A modular three-dimensional finite-difference ground-water flow model. USGS. Book 6, Chapter A1, 528 p. (Geological Survey Open File Report 83-875).

MITCHELL, J.K. (1991). Conduction phenomena: from theory to geotechnical pratice. 31st. [s.l.].: [s.n.].

NEWELL C.J.; R.K. MCLEOD \& J. R. GONZALES (1997). Bioscreen Natural Attenuation Decision Support System, User's Manual v 1.4 Groundwater Services, Inc., Houston, Texas.

NOBRE, M.M.M. (1987). Estudo experimental do transporte de poluentes em solos argilosos compactados. Rio de Janeiro, 1987. 214p. Dissertação (Mestrado em Engenharia Civil), Departamento de Engenharia Civil, PUC-RIO.

NOMMIK, H.; VAHTRAS, K. (1982). Nitrogen in Agricultural Soil. Agronomy, v. 22, p. 123-171.

PALMÉR RIVERA, M. I. (2002). A numerical model as a tool to understand groundwater circulation in Urânia (SP, Brazil). Suécia, 143 p. (Dissertação -Mestrado) - Universidade de Tecnologia de Luleå/Suécia. 
PAULA E SILVA, F.; CHANG, H.K.; CAETANO-CHANG, M.R. (2005) Hidroestratigrafia do Grupo Bauru (K) no Estado de São Paulo. Revista Águas Subterrâneas. 2005. v.19, n.2, p.19-36.

PAULA E SILVA, F. (2003) Geologia de subsuperfície e hidroestratigrafia do Grupo Bauru no Estado de São Paulo. Rio Claro, 2003. 166 p. Tese (Doutorado em Geociências) Instituto de Geociências e Ciências Exatas, Universidade Estadual Paulista.

PAULA E SILVA, F.; CHANG, H.K.; CAETANO-CHANG, M.R. (2003) Estratigrafia de subsuperfície do Grupo Bauru (K) no Estado de São Paulo. Revista Brasileira de Geociências. 2003. v. 22, N. Especial, p. 21-32, 2003.

PAULA E SILVA, F.; CAVAGUTI, N. (1994) Nova caracterização estratigráfica e tectônica do Mesozóico na Cidade de Bauru - SP. Geociências, v. 13, p. 83-99.

POLLOCK, D. W. (1989). Documentation of computer programs to compute and display pathlines using results from the U. S. Geological Survey nodular three dimensional finite-difference ground-water model. USGS, Open File Report 89-381, 81 p.

ROBERTSON, W.; CHERYY, J. A.; SUDICKY, E. A. (1991). Groundwater contamination from two small septic systems on sand aquifers. Groundwater. v. 29, n. 1, p. 82-92.

ROBERTSON, W.; CHERRY, J. (1992). Hydrogeology of an unconfined sand aquifer and its effect on the behavior of nitrogen from a large-flux septic system. Apply Hydrogeology, v. 1, p.32-44.

ROBINSON, R.A.; STOKES, R.H. (1965). Eletrolyte solutions, 2nd ed. London: [s.n.].

ROCHA, G. A.; BERTACHINI, C. A.; CAMPOS, H. C. N. S.; CAIXETA, J. B. (1982). Tentativa de zoneamento das características hidráulicas e hidroquímicas do Aquífero Bauru. In: ENCONTRO DE GEOLOGIA E HIDROGEOLOGIA DO GRUPO BAURU NO ESTADO DE SÃO PAULO, 1., São Paulo, 1981. São Paulo, SBG - Núcleo São Paulo/ABAS, p. 37-57.

ROSS, J. L. S.; MOROZ, I. C. (1997). Mapa Geomorfológico do Estado de São Paulo. Escala 1:500 000. São Paulo. Laboratório de Geomorfologia. Departamento de Geografia - FFLCH - USP/ Laboratório de Cartografia Geotécnica - IPT/ FAPESP. v. 2.

ROSSATO, F. (1999). Modelação Matemática Bidimensional na Definição de Zonas de Captura de Poços no Aquífero Adamantina, Município de Urânia, Noroeste do Estado de São Paulo. São Paulo, 40 p. (Trabalho de Formatura). Instituto de Geociências, Universidade de São Paulo. 
SABESP - Companhia de saneamento básico do estado de São Paulo (1979a). Teste de produção e avaliação de poço tubular, Urânia, Poço 1. Maio, 1979. 3 pp.

SABESP - Companhia de saneamento básico do estado de São Paulo (1979b). Teste de produção e avaliação de poço tubular, Urânia, Poço 2. Maio, 1979. 3 pp.

SABESP - Companhia de saneamento básico do estado de São Paulo (1979c). Teste de produção e avaliação de poço tubular, Urânia, Poço 3. Maio, 1979. 3 pp.

SABESP - Companhia de saneamento básico do estado de São Paulo (1979d). Relatório final de poço, Urânia, Poço 4. 17 de abril de 1979. Projeto: Luiz Guidori. 6 pp.

SABESP - Companhia de saneamento básico do estado de São Paulo (1979e). Relatório final de poço, Aspásia (Urânia), Poço 1. 20 de abril de 1979. Hidrogeólogo responsável: Carlos E. Q. Giampá. 5 pp.

SABESP - Companhia de saneamento básico do estado de São Paulo (1979f). Relatório final de poço, Santa Salete (Urânia), Poço 1. 06 de junho de 1979. Hidrogeólogo responsável: Carlos E. Q. Giampá. 5 pp.

SABESP - Companhia de saneamento básico do estado de São Paulo (1979g). Relatório final de poço, Urânia, Poço 5. 03 de dezembro de 1979. Hidrogeólogo responsável: Carlos E. Q. Giampá. 5 pp.

SABESP - Companhia de saneamento básico do estado de São Paulo (1980). Relatório final de poço, Santa Albertina, Poço 5. 22 de fevereiro de 1980. Hidrogeólogo responsável: Carlos E. Q. Giampá. 6 pp.

SABESP - Companhia de saneamento básico do estado de São Paulo (1981). Relatório final de poço, Aspásia (Urânia), Poço 2. 13 de abril de 1981. Hidrogeólogo responsável: Carlos E. Q. Giampá. 6 pp.

SABESP - Companhia de saneamento básico do estado de São Paulo (1982a). Relatório final de poço tubular profundo, Urânia, Poço 6. 01 de outubro de 1982. Projeto: João Carlos de Souza. 8 pp.

SABESP - Companhia de saneamento básico do estado de São Paulo (1982b). Relatório final de poço, Aspásia (Urânia), Poço 3. 14 de julho de 1982. Hidrogeólogo responsável: Carlos E. Q. Giampá. 6 pp.

SABESP - Companhia de saneamento básico do estado de São Paulo (1991). Relatório final de poço tubular profundo, Urânia, Poço 8. 17 de janeiro de 1991. Projeto: Cesar Bianchi Neto. 8 pp. 
SABESP - Companhia de saneamento básico do estado de São Paulo (1992). Relatório final de poço tubular profundo, Jales, Poço 2. 17 de agosto de 1992. Projeto: Geól. Antonio Eduardo Marques Ricaldi. 8 pp.

SANTOS, E. L. D. (2006). Impacto de fossas negras nas zonas saturada e não-saturada do Aquífero Adamantina-SP. São Paulo. Iniciação Científica - Instituto de Geociências da Universidade de São Paulo, Fundação de Amparo à Pesquisa do Estado de São Paulo.

SIGRH (2010). Banco de Dados Pluviométricos do Estado de São Paulo Diponível em: http://www.sigrh.sp.gov.br/sigrh.exe/grafico?=Bco=Plu\&Pref=B7 006. Acesso em 10 de janeiro de 2010.

SOARES, P.C.; LANDIM, P.M.B.; FÚLFARO, V.J.; SOBREIRO NETO, A.F. (1980). Ensaio de caracterização estratigráfica do Cretáceo no Estado de São Paulo: Grupo Bauru. Revista Brasileira de Geociências, v. 10, n. 3, p. 177-185.

STARR, J. L; SAWHNEY, B. L. (1980). Movement of nitrogen and carbon from a septic system drain field. Water, Air and Pollution. v. 13, n. 1, p. 113-123.

STUMM, W.; MORGAN, J. J. (1996). Aquatic chemistry. $3^{\text {a }}$ ed. New York, Wiley Interscience Publication. $1022 \mathrm{p}$.

SUAREZ, J. M. (1999). O sítio fossilifero de Pirapozinho, SP. In: Schobbenhaus,C.; Campos,D.A.; Queiroz,E.T.; Winge,M.; Berbert-Born,M. (Edit.) Sítios Geológicos e Paleontológicos do Brasil. Publicado na Internet em 23/09/1999 no endereço http://www.unb.br/ig/sigep/sitio032/sitio032.htm

UNITED STATES ENVIRONMENTAL PROTECTION AGENCY (1994). Nitrogen Control (Manual). Lancaster, Technomic Publishing Company, USEPA. p. 35-36.

UNITED STATES ENVIRONMENTAL PROTECTION AGENCY (1995). Drinking water regulations and health advisories. USEPA. Disponível em: http: www.epa.gov

VARNIER, C. L. (2001). O efeito do nitrogênio proveniente de sistemas de saneamento in situ na qualidade das águas subterrâneas em aquíferos livres e rasos. São Paulo. São Paulo, 150 p. (Dissertação - Mestrado) - Instituto de Geociências da Universidade de São Paulo.

VARNIER, C. L. (2007). Avaliação da contaminação de uma fossa negra desativada na zona não-saturada do Aquífero Adamantina em Urânia (SP). São Paulo, 144 p. (Tese Doutorado) - Instituto de Geociências da Universidade de São Paulo. 
VIRARAGHAVAN, T.; WARNOCK, R.G. (1976). Groundwater quality adjacent to a septic tank system. Journal of the American Water Works Association, v. 11, n. 68, p.611-614.

VIVIANI-LIMA, J. B. (2007). Estimativa da recarga dos aquíferos urbanos na Bacia do Alto Tietê. São Paulo , 220 p. (Tese - Doutorado) - Instituto de Geociências da Universidade de São Paulo.

XU, M. \& ECKSTEIN, Y. (1995). Use of Weighted Least-Squares Method in Evaluation of the Relationship Between Dispersivity and Scale. J. Ground Water, Vol. 33, No. 6, pp 905908.

WALKER, W.; BOUMA, J.; KEENEY, D.; OLCOTT, P. (1973). Nitrogen transformation during subsurface disposal of septic tank effluent in sands: II Groundwater quality. Journal of Environmental Quality. v. 2, p. 521-525.

WALTON, W. C. (1992). Groundwater modeling utilities. Lewis Publishers, Inc., EUA, 640 p.

WANG, H. F.; ANDERSON, M. P. (1982). Introduction to groundwater modeling: Finite difference and finite element methods. Freeman and Co, 237 pp. (reprinted in 1995 by Academic Press). Source listings of several FORTRAN programs and data files are available on this server.

WIKIPÉDIA (2009). Enciclopédia livre. Disponível em: http://pt.wikipedia.org/. Acesso em 09 de abril de 2009.

WILHELM, S.; SCHIFF, S.; CHERRY, J. (1994). Biogeochemical evolution of domestic waste in septic systems: Conceptual Model. Ground Water, v. 32, n. 6, p. 905-916.

WHITE, P.A. (1997). A postaudit study of the Waimea Plains Aquifer model. Report 97/17. Lower Hutt, New Zealand: Institute of Geological \& Nuclear Sciences. 91 pp.

WOODWARD, F.; KILPATRICK, F.; JOHNSON, P. (1961). Experiences with groundwater contamination in unsewered areas in Minnesota. American Journal of Public Health, v. 51, n. 8, p. 1130-1136.

ZHENG, C.; WANG, P. P. (1999). MT3DMS: A modular three-dimensional multispecies model for simulation of advection, dispersion and chemical reactions of contaminants in groundwater systems; Documentation and User's Guide, Contract Report SERDP-991, U.S. Army Engineer Research and Development Center, Vicksburg, MS.

ZHENG, C. (2006). MT3DMS v. 5.2 Supplemental User's Guide, Report to the US Army Engineer Research and Development Center, Department of Geological Sciences, University of Alabama. (em http://hydro.geo.ua.edu/mt3d). 